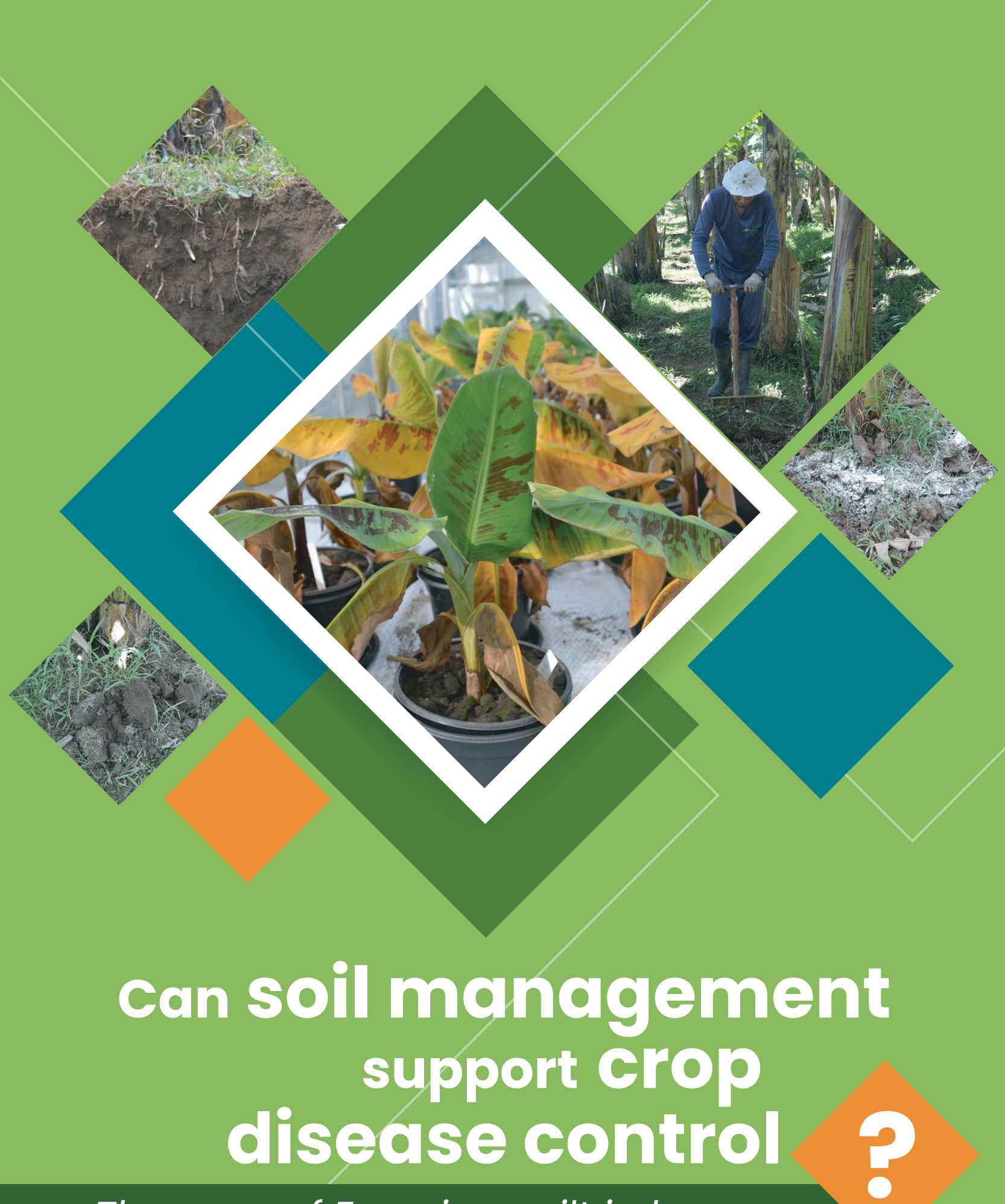

The case of Fusarium wilt in banana

Rafael A. Segura Mena 



\section{PROPOSITIONS}

1. Soil liming of acid soils is indispensable to reduce the impact of Fusarium wilt in banana. (this thesis)

2. Silver bullet solutions do not exist in crop disease management due to agro-ecological variation. (this thesis)

3. The lack of a publication tradition in tropical agriculture results in a repetition of failures by scientists and farmers.

4. Agricultural research should be funded with public money given the pivotal role of agriculture for society.

5. Social impact is a key measure of scientific progress.

6. Sustainable development is impossible without multi-sectoral engagement.

Propositions belonging to the thesis, entitled:

"Can soil management support crop disease control? the case of Fusarium wilt in banana"

Rafael A. Segura Mena

Wageningen, 30 June 2021 

Can soil management support crop disease control?

the case of Fusarium wilt in banana

Rafael A. Segura Mena 


\section{Thesis committee}

\section{Promotor}

Dr Jetse J. Stoorvogel

Associate Professor, Soil Geography and Landscape

Wageningen University \& Research

\section{Co-promotor}

Dr Jorge A. Sandoval F.

Research Director of CORBANA, Guápiles, Costa Rica

\section{Other members}

Prof. Dr V. Geissen, Wageningen University \& Research

Dr L. de Lapeyre de Bellaire, CIRAD, Montpellier, France

Dr M. Slingeland, Wageningen University \& Research

Dr K. Jansen, Wageningen University \& Research

This research was conducted under the auspices of the C.T. de Wit Graduate School for Production Ecology and Resource Conservation. (PE\&RC) 


\title{
Can soil management support crop disease control? the case of Fusarium wilt in banana
}

\author{
Rafael A. Segura Mena
}

Thesis

submitted in fulfilment of the requirements for the degree of doctor at Wageningen University by the authority of the Rector Magnificus Prof. Dr A.P.J. Mol, in the presence of the

Thesis Committee appointed by the Academic Board to be defended in public on Wednesday 30 June 2021 at 4:00 p.m. in the Aula. 
Rafael A. Segura Mena

Can soil management support crop disease control? the case of Fusarium wilt in banana, 166 pages.

PhD thesis, Wageningen University, Wageningen, the Netherlands (2021)

With references, with summaries in English and Spanish

ISBN: $\quad 978-94-6395-837-0$

DOI: $\quad 10.18174 / 547770$ 
Dedicado a mi Madre María Luisa por su entereza y lucha de vida, a mi padre Cristian (†) y especialmente al motor de mi vida mi hijo Rafael E. Segura Barboza. Esto es de Ustedes.

"Soy el amo de mi destino y el capitán de mi alma"

Mandela, 1918-2013 



\section{INDEX}

Chapter 1 .................................................................................................................................... 13

General introduction .......................................................................................................... 13

1.1. Crop diseases, a permanent problem.................................................................... 14

1.2. Alternative options to deal with crop diseases ............................................................. 14

1.3. The relationship between soil properties and crop diseases........................................ 16

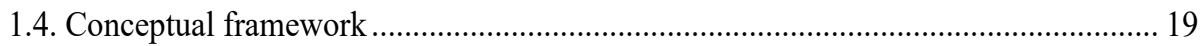

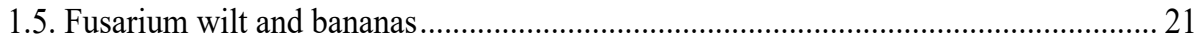

1.5. Scope, hypothesis, objective and research questions ................................................. 23

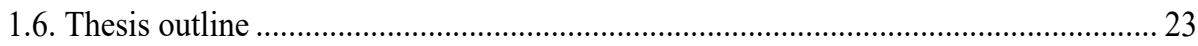

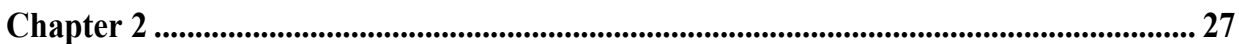

The complex chemical and microbiological interactions between soils and plants in commercial banana plantations.................................................................................................... 27

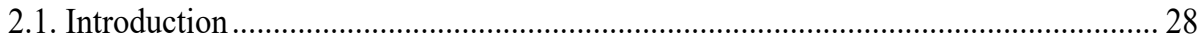

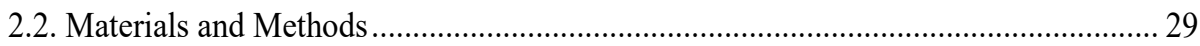

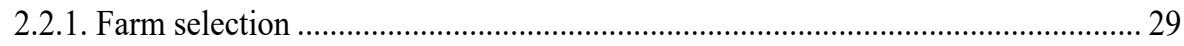

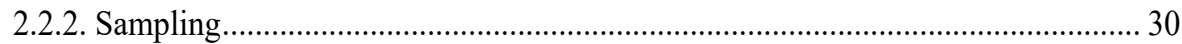

2.2.3. Chemical and microbiological analyses ............................................................. 32

2.2.4. Statistical Analysis ......................................................................................... 32

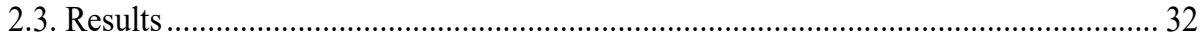

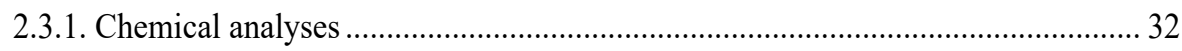

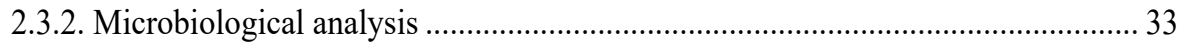

2.3.3. Chemical properties and microorganism count in banana roots ........................... 36

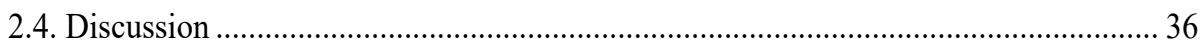

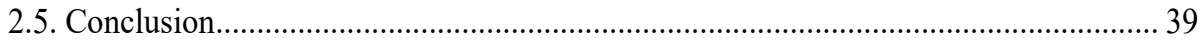


Evaluating the potential of soil management to reduce the effect of Fusarium oxysporum

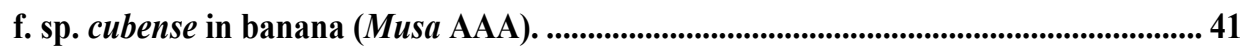

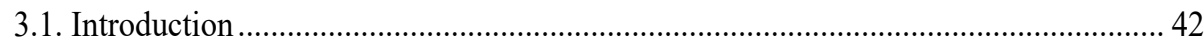

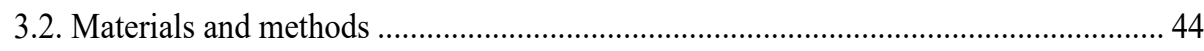

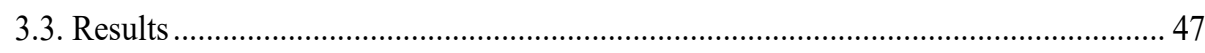

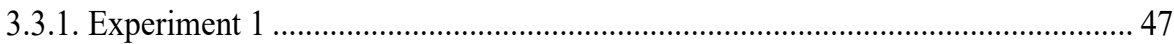

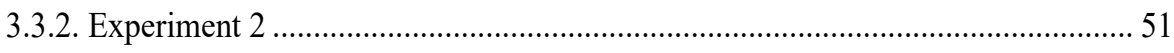

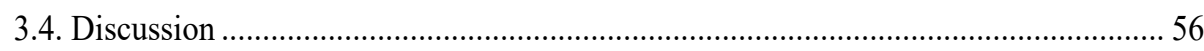

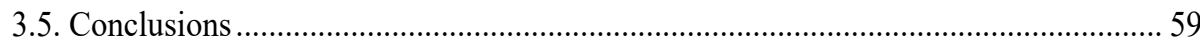

Chapter 4 ..................................................................................................................................................... 61

The role of soil types on the relation between individual soil properties and Fusarium

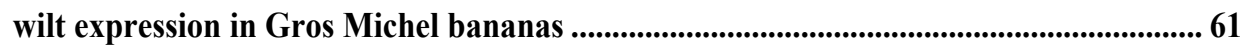

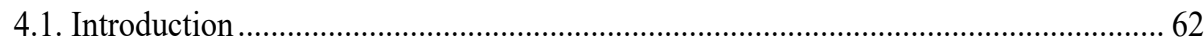

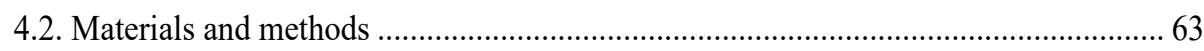

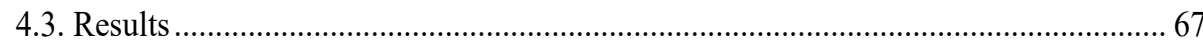

4.3.1. Natural effect of the soil type and soil $\mathrm{pH}$ in not inoculated plants ...................... 67

4.3.2. Soil $\mathrm{pH}$ and $\mathrm{N}$ interactions and plant biomass and disease index ........................ 68

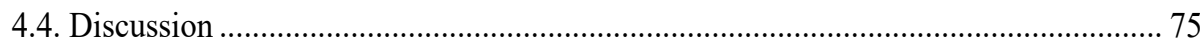

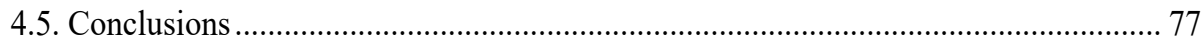


Chapter 5

The effect of soil management on Fusarium wilt in banana (Musa AAA) in a medium-

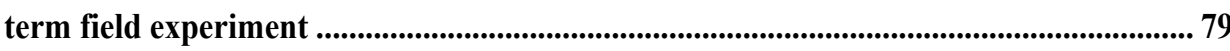

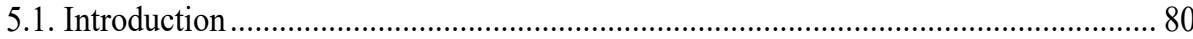

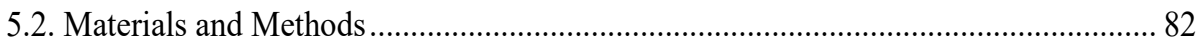

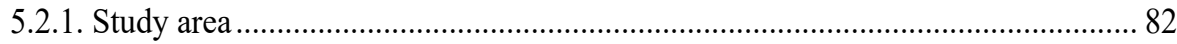

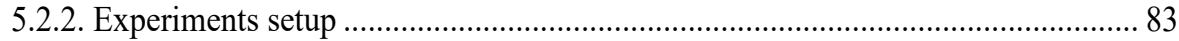

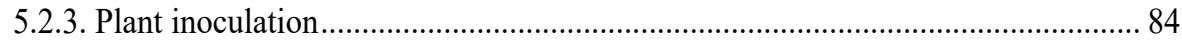

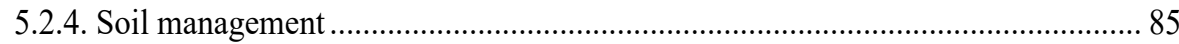

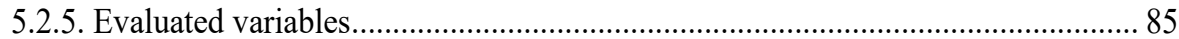

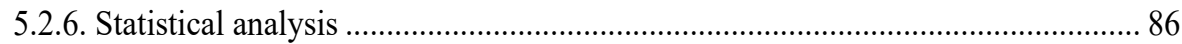

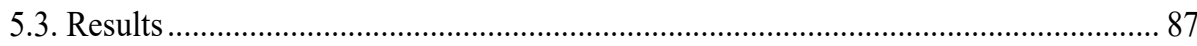

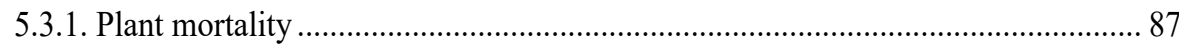

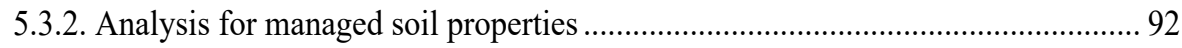

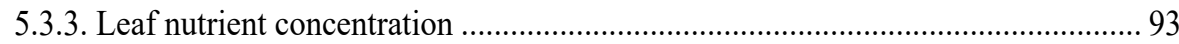

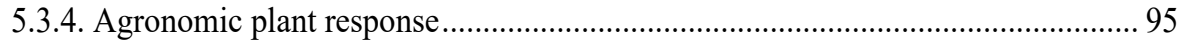

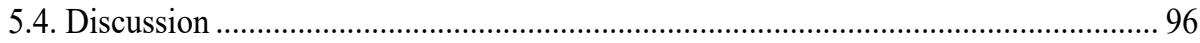

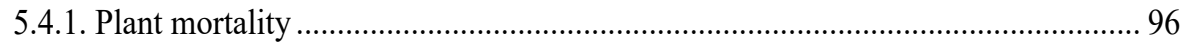

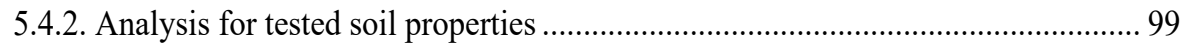

5.4.3. Leaf nutrient concentration according to soil properties management ................. 99

5.4.4. Agronomic plant response according to soil management................................... 99

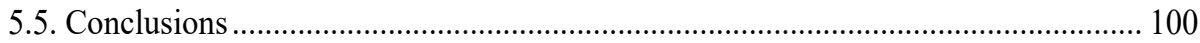


Fusarium wilt (Foc Race 1) in relation with soil properties in smallholder's farms of 'Gros Michel' banana (Musa AAA) in Costa Rica ........................................................... 103

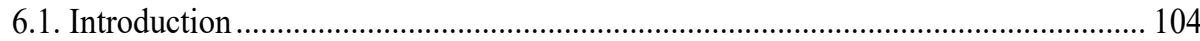

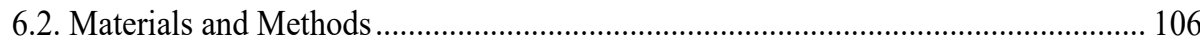

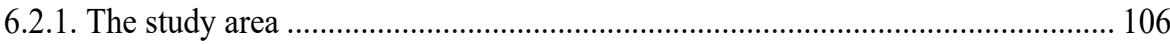

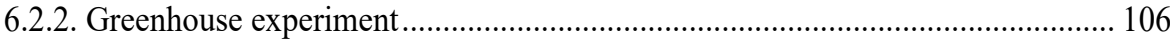

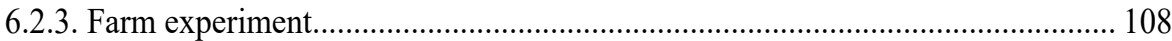

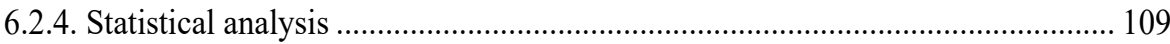

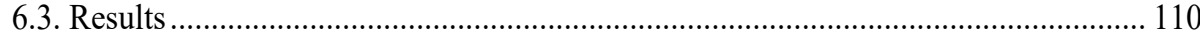

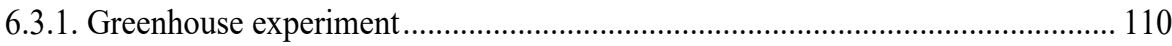

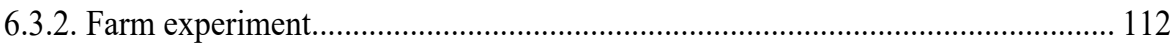

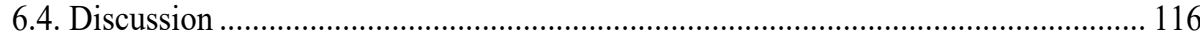

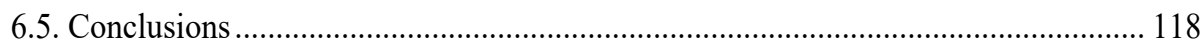

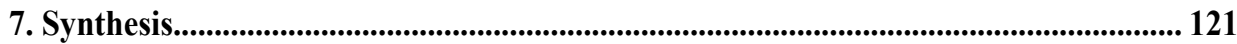

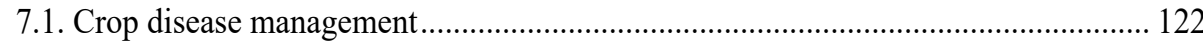

7.2. Studying the potential of soil management for Foc control ................................... 123

7.3. Different methodological approaches (Research line A) ......................................... 125

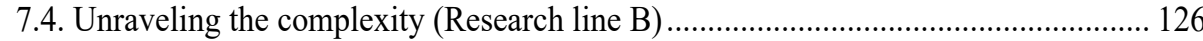

7.5. From research to management recommendations.................................................. 129

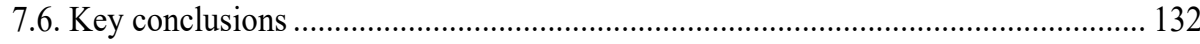

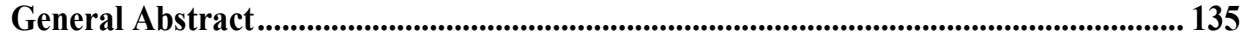

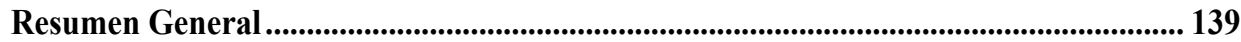

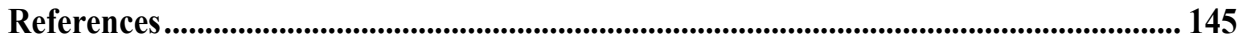

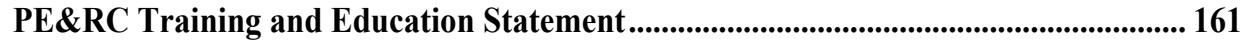

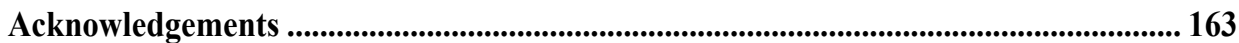

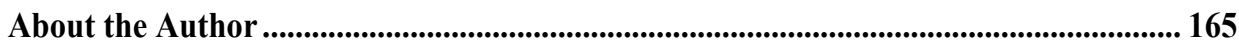

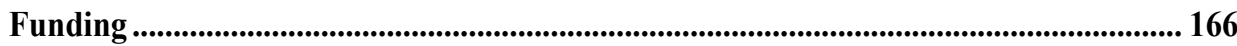




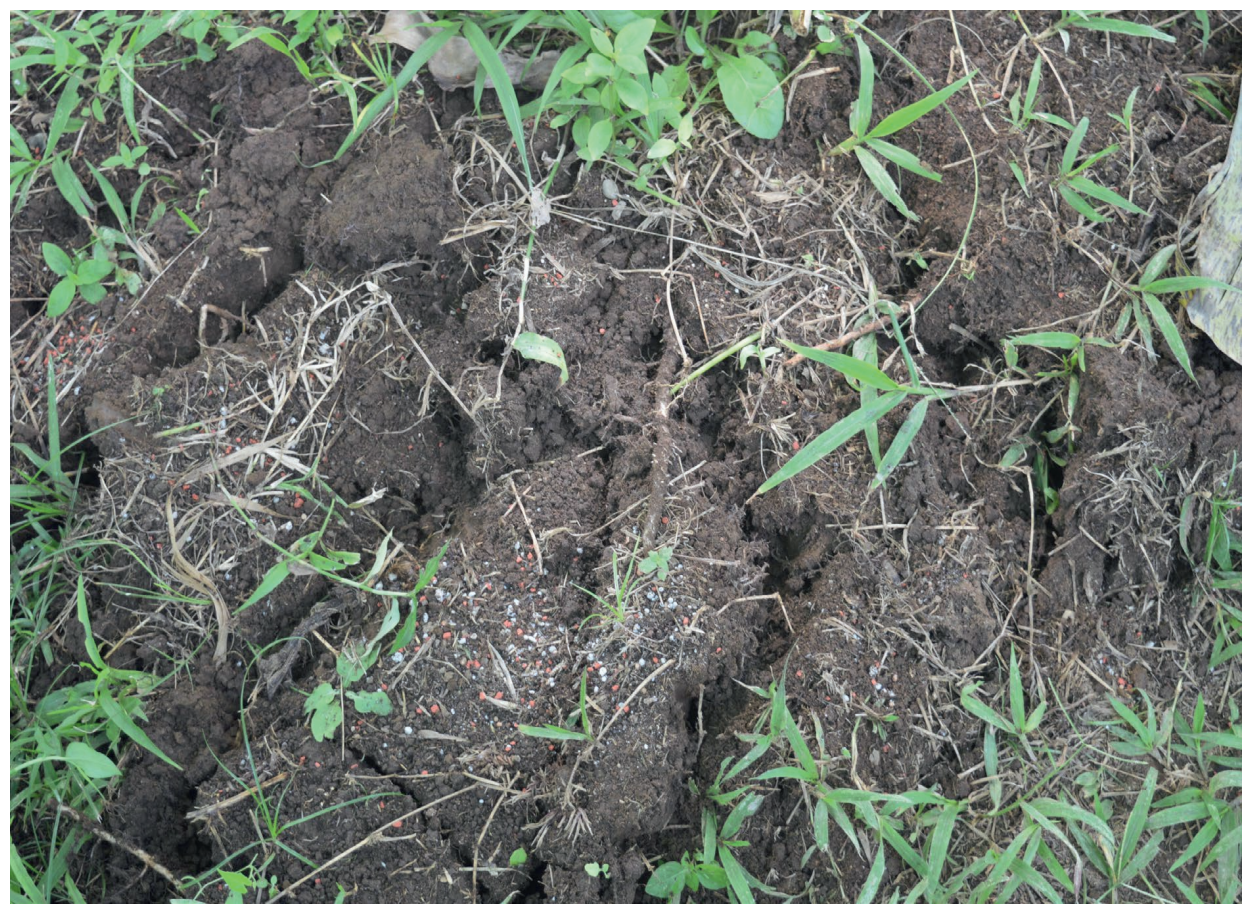


Chapter 1

General introduction 


\subsection{Crop diseases, a permanent problem}

Crop diseases have proven to be one of the most constraining, difficult-to-manage, and unpredictable aspects of crop production. The pathogens (fungi, bacteria and viruses) cause large losses in crop yield and crop quality, resulting in economic losses and an increasing risk for food security (Oerke 2005). Losses in crop yield due to diseases were found to range between $20 \%$ and $40 \%$ of global agricultural productivity (Oerke 2005; Savary et al. 2012). A projection into the future indicates an upward trend in yield losses caused by crop diseases. The magnitude of the effect will vary between crops and regions and is caused by, amongst other, agricultural intensification, new diseases, and climate change (Juroszek and von Tiedemann 2015).

The most common way to prevent or alleviate crop diseases is the use of pesticides. An adequate use of pesticides can ensure and improve yields, limiting the impact of the diseases in the crops (Popp et al. 2013). However, pesticides are not always effective. Sometimes pesticides simply do not exist. In other cases, induced resistance of the pathogens to the pesticides and inactivation due to biological activity (especially in soils) reduces their effectiveness. These conditions result in a dependence on the continuous application of higher pesticide amounts with a lower effectiveness and a constant rise in pesticide costs. At the same time, pesticide use is subject of a controversial discussion in society. Although it is necessary to maintain (and increase) a high production for food security, society increasingly calls for a reduction in pesticide use, because of the potential adverse effects on human health and the environment (Ecobichon 2001; Oerke and Dehne 2004). All these aspects make it necessary to find alternative strategies to manage crop diseases.

\subsection{Alternative options to deal with crop diseases}

The strategies to control crop diseases include options such as breeding for resistance (Ronald 2011), crop rotation, intercropping, and replanting (Conway 1996). Although these alternatives have not the environmental risks of pesticides, they do exhibit specific disadvantages. Breeding for resistant plants, for example, is costly, slow, and its results are unpredictable. Specific agricultural practices (e.g., crop rotation, intercropping, and replanting) 
can be an alternative to deal with diseases, but it can increase costs and its effectiveness depends on the cropping system and the environmental conditions. While these considerations exist, the problem of crop diseases still represents an important threat to agriculture sustainability (Pinstrup-Andersen 2000). It is therefore necessary to constantly explore different alternatives for crop disease management.

The conceptual triangle of crop diseases places identifies the role of the pathogen, the host (i.e., the crop), and the environment (and their interactions) as the three main factors for the occurrence of a crop disease (Figure 1-1; (Francl 2001). Crop disease management focuses on these three driving factors where i) pesticides typically aim to directly affect the pathogen population, ii) breeding programs aim to adapt the host, and iii) agricultural management may change the environmental conditions. Although soil management receives little attention as a strategy for crop disease management, it can offer opportunities for being included in crop disease control packages by directly changing the environmental conditions.

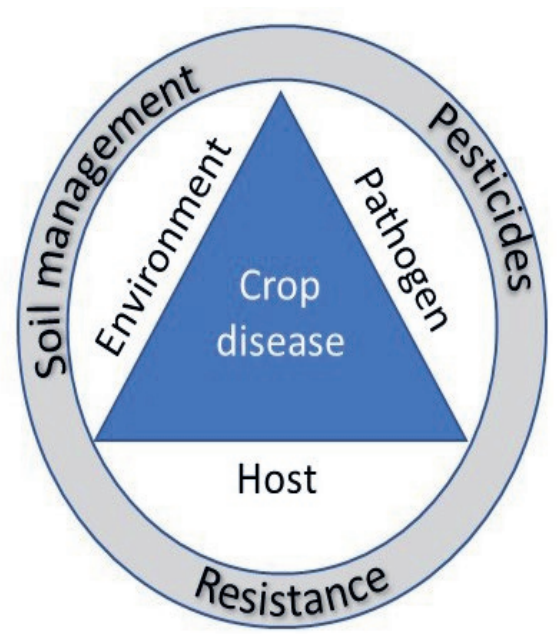

Figure 1-1 The crop disease triangle with the three main determining factors for crop diseases and options for crop management (adapted from Francl 2001). 
The role of soil properties is well known in crop nutrition. Additionally, soil properties are known to influence the predisposition of crops to diseases (Doran et al. 1996; Ghorbani et al. 2008; Huber et al. 2012). Therefore, it is likely that the predisposition of a crop to diseases can be influenced by changing soil properties (Dordas 2008; Amtmann et al. 2008; Romero et al. 2011; Lambert 2019). However, given the plethora of soil properties, it is important to identify which soil properties influence the crop's predisposition to diseases. Soil properties that can be changed easily through management (e.g., fertilization, liming, tillage, and drainage) can be considered as first candidates to modulate the crop's predisposition to diseases. An ex ante screening of soil properties to select the candidate soil properties with the highest potential in crop disease management is highly important.

Soil management offers advantages in crop production and environmental sustainability as an alternative in the package for controlling crop diseases (Amir and Alabouvette 1993; Höper and Alabouvette 1996). An integrated control package, including soil management, implies, in theory, a lower application of pesticides. Furthermore, a reduction in the total amount of pesticides, can improve their efficiency because of a lower consistent pressure on the pathogens. This could reduce the possibilities of induced pathogen resistance to the molecules. In addition, this can be an opportunity to have more sustainable crop systems and to bring about a change in the concept of crop disease management.

\subsection{The relationship between soil properties and crop diseases}

Although many soil properties and their interactions are involved in crop development and production, some soil properties are commonly referred to in the scientific literature as important drivers for disease development in crops. Nonetheless, the scientific community still lacks a proper understanding of the role of soil properties on crop disease development. In this study, we focus on abiotic soil properties that can be influenced by soil management. Soil $\mathrm{pH}$ and $\mathrm{N}$, for instance, are two important soil factors in crop production. Besides, they are frequently mentioned to influence the crop response to diseases (Oritsejafor 1986; Höper and Alabouvette 1996; Harrison and Shew 2001; Janvier et al. 2007).

The influence of soil $\mathrm{pH}$ on crop production is well known in a variety of crops (Datnoff et al. 2007; Jones 2012). One of the most important effects is the relationship between low $\mathrm{pH}$ 
and the higher availability of spore elements, heavy metals, and aluminum (Singh et al. 2017). Aluminum negatively affects the crop nutritional status because it directly interferes with crop nutrient uptake. One of the main physiological causes is root growth inhibition due to a reduction in root cell division and elongation (Kochian et al. 2005; Singh et al. 2017). This effect has a direct negative influence on crop nutrition due to the decrease in the capability of nutrient take-up by roots (especially of macronutrients). A low soil $\mathrm{pH}$ can also result in toxic levels and imbalances caused by the hyper accumulation of spore elements in crop tissue (Huber and Graham 1999; White 2012).

Literature confirms the effects of soil $\mathrm{pH}$ on crop disease incidence. On the one hand, low soil $\mathrm{pH}$ has been linked with a higher predisposition to diseases in crops (Huber et al. 2012; Rengel 2000): Fusarium wilt in flax (Höper et al. 1995)and bananas (Domínguez et al. 2008), root rot (Aphanomyces spp.) in pea (Persson and Olsson 2000), common scab (Streptomyces scabiei) in potatoes (Goto 1985; Lacey and Wilson 2001; Lambert et al. 2005), and phytophtora root rot (Phytophthora cinnamomi) in avocado (Fernandez-Falcon et al. 1984). On the other hand, a high soil $\mathrm{pH}$ is associated with a higher crop disease incidence: black root (Thielaviopsis basicola), causing black root rot in tobacco (Oyarzun et al. 1998; Harrison and Shew 2001) and take-all (Gaeumannomyces graminis Sacc.) in wheat (Duffy et al. 1997). Despite these reports, while a relation between soil $\mathrm{pH}$ and the incidence of crop diseases was found, there are also other studies that did not confirm this relationship (Janvier et al. 2007).

It is generally accepted that soil $\mathrm{N}$ influences crop diseases (Rengel 2000; Janvier et al. 2007; Huber et al. 2012). However, the results are inconsistent and varied according to e.g., the applied $\mathrm{N}$ form, the pathogen, the crop, or its growth stage (Dordas 2008; Harrison and Shew 2001; Huber and Watson 1974). Both positive and negative relationships between N concentrations and crop disease incidence have been reported. For instance, a lower $\mathrm{N}$ concentration was related with increased incidence of early blight (Alternaria solani) in potatoes (Miller and Rosen 2005), Xanthomonas wilt (Xanthomonas campestris pv. musacearum) in bananas (Atim et al. 2013), grey mould (Botrytis cinerea) in tomatoes (E Hoffland et al. 1999), and bacterial speck (Pseudomonas syringae) and powdery mildew (Oidium lycopersicum) in tomatoes (Hoffland et al. 2000). N concentrations are especially important for disease incidence in wheat and other cereals. The incidence of take-all caused by 
Gaeumannomyces graminis (Brennan 1992), Septoria tritici blotch (by Mycosphaerella graminicola), brown rust (Puccinia recondite), powdery mildew (Blumeria graminis) and foot rot (Fusarium spp.) increased with higher N concentrations (Walters et al. 1984; Leitch and Jenkins 1995; Tiedemann 1995; Rodgers-Gray and Shaw 2000; Olesen et al. 2003).

Many other soil properties are involved in disease incidence and development. In the literature, calcium $(\mathrm{Ca})$, magnesium $(\mathrm{Mg})$, potassium $(\mathrm{K})$ and silicon $(\mathrm{Si})$ stand out (Huber et al. 2012). Higher Ca concentrations reduced stem rot (Phytophthora sojae) in soybeans (Sugimoto et al. 2007), in oak (Serrano et al. 2012), Aphanomyces root rot in peas (Heyman et al. 2007), and Phytophthora nicotianae in citrus (Campanella et al. 2002). Higher Mg concentrations resulted in an increased incidence of southern leaf blight (Bipolaris maydis) in maize, pot rot (Fusarium spp.) in peas, bacterial spot (Xanthomonas campestris pv. vesicatoria) in tomatoes, root rot (Rhizoctonia solani) in soybeans and early blight (Alternaria solani) in potatoes (Huber and Jones 2012).

The influence of high concentrations of potassium on the reduction of crop disease incidence has also been reported (Amtmann et al. 2008; Huber and Jones 2012). Applications of K fertilizers reduced the incidence of Fusarium wilt in oil palm (Ollagnier 1976), the severity of black spot disease (Alternaria brassicae) in oilseed rape (Sharma and Kolte 1994), anthracnose (Nam et al. 2006) in strawberries, and powdery mildew (Sphaerotheca fuliginea) in cucumbers (Reuveni et al. 1995). Besides silicon ( $\mathrm{Si}$ ) has been reported as an important soil property for the reduction of disease severity in crops (Bélanger et al. 2003; Romero et al. 2011; Huang et al. 2011). Si amendments have been linked with a decrease in crop disease incidence: Fusarium wilt in bananas (Fortunato et al. 2012) and rust (Phakopsora pachyrhizi) in soybeans (Lemes et al. 2011). Higher Si concentrations in crops are also linked with a decreased disease incidence in crops, such as potatoes, cucumbers, and wheat (Bélanger et al. 2003; Chérif et al. 1992; Klikocka et al. 2005). Various studies show the complexity of the interaction between this nutrient and crop diseases. For example, $\mathrm{Si}$ is involved in the activation of resistance mechanisms or systemic acquired resistance, particularly in induced resistance driven by the jasmonic and salicylic acid pathways (Datnoff et al. 2007). In addition, the fortification of cell wall through increased $\mathrm{Si}$ availability can contribute to the positive effect in crop resistance to diseases (Kim et al. 2002). 
Also soil physical properties can affect the incidence of crop disease. Other soil properties can play a role in crop diseases. Soil drought can increase the incidence of root rot (caused by Aphanomyces euteiches) in pea (Allmaras 2003). Moreover, other physical soil properties, such as soil bulk density and texture, have also been reported as soil properties influencing the incidence of diseases in crops (Höper et al. 1995; Höper and Alabouvette 1996; Wiese et al. 2004). For instance, soil compaction is related with a higher incidence of root rot (Cicer arietinum) in chickpea (Bhatti 1992) and Persson and Olsson (2000) indicated that a higher clay content reduced Aphanomyces root rot in pea. Clay content and soil type also reduced the incidence of take-all disease (Gaeumannomyces graminis Sacc.) in wheat (Duffy et al. 1997) and Fusarium wilt (Fusarium oxysporum f.sp. lini) in oil palm groves (Amir and Alabouvette 1993).

\subsection{Conceptual framework}

The pathway between soil properties and soil-borne crop diseases can be twofold. First, soil properties can directly influence pathogen populations in the soil. Soils can be suppressive or conducive for certain soil-borne pathogens as a result of a complex myriad of interconnected biotic and abiotic conditions (Weller et al. 2002). Second, soil conditions influence crop development, thereby indirectly affecting the predisposition of a crop to a particular disease (Sugimoto et al. 2007; Dordas 2008; Romero et al. 2011). Changes in crop stress modulate the predisposition of crops and consequently the incidence of crop diseases (Persson and Olsson 2000; Schoeneweiss 1975; Wiese et al. 2003; 2004).

The response of crop development to soil conditions is often represented by a bellshaped curve (Figure 1-2 ${ }^{\mathrm{A}}$ ). Optimal crop development is found in a certain range and stress occurs at both the low and high end of the curve, resulting in a reduction in crop performance (Huber et al. 2012). Optimal soil conditions provide the basis for a balanced crop nutrition (Huber and Graham 1999). Proper crop nutrition could reduce the impact of biotic stress caused by pathogens (Dordas 2008; Huber and Graham 1999; Jones 2012). In addition, nutrient deficiencies, toxic levels, or extreme $\mathrm{pH}$ levels (high or low) can lead to a poor crop performance and, consequently, to an increase in the crop's predisposition to diseases (Brennan 1992; Datnoff et al. 2007). As a result, there is an indirect effect between the soil properties and the crop's 
predisposition to diseases, as illustrated in Figure $1-2^{\mathrm{B}}$. This relation is expected to be inverse to the relation between soil properties and crop development. Soil properties can also play a direct role in suppressing or conducing soil pathogens, as illustrated in Figure $1-2^{\mathrm{C}}$. Under certain conditions the pathogen population will be favored, resulting in a higher disease pressure. Other conditions may suppress the pathogen population (resulting in so-called suppressive soils). The relationships in Figure 1-2 need to be identified in more detail before establishing that soil management can be used as an alternative strategy for crop disease management. Reality is often more complex, as a plethora of biotic and abiotic soil properties interact in agricultural systems. Hence, crop response (in yield and predisposition to diseases) is likely to be the result of the aggregated effect of all soil properties.

With a vast number of crops and diseases, the possibilities are endless to test the conceptual framework. The risk of missing the effect of managing soil conditions as an alternative is also part of the scenario. In some cases, for instance, conventional management is effective against crop diseases, and then other natural effects (e.g., from soils) are not visualized in the crop's response to the disease. A systematic approach to study the effect of soil conditions on crop response to diseases is required. 

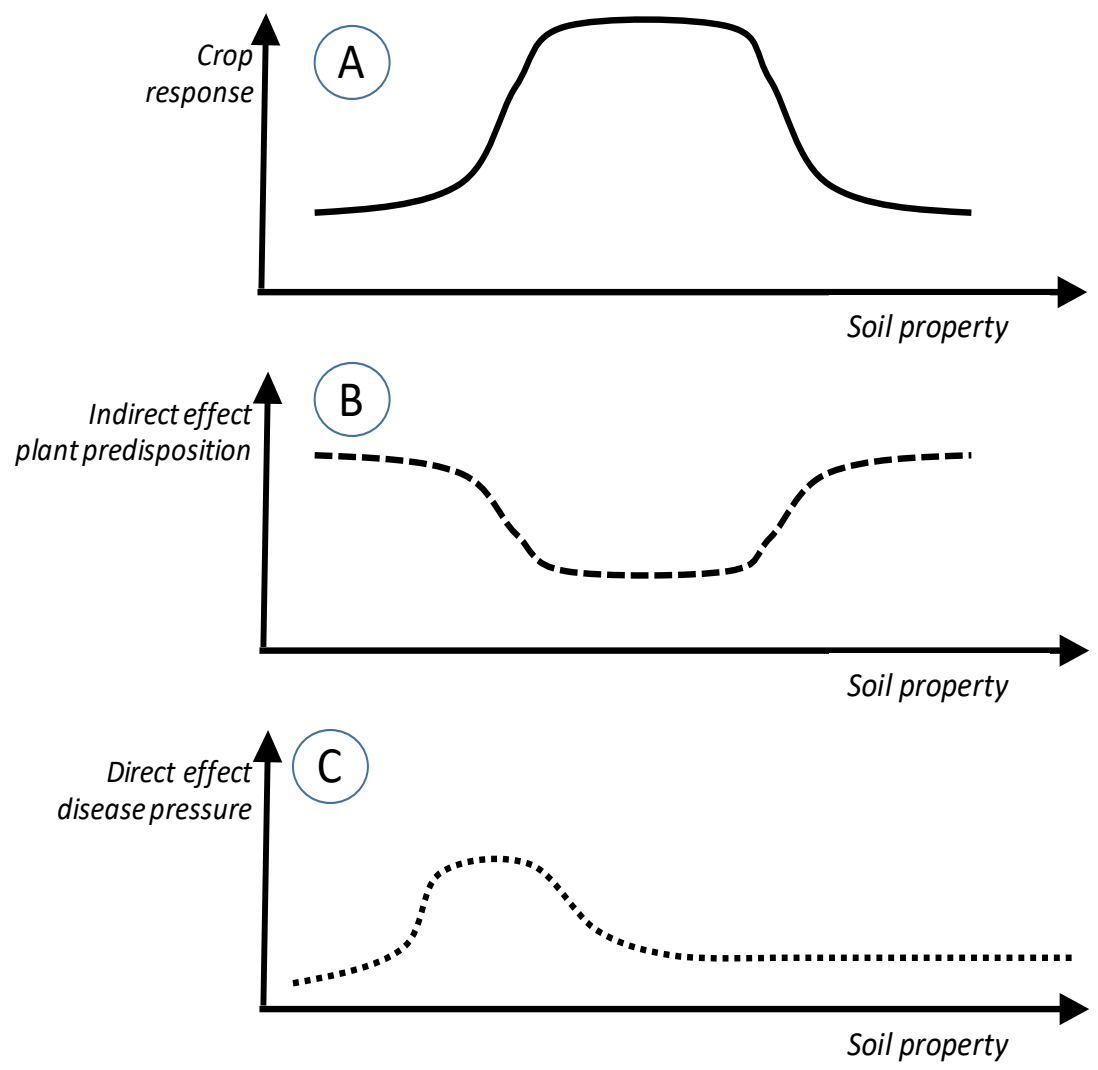

Figure 1-2 Conceptual model relating the effect of soil abiotic stress on crop development and production, and both direct and indirect effect on the incidence of crop diseases.

\subsection{Fusarium wilt and bananas}

Fusarium wilt (also known as 'Panama disease') strongly affects banana plantations worldwide, especially in developing countries (Ordoñez et al. 2015). The causal agent is the soil-borne fungus Fusarium oxysporum f. sp. cubense (Foc). In the 1950s, the Race 1 strain of the fungus (Foc Race 1) virtually devastated commercial production of the Gros Michel banana, the former main cultivar for exportation in Latin America and the Caribbean (LAC). The export-oriented banana industry in LAC gradually shifted to cultivars from the subgroup 
Cavendish, which is resistant to Foc Race 1 (Harper 1950; Stover 1962; Ploetz 1990; PerezVicente 2004). This illustrates the impact of Fusarium wilt in banana, a main crop in a vast region of the world. Despite the negative effect of Foc Race 1, Gros Michel and other staple banana cultivars and plantains are still grown in LAC and other locations in developing countries, for instance, in Africa. This production focuses particularly on local trade and local consumption (Aurore et al. 2009). Fusarium wilt by Foc Race 1 continues to hamper those banana systems.

To make matters worse, Tropical Race 4 (Foc TR4), the vegetative compatibility group VCG 01213 of Foc, currently threatens banana production worldwide because of the greater aggressiveness of this strain (Molina et al. 2008; Ordoñez et al. 2016). The presence of Foc TR4 is confirmed in various banana-producing countries, such as Malaysia, China, Indonesia and the Philippines in South East Asia (Molina et al. 2008), the Jordan Valley (García-Bastidas et al. 2016), and Pakistan and the Middle East (Ordoñez et al. 2016), where it has decimated thousands of hectares. Recently, Foc TR4 has also been reported in LAC (García-Bastidas et al. 2020) Cavendish, Gros Michel cultivars, and the rest of banana and plantain grown in LAC are important and valuable agricultural commodities (Butler 2013; Ploetz 2015a). Most of them are under the current effect (by Foc Race 1) and the threat (by Foc TR4) of Fusarium wilt.

Conventional alternatives have proven to be ineffective to control the disease. It is almost impossible to eradicate the fungus from infested soils with e.g., fungicides and soil disinfectants. Currently, there is an urgent need to find alternatives for disease management to alleviate the effects of this disease in bananas. Several authors discuss the potential role of soil properties (e.g., pH, drainage, and nutrients) in relation to Fusarium wilt in bananas (Rishbeth 1955; Stover 1962; Haddad et al. 2018; Orr and Nelson 2018). However, the reported role of soil properties on Fusarium wilt in banana is inconsistent in the interactions described between soil properties, the crop, and the disease. They require deeper studies and confirmation. The conceptual framework can be tested in the model of Fusarium wilt and bananas. This could offer insight into the solutions that may alleviate this disease with a consequent positive effect in the productive systems of the developing countries. At the same time, new knowledge can be uncovered about the relationship between soil properties and crop diseases, which could in turn be extrapolated or adapted to other cases of crop-disease relationships. 


\subsection{Scope, hypothesis, objective and research questions}

This research focused on the opportunities of soil management as an additional tool in crop disease control. The research focused on soil abiotic properties that can be managed directly. The interaction between Fusarium wilt (Foc) and banana was selected to study the influence of abiotic properties of soil in crop disease incidence. A systematic approach was designed including i) a literature review, ii) greenhouse experiments, iii) medium-term field experiments, and iv) a farm survey. The influence of soil properties in the selected model of Foc and bananas is studied step-by-step. Crucial steps in the process include the selection of potential abiotic soil properties with potential influence in crop disease expression and to test him in various experiments. The hypothesis is that by managing soil abiotic properties, the predisposition of the banana plant to Foc and the aggressiveness of the fungus can be modulated. The main objective was to establish the potential role of soil management in the control of Fusarium wilt in bananas.

The research questions are:

- Do abiotic soil properties influence crop disease incidence?

- Do agro-ecological conditions influence the relationship between soil properties and crop disease incidence?

- What is the most effective methodology to test the relationship between abiotic soil properties on crop diseases?

- Is it possible to modulate the expression of Fusarium wilt in banana though soil management?

\subsection{Thesis outline}

The thesis is divided into seven Chapters (Figure 1-3). In Chapter 1, the general introduction, a literature review was performed to select the main soil abiotic properties involved in crop response to diseases in general. The relationship between main soil properties (biotic and abiotic) and crop production was studied in commercial Costa Rican banana farms as presented in Chapter 2. In Chapter 3, subsequently, the impact of two soil $\mathrm{pH}$ and $\mathrm{N}$ on Fusarium wilt was tested in two greenhouse experiments (one in Costa Rica and one in the 
Netherlands). The objective was to confirm relationships between soil properties and the Foc Race 1 in Gros Michel bananas and to evaluate whether similar relationships are found Foc TR4 in Cavendish bananas. In Chapter 4, the effect of soil types on the relation between soil properties and Fusarium wilt was studied as a possible cause for the inconsistencies found in the literature. Eight representative soil types from the Costa Rican banana region were studied. In Chapter 5, the relationships between multiple soil properties and Fusarium wilt were tested in a medium-term factorial field trial for 4 crop cycles. In Chapter 6, a retrospective analysis of the previous results was carried out under real farm conditions. A rapid survey in mostly smallholder farms that grow Gross Michel was performed studying soil variation and the presence of Fusarium wilt. A synthesis of the main results of the overall research is presented in Chapter 7. 
- Chapter 2

\section{Banana production $=\mathrm{f}($ Soil $($ chemical, physical, biological $))$}

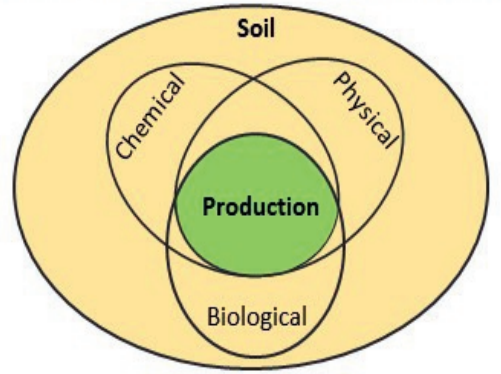

- Chapter 3

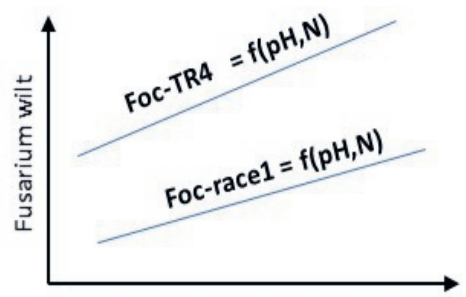

Soil properties

- Chapter 5

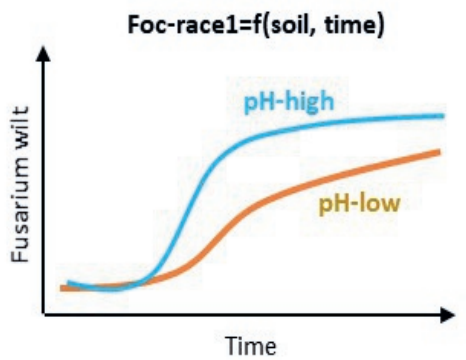

- Chapter 4

Foc-race1 = $\mathrm{f}($ soil, $\mathrm{pH}, \mathrm{N})$

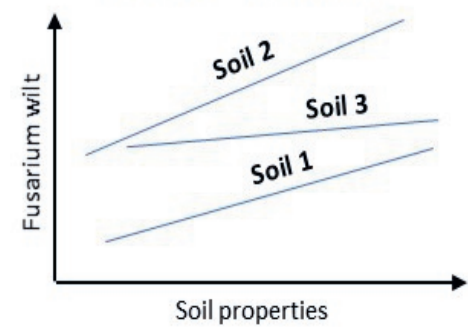

- Chapter 6

Foc-race1=f(soil, agro-ecology)

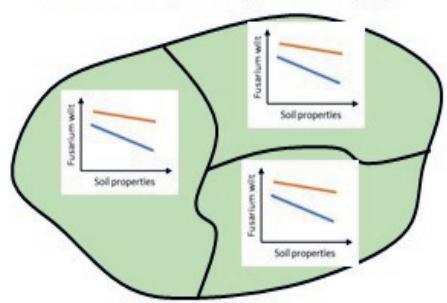

\section{- Chapter 7}

\section{Synthesis}

Figure 2-3 Thesis outline. 


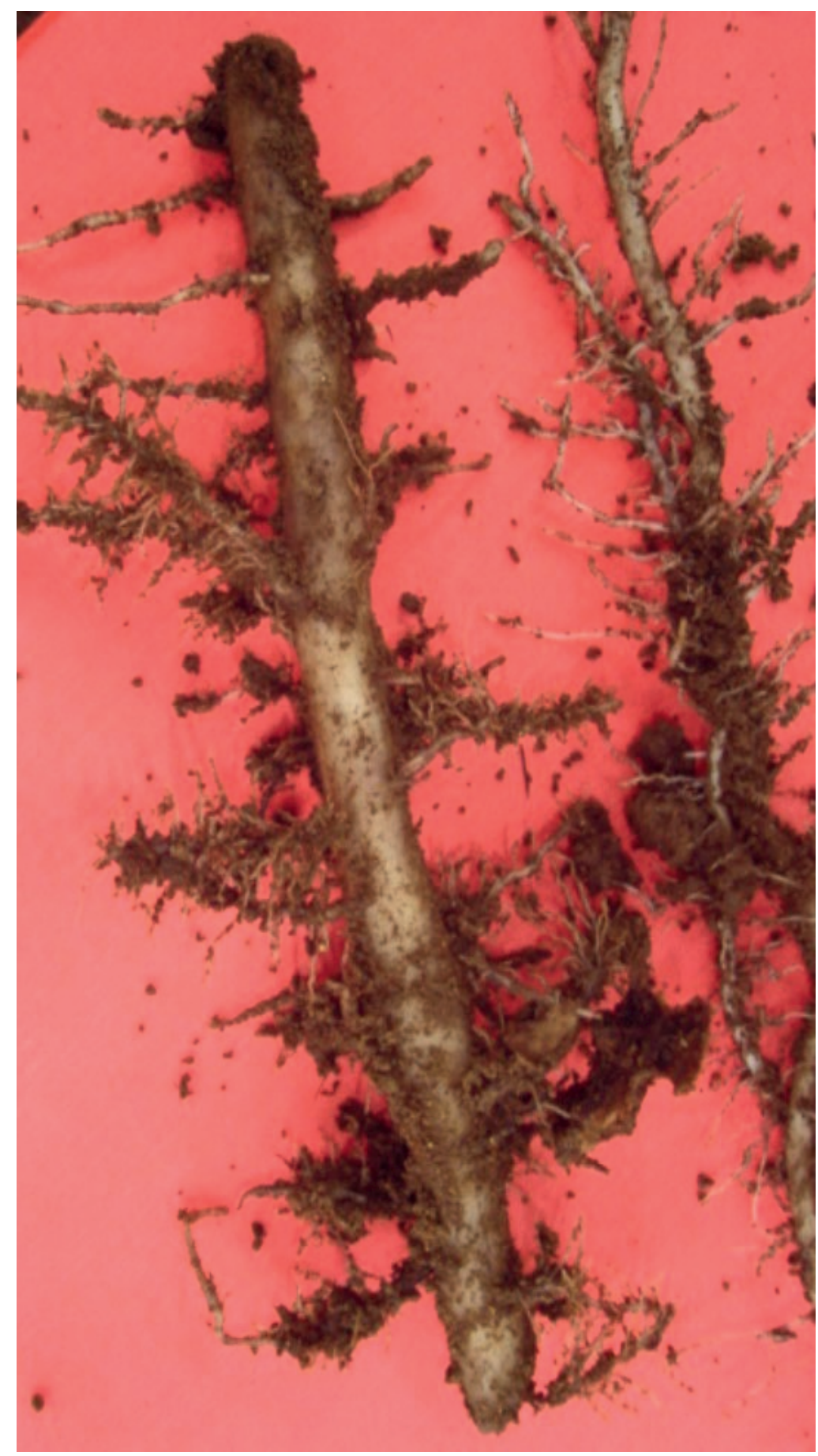




\section{Chapter 2}

\section{The complex chemical and microbiological interactions between soils and plants in commercial banana plantations}

Soils are known to have an important impact on crop production. A study was performed to explore the relationships between soil chemical and microbiological properties and how they impact crop production. The study was carried out in six Costa Rican commercial banana farms with high, medium and low productivity. In each of the farms, sectors with relatively good and poor crop development were identified. In these sectors, microbiological and chemical properties of the soil and banana roots were characterized in the fertilization band, the interrow, and the rhizosphere. In addition, crop performance was evaluated in terms of plant height, the trunk circumference, and the number of hands per bunch. Higher biometric values were found in the sectors with good development, regardless of the farm, than in those with poor plant development. The $\mathrm{pH}$ was significantly lower in the sectors with poor crop performance in both the fertilization band and the rhizosphere. The soil chemical and microbiological properties differed significantly between the good and poor performing areas, but also between the fertilization band, the interrow, and the rhizosphere. There were less bacteria, fungi and actinomycetes in roots from plants in the sectors with poor performance. Chemical and microbiological soil properties in influenced the root conditions, the banana plant development and production. This study shows the complex interactions between soil chemical and microbiological properties and how they affect banana production.

This chapter is based on:

Segura RA, Stoorvogel JJ, Samuels JZ, Sandoval JA (2018) Managing the interactions between soil abiotic factors to alleviate the effect of Fusarium wilt in bananas. Acta Hortic 163-168. https://doi.org/10.17660/ActaHortic.2018.1196.19 


\subsection{Introduction}

Soil chemical and microbiological properties are known to interact and influence crop production. For example, low soil $\mathrm{pH}$ is known to negatively affect the quality of agricultural soils and, consequently, crop production. Although crops can be tolerant to a low soil $\mathrm{pH}$ itself, the acid conditions may result in an increase in soluble Al that can become toxic with adverse effects on growth and production (Pattison and Lindsay 2006). These complex interactions between soil chemistry, microbiology and crop production are known to occur in many cropping systems. A good example where complex interactions seem to play an important role and seriously constrain management recommendations is the commercial banana production in Costa Rica. A rapid decline in $\mathrm{pH}$ and an increase in $\mathrm{Al}$ in Costa Rican banana soils have resulted in a lower number of functional roots and a drop in crop production (Serrano 2005; Serrano et al. 2008). Araya and Blanco (2001) found a positive relation between the root system and crop performance (in terms of trunk circumference and bunch weight). In addition, banana roots from acid soils with a high content of soluble $\mathrm{Al}$ showed a lower content of $\mathrm{Ca}$ and $\mathrm{Mg}$ (Delvaux et al. 2005). Low pH values also produce a drop in soil bacteria activity, which may result in a decrease in nitrogen availability due to a reduction in nitrification, ureases and dehydrogenases activity (Tate 2000; Chaperon and Sauvé 2007). Acuña et al. (2006) determined that a low $\mathrm{pH}$ level and a high $\mathrm{Al}$ content in the soil coincide with a lower microbiological activity and a lower content of bacteria, fungi and actinomycetes. In addition, this decline in soil respiration coincided with a poor crop development (smaller trunk and less hands per bunch).

Many of the above studies focused on a relationship between a single soil property and banana production. Integrated studies where the soil chemical and microbiological properties and the crop performance were combined are lacking. In addition, many studies focus on the so-called fertilization band in the banana system. This fertilization band is the area in front of the following sucker of the plant where nutrients are applied through fertilization. However, the interrow, which is the area in-between plant lines, is not affected by applied fertilization and has fewer roots. The rhizosphere is mostly located in the fertilization band. This is the most dynamic part of the soil and it plays an important role in the root-soil interface (Hinsinger et al. 2006). Because the rhizosphere is located around the roots and it is not possible to sample 
through conventional methods, there is no scientific data available for this soil in banana systems. In addition, there is no information available in written scientific documentation on optimum microbiological and chemical conditions for banana roots and their relationship to banana plant development and production.

Due to the foregoing, a study was conducted with the objective of determining the relationship between chemical and microbiological soil properties (in the fertilization band, the interrow and the rhizosphere) with root microbiological and chemical conditions in the banana plant development and production.

\subsection{Materials and Methods}

\subsubsection{Farm selection}

Soil sampling took place in six commercial banana plantations (Musa AAA) in the Atlantic Zone of Costa Rica, located between $82^{\circ} 33^{\prime}$ and $84^{\circ} 0^{\prime}$ Western longitude and between $9^{\circ} 28^{\prime}$ and $10^{\circ} 40^{\prime}$ Northern latitude. The area has a tropical humid climate with an average annual rainfall of $2500 \mathrm{~mm}$, well distributed throughout the year. The region is divided into two sub-regions, to the east and west of the Reventazón River, respectively (Lopez and Solís 1991). Soils in the east are of sedimentary origin with an average to high fertility. Soils in the west are of volcanic origin with low-medium fertility (Lopez and Espinosa 2000). More than 95\% of Costa Rican banana farms are located in these two sub regions. Based on the productivity history of all Costa Rican farms, three productivity ranges were established according to average fruit production: low $(<45,000 \mathrm{mt}$ ha year-1 $)$, average $(45,000-53,000 \mathrm{mt}$ ha year $\left.{ }^{-1}\right)$ and high $\left(>53,000 \mathrm{mt}\right.$ ha year $\left.{ }^{-1}\right)$. Six farms with known management history were randomly selected: 3 per region, one for each productivity range. To the west of the Reventazón River, the following farms were selected: Cartagena (high productivity, 9 years in production), Calinda (average productivity, 16 years in production) and Las Juntas (low productivity, 19 years in production). To the east of the Reventazón, the following were selected: Palo Verde 1 (high productivity, 17 years in production), El Esfuerzo (average productivity, 17 years in production) and San Pablo (low productivity, 40 years in production). 


\subsubsection{Sampling}

On each of the farms, sectors with relatively low and high production (in total harvested tons of fruit per area per year) were identified in the historical yield records of the farm administration. These sectors were designated as good plant development ( $\left.\mathrm{S}_{\mathrm{good}}\right)$ and poor plant development $\left(\mathrm{S}_{\mathrm{poor}}\right)$, respectively. Then, four plots of two hectares were randomly selected in the two plant development sectors, i.e., eight plots per farm. In each plot, twenty plants were evaluated in terms of

- plant height, measured from the ground level to the neck of the bunch at flowering (Eckstein et al. 2000),

- trunk circumference, taken at $1 \mathrm{~m}$ from the ground for the mother plant and at $0.5 \mathrm{~m}$ (Cabrera and Galán 2005) for the suckers (Figure 2.1), and

- number of hands per bunch.

A mini-pit was dug in the center of each plot in the fertilization zone in front of the following sucker of a recently flowered plant, measuring $60 \mathrm{~cm}$ wide, $60 \mathrm{~cm}$ long and $60 \mathrm{~cm}$ deep, in accordance with the method described by Jaramillo and Vásquez (1990) and (Serrano et al. 2006). In each mini-pit, a sample was taken from the first $30 \mathrm{~cm}$ depth of soil in the fertilization band, another sample was taken in the interrow, and the rest of the soil in the plot was sampled. Samples of the rhizosphere soil and the root were collected in each mini-pit. Total roots from the mini-pit were collected, and the soil that was tightly bonded to those roots (rhizosphere) was separated by hand (see Figure 2-1).

In addition, soil samples were collected up to $10 \mathrm{~cm}$ deep with a tubular auger for microbiological analyses of band and interrow samples. Samples of the soil areas (fertilization band, interrow and rhizosphere) and roots were divided into two equal portions for chemical and microbiological analyses. 


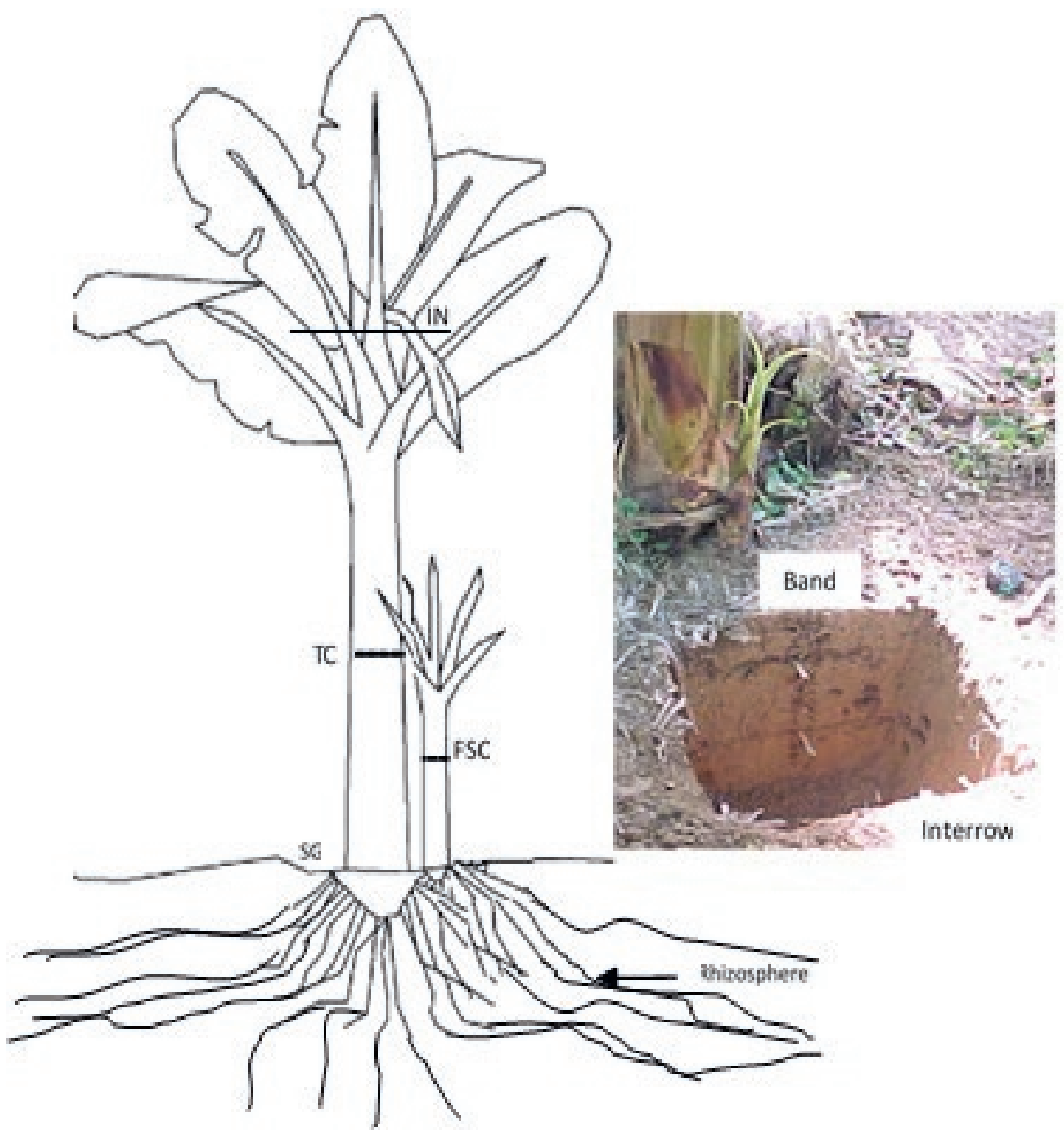

Figure 2-1 Schematic representation of performed measures of plant and soil survey per plot. Left: Plant height from soil ground (SG) to the inflorescence neck (IN) at flowering, trunk circumference (TC) and following sucker circumference (FSC) $100 \mathrm{~cm}$ and $50 \mathrm{~cm}$ above SG respectively. Right: Detail of a mini-pit dug for soil sampling in three areas, fertilization band, interrow and the theoretical location of the rhizosphere in the banana root system. 


\subsubsection{Chemical and microbiological analyses}

Soil samples were analyzed chemically (Díaz-Romeu and Hunter 1978) for $\mathrm{pH}$, organic matter (SOM) and exchangeable $\mathrm{Al}, \mathrm{Ca}, \mathrm{Mg}, \mathrm{K}, \mathrm{P}, \mathrm{Zn}, \mathrm{Cu}, \mathrm{Fe}$, and $\mathrm{Mn}$ using a Mehlich III extraction (Mehlich 1984). The microbiological analysis consisted of a count of bacteria (CFU $\mathrm{g}$ of soil $^{-1}$ ), fungi and actinomycetes. Dextrose-potato agar media in Petri dishes were used in the determination of fungi, nutrient agar media were used for the bacteria count, and actinomycete agar media were used for the actinomycete count (Brock and Madigan 1991; Seeley et al. 1991; Bottomley et al. 1994). Nutrient and spore element contents (N, P, K, Ca, $\mathrm{Mg}, \mathrm{S}, \mathrm{Fe}, \mathrm{Cu}, \mathrm{Zn}, \mathrm{Mn}$ and $\mathrm{B}$ ) and $\mathrm{Al}$ were determined in the root samples. Microbiological analyses were made from root samples, and a CFU/g of root count was made for bacteria, fungi and actinomycetes.

\subsubsection{Statistical Analysis}

Results were subjected to a variance analysis through a set of mixed linear models (PROC MIXED of SAS Institute 1999), taking into account that the mini-pits are randomly selected on each farm and that the three soil sampling areas (fertilization band, interrow and rhizosphere) and root samples constitute of repeated measurements in each mini-pit. Results were subjected to a variance analysis where the farms and plant development levels constituted a $6 \times 2$ bi-factorial structure. Surveyed farms were considered as a randomly taken sample of banana farms in the Caribbean region of Costa Rica. The data analyses of the soil samples were done separately from the root samples.

\subsection{Results}

\subsubsection{Chemical analyses}

The different farm sectors showed clear and significant differences in crop performance (Table 2-1). The average $\mathrm{pH}$ in the rhizosphere was $5.8 \mathrm{in} \mathrm{S}_{\text {good }}$ and $5.5 \mathrm{in} \mathrm{S}_{\text {poor. }}$ The soil $\mathrm{pH}$ in the fertilization band was 5.7 in $S_{\text {good }}$ and 5.4 in $S_{\text {poor. }}$ In both sampling areas the differences were significant $(\mathrm{P} \leq 0.016)$. A similar trend was found in the area of interrow, but the difference was not significant $(\mathrm{P}=0.063)$. The $\mathrm{Zn}$ content was $12 \mathrm{mg} \mathrm{kg}^{-1}$ in the rhizosphere 
and $17 \mathrm{mg} \mathrm{kg}^{-1}$ in the fertilization band in $\mathrm{S}_{\text {good }}$; these values were significantly higher (P $\leq 0.003)$ than in $\mathrm{S}_{\text {poor }}\left(5\right.$ and $11 \mathrm{mg} \mathrm{kg}^{-1}$, respectively). $\mathrm{P}$ was higher $(\mathrm{P} \leq 0.050)$ in the fertilization band and interrow in $\mathrm{S}_{\text {good }}$ (84 and $65 \mathrm{mg} \mathrm{kg}^{-1}$ respectively) than in $\mathrm{S}_{\text {poor }}$ (63 and $\left.48 \mathrm{mg} \mathrm{kg}^{-1}\right)$, while in the rhizosphere both sectors had similar values $\left(35 \mathrm{mg} \mathrm{kg}^{-1}\right.$ in $\mathrm{S}_{\text {good }}$ and $44 \mathrm{mg} \mathrm{kg}^{-1}$ in $\left.\mathrm{S}_{\text {poor }}\right)$. $\mathrm{Cu}$ was higher only in the rhizosphere of $\mathrm{S}_{\text {poor }}(\mathrm{P}=0.011)$ with a value of

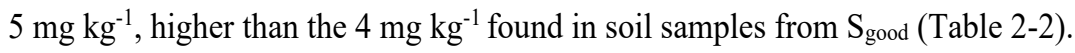

Manganese $(\mathrm{Mn})$ was higher $(\mathrm{P} \leq 0.031)$ in the fertilization band $\left(75 \mathrm{mg} \mathrm{kg}^{-1}\right)$ and interrow (72 $\mathrm{mg} \mathrm{kg}^{-1}$ ) of $S_{\text {poor }}$ compared to the values in $S_{\text {good }}$ (55 and $54 \mathrm{mg} \mathrm{kg}^{-1}$ respectively). Organic matter accumulated in the fertilization band $(\mathrm{P} \leq 0.048)$ and the rhizosphere $(\mathrm{P} \leq 0.001)$ of $\mathrm{S}_{\text {poor }}$ with values of $4.56 \%$ and $4.40 \%$, respectively, compared to $3.32 \%$ and $3.70 \%$ in $\mathrm{S}_{\text {good. }}$ A similar but not significant trend was found in the interrow. No differences $(\mathrm{P}>0.050)$ were found for $\mathrm{Al}, \mathrm{Ca}, \mathrm{Mg}, \mathrm{K}, \mathrm{Fe}$ and $\mathrm{SOM}$ in any sampling area according to the plant development (Table 2-2).

\subsubsection{Microbiological analysis}

There was a higher number of the three types of analyzed microorganisms in $S_{\text {good }}$ in at least one of the sampling areas, whether rhizosphere, fertilization band or interrow. Bacteria counts (CFU g of soil ${ }^{-1}$ x 10 $0^{3}$ ) in $S_{\text {good }}$ were 336.3 in the rhizosphere, 190.4 in the fertilization band and 125.0 in the interrow. Those contents were higher than similar areas in $\mathrm{S}_{\text {poor, }}$ which showed 172.5 in the rhizosphere, 49.6 in the band and $57.5 \mathrm{CFU} g$ of soil $^{-1} \times 10^{3}$ in the interrow. Total number of actinomycete CFU $g$ of $\operatorname{soil}^{-1}$ was higher $(\mathrm{P} \leq .0001)$ in $\mathrm{S}_{\text {good }}$ for the fertilization band and interrow and no differences were found in $\mathrm{S}_{\text {poor }}$ in the rhizosphere (P $=0.154)$. The fungi differed only in the rhizosphere, being higher $(\mathrm{P} \leq 0.0001)$ in $\mathrm{S}_{\text {good. }}$. Larger populations of bacteria were found in the two plant development sectors and the three sampling areas, with the rhizosphere giving the highest values (Table 2-2). 


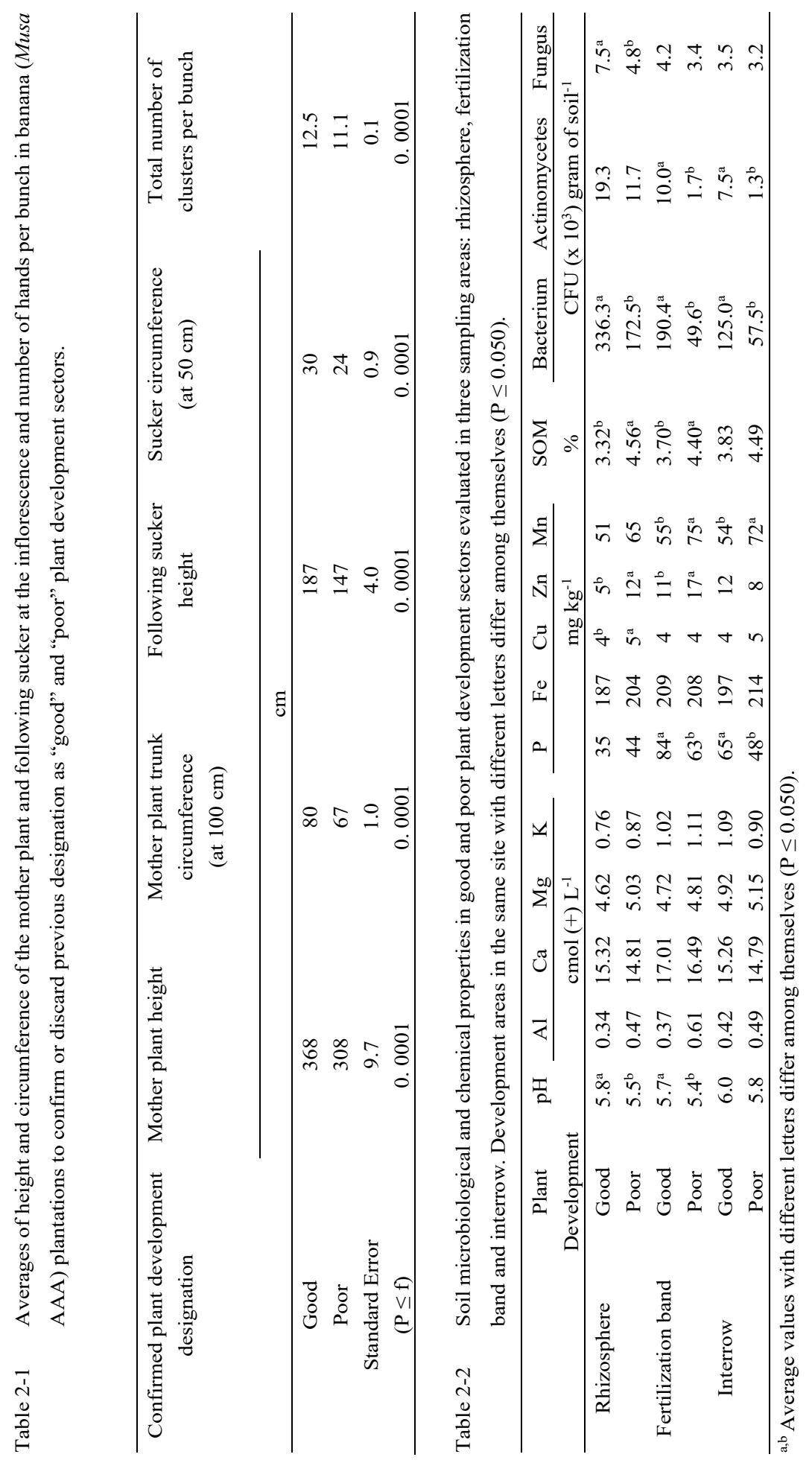




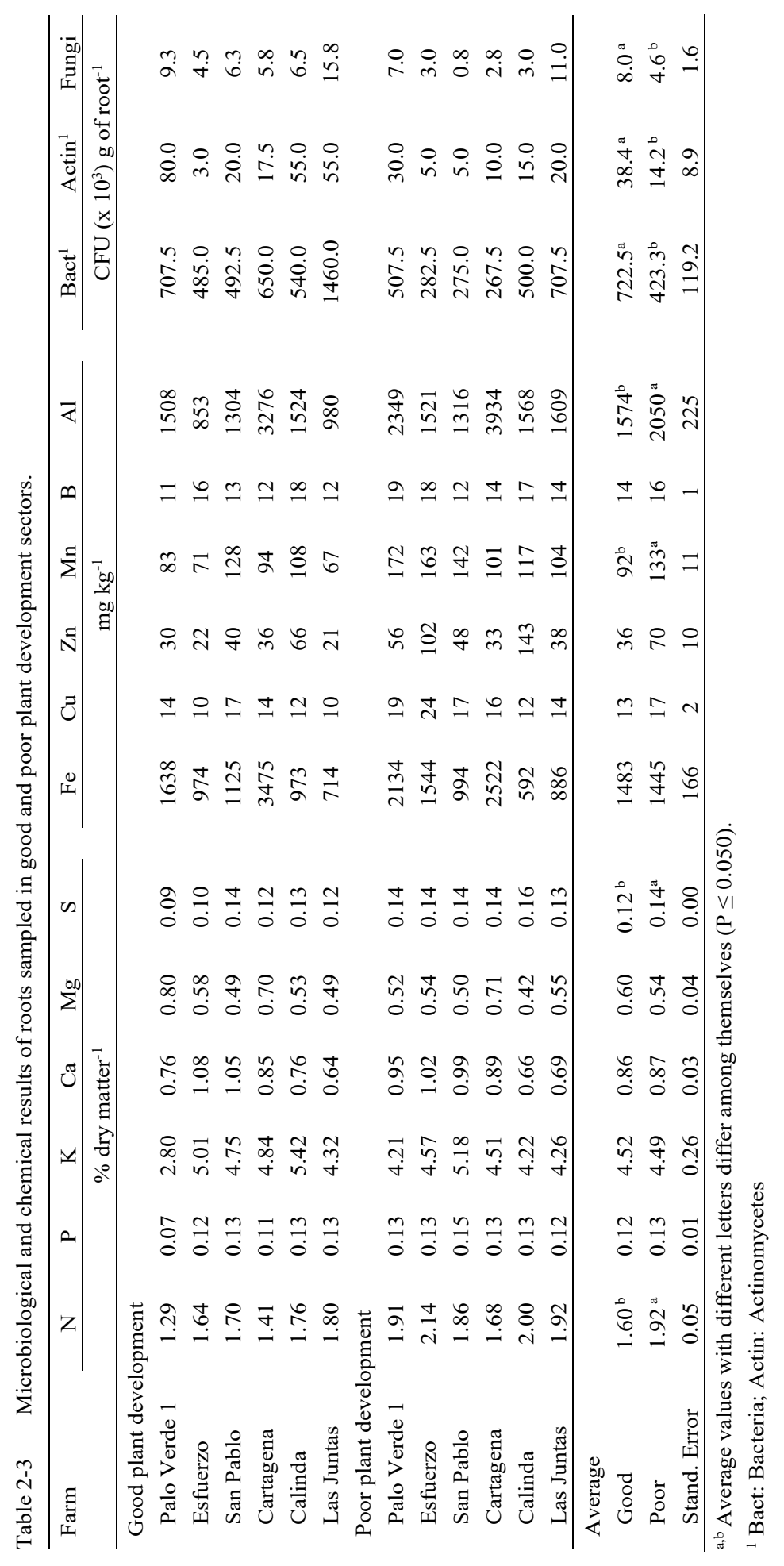




\subsubsection{Chemical properties and microorganism count in banana roots}

Concentrations of $\mathrm{N}, \mathrm{S}$ and $\mathrm{Mn}$ in roots were higher $(\mathrm{P} \leq 0.053)$ in $\mathrm{S}_{\text {poor }}(1.92 \%, 0.14 \%$ and $\left.133 \mathrm{mg} \mathrm{kg}^{-1}\right)$ compared to the roots of plants from $\mathrm{S}_{\text {good }}\left(1.60 \%, 12 \%\right.$ and $\left.92 \mathrm{mg} \mathrm{kg}^{-1}\right)$. No significant differences $(\mathrm{P} \geq 0$.066) were found for the other nutrients and spore elements. Al content in the roots from $S_{\text {poor }}(2,050 \mathrm{mg} / \mathrm{kg})$ was significantly higher $(\mathrm{P} \leq 0.022)$ compared to $1,574 \mathrm{mg} \mathrm{kg}^{-1}$ in the roots from $S_{\text {good. }}$ This toxic element showed the highest concentration in comparison with the analyzed microelements for both degrees of plant development (Table 2-3). The microbiological colonization of the root system, measured as the average CFU g-1 of root of bacteria, actinomycetes and fungi, was higher $(\mathrm{P} 0 \leq .033)$ in roots obtained from $\mathrm{S}_{\text {good. }}$. The microorganisms found in the highest concentration of CFU g of root $^{-1}$ in all farms and degrees of plant development were bacteria, with higher values compared with actinomycetes and fungi. Expressed as CFU g ${ }^{-1}$ (x 10 $\left.0^{3}\right), 722.5$ of bacteria, 38.4 of fungi and 8.0 of actinomycetes were found in $S_{\text {good, }}$ compared to what was obtained in $S_{\text {poor: }} 423.3$ of bacteria, 14.2 of fungi and 4.6 of actinomycetes CFU g-1 (x 103) (Table 2-3).

\subsection{Discussion}

The differences in biometric variables between the good and poor plant development sectors in the six farms confirm the prior designation by production of each of those sectors. These results agree with those found by Serrano (2005) and Serrano et al. (2006), who analyzed sectors of several farms and found differences in biometric variables related to productivity.

Lower $\mathrm{pH}$ was found to be one of the main causes for poor plant development in the poor sectors. This variable is an indicator of the soil quality (Karlen et al. 2003). Pattison et al. (2008) mentioned this variable as an important indicator for the health (or quality) of banana soils in Australia, which concurs with what was found in this study. One of the most important causes of the drop in soil $\mathrm{pH}$ of banana soils is the continuous application of ammonium fertilizers (Delvaux et al. 2005; Robinson and Galán 2010). Options for nitrogen management of banana farm soil to counteract the decline in soil $\mathrm{pH}$ include the application of alkaline nitrogen sources, organic nitrogen fertilizers and fractioning. Although the fertilization band gave a lower $\mathrm{pH}$ than the interrow, the $\mathrm{pH}$ in the rhizosphere (physically located in the fertilization band) was slightly higher. This is attributed to the presence of root exudates that modify the rhizosphere microenvironment to keep it in adequate condition for the root system (Hawes et al. 2000; Walker et al. 2003). The higher $P$ in the fertilization 
band of the sectors with good plant development was attributed to the higher $\mathrm{pH}$ in these soils resulting in less P immobilization (Bertsch 1998; Orcutt and Nilsen 2000). P is applied in large quantities to Costa Rican banana soils in both conventional and organic fertilizers. In the rhizosphere, where the $\mathrm{pH}$ was higher than in the fertilization band, there were no differences in $\mathrm{P}$ concentrations between the good and poor areas due to the extraction that occurs in this portion of the plantation soil (Steingrobe and Claassen 2000; Rufyikiri et al. 2003; Marschner 2008).

The higher $\mathrm{Zn}$ and $\mathrm{Mn}$ concentrations in the poor development areas are related to the lower $\mathrm{pH}$ found in the soils of this plant development sector (Fassbender and Bornemisza 1987; Bertsch 1998; Orcutt and Nilsen 2000; Singh et al. 2008). There was a significant difference in $\mathrm{Zn}$ concentrations since it is applied regularly in the fertilization programs. Mn is not applied through fertilization but is naturally high in the studied soils (Lopez and Solís 1991). Despite being essential elements for the banana plant, the accumulation of both $\mathrm{Zn}$ and $\mathrm{Mn}$ are related to low soil $\mathrm{pH}$ levels and sectors of poor plant development.

SOM concentration is considered as an indicator for determining soil health, fertility and degradation (Karlen et al. 2003; Manlay et al. 2007). Its accumulation in the poor plant development sectors could be due to a low mineralization rate. Moreover, the smaller amount of SOM in the fertilization band and rhizosphere of the good plant development sectors indicates a higher mineralization. This could increase availability of organic $\mathrm{P}$ and $\mathrm{Cu}$ in the soil (Fassbender and Bornemisza 1987). Both are important elements for soil microbiological activity and banana plant nutrition.

It is generally accepted that applications of SOM sources, such as compost and bocashi, can improve soil quality and productivity (Rivero et al. 2004; Riveros et al. 2006). These organic amendments have been applied regularly in banana plantations in Costa Rica. This practice could influence the analyzed soil samples taken in both the good and poor development sectors because those SOM fertilizers are applied in front of the developing suckers. However, the lower $\mathrm{pH}$ in the poor sectors decreases the potential benefit of SOM sources in plant development and production.

The larger number of microorganisms found in the rhizosphere in the two development sectors is attributed to the changes made by the plant roots in the microenvironment to maintain, besides other conditions, larger populations of microorganisms in this area of the soil. This is largely a result of the production of root exudates with a strong stimulating effect on microbiological activity (McCully 1995; Flores 1999; Gilroy and Jones 2000; Hawes et al. 2000; Nardi et al. 2000; Walker et al. 2003). 
Despite the larger concentration of bacteria, fungi and actinomycetes in the soil of good plant development sectors, the three are below the expected minimum average values (in CFU g of soil ${ }^{-1}$ ) of $10^{6}$ for bacteria, $10^{5}$ for actinomycetes and $10^{4}$ for fungi (Portugal and Aguilera 1998; Uribe 1999; Tate 2000). The chemical soil properties found in the poor sectors, such as low $\mathrm{pH}$ and high concentrations of heavy elements, such as $\mathrm{Zn}$ and $\mathrm{Mn}$, could act as suppressors of microbial activity in these areas.

The accumulation of $\mathrm{N}$ and $\mathrm{S}$ in root tissues from the poor plant development sectors was attributed to the continuous application in fertilization programs. The Mn was higher in the rhizosphere of the poor development sectors, so its accumulation in the root system concurs with high soil contents of Mn for this type of plant development. Since the root acts as an absorbent and reserve organ, in a poor plant development regime, these nutrients (N, S and Mn) are not likely to be the limiting factors and the plant is accumulating them in its reserve tissues.

The higher $\mathrm{Al}$ content in the root system in the poor plant development sectors could be related to the lower productivity of these sectors. This element has negative effects on the physiology and nutrition of the plant. Physiologically, Al has been shown to affect, among other processes, root elongation and cell division, and to interfere with the activity of nucleic acids in the root apex (Ciamporova 2002). These effects could be occurring in the roots of plants in the poor development sectors, reducing in turn root production and nutrient uptake. Roots from plants with poor development could uptake fewer nutrients as a result of the $\mathrm{Al}$ accumulation in the root tissues. This could be defined as an aluminum 'plug' located in the external root surface, the rhizodermis, and it can cause inhibition of root growth due to the toxic effect of this accumulation and other heavy metals (Marschner 2012; Serrano 2005).

The Al root accumulation could also be a defense mechanism of the banana plant to keep Al from reaching other tissues with more physiological activity. This mechanism is regulated by processes of aluminum compartmentalization in the root cells, and by complexation of this element using weak organic acids at the cellular level (Delhaize and Ryan 1995; Illes et al. 2006; Ma et al. 2001; Rengel 1996). Even so, the presence of a high amount of Al in the root tissue affects cell division and growth. Prior research on other crops indicates that nitrate uptake and nitric oxide production is negatively affected, both of them important for root growth, which is reduced under this condition (Durieux et al. 1995; Matsumoto and Yamamoto 2002; Kochian et al. 2005; Illes et al. 2006). 
The lower concentration of microorganisms in the roots of poor development sectors could be a result of a biochemical relationship between $\mathrm{Al}$ and other minerals, such as $\mathrm{Cu}, \mathrm{Zn}, \mathrm{Hg}$ and $\mathrm{Ag}$, and other heavy metals (Hg and Ag were not analyzed) and the microorganisms. These elements can be part of important enzymatic processes in the rhizosphere and root tissue (Joner et al. 2005; Chaperon and Sauvé 2007). Heavy metals, including Al, are more available at low soil pH (lower than 5.5), as was found in soils from the poor plant development. Microbial biomass and diversity are reduced with the presence of these elements, which could explain the lower number of microorganisms found per gram of root in this development area.

$\mathrm{Al}$ accumulation in root tissues adversely affects the N, P and S cycles (Kandeler et al. 1996). This could explain the accumulation of $\mathrm{N}$ and $\mathrm{S}$ in the roots taken from plants in the poor development sectors, which has an effect on their cycle and produces a reduced uptake of these elements. This could partially explain the lower productivity of plants in this development sector. Primarily, $\mathrm{N}$ uptake is limited with $\mathrm{Al}$ accumulation in root tissue, as well as root elongation, though this was not evaluated in this study. The relationship between $\mathrm{Al}$ accumulation and the limited development of banana plants should be explored in greater depth and, if necessary, corrective measures should be evaluated. Immobilization of $\mathrm{Al}$ at the cellular level with the application of organic acids could be an option in the future for this problem (Delhaize and Ryan 1995; Ma et al. 2001). In addition, the continuous application of lime is an appropriate option to maintain a higher soil $\mathrm{pH}$ and achieve lower contents of Al in banana farm soils.

\subsection{Conclusion}

This study shows the complex interactions between soil chemical and microbiological properties and how they affect banana production. Soil $\mathrm{pH}$ influences other soil properties. Banana plant development and the soil chemical and microbiological status, as well as the banana roots, were affected by the low $\mathrm{pH}$ of the soil. This information is new in banana cultivation and shows that microbiological activity of banana soils is suppressed, which in turn affects banana development (and production), and that larger microorganism populations in both the soil and the roots are related to a higher crop development. Practices to increase and maintain higher soil $\mathrm{pH}$ and stimulate microbiological populations and activity in soils could have a positive effect on banana farm production, not only for poor development areas, but also for good plant development sectors. 


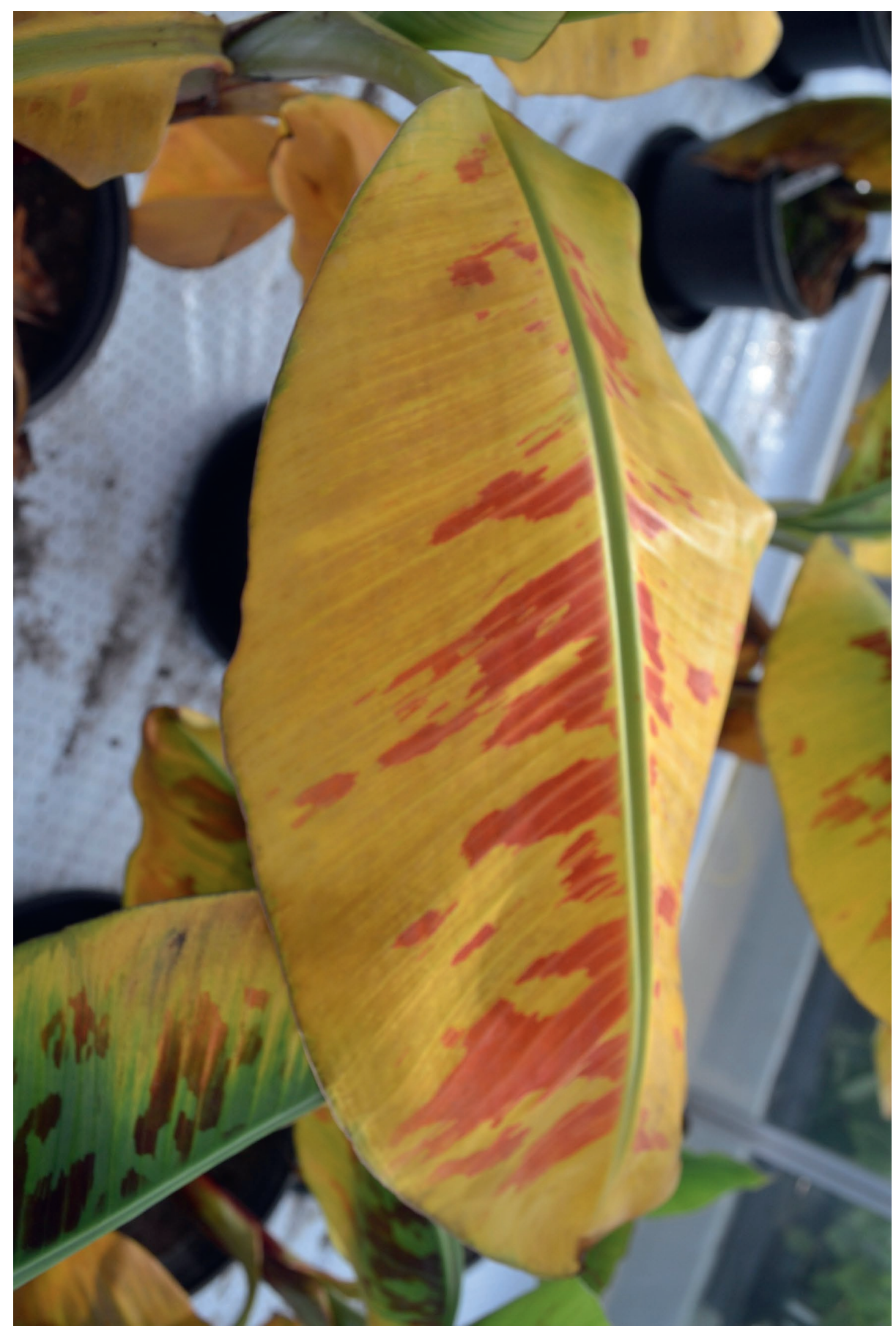




\section{Chapter 3}

\section{Evaluating the potential of soil management to reduce the effect of Fusarium oxysporum f. sp. cubense in banana (Musa AAA).}

Fusarium oxysporum f. sp. cubense (Foc) causes Fusarium wilt in banana (Musa AAA). Foc Race 1 devastated the subgroup Gros Michel during the first half of the $20^{\text {th }}$ century. The Gros Michel was largely replaced by the resistant subgroup Cavendish in the 1950s. However, in the 1980s, Foc Tropical Race 4 started to spread affecting Cavendish bananas. No proper control measures have been found to deal with the disease. This paper re-takes an important research line from the $1950 \mathrm{~s}$ to evaluate the potential of soil management for Fusarium wilt management. The role of soil properties on Fusarium wilt in bananas was studied in two greenhouse experiments. It was evaluated whether the influence of two main soil properties ( $\mathrm{pH}$ and $\mathrm{N}$ ) on Fusarium wilt is similar for Race 1 and Tropical Race 4. Two soil pH levels (lower than 5.2 and higher than 6.0) respectively ensured through acidification and liming; and three levels of $N$ (ammonium nitrate, 33.5\% N) weekly doses (low:0 $\mathrm{Ng}$, medium: $0.08 \mathrm{Ng}$ and high: $0.25 \mathrm{~N} g$ per plant) were achieved. The first experiment in Costa Rica confirmed the earlier results about the influence of soil pH and nitrogen on Fusarium wilt (Race 1) on Gros Michel bananas. The second experiment in The Netherlands evaluated the influence of pH and $N$ on interactions between Foc (both Race 1 and Tropical Race 4) and Cavendish bananas. Results in both experiments showed that soil pH affected crop development and the disease. Besides, the interaction of the lower $p H x$ the higher $N$ accelerated the infection and reduced plant development. As such, the results showed that soil management has the potential to reduce the impacts of Fusarium wilt while dealing with Race 1 and Tropical Race 4 although it requires confirmation and further evaluation under field conditions.

\section{This chapter is based on:}

Segura-Mena RA, Stoorvogel JJ, Garcia-Bastidas F, et al (2021) Evaluating the potential of soil management to reduce the effect of Fusarium oxysporum $f$. sp. cubense in banana (Musa AAA). Eur J Plant Pathol 160:441-455. https://doi.org/10.1007/s10658-021-02255-2 


\subsection{Introduction}

Fusarium wilt (also known as 'Panama disease') is a soil-borne disease caused by the fungus Fusarium oxysporum f. sp. cubense (Foc). The disease has strongly affected global banana production (Ordoñez et al. 2015; Pocasangre et al. 2017; Dita et al. 2018). Desert bananas and cooking bananas (including plantain) are an important staple in developing countries, where they represent a major part of the subsistence economy for millions of people (Aurore et al. 2009). In addition, desert bananas, dominated by the subgroup Cavendish (Musa AAA), are an important and valuable agricultural commodity for many exporting countries (Butler 2013; Ploetz 2015a). The first major outbreak of Fusarium wilt (caused by the so-called Race 1 strain of Foc) decimated the large-scale production of the susceptible banana subgroup Gros Michel (Musa AAA). A gradual shift to resistant Cavendish (Musa AAA) cultivars controlled the epidemic in Latin America and the Caribbean during the last century (Harper 1950; Stover 1961; Ploetz 1990; Perez-Vicente 2004). This shift to Cavendish cultivars saved the banana industry. However, another Foc strain, commonly called Tropical Race 4 (TR4; Foc vegetative compatibility group VCG 01213), currently affects or threats Cavendish plantations worldwide.

Foc TR4 may lead to a new, more widespread, wave of Fusarium wilt, as many banana cultivars are susceptible to this strain (Molina et al. 2008; Ordoñez et al. 2016). Foc TR4 has been reported in various countries, such as Malaysia, China, Indonesia, and the Philippines in South East Asia (Molina et al. 2008), Jordan (García-Bastidas et al. 2014) and Pakistan (Ordoñez et al. 2016), where it already destroyed thousands of hectares. Recently, Foc TR4 has also been reported in Latin America (García-Bastidas et al. 2020). The potential effect of further dissemination could cause chaos, damage the economies of many banana-producing countries, and affect food security (Dita et al. 2013). There are no effective control measures (such as fungicides or cultural practices) for the disease. A transgenic TR4 resistant Cavendish cultivar (Dale et al. 2017) and somaclonal variation resistance in Cavendish cultivars (Hwang and Ko 2004) are being promoted, but these options require more validation and studies before large-scale implementation. Given the fact that it takes several years to develop and distribute resistant banana cultivars, and the ineffectiveness of fungicides or other crop protection agents, it is appropriate to consider alternative strategies to reduce disease incidence in the short term (Geense et al. 2015).

Soil properties are known to influence the predisposition of crops to diseases (Doran and Zeiss 2000; Ghorbani et al. 2008; Huber et al. 2012) and they can be managed through e.g., fertilization, 
liming, tillage, and drainage. Therefore, soil management can potentially reduce the impact of crop diseases (Amir and Alabouvette 1993; Höper et al. 1995). Nevertheless, soil management receives little attention as a strategy for crop disease management. Although Rishbeth (1955) and Stover (1961) already discussed the potential of soil management in the case of Foc Race 1 in bananas, the research into soil management to control Fusarium wilt became less relevant with the discovery and introduction of Cavendish bananas. Problems with Race 1 in the small-scale production of susceptible varieties and the recent spread of Foc TR4 renewed the interest into soil management for Fusarium wilt management. Recently, several authors discussed the potential role of soil properties (e.g., $\mathrm{pH}$, drainage, and nutrients) in relation to Fusarium wilt in bananas, mainly focusing on Fusarium wilt by Foc Race 1 (Domínguez et al. 2008; Geense et al. 2015; Haddad et al. 2018; Segura et al. 2018, 2019; Orr and Nelson 2018). The current threat of Fusarium wilt by Foc TR4 makes it necessary to corroborate the previous results obtained with Foc Race 1. However, despite the need for more insight in Foc TR4, it is practically impossible to carry out field experiments with Foc TR4 in most places around the world for phytosanitary reasons. As a result, many studies use Foc Race 1 and susceptible varieties under the assumption that these results are also valid for Foc TR4 (e.g., Bowen et al. 2019).

Literature confirms the effects of soil $\mathrm{pH}$ on crop disease incidence. A low soil $\mathrm{pH}$ has been linked with a higher predisposition to diseases in crops (Rengel 2000; Huber et al. 2012): Fusarium wilt in flax (Höper et al. 1995) and bananas (Domínguez et al. 2008), root rot (Aphanomyces spp.) in pea (Persson and Olsson 2000), common scab (Streptomyces scabiei) in potatoes (Goto 1985; Lacey and Wilson 2001; Lambert et al. 2005), and phytophtora root rot (Phytophthora cinnamomi) in avocado (Fernandez-Falcon et al. 1984). However, there are also examples that a high soil pH is associated with a higher crop disease incidence: black root (Thielaviopsis basicola), causing black root rot in tobacco (Oyarzun et al. 1998; Harrison and Shew 2001) and take-all (Gaeumannomyces graminis Sacc.) in wheat (Duffy et al. 1997). Despite these reports, where a relation between soil pH and the incidence of crop diseases was found, there are also other studies that did not confirm this relationship (Janvier et al. 2007).

It is generally accepted that soil $\mathrm{N}$ influences crop diseases (Rengel 2000; Janvier et al. 2007; Huber et al. 2012). However, the results are inconsistent and varied according to e.g., the applied $\mathrm{N}$ form, the pathogen, the crop or its growth stage (Huber and Watson 1974; Harrison and Shew 2001; Dordas 2008). Both positive and negative relationships between $\mathrm{N}$ concentrations and crop disease incidence have been reported. For instance, a lower $\mathrm{N}$ concentration was related with increased incidence of early blight (Alternaria solani) in potatoes (Miller and Rosen 2005), Xanthomonas wilt 
(Xanthomonas campestris pv. musacearum) in bananas (Atim et al. 2013), grey mould (Botrytis cinerea) in tomatoes (Hoffland et al. 1999), and bacterial speck (Pseudomonas syringae) and powdery mildew (Oidium lycopersicum) in tomatoes (Hoffland et al. 2000). N concentrations are especially important for disease incidence in wheat and other cereals. The incidence of take-all caused by Gaeumannomyces graminis (Brennan 1992), Septoria tritici blotch (Mycosphaerella graminicola), brown rust (Puccinia recondite), powdery mildew (Blumeria graminis) and foot rot (Fusarium spp.) increased with higher N concentrations (Walters et al. 1984; Leitch and Jenkins 1995; Tiedemann 1995; Rodgers-Gray and Shaw 2000; Olesen et al. 2003).

This paper aims to re-take an important research line from the 1950 s to evaluate the potential of soil management to control Fusarium wilt in bananas. Based on the importance of soil $\mathrm{pH}$ and $\mathrm{N}$ in crop production and the reported impact of these soil properties on crop response to diseases their role on the expression of Fusarium wilt in bananas was studied. In addition, this study evaluates whether the influence of those soil properties on the occurrence of Fusarium wilt is similar for Foc Race 1 and Foc TR4.

\subsection{Materials and methods}

Two separate greenhouse experiments with a similar experimental setup were carried out. The first experiment, performed in Costa Rica, aimed to evaluate previous results about soil properties and the disease reported in the literature with the model between the subgroup Gros Michel and Foc Race 1 (present in Costa Rican soils). The second experiment, performed in The Netherland under strict biosecurity rules, aimed to study the effect of soil properties on the subgroup Cavendish and Foc TR4 to evaluate whether this new strain of the fungus provides similar results.

In the first greenhouse experiment (in Costa Rica), the development of Fusarium wilt by Foc Race 1 was studied. The aim was corroborating previous results reported in the literature about the incidence of Fusarium wilt in the model between Gros Michel banana and Foc Race 1. It was

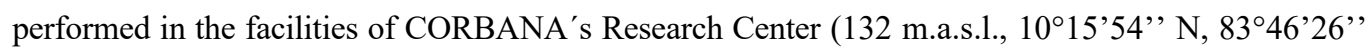
$\mathrm{W}$, minimum temperature of $17{ }^{\circ} \mathrm{C}$ and maximum temperature of $35^{\circ} \mathrm{C}$ ). Two types of inoculation were tested in this experiment: a control without any inoculation and inoculation with Foc Race 1 (collected from Costa Rican soils and cultivated by CORBANA's Laboratory of Biological Control). Plant inoculation was performed following protocols previously reported (García-Bastidas et al. 2014; 
Ordoñez et al. 2016), using root dipping for $30 \mathrm{~min}$ in a solution of $1.10^{-6}$ Foc conidia per mL. After inoculation, plants were transferred to $2 \mathrm{~L}$ pots filled with a medium-texture and fertility $(2.5 \%$ organic matter, $11.3 \mathrm{~g} \mathrm{~kg} \mathrm{soil}^{-1} \mathrm{Ca}, 7.05 \mathrm{~g} \mathrm{~kg} \mathrm{soil}^{-1} \mathrm{Mg}, 0.16 \mathrm{~g} \mathrm{~kg} \mathrm{soil}^{-1} \mathrm{~K}$ and $0.01 \mathrm{~g} \mathrm{~kg} \mathrm{soil}^{-1} \mathrm{P}$ ) soil. This soil type is commonly used for growing bananas in Costa Rica and was therefore also used to test the plant response against the disease according to soil management. Treatments of the evaluated soil properties ( $\mathrm{pH}-\mathrm{N}$ ) consisted in two soil $\mathrm{pH}$ levels (lower than 5.2 and higher than 6.0) and three $\mathrm{N}$ doses (low, medium, and high). The natural soil $\mathrm{pH}$ was approximately 6.1 and it was considered the higher level of soil $\mathrm{pH}$ ( $\mathrm{pH}$ high). For the low $\mathrm{pH}$ level ( $\mathrm{pH}$ low $)$, the $\mathrm{pH}$ was decreased to 5.1 through the application of a hydrochloric acid solution $(10 \% \mathrm{HCl}) . \mathrm{N}$ doses were achieved through weekly differentiated $\mathrm{N}$ doses of ammonium nitrate $(\mathrm{AN}, 33.5 \% \mathrm{~N})$ : $\mathrm{N}_{\text {low }}$ with no $\mathrm{N}$ addition relying on natural $\mathrm{N}$ in the soil; 2) $\mathrm{N}_{\text {med }}$ with $0.08 \mathrm{~N} \mathrm{~g} \mathrm{plant}^{-1}$ week $^{-1}$ supplied through $0.24 \mathrm{~g}$ of AN plant $^{-1}$ week $^{-}$

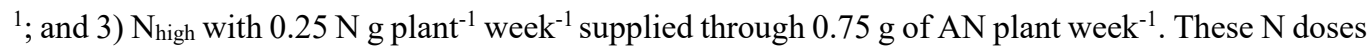
were respectively achieved through applications of $300 \mathrm{~mL}$ of solutions of $\mathrm{AN}$ in water with concentrations of respectively $0.00 \mathrm{~g} \mathrm{~L}^{-1} \mathrm{~N}, 0.14 \mathrm{~g} \mathrm{~L}^{-1} \mathrm{~N}$ and $0.43 \mathrm{~g} \mathrm{~L}^{-1} \mathrm{~N}$, two times week $\mathrm{k}^{-1}$. Because the soil in this experiment originated from a banana plantation, also the pots not receiving any additional AN had a basic level of available N. Each treatment was replicated three times resulting in a total of 36 hardened tissue culture plants (approximately 3 months-old). Although the greenhouse in this experiment gave some protection, the plants were exposed to the climatic conditions of a banana growing region.

The second experiment (in The Netherlands) aim was to explore the impact of soil properties on the response of Cavendish bananas to both Fusarium wilt by Foc Race 1 and Foc TR4. The experiment was performed under controlled greenhouse conditions $\left(28^{\circ} \mathrm{C}, 80 \%\right.$ relative humidity and $16 \mathrm{~h}$ of light) at the facilities of Plant Research International of Wageningen University and Research (WUR). It was possible to include Foc TR4 in this experiment due to the controlled and strict biosecurity conditions offered by the greenhouse facilities and because there is no risk of spreading the disease to banana plantations. Three types of inoculation were tested in this experiment: a control without any inoculation, inoculation with Foc Race 1 (Foc CNPMF 008-01-R1 collected from Brazil and stored at WUR collection), and inoculation with Foc TR4 (Foc II-5 TR4 reference isolate collected from Indonesia and stored at WUR collection). The experimental setup in regarding of plant inoculation and the treatment of the selected soil properties $(\mathrm{pH}-\mathrm{N})$ was similar than in the first experiment. 
Plants from this experiment were transferred to $2 \mathrm{~L}$ pots filled with a light-textured soil with intermediate fertility $\left(2.6 \%\right.$ organic matter, $0.04 \% \mathrm{~N}, 0.09 \mathrm{~g} \mathrm{~kg} \mathrm{soil}^{-1} \mathrm{Ca}, 0.06 \mathrm{~g} \mathrm{~kg} \mathrm{soil}^{-1} \mathrm{Mg}, 0.03 \mathrm{~g}$ $\mathrm{kg} \mathrm{soil}^{-1} \mathrm{~K}$ and $0.0013 \mathrm{~g} \mathrm{~kg} \mathrm{soil}^{-1} \mathrm{P}$ ). The same level of soil $\mathrm{pH}$ (lower than 5.2 and higher than 6.0) and the same three $\mathrm{N}$ doses $\left(0,0.08\right.$ and $0.25 \mathrm{~g} \mathrm{~N}$ plant week $\left.^{-1}\right)$ were tested with four replications per each inoculation (control, Foc Race 1, and Foc TR4) resulting in an experimental design in which 72 approximately 3 months old plants were evaluated. The natural soil $\mathrm{pH}$ level was approximately 5.1 considered the lower soil $\mathrm{pH}$ ( $\mathrm{pH}$ Low). For the higher $\mathrm{pH}$ level ( $\mathrm{pH}$ high), it was increased applying liming (with $\mathrm{CaCO}_{3}$ ). Inputs of $\mathrm{Ca}$ in this treatment were compensate with $\mathrm{CaCl}$ in the $\mathrm{pH}$ low. $\mathrm{N}$ doses per plant were achieved following the same experimental setup with the same $N$ source (AN) as in the first experiment. Also, this soil had a basic level of available N.

The disease expression was measured in terms of its (negative) effect on the total biomass and leaf area per plant at the harvesting moment, 54 days after inoculation (d.a.i.) in the first experiment and at 33 d.a.i. in the second experiment. Because the inoculated plants were exposed to the fungus, the presence of symptoms can be attributed to Foc. This was further confirmed as the non-inoculated plants did not show symptoms. Therefore, a non-intrusive way to measure the disease according to the management of the soil properties was used to follow the development of the wilting. A disease index (DI) was calculated in each treatment of each experiment. The DI was obtained adapting the McKinney’s formula (McKinney 1923) that was also used by Haddad et al. (2018) and Rocha et al. (2020) in the same way. However, in this case, it was based on the number of sick plants and the wilted leaves: $\mathrm{DI}(\%)=100 \cdot \sum(\mathrm{f} / \mathrm{n}) \cdot(\mathrm{v} / \mathrm{x})$, where; $\mathrm{f}=$ number of sick plants; $\mathrm{n}=$ total of plants; $\mathrm{v}=$ number of leaves with symptoms; and $\mathrm{x}=$ total number of leaves (with symptoms and healthy). The presence of the typical symptoms of the wilting of the leaves in previously inoculated plants is reported as a valid element to corroborate the presence of the disease in bananas (Dita et al. 2010; García-Bastidas et al. 2014, 2020; Ordoñez et al. 2016). In addition, the dissection of wilted plants was performed to corroborate the presence of the typical internal symptoms of the disease. The data results of the experiments were independently analyzed through a factorial analysis of variance, considering in each case three factors (inoculation, soil $\mathrm{pH}$ and $\mathrm{N}$ dose) and their interactions. Differences between factors were evaluated for significance through a Tukey's range test. 


\subsection{Results}

\subsubsection{Experiment 1}

Plant biomass and leaf area in non-inoculated plants were different $(\mathrm{P} \leq 0.050)$ between $\mathrm{pH}_{\text {high }}$ and $\mathrm{pH}_{\text {low }}$ for all the $\mathrm{N}$ doses (Table 3-1). For both variables, $\mathrm{pH}_{\text {high }}$ plants had a better performance. The differences were more evident in the case of leaf biomass. Plants grown in a pHhigh produced around 6 times biomass than those grown in the $\mathrm{pH}_{\text {low. }}$. The difference followed the same behavior for the leaf area but with a less dramatic difference. In this case plants from $\mathrm{pHhigh}$ produced around 4 times the leaf area produced in plants grown in $\mathrm{pH}$ low. Although, $\mathrm{N}$ soil concentrations appeared in most of the cases to be enough for fulfill the plant requirements, the lower value of the biomass was found in $\mathrm{N}_{\text {high }}$ of the $\mathrm{pH}$ low group. The natural effect of the soil $\mathrm{pH}$, the $\mathrm{N}$, and their interactions in the development of the banana plant was evidenced with those results.

Table 3-1 Tukey's analysis of the comparison of biomass and leaf area at 54 days after planting from non-inoculated (c control) Gros Michel banana plants (Musa AAA) grown in two soil pH levels (lower than 5.2 and higher than 6.0) and three $\mathrm{N}$ (with ammonium nitrate, $33.5 \% \mathrm{~N})$ doses $\left(\mathrm{N}_{\text {low }}\right.$ with no $\mathrm{N}, \mathrm{N}_{\text {med }} 0.08 \mathrm{~N}$ g plant week ${ }^{-1}$, and $\mathrm{N}_{\text {high }} 0.25 \mathrm{~N}$ g plant week $^{-1}$ ) in a greenhouse experiment in Costa Rica (standard deviation between parentheses).

\begin{tabular}{|c|c|c|c|c|c|}
\hline \multirow{2}{*}{ Variable } & \multirow[t]{2}{*}{ Soil pH } & \multicolumn{4}{|c|}{$\mathrm{N}$ dose } \\
\hline & & Low & Med & High & Average \\
\hline \multirow[t]{4}{*}{ Biomass (g plant ${ }^{-1}$ ) } & Low & 4.2 & 6.0 & 2.8 & 4.4 \\
\hline & High & 24.6 & 29.7 & 29.0 & 27.8 \\
\hline & Average & 14.4 & 17.9 & 15.9 & 16.1 \\
\hline & & (15) & (17) & (19) & (12) \\
\hline$\left(\mathrm{pH}_{\text {low }}-\mathrm{pH}_{\text {high }}\right)$ & & $-20.4 *$ & $-23.7^{*}$ & $-26.2 *$ & $-23.4 *$ \\
\hline \multirow[t]{4}{*}{ Leaf area $\left(\mathrm{cm}^{2}\right.$ plant $\left.^{-1}\right)$} & Low & 57.1 & 95.4 & 62.8 & 71.7 \\
\hline & High & 210.4 & 247.8 & 316.0 & 258.0 \\
\hline & Average & 133.8 & 171.6 & 189.4 & 164.9 \\
\hline & & (108) & (108) & (179) & $(132)$ \\
\hline$\left(\mathrm{pH}_{\text {low }}-\mathrm{pH}_{\text {high }}\right)$ & & $-153.3 *$ & $-152.4^{*}$ & $-126.6^{*}$ & $-186.3 *$ \\
\hline
\end{tabular}

$* * \mathrm{P} \leq 0.010 ; * \mathrm{P} \leq 0.050$ 
A higher biomass and leaf area per plant were found in plants from the control treatment for both $\mathrm{pH}$ low and $\mathrm{pH}$ high $(\mathrm{P} \leq 0.0001)$ in comparison with those which were inoculated. However, both variables were lower at $\mathrm{pH}_{\text {low }}(\mathrm{P} \leq 0.0001)$ for both the control and the inoculated plants (Figure 3-1). Even inside the inoculated group of plants the lower biomass was found in those growing in $\mathrm{pH}$ low. A highly significant interaction of $\mathrm{pH} x$ inoculation was observed $(\mathrm{P} \leq 0.0001)$. A higher plant development and growth were found in $\mathrm{pHhigh}$. A high correlation $(r=0.95)$ between those variables (biomass and leaf area per plant) was found in these plants. The single effect of the $\mathrm{N}$ doses did not induce a significant difference on the evaluated variables. However, the soil $\mathrm{pH} x \mathrm{~N}$ interaction was almost significant $(\mathrm{P}=0.068)$.
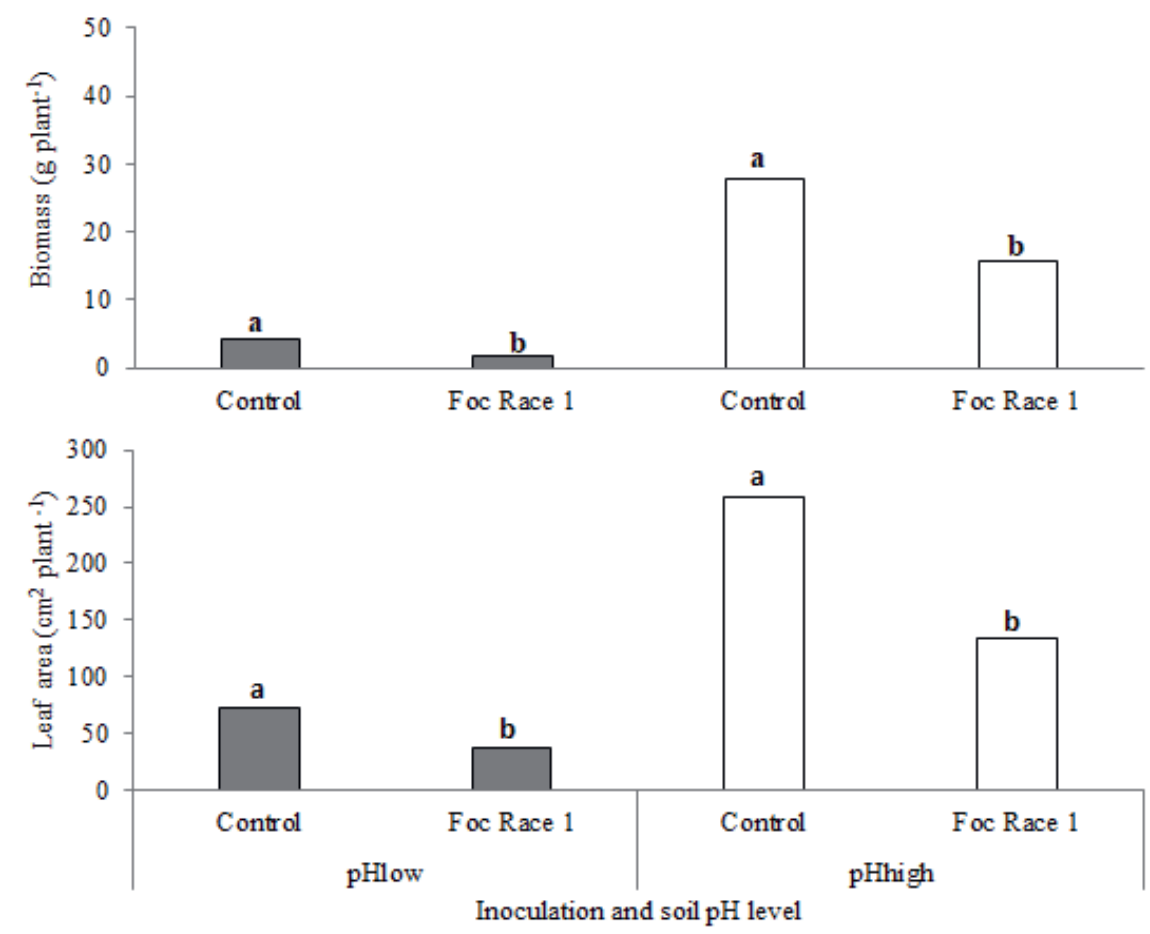

Figure 3-1 Biomass and leaf area from non-inoculated(control) and inoculated Gros Michel banana plants (Musa AAA) with Fusarium oxysporum f. sp. cubense Race 1 grown in two soil $\mathrm{pH}$ levels (lower than 5.2 and higher than 6.0) at 54 days after inoculation in a greenhouse experiment in Costa Rica. Small letters indicate differences between the treatments in each $\mathrm{pH}$ level. 
There were differences $(\mathrm{P} \leq 0.0001)$ in each $\mathrm{N}$ dose for both variables when changes of obtained values were compared between the inoculated and the control groups. At the same time, the more extended gaps in this comparison (control-inoculation) were observed for $\mathrm{N}_{\text {med }}$ and $\mathrm{N}_{\text {high. }}$ The differences in $\mathrm{N}_{\text {low }}$ kept the $\mathrm{pH} \times$ inoculation significance, but this $\mathrm{N}$ dose had a minor difference between inoculated and control plants (Table 3-2).

The DI of Fusarium wilt was higher in plants from the $\mathrm{pH}_{\text {low }}(\mathrm{P} \leq 0.050)$. For both $\mathrm{pH}$ low and $\mathrm{pH}$ high, first symptoms were detected after the third week since planting. The $\mathrm{pH} \times \mathrm{N}$ interaction was found significant $(\mathrm{P} \leq 0.050)$ to the $\mathrm{DI}$. Besides, a higher DI was calculated in the higher $\mathrm{N}$ doses for both soil $\mathrm{pH}$ levels. This interaction $\left(\mathrm{pH} \times \mathrm{N}\right.$ ) was linear and more accentuated in $\mathrm{pH}_{\text {low }}$ (Figure 3-2). No symptoms were identified in non-inoculated plants. However, some plant from $\mathrm{pH}_{\text {low }}$ showed a chlorotic (not wilted) appearance attributed to the extreme lower $\mathrm{pH}$ in this treatment (Figure 3-3).

Table 3-2 Tukey's analysis of the comparison of biomass and leaf area at 54 days after inoculation between the inoculation with Fusarium oxysporum f. sp. cubense Race 1 against the control from Gros Michel banana plants (Musa AAA) grown in two soil pH levels (lower than 5.2 and higher than 6.0) and three $\mathrm{N}$ (with ammonium nitrate, $33.5 \% \mathrm{~N})$ doses $\left(\mathrm{N}_{\text {low }}\right.$ with no $\mathrm{N}, \mathrm{N}_{\text {med }} 0.08 \mathrm{~N}$ g plant week ${ }^{-1}$, and $\mathrm{N}_{\text {high }} 0.25 \mathrm{~N}$ g plant week $^{-1}$ ) in a greenhouse experiment in Costa Rica.

\begin{tabular}{cccccc}
\hline \multirow{2}{*}{ Variable } & Soil $\mathrm{pH}$ & \multicolumn{4}{c}{$\mathrm{N}$ dose } \\
\cline { 3 - 6 } & & $\mathrm{N}_{\text {low }}$ & $\mathrm{N}_{\text {med }}$ & $\mathrm{N}_{\text {high }}$ & Average \\
\hline Change in biomass $\left(\mathrm{g} \mathrm{plant}^{-1}\right)$ & Low & $-1.3^{* *}$ & $-6^{* *}$ & $-0.7^{* *}$ & $-2.7^{* *}$ \\
& High & $-5.4^{* *}$ & $-11.2^{* *}$ & $-20^{* *}$ & $-12.2^{* *}$ \\
& Average & -3.4 & -8.6 & -10.4 & -7.5 \\
\hline Change in leaf area $\left(\mathrm{cm}^{2}\right.$ plant $\left.^{-1}\right)$ & Low & $-4.5^{* *}$ & $-95.4^{* *}$ & $-2.3^{* *}$ & $-34.1^{* *}$ \\
& High & $-55.4^{* *}$ & $-96.8^{* *}$ & $-222^{* *}$ & $-87.8^{* *}$ \\
& Average & -29.9 & -96.1 & -112.2 & -60.9 \\
\hline
\end{tabular}

$* * \mathrm{P} \leq 0.010 ; * \mathrm{P} \leq 0.050$ 


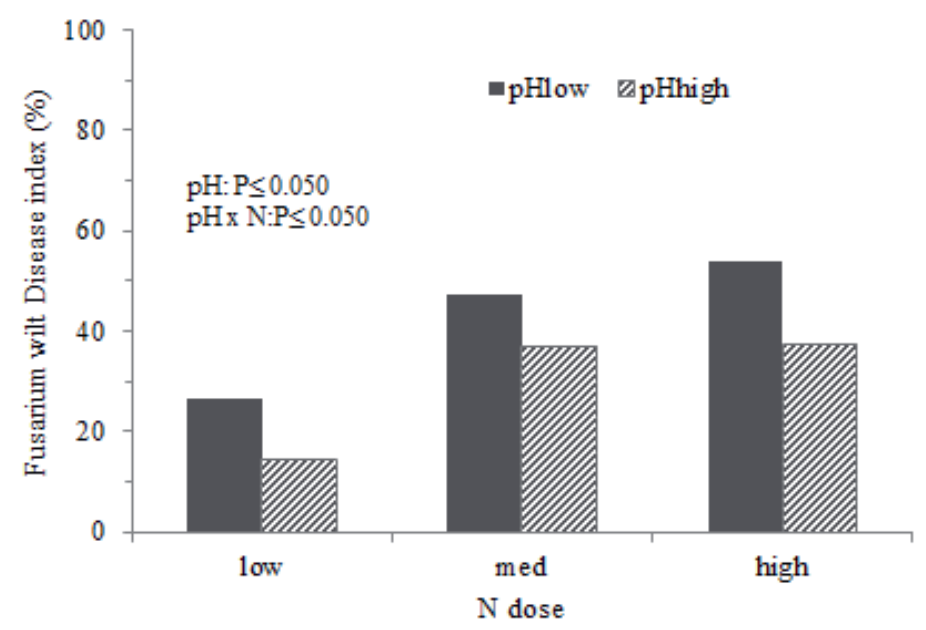

Figure 3-2 Disease Index of Fusarium wilt by Fusarium oxysporum f. sp. cubense Race 1 at 54 days after inoculation from Gros Michel banana plants (Musa AAA) grown in two soil $\mathrm{pH}$ levels (lower than 5.2 and higher than 6.0 ) and three $\mathrm{N}$ (with ammonium nitrate, $33.5 \% \mathrm{~N})$ doses $\left(\mathrm{N}_{\text {low }}\right.$ with no $\mathrm{N}, \mathrm{N}_{\text {med }} 0.08 \mathrm{~N} \mathrm{~g}$ plant week $^{-1}$, and $\mathrm{N}_{\text {high }} 0.25 \mathrm{~N} \mathrm{~g}$ plant week $^{-1}$ ) in a greenhouse experiment in Costa Rica.

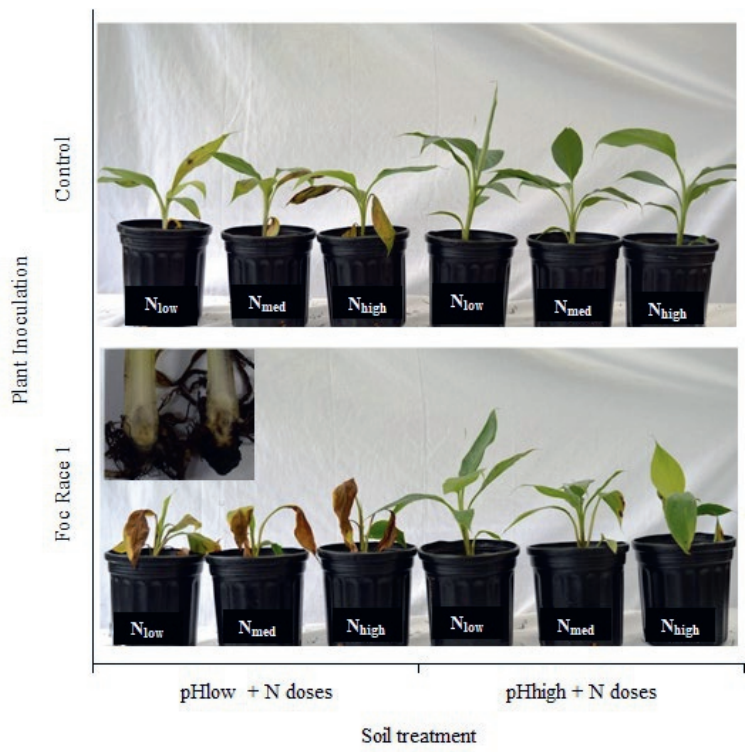

Figure 3-3 External and internal Fusarium wilt symptoms by Fusarium oxysporum f. sp. cubense Race 1 at 54 days after inoculation from Gros Michel banana plants (Musa AAA) grown in two soil pH levels (lower than 5.2 and higher than 6.0) and three $\mathrm{N}$ (with ammonium nitrate, $33.5 \% \mathrm{~N})$ doses $\left(\mathrm{N}_{\text {low }}\right.$ with no $\mathrm{N}, \mathrm{N}_{\text {med }} 0.08 \mathrm{Ng}$

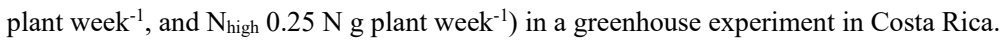




\subsubsection{Experiment 2}

Biomass and leaf area in plants from the control (not inoculated) group are presented in table 3-3. Although there were higher values in biomass and the leaf area for plants grown in $\mathrm{pH}$ high, only the biomass $(\mathrm{P} \leq 0.050)$ was found different according to soil $\mathrm{pH}$. Although $\mathrm{N}_{\text {low }}$ presented a lower biomass on average, no significant differences were found for $\mathrm{N}$ doses. Inoculated and non-inoculated plants grown at $\mathrm{pH}_{\text {high }}$ had significantly $(\mathrm{P} \leq 0.001)$ higher biomass and leaf area than those plants grown at $\mathrm{pH}_{\text {low }}$ (Figure 3-4). Soil $\mathrm{pH}$ and the inoculation interacted on the plant biomass and leaf area $(\mathrm{P} \leq 0.0001)$. Inoculated plants at $\mathrm{pH}_{\text {low }}$ had less biomass and leaf area than those of the control. At pHhigh, Foc Race 1 inoculated plants equaled the biomass and surpassed the leaf area of the control. The lower soil $\mathrm{pH}$ resulted in a significant reduction of biomass and leaf area in inoculated plants. Comparing inoculation against non-inoculation, the biomass in the control exceeded the average of the inoculated groups (both Foc Race 1 and Foc TR4). Inoculated plants with Foc TR4 had consistently lower biomass and leaf area in both soil $\mathrm{pH}$ levels. Although the biomass and the foliar area were higher in the plants from $\mathrm{pHhigh}$, this effect was hidden through Foc TR4 $(\mathrm{P}=0.703)$ inoculation due to the stronger pathogenic effect of this fungus. At the end of the experiment, inoculated plants from $\mathrm{pH}_{\text {low }}$ manifested more symptoms than those from $\mathrm{pH}$ high for both Foc Race 1 and Foc TR4 inoculation. All (100\%) inoculated plants for both Foc strains showed symptoms of the disease. A higher aggressive level of the symptoms was shown in $\mathrm{pH}_{\text {low }}$ with Foc TR4 inoculation. No Fusarium wilt incidence was detected in the control group. 
Table 3-3 Tukey's analysis of the comparison of biomass and leaf area at 33 days after planting from non-inoculated (control) Cavendish banana plants (Musa AAA) grown in two soil pH levels (lower than 5.2 and higher than 6.0 ) and three $\mathrm{N}$ (with ammonium nitrate, $33.5 \% \mathrm{~N})$ doses $\left(\mathrm{N}_{\text {low }}\right.$ with no $\mathrm{N}, \mathrm{N}_{\text {med }} 0.08 \mathrm{~N} \mathrm{~g}$ plant week $^{-1}$, and $\mathrm{N}_{\text {high }} 0.25 \mathrm{~N} \mathrm{~g}$ plant week $^{-1}$ ) in a greenhouse experiment in the Netherlands (standard deviation between parentheses).

\begin{tabular}{|c|c|c|c|c|c|}
\hline \multirow{2}{*}{ Variable } & \multirow[t]{2}{*}{ Soil pH } & \multicolumn{4}{|c|}{$\mathrm{N}$ doses } \\
\hline & & Low & Med & High & Average \\
\hline \multirow[t]{5}{*}{ Biomass $\left(\mathrm{g} \mathrm{plant}^{-1}\right)$} & Low & 223 & 291 & 292 & 269 \\
\hline & & $(107)$ & $(102)$ & (73) & (104) \\
\hline & High & 312 & 364 & 335 & 337 \\
\hline & & (40) & $(50)$ & (41) & (44) \\
\hline & Average & 268 & 328 & 313 & 303 \\
\hline$\left(\mathrm{pH}_{\text {low }}-\mathrm{pH}_{\text {high }}\right)$ & & -189 & -73 & -43 & $-68 *$ \\
\hline \multirow[t]{5}{*}{ Leaf area $\left(\mathrm{cm}^{2}\right.$ plant $\left.\mathrm{t}^{-1}\right)$} & Low & 1423 & 1259 & 1574 & 1419 \\
\hline & & $(962)$ & $(412)$ & $(287)$ & $(554)$ \\
\hline & High & 1524 & 1878 & 1460 & 1621 \\
\hline & & $(321)$ & $(118)$ & $(449)$ & (296) \\
\hline & Average & 1473 & 1569 & 1517 & 1520 \\
\hline$\left(\mathrm{pH}_{\text {low }}-\mathrm{pH}_{\text {high }}\right)$ & & -101 & -619 & 114 & -202 \\
\hline
\end{tabular}



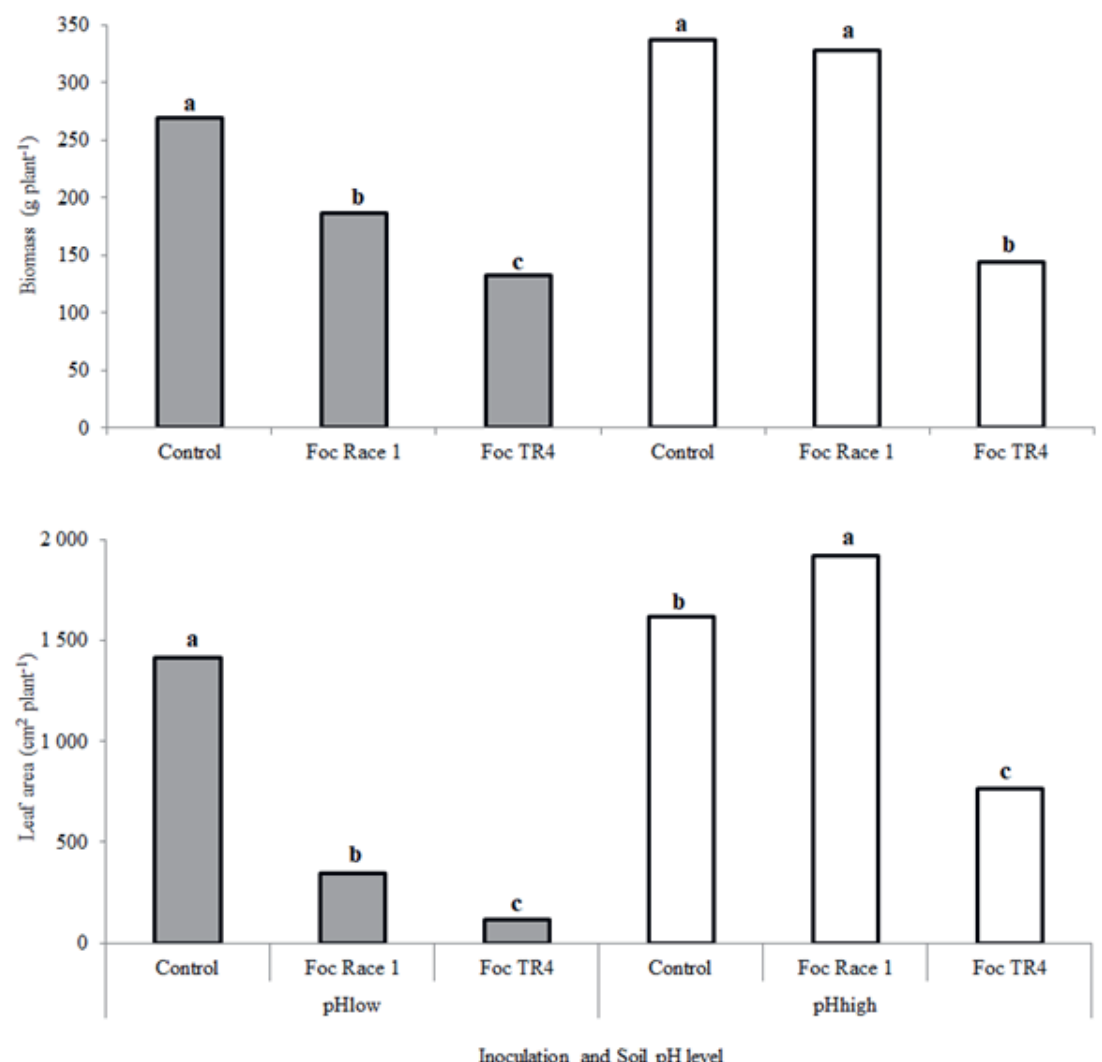

Figure 3-4 Biomass and leaf area at 33 days after inoculation from non-inoculated (control) and inoculated Cavendish banana plants (Musa AAA) with Fusarium oxysporum f. sp. cubense (Race 1 and TR4) grown in two soil pH levels (lower than 5.2 and higher than 6.0) in a greenhouse experiment in the Netherlands. Small letters indicate differences between the treatments in each $\mathrm{pH}$ level.

A significant $\mathrm{pH} \times \mathrm{N}$ interaction $(\mathrm{P} \leq 0.050)$ was found in most of the plant growth variables. Plants from the control group were compared against those from inoculated groups (Table 3-4). Differences between the variables of inoculated plants were lower than those from the control. The $\mathrm{N}$ dose determined the magnitude of the differences. A higher significance $(\mathrm{P} \leq 0.010)$ was found in $\mathrm{pH}_{\text {low }}$ for both Foc strains. Although infected plants showed lower values than the control in both $\mathrm{pH}$ levels, with $\mathrm{N}_{\text {high }}$ those differences were significant and more contrasting for the Foc Race 1 inoculated group. Differences according to $\mathrm{N}$ dose in Foc Race 1 infected plants against the control were not significant in $\mathrm{pH}_{\text {high. }}$ Foc TR4 showed stronger $(\mathrm{P} \leq 0.005)$ differences in $\mathrm{pH}_{\text {low }}$ and $\mathrm{N}_{\text {high }}$ in 
almost all the variables, except for biomass. The effect of the Foc TR4 inoculation was significant in most of the cases, but less contrasting in the case of $\mathrm{pHhigh}$. Furthermore, the effect of the $\mathrm{N}$ doses was significant at least in one of the measured variables in both soil pH levels in Foc TR4 inoculation. Both Foc strains (Race 1 and TR4) induced symptoms in the tested banana cultivar, the Cavendish. Symptoms appeared during the first and second weeks after the inoculation and they were stronger at $\mathrm{pH}_{\text {low }}$ and with Foc TR4 inoculation. Symptoms from Foc race 1 inoculation were fewer and more attenuated at the end of the experiment. However, even at the end of the experiment, plants showed symptoms for both Foc strains (Figure 3-5).

Table 3-4 Tukey's analysis of the comparison of biomass and leaf area at 33 after inoculation between Fusarium oxysporum f. sp. cubense (Race 1 and TR4) inoculation against not inoculation (control) in Cavendish banana plants (Musa AAA) grown in two soil pH levels (lower than 5.2 and higher than 6.0) and three $\mathrm{N}$ (with ammonium nitrate, $33.5 \% \mathrm{~N})$ doses $\left(\mathrm{N}_{\text {low }}\right.$ with no $\mathrm{N}, \mathrm{N}_{\text {med }} 0.08 \mathrm{~N}$ g plant week ${ }^{-1}$, and $\mathrm{N}_{\text {high }} 0.25 \mathrm{Ng}$ plant week ${ }^{-1}$ ) in a greenhouse experiment in the Netherlands.

\begin{tabular}{|c|c|c|c|c|c|c|c|c|c|}
\hline \multirow{2}{*}{ Variable } & \multirow{2}{*}{$\begin{array}{l}\text { Soil } \\
\mathrm{pH}\end{array}$} & \multicolumn{4}{|c|}{ Foc Race 1 - Control } & \multicolumn{4}{|c|}{ Foc TR4 - Control } \\
\hline & & $\mathrm{N}_{\text {low }}$ & $\mathrm{N}_{\text {med }}$ & $\mathrm{N}_{\text {high }}$ & Average & $\mathrm{N}_{\text {low }}$ & $\mathrm{N}_{\text {med }}$ & $\mathrm{N}_{\text {high }}$ & Average \\
\hline \multirow{3}{*}{$\begin{array}{l}\text { Change in biomass } \\
\left(\mathrm{g}_{\text {plant }}{ }^{-1}\right)\end{array}$} & Low & -34 & -10 & -32 & $-82 *$ & -121 & -124 & -164 & $-136^{*}$ \\
\hline & High & 33 & -31 & -29 & 9 & -161 & $-187 *$ & $-232 *$ & $-193 *$ \\
\hline & Average & -1 & 21 & -31 & 24 & -141 & -156 & -198 & -165 \\
\hline \multirow{3}{*}{$\begin{array}{l}\text { Change in leaf area } \\
\left(\mathrm{cm}^{2} \text { plant }^{-1}\right)\end{array}$} & Low & $-1008 *$ & $-923 *$ & $-1293 * *$ & $-1075 * *$ & $-1345 * *$ & $-1142 * *$ & $-1426 * *$ & $-1304 * *$ \\
\hline & High & 414 & 72 & 415 & 300 & -797 & -755 & $-1018 *$ & $-857 * *$ \\
\hline & Average & -297 & -426 & -439 & -388 & -1071 & -949 & -1222 & -1081 \\
\hline
\end{tabular}

$* * \mathrm{P} \leq 0.010 ; * \mathrm{P} \leq 0.050$ 


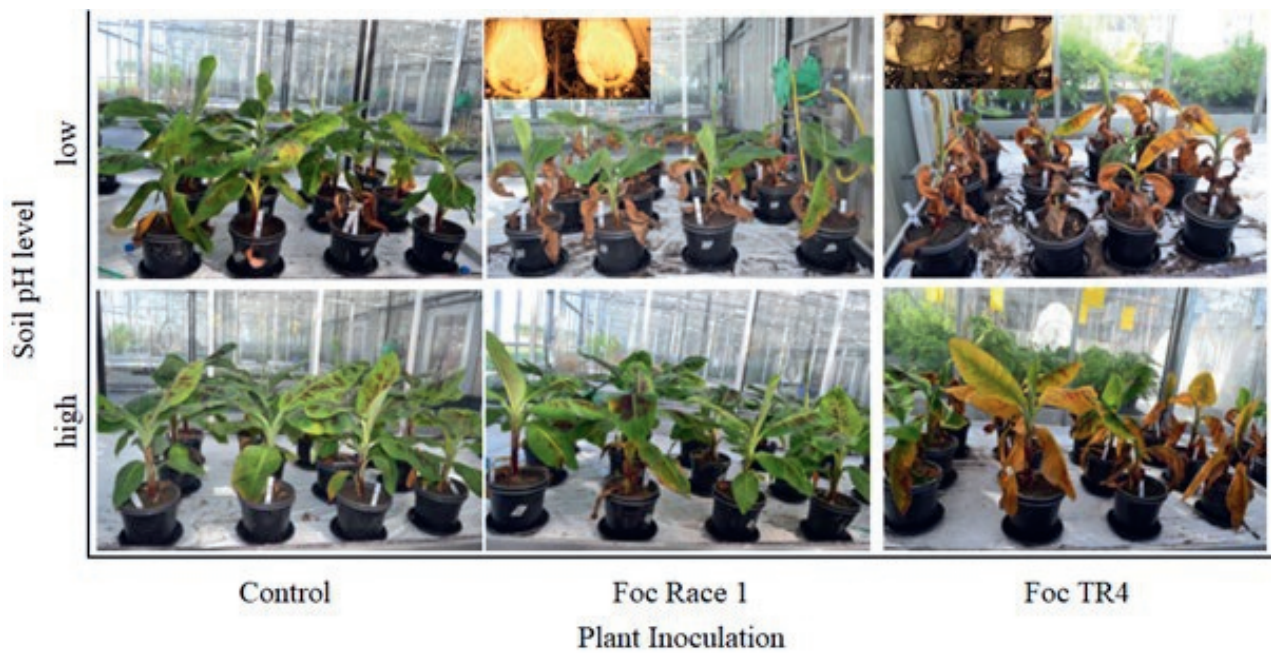

Figure 3-5 External and internal Fusarium wilt symptoms by Fusarium oxysporum f. sp. cubense (Race 1 and TR4) at 33 days after inoculation from Cavendish banana plants (Musa AAA) grown in two soil pH levels (lower than 5.2 and higher than 6.0) in a greenhouse experiment in the Netherlands.

The DI (Figure 3-6) showed a significant effect of a $\mathrm{pH} \times \mathrm{N}$ interaction $(\mathrm{P} \leq 0.010)$. The wilting was more aggressive in Foc TR4 infected plants for both soil $\mathrm{pH}$ levels and all the $\mathrm{N}$ doses. DI in TR4 infected plants from $\mathrm{pH}_{\text {low }}$ reached almost $100 \%$ and around $80 \%$ in Foc Race 1 . In $\mathrm{pH}_{\text {high }}$ the DI in the plants was higher for TR4 inoculation respect to the Race 1 inoculation, but it was lower than in $\mathrm{pH}_{\text {low }}$ from both inoculations. 


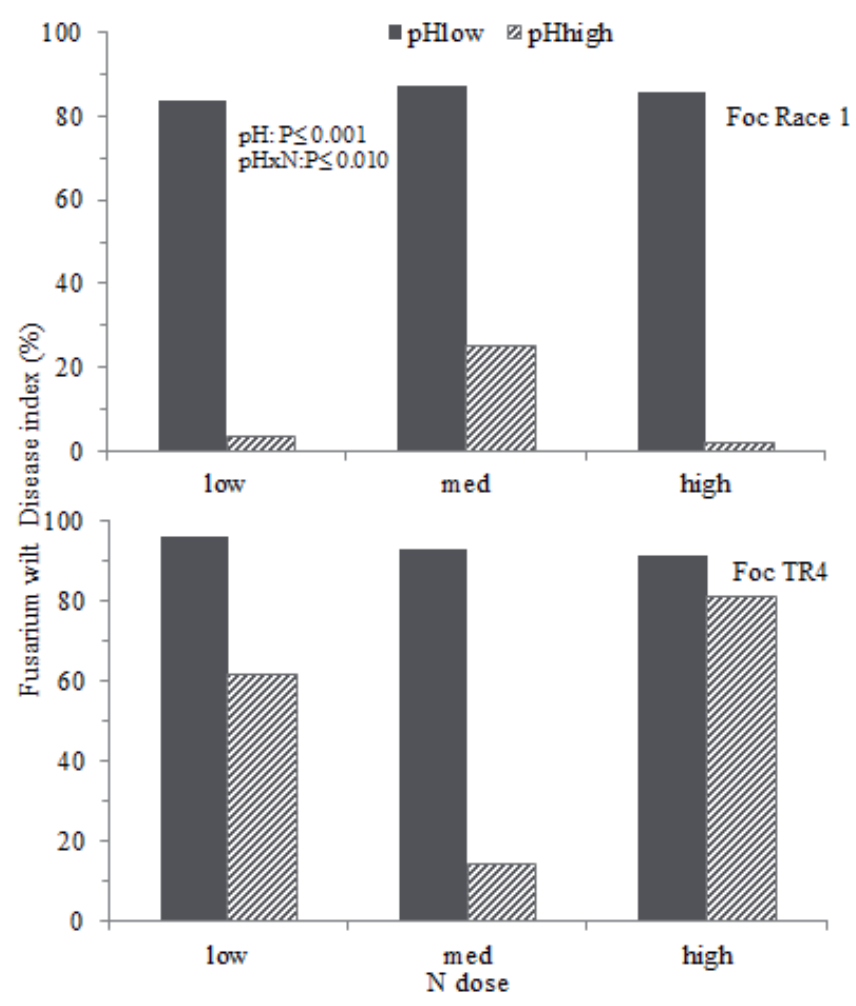

Figure 3-6 Disease index of Fusarium wilt by Fusarium oxysporum f. sp. cubense (Race 1 and TR4) at 33 days after inoculation from Cavendish banana plants (Musa AAA) grown in two soil pH levels (lower than 5.2 and higher than 6.0) and three $\mathrm{N}$ (with ammonium nitrate, $33.5 \% \mathrm{~N}$ ) doses $\left(\mathrm{N}_{\text {low }}\right.$ with no $\mathrm{N}, \mathrm{N}_{\text {med }} 0.08 \mathrm{~N}$ g plant week $^{-1}$, and $\mathrm{N}_{\text {high }} 0.25 \mathrm{~N}$ g plant week ${ }^{-1}$ ) in a greenhouse experiment in the Netherlands.

\subsection{Discussion}

Although the literature shows the opportunities for the use of soil management in crop disease control, its actual implementation requires insight into the relationships between individual soil properties and crop diseases. However, reality is complex and, in general, a combination of multiple soil properties determines crop development and disease expression. Therefore, the relationship between a soil property and a crop disease is found to be context-specific, and the response to individual soil properties, hard to establish. In addition, it is well known that crop status differs according to the multitude of soil properties. As a result, the relatively simple conceptual plant disease 
triangle (Huber and Haneklaus 2007) representing host, pathogen and environment interaction is actually comprised of highly complex interrelationships involving a plethora of different factors that are extremely difficult to unravel and translate in straightforward soil management recommendations. This is probably also the underlying explanation for the inconsistencies in reported results in the literature.

The complex puzzle that represents implementing soil management is constrained by the limitations of this practice. Soil properties differ in the way they can be managed. Soil texture, for instance, is reported as a property that can influence crop diseases, but it is a given and, except in some very specific cases, cannot be changed through soil management. However, it can be considered while planning new plantations. Other soil properties, for example, nutrient concentrations and soil organic matter, can be managed through mineral and organic fertilizers.

Some soil properties, such as soil $\mathrm{pH}$ and nutrient concentration, appear as attractive options to develop strategies for crop diseases control, as i) they can be managed through e.g., fertilization and liming, and ii) they play a role in crop diseases. However, for the development of management strategies, quantitative insight into the relation between soil properties and crop diseases is needed. This insight would allow farmers to take the economic decisions to invest in soil management. However, if the relationship is context-specific, the general validity of a relationship is limited, and it almost needs to be derived for each individual case.

Banana is an important crop with a very aggressive disease as Fusarium wilt, but with no effective conventional control options. Besides, there are not indications of soil suppressiveness against this pathogen (Deltour et al. 2017). The experiments demonstrated the role of soil $\mathrm{pH}$ and $\mathrm{N}$ and their interactions with disease incidence and severity. Soil $\mathrm{pH}$ is an important soil quality indicator in banana soils and higher crop productions generally coincide with a higher soil $\mathrm{pH}$ (Segura et al. 2015). Acidification due to heavy fertilization is indicated as a serious problem in crop management and liming is common practice (Stoorvogel and Segura 2018). In intensive production systems, banana plants are highly fertilized with up to $400 \mathrm{~kg} \mathrm{~N}$ ha year ${ }^{-1}$. Following the literature on Fusarium wilt, the intensively managed system may be highly susceptible to this disease due to the acidification and $\mathrm{N}$ fertilization. General recommendations based on current literature would include liming and possibly a reduction in $\mathrm{N}$ fertilization.

The difference in the duration of the experiments was due to the rapid development of the plants in the second experiment under the optimal and controlled conditions relative to the more natural conditions in the first experiment. However, for both experiments, the effect of soil $\mathrm{pH}$ and 
the interaction of soil $\mathrm{pH}$ and $\mathrm{N}$ on the disease expressed as the biomass, the leaf area and the DI evaluated how the predisposition of Gros Michel banana to Foc Race 1 (and TR4) can be modulated. The effect of those soil properties was also reported in field experiences (Rishbeth 1955; Stover 1961). This effect of those soil properties could have played a role in the devastation of Gros Michel by Foc Race 1 in Latin America during the last century. The decimation of the former main banana subgroup (the Gros Michel) appears expectable with the incipient knowledge about the fungus and its dissemination (Dita et al. 2018) and the recently reported interactions of Foc with e.g., soil nematodes (Rocha et al. 2020) and the banana weevil (Guillén et al. 2021). Due the lack of awareness about the importance of tested soil properties in the expression of the disease, the standard management of the crop with the common application of high rates of $\mathrm{N}$ (and the consequent drop of $\mathrm{pH}$ ) could increase the severity of the disease. In the case of this research, the effect of the $\mathrm{N}$ doses in dropping soil $\mathrm{pH}$ was almost absent due the implemented procedure of $\mathrm{N}$ application in a solution.

The potential of soil management in Fusarium wilt incidence was clear when the Cavendish cultivar showed symptoms caused by Foc Race 1 in the second experiment. Although those cultivars are widely accepted as resistant to Foc Race 1(Harper 1950; Ploetz 1990; Perez-Vicente 2004), the extreme stress in $\mathrm{pH}_{\text {low }}$ induced a higher predisposition to the disease. It is reported that Cavendish can be affected by Foc Race 1 in young stages under stress conditions, such as extreme soil temperatures and high inoculum level (Brake et al. 1995; Smith et al. 2008). Besides, a lower pH can be considered as an extreme condition with potential to accelerate the disease incidence in young Cavendish plants, as was found in the second experiment.

The differences in biomass and leaf area between $\mathrm{pH}$ levels in the control plants for both experiments can be attributed to the effect of soil $\mathrm{pH}$ on the plant nutritional intake. At the same time, this condition could more highly predispose the plant to Fusarium wilt because of the lack of nutrients. Besides, the additional effect of the lower $\mathrm{pH}$ is a higher solubilization of aluminum (A1). A higher $\mathrm{Al}$ concentration is reported to negatively affect banana production (Segura et al. 2015). Nutrients may be required to grow and to activate the plant responses against the fungus. Under the extreme soil condition of pHlow, even a Foc Race 1- resistant plant as the Cavendish, can be affected by the diseases. In $\mathrm{pH}$ high, the plant can take up more nutrients and water from the soil (Neumann and Römheld 2012) which increased the biomass production.

The experiments showed that previous reports on Fusarium wilt and Gros Michel banana can be replicated. It was shown that soil properties can modulate disease incidence by Foc TR4 in Cavendish. Besides, it seems like the response of Gros Michel to the disease according to soil $\mathrm{pH}$ 
differences is more contrasting than the Cavendish cultivar. The experiments showed a slightly higher predisposition of Gros Michel to Foc Race 1 than Cavendish to Foc TR4 to the management of this soil property. This could suggest that the impact of Foc TR4 on Cavendish would be less severe than the impact of Foc race 1 on Gros Michel. However, this comparison is difficult, as conditions differ between greenhouse and the field, and because crop management has been intensified over the years.

Both experiments showed the potential of soil management as a component for an integrated control of Fusarium wilt in bananas. The effect of managing soil properties on Foc Race 1 in the Gros Michel subgroup was confirmed. In addition, soil management appears to have similar effects on Foc TR4. The results indicate the importance of the selected soil properties ( $\mathrm{pH}$ and $\mathrm{N}$ ) and their role in the predisposition of banana to the disease. The concept of soil management strategy in crop disease management requires more detailed studies, but the results support investing in this alternative approach to crop disease management in present and future crop production. This is particularly applicable for Fusarium wilt in banana, where this kind of studies is highly needed due to the direct threat of Foc TR4.

\subsection{Conclusions}

Crop production is constantly threatened by diseases. There are an important number of diseases for each crop and new diseases are also common in crop production. The role of soil properties in crop disease expression differs according to the disease and the soil property. The case of $\mathrm{pH}$ and $\mathrm{N}$ in Fusarium wilt in banana illustrates the opportunity for soil management to deal with this disease. The relationship of these soil properties in the incidence of the disease by Foc Race 1 in Gros Michel subgroup was confirmed. Besides, it was demonstrated that Cavendish and TR4, the current major threat in banana production, followed similar trends than those found for Gros Michel and Foc Race 1. Since the Cavendish is largely resistant to Foc Race 1, the induced expression of symptoms shows the potential of soil properties in the plant predisposition to the disease. Based on these results and given the current impact of Foc TR4 in banana production, continuing the studies in this discipline appears to be attractive and necessary. Although practices of soil management as liming to increase soil $\mathrm{pH}$ and balanced use of $\mathrm{N}$ sources (e.g., ammonium nitrate as in this case) can be considered as preventing measures to reduce Fusarium wilt in the banana crop, the results need to be confirmed in experiments under field and/or farm conditions. 


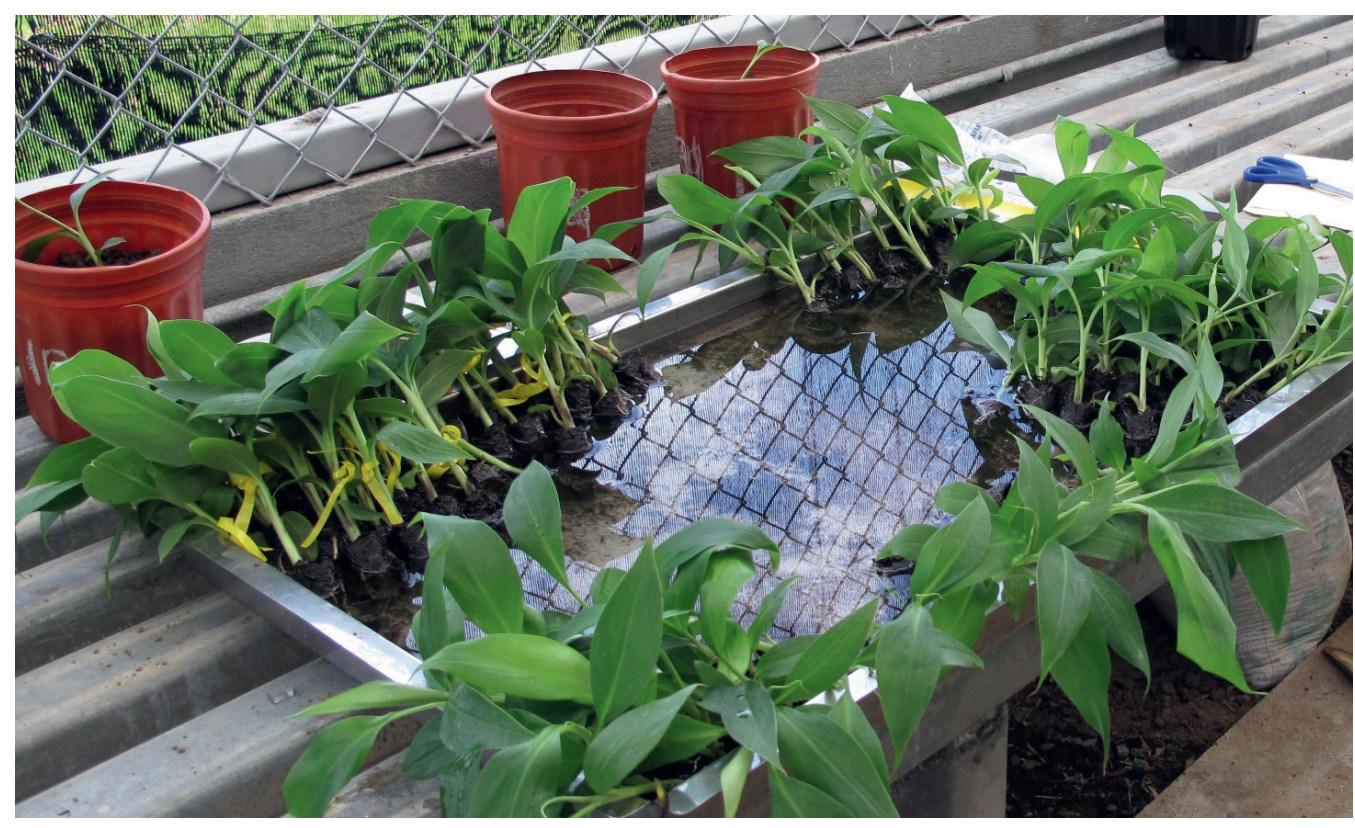




\section{Chapter 4}

\section{The role of soil types on the relation between individual soil properties and Fusarium wilt expression in Gros Michel bananas}

Aims This study looks whether the response of soil management (liming and nitrogen fertilization) on the incidence of Fusarium wilt (Foc Race 1) in Gros Michel banana (Musa AAA) is influenced by soil types.

Methods The effect of inoculation with Foc Race 1 was studied in a factorial greenhouse trial with eight representative soil types of the Costa Rican banana region, two pH levels and three levels of $N$-fertilization. After an 8-week period, plant biomass, leaf area, and a disease index were measured. Results There were significant effects of soil pH and $\mathrm{N}$, and their interactions on disease expression. Low pH levels and high $\mathrm{N}$-fertilization increased the disease expression. The response to changes in soil pH and $\mathrm{N}$-fertilization differed considerably between the different soil types.

Conclusions Although soil pH and $N$ influence Fusarium wilt in banana, each soil type differs in its response to these soil properties. This complicates the development of standard soil management strategies in terms of e.g., $\mathrm{N}$-fertilization and liming to mitigate or fight the disease.

\section{This chapter is based on:}

Segura M. RA, Stoorvogel JJ, Sandoval F. JA, (2021). The role of soil types on the relation between individual soil properties and Fusarium wilt expression in Gros Michel bananas. Submitted to Plant and Soil. Doi: 10.21203/rs.3.rs-264937/v1 


\subsection{Introduction}

Fusarium wilt, also known as 'Panama disease' (caused by the soil-borne fungus Fusarium oxysporum f. sp. cubense or Foc), is one of the most critical diseases affecting banana production. Foc Race 1 devastated the subgroup Gros Michel (Musa AAA), which was the main cultivar exported from Latin America and the Caribbean (LAC) during the first half of the $20^{\text {th }}$ century. Foc Race 1 remains a serious problem in small-scale production systems in LAC where the specific traits of the Gros Michel banana are preferred (Pocasangre et al. 2011). The gradual shift of the production systems to the cultivars of the subgroup Cavendish (Musa AAA), which are resistant to Foc Race 1, was a temporary solution to the problem (Harper 1950; Stover 1961, 1962; Ploetz 1990; PerezVicente 2004). A new, more aggressive strain of the fungus denominated Foc Tropical Race 4 (TR4) is spreading over the world and has recently been reported in LAC (García-Bastidas et al. 2020). Most of the varieties produced in LAC, including the Gros Michel and the Cavendish subgroups, are susceptible to Foc TR4. The spread of Foc TR4 in LAC would have a tremendous impact given the economic and social importance of banana production in the region (Aurore et al. 2009; Pocasangre et al. 2011; Dita et al. 2013).

Conventional control options such as fungicides, replanting or crop rotation are ineffective in controlling or eradicating the disease (Ploetz 2006, 2015b; Ordoñez et al. 2015). Other alternatives, such as the evaluation of partially resistant cultivars or breeding new resistant cultivars ( $\mathrm{Su}$ et al. 1986; Hwang and Ko 2004; Dale et al. 2017), can take a long time to be available for practical implementation. In the short run, it is important to develop a control package that allows farmers to face the disease.

Soil management in agriculture mainly focuses on crop production and rarely considers crop disease control. However, specific soil conditions can suppress diseases in agricultural crops (Janvier et al. 2007). Managing soil properties can i) influence the soil microbiome and as a result change disease pressure or ii) influence the crop nutritional status and change the crop's predisposition to diseases (Dordas 2008; Ghorbani et al. 2008; Huber et al. 2012). Already in 1946, there were reports that liming, fertilization, and crop rotation may be a "cure" to Fusarium Wilt in Banana (Taylor (1946) cited by Jones and Morrison 1952). Studies also included flooding of infected areas to aim for soil disinfection or a reduction of the fungus population (Stover 1962). However, through the production of chlamydospores Foc can survive extreme conditions like the anaerobic conditions under flooding (Ploetz 2015a). Recently, flooding and irrigation are increasingly being attributed to also increase the 
spread of the disease (Salacinas et al. 2019). After the shift from Gros Michel to the resistant Cavendish cultivars, research on Fusarium wilt control was limited for more than 30 years. However, since reports of the new and more aggressive strain Foc TR4 (Stover 1986) were published, research on controlling this disease came back. Studies show that Foc Race 1 and Foc TR4 respond in a similar way and that soil properties play an important role in conducing or suppressing the fungus in banana (Domínguez et al. 2008; Orr and Nelson 2018; Segura-Mena et al. 2021). However, the results in the literature are found to be inconsistent. This seriously hampers the translation of research results into operational management recommendations. Bananas are grown under a wide variety of agroecological conditions (Jaramillo and Vásquez 1990; Stoorvogel and Segura 2018). One possible reason for these inconsistencies could be that the interactions between Fusarium wilt and soil properties differ with agro-ecological conditions. Soil types have long been known to play a role in this relationship (Stotzky et al. 1961).

This study aims to evaluate the role that soil types play on the effect of liming and Nfertilization on the incidence of Fusarium Wilt. Eight representative soil types from the Costa Rican banana region are evaluated studying the incidence of Fusarium wilt by Foc Race 1 in Gros Michel bananas in a large greenhouse experiment. The results may help to better identify the role of soil types in explaining the inconsistencies in results and to support the development soil management strategies to reduce the impact of Fusarium wilt race 1 and help to identify research strategies to similarly develop strategies to control TR4.

\subsection{Materials and methods}

Banana production in Costa Rica is concentrated in the perhumid Atlantic zone (Figure 4-1). Soil conditions vary considerably in the area. Soil types were selected during a survey in the banana regions and they represent the variety that was found in the region (Klinkert 2014). The survey included the Caribbean lowlands, which include over 40,000 has of large intensive production of Cavendish cultivars for export (Segura et al. 2015). In addition, the Turrialba region, which has a more extensive production of Gros Michel cultivars for local markets (Ramirez et al. 2010), was incorporated into the study. Soils in the Caribbean lowlands are highly variable (Lopez and Espinosa 2000; Segura et al. 2015). Soils to the east of the Reventazón river (Figure 1) are predominantly sedimentary with a high clay content and high fertility. Soils to the west of the Reventazón river 
originate from volcanic ashes with a low clay content and medium fertility (Arias et al. 2010a,b). Soils in the Turrialba region are deep, well-drained, tropical red soils with a high clay percentage and medium fertility (Dijkshoorn et al. 2005). The climate is tropical and humid with an average annual rainfall of 3000-3500 $\mathrm{mm}$ distributed throughout the year.

Selected soils were described in situ and large topsoil samples $(0-30 \mathrm{~cm})$ were taken. Two soils were selected from the west of the Caribbean lowlands (S1 and S6), four soils were selected from the larger east of the Caribbean lowlands(S2, S3, S4 and S5), and two soils were selected from the Turrialba region (S7 and S8). The soils were analyzed for $\mathrm{pH}$, acidity, organic matter (SOM), and the concentrations of $\mathrm{Ca}, \mathrm{Mg}, \mathrm{K}, \mathrm{P}, \mathrm{Zn}, \mathrm{Cu}, \mathrm{Fe}, \mathrm{Cu}$, and $\mathrm{Mn}$, following the methodologies described by Díaz-Romeu and Hunter (1978) and Mehlich (1984). The location and main properties of the soils are presented in Figure 4-1 and Table 4-1.

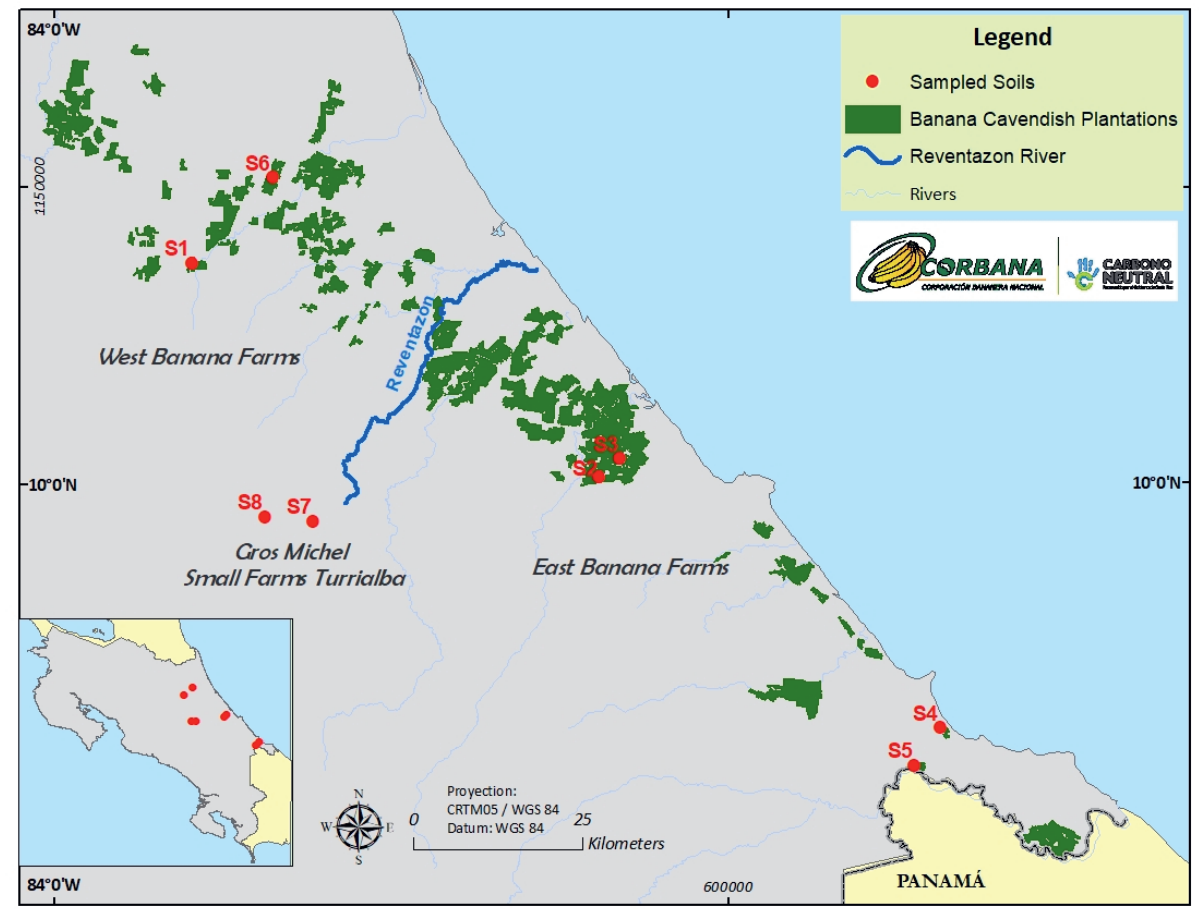

Figure 4-1 Distribution of sample collection points of eight representative soil types (S) from the Costa Rican banana region: Caribbean East and Caribbean West from the Reventazón River, and Turrialba. 
Table 4-1. Soil properties for eight representative soil types from the Costa Rican banana region.

\begin{tabular}{|c|c|c|c|c|c|c|c|c|c|c|c|c|c|}
\hline \multirow[t]{2}{*}{ Code } & \multicolumn{2}{|c|}{ Location } & \multirow[t]{2}{*}{$\mathrm{pH}$} & \multirow[t]{2}{*}{ Acidity } & $\mathrm{Ca} \quad \mathrm{I}$ & \multirow[t]{2}{*}{$\mathrm{Mg}$} & \multirow[t]{2}{*}{$\mathrm{K}$} & \multirow[t]{2}{*}{$\mathrm{P}$} & \multirow[t]{2}{*}{$\mathrm{Fe}$} & \multicolumn{2}{|c|}{$\mathrm{Cu} \quad \mathrm{Zn}$} & \multirow[t]{2}{*}{$\mathrm{Mn}$} & \multirow{2}{*}{$\begin{array}{c}\text { SOM. } \\
\% \\
\end{array}$} \\
\hline & $\begin{array}{c}\text { W. } \\
\text { Longitud }\end{array}$ & $\begin{array}{c}\mathrm{N} . \\
\text { Latitude }\end{array}$ & & & $\operatorname{nol}(+) \mathrm{L}^{-1}$ & & & & & \multicolumn{2}{|c|}{$\mathrm{mg} \mathrm{kg}^{-1}$} & & \\
\hline \multicolumn{14}{|l|}{ West } \\
\hline $\mathrm{S} 1^{\mathrm{a}}$ & $83^{\circ} 48^{\prime \prime} 49$ & $10^{\circ} 17^{\prime \prime} 50$ & 5.7 & 0.20 & 6 & 2.4 & 1.0 & 24 & 60 & 3 & 7 & 17 & 8.2 \\
\hline$S 6^{a}$ & $83^{\circ} 45^{\prime \prime} 15$ & $10^{\circ} 25^{\prime \prime} 40$ & 5.3 & 0.36 & 2 & 0.8 & 0.3 & 3 & 54 & 1 & 0 & 14 & 7.6 \\
\hline \multicolumn{14}{|l|}{ East } \\
\hline $\mathrm{S} 2^{\mathrm{b}}$ & $83^{\circ} 17^{\prime \prime} 06$ & $09^{\circ} 58^{\prime \prime} 48$ & 6.6 & 0.03 & 28 & 3.9 & 0.3 & 8 & 366 & 7 & 2 & 65 & 2.6 \\
\hline $\mathrm{S} 3^{\mathrm{c}}$ & $83^{\circ} 42^{\prime \prime} 17$ & $10^{\circ} 24 " 49$ & 4.9 & 2.61 & 19 & 9.3 & 1.2 & 47 & 320 & 6 & 6 & 71 & 2.7 \\
\hline $\mathrm{S} 4^{\mathrm{d}}$ & $82^{\circ} 48^{\prime \prime} 09$ & $09^{\circ} 40^{\prime \prime} 16$ & 6.1 & 0.52 & 29 & 8.8 & 0.4 & 10 & 301 & 6 & 4 & 71 & 2.5 \\
\hline $\mathrm{S} 5^{\mathrm{d}}$ & $82^{\circ} 50^{\prime \prime} 16$ & $09^{\circ} 37^{\prime \prime} 15$ & 6.1 & 0.11 & 21 & 5.8 & 1.2 & 50 & 302 & 12 & 5 & 47 & 2.4 \\
\hline \multicolumn{14}{|c|}{ Turrialba } \\
\hline$S 7^{e}$ & $83^{\circ} 38^{\prime \prime} 58$ & $09^{\circ} 57^{\prime \prime} 02$ & 5.6 & 0.24 & 14 & 3.9 & 0.6 & 14 & 226 & 7 & 3 & 44 & 6.3 \\
\hline$S 8^{f}$ & $83^{\circ} 42^{\prime \prime} 54$ & $09^{\circ} 57^{\prime \prime 22}$ & 6.1 & 0.05 & 5 & 0.9 & 0.6 & 3 & 78 & 4 & 1 & 13 & 12.3 \\
\hline
\end{tabular}

The experiment was performed in a greenhouse at the experimental station of CORBANA in

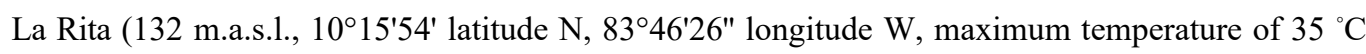
and minimum temperature of $17{ }^{\circ} \mathrm{C}$, average temperature of $28{ }^{\circ} \mathrm{C}$ with an $85 \%$ relative humidity and approx. $12 \mathrm{~h}$ of daylight). The factorial design included 8 soil types $\mathrm{x} 2$ levels of Foc Race 1(with and without) inoculation x 2 levels of soil pH x 3 levels of $\mathrm{N}$-fertilization x 3 replications resulting in 288 pots. Two contrasting soil $\mathrm{pH}$ levels were tested: 1) $\mathrm{pH}_{\text {low }}$ with a $\mathrm{pH}$ of 5.2 or lower, and 2) $\mathrm{pH}$ high with a $\mathrm{pH}$ equal to or higher than 6.0. Soil $\mathrm{pH}$ was adjusted to these target levels by applying a hydrochloric acid solution $(10 \% \mathrm{HCl})$ to decrease $\mathrm{pH}$ or lime $\left(\mathrm{CaCO}_{3}\right)$ to increase soil $\mathrm{pH}$. Soil $\mathrm{pH}$ was adapted before any other treatment were applied. In each case, the acid or alkaline units of solution required to achieve the lower and the higher $\mathrm{pH}$ were calculated before liming and/or acidifying. Soil $\mathrm{pH}$ was analyzed before each treatment and eight days after the liming or the acidification treatments (where they proceed). In the low $\mathrm{pH}$ treatment, $\mathrm{pH}$ levels between 4.0 and 5.1 were measured and in the high $\mathrm{pH}$ treatment, $\mathrm{pH}$ levels between 6.2 and 6.8 were measured.

Hardened, approximately 3-month-old, tissue culture banana plants (Musa AAA, subgroup Gros Michel) were used in the experiment. The plants grew in a standard potting mix before the experiment. Banana plants in young stages from tissue culture, such as the ones used in the experiment, are more sensitive to Foc infestation (Brake et al. 1995; Smith et al. 2008). This condition 
ensured the plant's response to the disease according to the treatments. Two levels of Foc Race 1 inoculation were achieved by root dipping (Dita et al. 2010; García-Bastidas et al. 2014; Ordoñez et al. 2016): 1) Ino: a control, 30 minutes in clean water, and 2) $\operatorname{In}_{1}$ : the inoculated group, 30 minutes in a solution of water with $10^{6}$ conidia $\mathrm{mL}^{-1}$ of Foc Race 1 . The fungus strain was collected from Costa Rican soils, tested, and cultivated by CORBANA's Center of Biological Control. It should be noted that plants in Ino could still be infected with Foc Race 1 present in the soils. It is widely accepted that Costa Rican banana soils are infested with Foc Race 1. As the soil samples were not sterilized before the experiment in order to not disturb the soil microbiome, the plants in the control are exposed to Foc Race 1 (typically at low concentrations). Immediately after the inoculation, plants were separately planted in $2 \mathrm{~L}$ pots (one plant per pot). Three levels of $\mathrm{N}$ doses were achieved through weekly differentiated $\mathrm{N}$-fertilization with ammonium nitrate $(\mathrm{AN}, 33.5 \% \mathrm{~N})$ : $\mathrm{N}_{\text {low }}$ with no $\mathrm{N}$ addition relying on natural $\mathrm{N}$ in the soil; 2) $\mathrm{N}_{\text {med }}$ with $0.08 \mathrm{~N}_{\text {g plant }}{ }^{-1}$ week $^{-1}$ supplied through $0.24 \mathrm{~g}$ of AN plant $^{-1}$ week $^{-1}$; and 3) $\mathrm{N}_{\text {high }}$ with $0.25 \mathrm{~N} \mathrm{~g}$ plant $^{-1}$ week $^{-1}$ supplied through $0.75 \mathrm{~g}$ of AN plant week ${ }^{-1}$. These $\mathrm{N}$ doses were respectively achieved through applications of $300 \mathrm{~mL}$ of solutions of $\mathrm{AN}$ in water with concentrations of respectively $0.00 \mathrm{~g} \mathrm{~L}^{-1} \mathrm{~N}, 0.14 \mathrm{~g} \mathrm{~L}^{-1} \mathrm{~N}$ and $0.43 \mathrm{~g} \mathrm{~L}^{-1} \mathrm{~N}$, two times week ${ }^{-1}$. Nmed emulated the average $\mathrm{N}$ requirement of plants during the first 10 weeks after planting in real field conditions. No other nutrients or agro-chemicals (e.g., fungicides, insecticides, etc.) were applied to the plants.

The experimental period was 8 weeks long and at the end of this period, total (above ground plus roots) fresh biomass ( $\mathrm{g}_{\text {plant }}{ }^{-1}$ ), the plant diameter at the base and the foliar area were measured. As the three variables were highly correlated to each other $(>95 \%)$, the data analysis was only carried out on the basis of the fresh biomass. In addition, a non-intrusive way to measure the disease according to the management of the soil properties was following the development of the wilting. The disease index (DI) was obtained adapting the McKinney's formula (McKinney 1923) that was also used by Haddad et al. (2018) and Rocha et al. (2020) in the same way. However, in this case, it was based on the number of sick plants and the wilted leaves: $\operatorname{DI}(\%)=100 \cdot \sum(\mathrm{f} / \mathrm{n}) \cdot(\mathrm{v} / \mathrm{x})$, where; $\mathrm{f}=$ number of sick plants; $\mathrm{n}=$ total of plants; $\mathrm{v}=$ number of leaves with symptoms; and $\mathrm{x}=$ total number of leaves (with symptoms and healthy). The presence of the typical symptoms of the wilting of the leaves in previously inoculated plants is reported as a valid element to corroborate the presence of the disease in bananas (Dita et al. 2010; García-Bastidas et al. 2014, 2016, 2020; Hung et al. 2018). Plant biomass from $\mathrm{In}_{0}$ and $\mathrm{In}_{1}$ and the wilting per plant data were analyzed using a factorial analysis of variance, which considered involved factors and their interactions: soil type, inoculation, soil $\mathrm{pH}$ and 
$\mathrm{N}$ for biomass, and only soil type, $\mathrm{pH}$ and $\mathrm{N}$ for wilting per plant. The differences between factors were evaluated through a Tukey's analysis.

\subsection{Results}

\subsubsection{Natural effect of the soil type and soil $\mathrm{pH}$ in not inoculated plants}

The control group ( $\mathrm{In}_{0}$ ) showed the effect of the soil type and the $\mathrm{pH}$ and $\mathrm{N}$ management on non (Figure 4-2). There were considerable differences in the mean biomass per plant according to soil type $(\mathrm{P}<0.001)$. Bananas grown on soils from the West and Turrialba showed the best mean performance with the plants grown on $\mathrm{pHhigh}$ being significantly $(\mathrm{P}<0.001)$ larger than plants grown

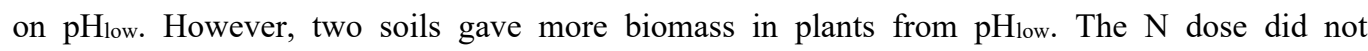
significantly affect the biomass over the eight soils $(\mathrm{P} \geq 0.73)$. The effect of $\mathrm{N}$ fertilization differed per soil type where in some cases the increased nitrogen levels resulted in an improved performance but in other cases there was a decline in the performance with the increases in Nitrogen. It is likely that these differences are related to the residual $\mathrm{N}$ in the original soil samples. 


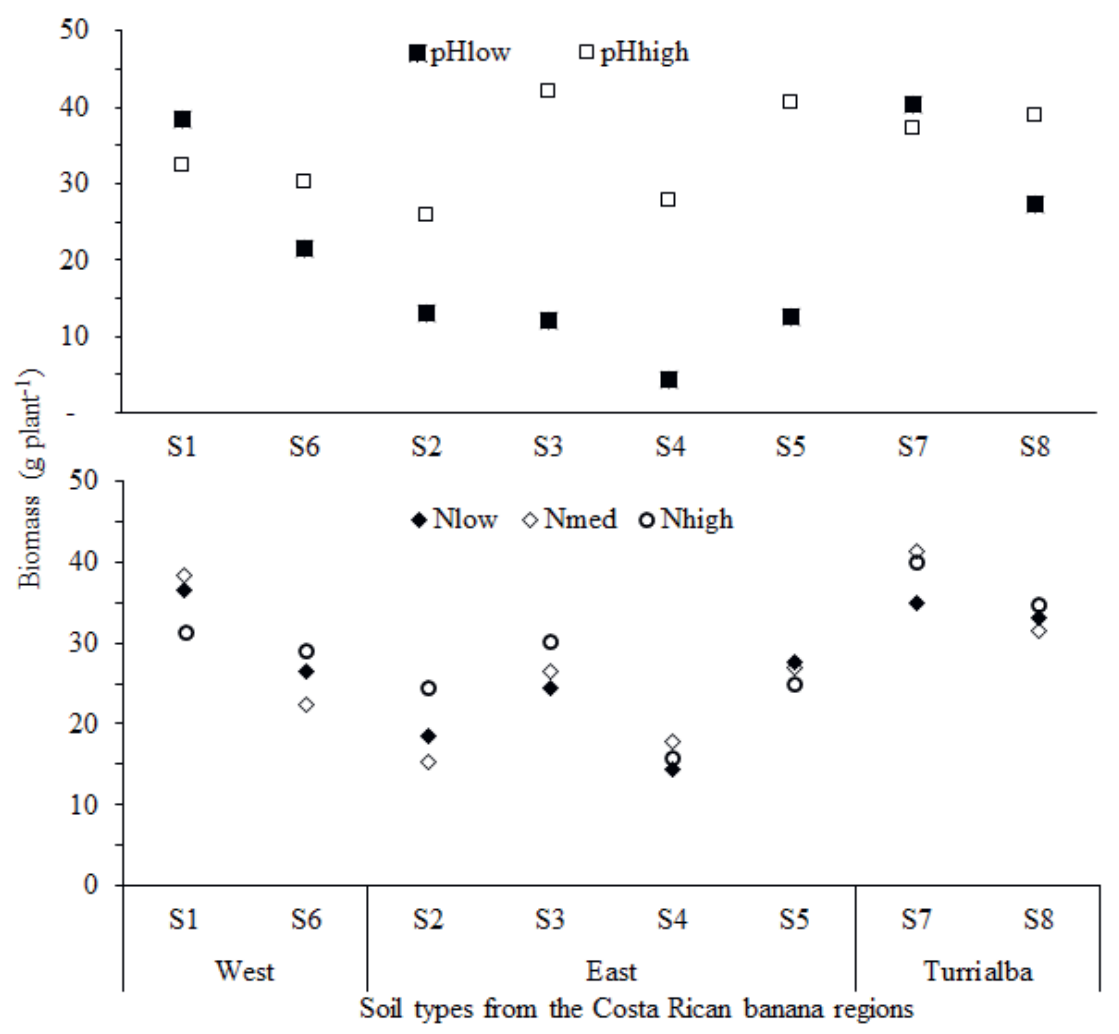

Figure 4-2 Biomass from control, not inoculated $\left(\mathrm{In}_{0}\right)$ Gross Michel (Musa AAA) banana plants grown in two soil $\mathrm{pH}$ levels (equal to or lower than 5.2 and equal to or higher than 6.0) and three $\mathrm{N}$ level (low, medium and high) in eight representative soil types from the Costa Rican banana region.

\subsubsection{Soil $\mathrm{pH}$ and $\mathrm{N}$ interactions and plant biomass and disease index}

Inoculation with Foc reduced plant biomass. Biomass in $\operatorname{In}_{1}$ was significantly lower than biomass in Ino for almost all the soil types and $\mathrm{pH}$ levels (Table 4-2) The effect of the inoculation expressed as a decline in plant biomass was higher in $\mathrm{pH}_{\text {low }}(61.6 \%)$ in contrast to $\mathrm{pH}$ high $(50.8 \%)$. However, $\mathrm{pH}$ differences resulted in a very different response to the inoculation of the disease for the different soil types as presented in Figure 4-3. The figure shows that for most soils a pH increase led to a greater biomass for both the control and the inoculated group. However, the direction and the length of the arrows differ indicating that there is a considerable effect of the soil. 
Inoculation led to a significant decline in almost all soil - $\mathrm{N}$ dose combinations (Table 4-3). With increasing N-fertilization, typically, the decline in biomass due to inoculation increased. In addition, the biomass according to the interactions of the inoculation with the soil type, the $\mathrm{pH}$ level and the $\mathrm{N}$ dose was also significant. A higher effect of the interaction of the soil and the inoculation was evident in all soils. The response of the Figure 4-4 shows a sample of plants grown in soils from the three regions. The detrimental effect of the interaction between $\mathrm{pH}_{\text {low }}$ and inoculation was evident in plants from the three regions. In spite of following the trend of a higher biomass in $\mathrm{pHhigh}$, the mean biomass in $\mathrm{In}_{1}$ was contrastingly lower against the control for both $\mathrm{pH}$ levels. The interaction of the inoculation and the $\mathrm{N}$ dose was expressed in different trends according the soil type and $\mathrm{pH}$ levels and the average biomass (Figure 4-5). The lower biomass in the $\mathrm{N}_{\text {high }}$ and $\mathrm{pH}_{\text {low. }}$. From the possible combinations, the higher wilting was took place in $\mathrm{N}_{\text {high }}$ and $\mathrm{pH}_{\text {high }}$.

The single effect of soil $\mathrm{pH}$ was significant in the DI expression with a higher average of

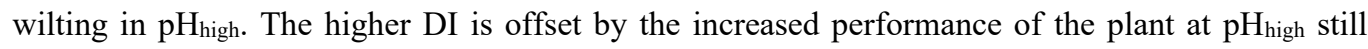
leading to a net benefit of the increased $\mathrm{pH}$. The $\mathrm{DI}$ according to the $\mathrm{N}$ doses was not significant, and its trend was more erratic. Plants from $\mathrm{pHhigh}$ remained more biomass and expressed a lower DI. The interaction $\mathrm{pH} \times \mathrm{N}$ was significant $(\mathrm{P} \leq 0.0040)$ in the DI and average biomass (Figure 4-6). There was a lower biomass in $\mathrm{N}_{\text {high }}$ and $\mathrm{pH}$ low. From the possible combinations, more wilting took place in Nhigh and $\mathrm{pHhigh}$. The single effect of soil $\mathrm{pH}$ was significant with a higher DI in $\mathrm{pH}$ high. The DI according to the $\mathrm{N}$ doses was not significant and its trend was more erratic. Plants from $\mathrm{pH}$ high maintained more biomass and expressed a lower DI. 


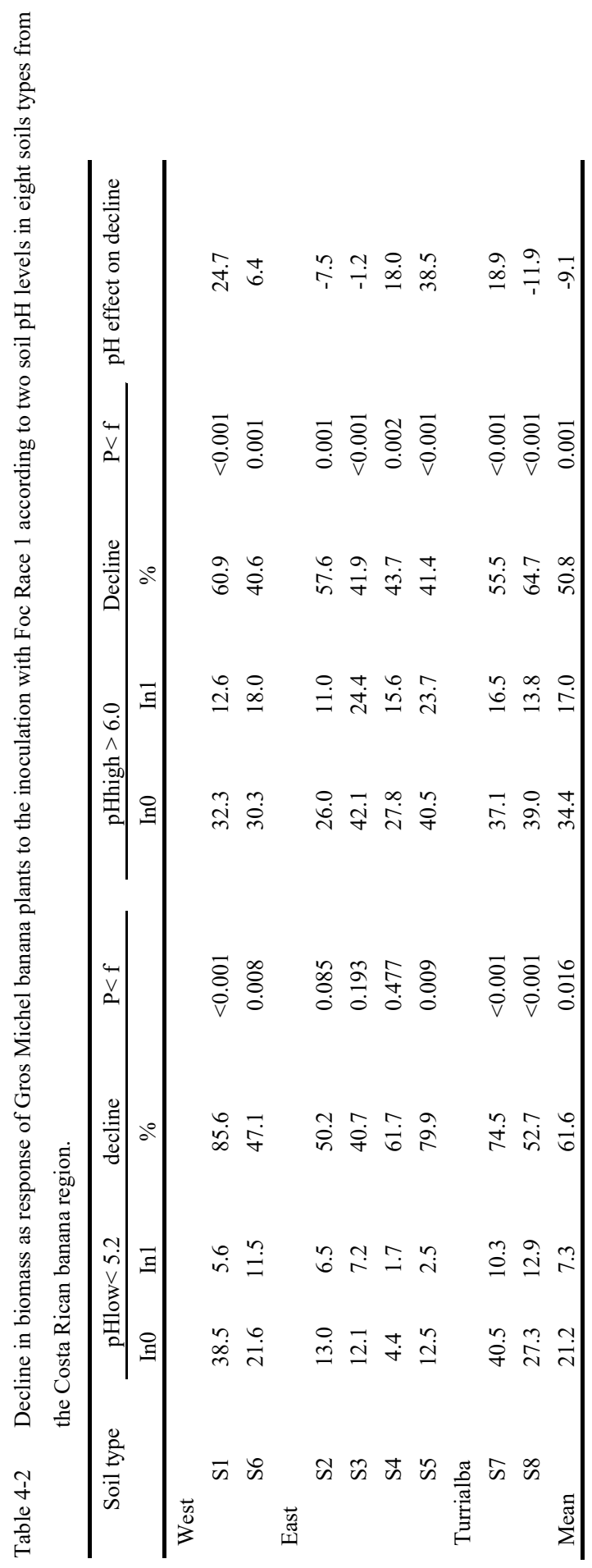




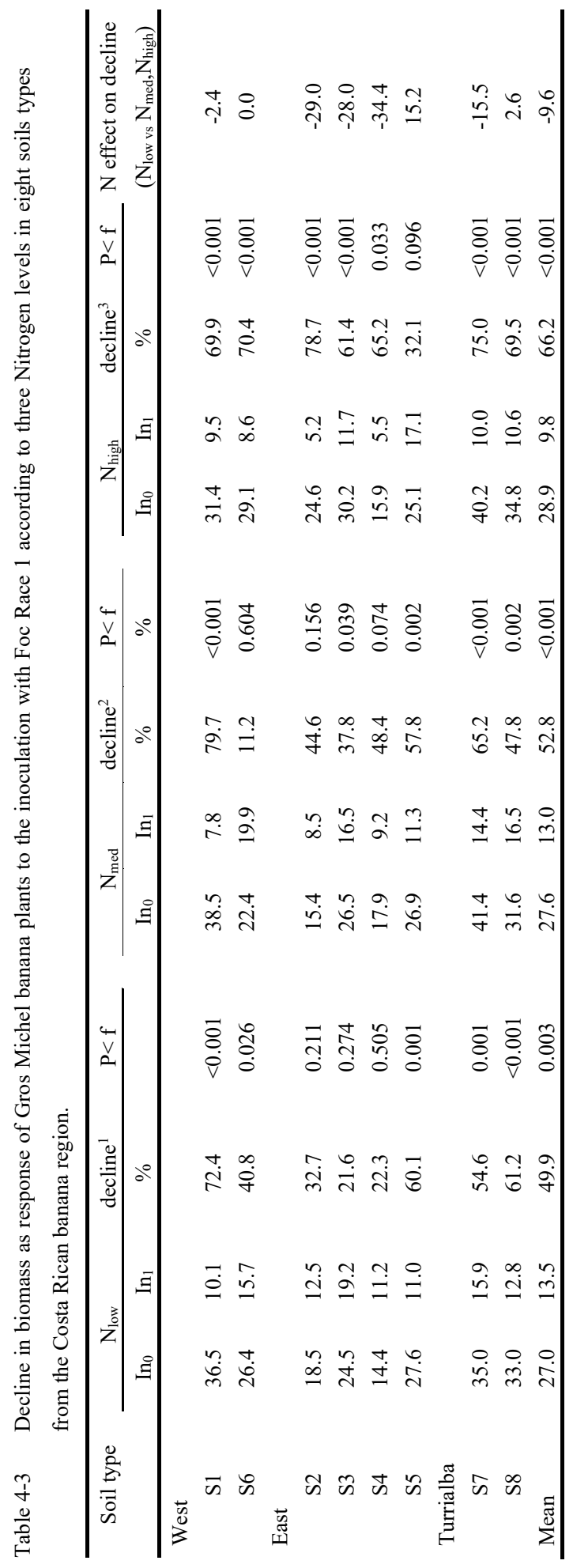




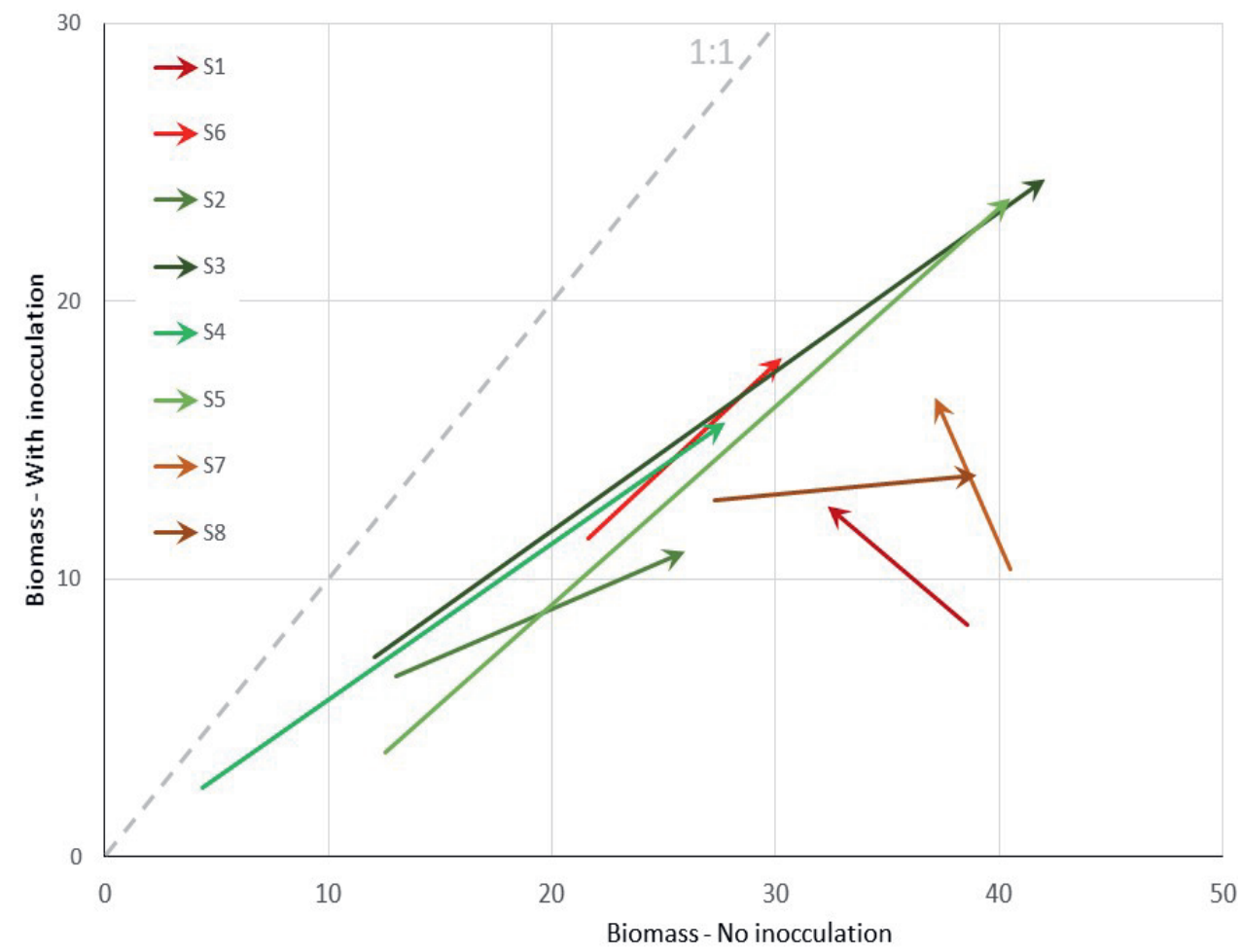

Figure 4.3 The effect of an increase of soil $\mathrm{pH}$ on the effect of Fusarium wilt on the leaf area in a pot experiment with 8 soil types from Costa Rican banana farms. The arrows represent the effect of the $\mathrm{pH}$ increase (representing liming). 

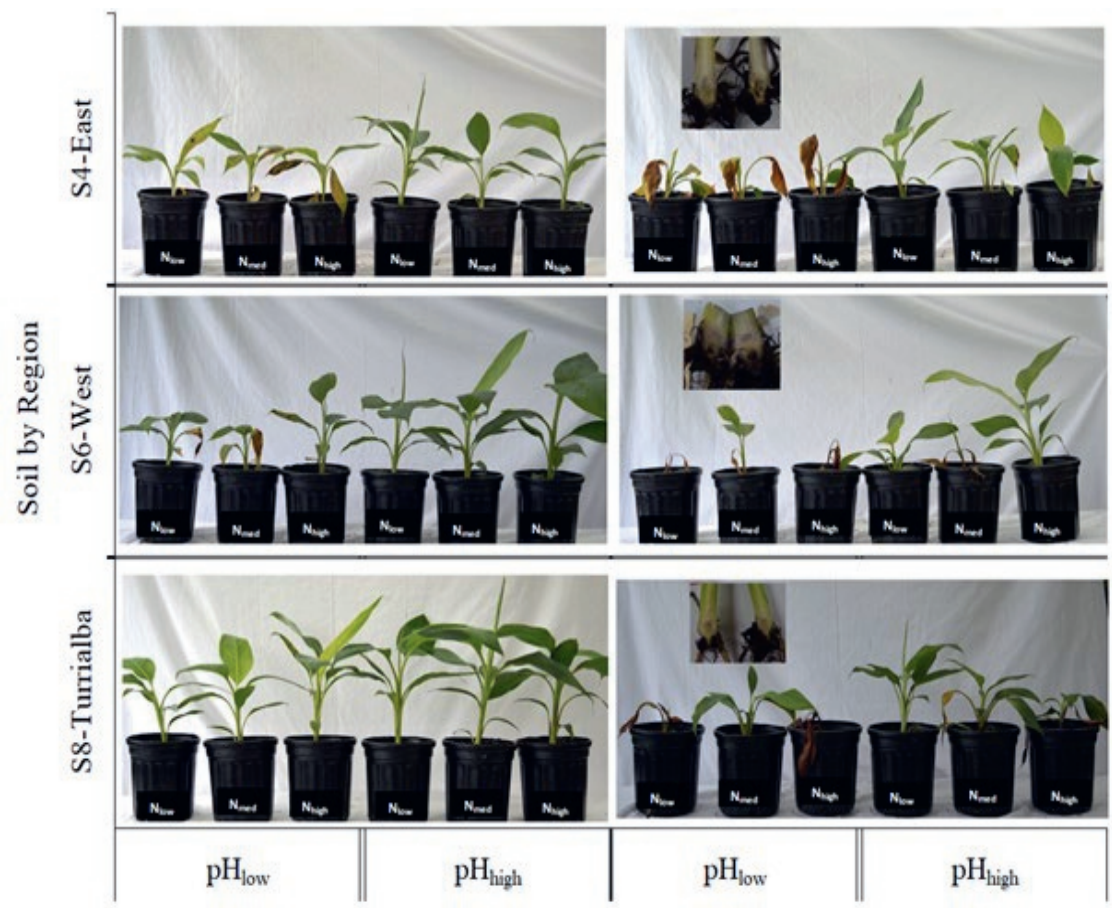

Control $\left(\ln _{0}\right)$

Foc Race 1 inoculated $\left(\ln _{1}\right)$

Figure 4-4 Condition of inoculated $\left(\mathrm{In}_{1}\right)$ and not inoculated ( $\left.\mathrm{In}_{0}\right)$ Gross Michel banana plants (Musa AAA) grown in three representative soil types from the Costa Rican banana region (east, west and turrialba) under two $\mathrm{pH}$ levels $\left(\mathrm{pH}_{\text {low }}\right.$ and $\left.\mathrm{pH}_{\text {high }}\right)$ and three $\mathrm{N}$ doses $\left(\mathrm{N}_{\text {low }}, \mathrm{N}_{\text {med }}\right.$ and $\left.\mathrm{N}_{\text {high }}\right)$. 


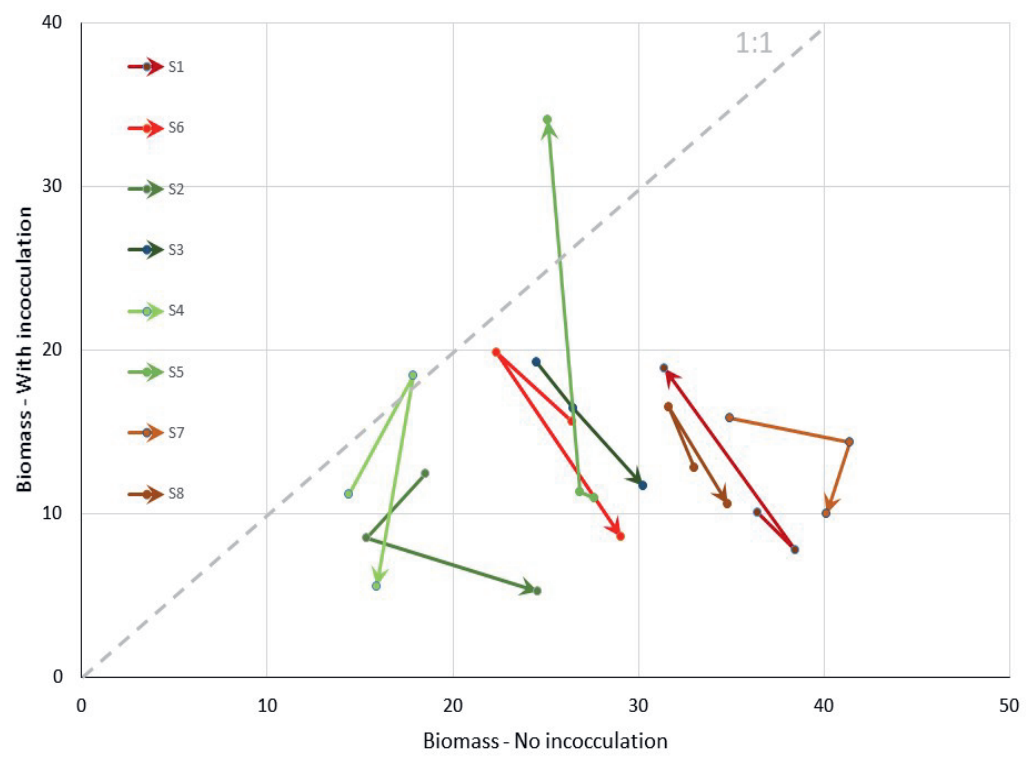

Figure 4-5 The effect of increases in soil Nitrogen on the effect of Fusarium wilt on the leaf area in a pot experiment with 8 soil types from Costa Rican banana farms. The arrows represent the effect of increases in Nitrogen concentrations (representing fertilization).

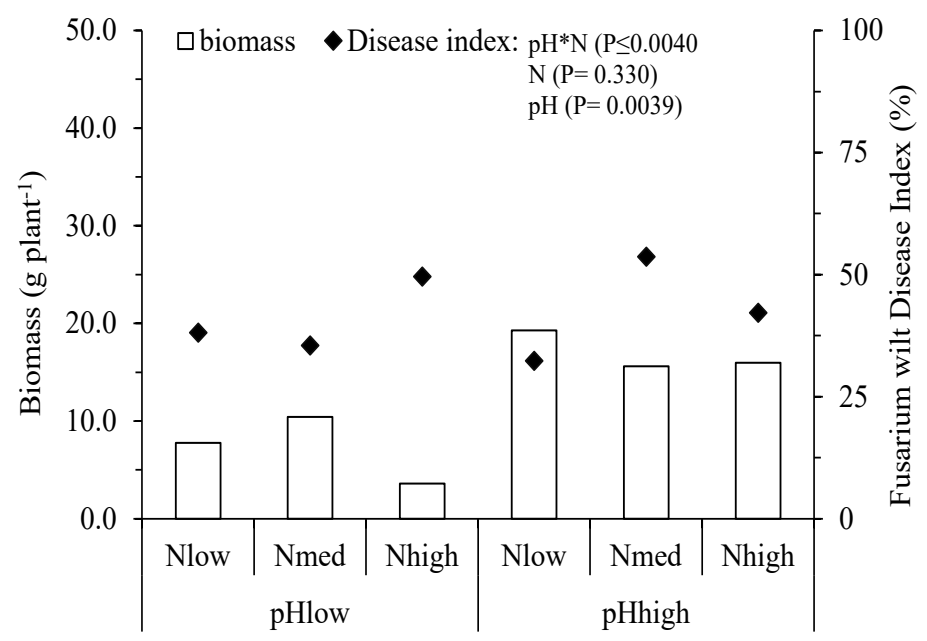

Figure 4-6 Average biomass (g) and DI ( \%) of inoculated ( $\left.\mathrm{In}_{1}\right)$ Gross Michel (Musa AAA) banana plants grown in eight Costa Rican banana soils types according pH levels (low and high) and $\mathrm{N}$ doses $\left(\mathrm{N}_{\text {low }}, \mathrm{N}_{\text {med }}\right.$ and $\mathrm{N}_{\text {high }}$. 


\subsection{Discussion}

Soil type were found to have a strong effect on plant performance under natural (not inoculated) and inoculated conditions. Losses in biomass in $\mathrm{In}_{1}$ can be attributed to the detrimental effect of Fusarium wilt on the plants. Due to the incidence, biomass in the inoculated plants was lower because of the loss of the tissue it produced in the plant. Soil $\mathrm{pHhigh}$ increased the biomass per plant for both $\mathrm{In}_{0}$ and $\mathrm{In}_{1}$ treatments. Besides, $\mathrm{pH}$ x inoculation interactions on the effect of the disease were stronger in $\mathrm{pH}_{\text {low. }}$ This they could imply a direct (Almeida et al. 2018), indirect effect, or both, of soil $\mathrm{pH}$ on the incidence of the disease. The role of $\mathrm{pH}$ as an indicator of soil health in banana and its influence in soil suppressiveness is known (Pattison et al. 2008; Geense et al. 2015; Segura et al. 2015). Low soil pH (less than 5.2) apparently can stimulate pathogen activity in the soil due to a detrimental effect on soil diversity. However, this was not evaluated in this trial. The lower $\mathrm{pH}$ also limits plant nutrient and water uptake (White 2012). This effect can increase banana predisposition to diseases led both by a higher Foc activity and a limited capacity to perform physiological processes against the infestation.

Despite the differences according to the interaction of soil type and inoculation, and the general effect of $\mathrm{pH}$ on plant response, the detrimental interaction of lower $\mathrm{pH} \mathrm{x}$ inoculation was higher in various soil types. The highest effect of the disease expressed as a lower biomass found in the eastern area could be due to the specific characteristics of these. Although all of them have a high fertility, plants from those soils were more sensible to the disease, especially in $\mathrm{pH}_{\text {low. }}$ The soil type as a package can play a natural role in plant status and it can define the plant's predisposition to the disease. Previous reports indicated that chemical and physical soil conditions would be linked to soil conduciveness of Fusarium wilt (Scher 1980; Domínguez et al. 2008). However, analyzing the interaction of soil properties and the disease in one single soil can lead to misunderstandings and inconsistent conclusions. Interactions of the soil type with $\mathrm{pH}, \mathrm{N}$ and other abiotic conditions, such as the higher clay content, Fe and Mn, for instance, would be involved in the plant's response. This knowledge is crucial when considering soil management to deal with or control Fusarium wilt in banana.

The plant's response to the disease can be ruled by the particular ecological condition of each soil. Soils with a lower concentration of SOM in the eastern region, for instance, showed the highest detrimental effect of the disease. In the western region, plant response was erratic 
according to the inoculation. In fact, the best plant performance under infected and $\mathrm{pH}$ low conditions took place with the highest soil SOM (S6, S7 and S8). Plants in $\mathrm{pH}_{\text {low }}$ were more predisposed to Fusarium wilt in all tested soils. Results allow us to define different degrees of risk to the disease, according to the study regions. However even in a same banana region, the magnitude of the response to the disease according to the management of $\mathrm{pH}$ and $\mathrm{N}$ differed depending on the soil type. Nevertheless, practices such as maintaining a higher $\mathrm{pH}$ and increasing SOM through management appear to be preventive measures that can decrease plant predisposition to the disease. This seems to be a standard recommendation for all banana locations could be complex or not applicable. With this information, strategies based on soil management to prevent and deal with Foc can be implemented, in this case specifically for the Costa Rican reality.

The interaction of soil type with $\mathrm{pH}$ and $\mathrm{N}$ management in the disease expression should be studied thoroughly. How and where this interaction is more significant in the disease can define the strategy that should be implemented in crop management. Soil $\mathrm{pH}$ low and $\mathrm{N}_{\text {high }}$ predisposed the plant to be more easily infected and more affected by the disease. A higher level of wilting was found with the $\mathrm{N}$ application in both $\mathrm{pH}$ levels and it was more significant in $\mathrm{pH}$ low. It appears that soil $\mathrm{pH}$ is a primary factor in the plant's predisposition to the disease in most of the studied soil types. $\mathrm{N}$ inputs have important impacts in soil conditions, but the plant's response to the disease was more erratic according to this soil property. At the same time, $\mathrm{N}$ ammonia sources are recognized as a main cause for a drop in $\mathrm{pH}$ in soils from agricultural lands. Therefore, an integral management of soil properties to alleviate or prevent Fusarium wilt should include $\mathrm{pH}$ management and choosing less acidity $\mathrm{N}$ sources. In addition, it is necessary to include a soil $\mathrm{N}$ analysis in order to define the $\mathrm{N}$ recommendation for banana plantations.

More integral soil conditions can be playing a role in plant response to the disease. Furthermore, the role that the soil type played in the plant's response to de disease was evident. Although it agrees with the response in terms of suppression or conduction of the disease according to the soil type in Australia (Bowen et al. 2019), the results that we found allowed us to see a complex interaction of the soil type, its properties and the incidence of the disease. The influence of specific soil properties linked to the soil type (chemical, physical and microbiological) in each type of soil or each banana region can be part of the scenario of the natural banana's response to the disease. This could be the reason why previous studies have shown an erratic behavior of the disease according to soil management. Probably these results could depend on the region where 
plantations are established in the different banana locations in Costa Rica. The specific study of at least soil type and its conditions on banana predisposition to Fusarium wilt in each location or banana region is necessary to better understand the role of soil conditions in Fusarium wilt in bananas. Even ecological and environmental aspects of each region can be playing a role in the incidence of the disease.

\subsection{Conclusions}

Soil properties like $\mathrm{pH}$ and $\mathrm{N}$ play an important role in banana predisposition to Fusarium wilt and in the disease incidence. However, this relation is strongly influenced by soil type, i.e., other properties. This complexity clearly hampers the development of uniform management recommendations. Nevertheless, general trends are found. An increase in soil pH supports, in almost all cases, the suppression of Fusarium wilt. For the development of more specific soil management strategies, it appears to be necessary to view the soil as an integral system of physical, chemical, and biological properties rather than looking at individual soil properties with their thresholds. This complexity could be the cause for the inconsistencies that were found in the literature with respect to the role of soil properties in suppressing or conducing Fusarium wilt in banana. 


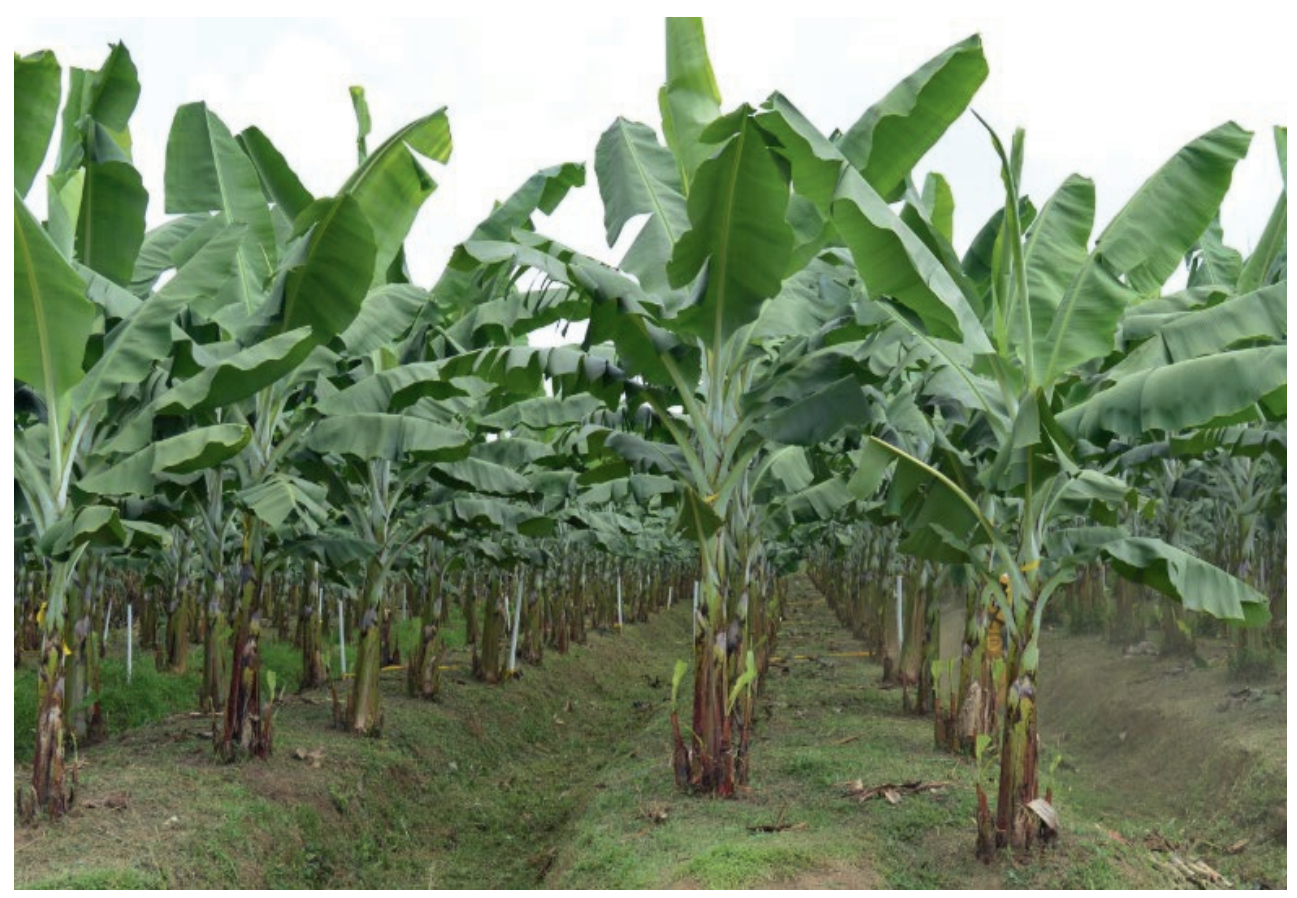




\section{Chapter 5}

\section{The effect of soil management on Fusarium wilt in banana (Musa AAA) in a medium-term field experiment}

Fusarium oxysporum f. sp. cubense (Foc) is a soil-borne fungus causing Fusarium wilt (FW) in banana. It is practically impossible to eradicate Foc in soils. Our understanding of soilFoc-banana interactions is hampered by inconsistent research results caused by agro-ecological variability and the complexity of the soil system. This study aimed to evaluate the options for soil management to reduce disease expression and maintain banana production. The expression of $F W$ (Foc Race 1) and the agronomic performance of Gros Michel (Musa AAA) banana were evaluated in two medium-term factorial field experiments at representative locations in the Costa Rican banana region. In the experiments, five soil properties ( $\mathrm{pH}, \mathrm{N}, \mathrm{Ca}, \mathrm{Mg}$ and $\mathrm{Mn}$ ) were managed to achieve a low and a high level. Plant mortality caused by $F W$, soil fertility, plant nutrition and agronomic performance were monitored during four crop cycles. After the first crop cycle, the treatments started to present differences in plant mortality. There was a significant rise of plant mortality after the second crop cycle resulting in a cumulative plant mortality exceeding $60 \%$ in both experiments. A lower soil $p H$ consistently resulted in a significant higher plant mortality. The interactions between soil properties ( $\mathrm{pH}-\mathrm{N}, \mathrm{pH}-\mathrm{CaMg}, \mathrm{pH}-\mathrm{Mn}, \mathrm{N}-\mathrm{Mn}$ and $\mathrm{CaMg-Mn}$ ) also influenced plant mortality. Soil $N$ was the most significant treatment affecting leaf nutrient concentrations, bunch weight and clusters per bunch. The experiments confirmed the potential role of soil management in FW expression in banana. However, although soil management may help to delay the disease development, it does not control the disease in the long run.

This chapter is based on:

Segura M. RA, Stoorvogel JJ, Blanco R. FA, Sandoval F. JA (2021) A Medium-Term Field Experiment to Study the Effect of Managing Soil Chemical Properties on Fusarium Wilt in Banana (Musa AAA). J Fungi 7:261. https://doi.org/10.3390/jof7040261 


\subsection{Introduction}

Global crop production is seriously hampered by crop diseases (Oerke and Dehne 2004; Oerke 2005; Savary et al. 2012). Fusarium wilt (FW) in banana is a prime example. FW (also known as Panama disease) is caused by the soil-borne fungus Fusarium oxysporum f. sp. cubense (Foc). Global banana production has been threatened by four Foc races: Race 1, Race 2, Subtropical Race 4 and Tropical Race 4 (TR4) (Stover 1962; Ploetz 2015a). Foc Race 1 decimated the commercial production of Gros Michel banana (a subgroup of Musa AAA), that used to be the main cultivar in Latin America and the Caribbean (LAC) until a major outbreak of FW in the first half of the $20^{\text {th }}$ century (Ploetz 2006). The social and economic impacts in the region were substantial (Jones and Morrison 1952). After struggling with the disease, Cavendish (another sub-group of Musa AAA) was found to be naturally resistant to Foc Race 1. The most effective option to maintain banana exports was to replace the Gros Michel banana by Cavendish bananas (Harper 1950; Stover 1962; Ploetz 1990; Perez-Vicente 2004). Despite the availability of the resistant Cavendish, Gros Michel is still being produced in LAC in smallholder systems, as its specific traits are preferred for local trade and consumption (Escobedo 2010). Bananas (Musa AAA) that are susceptible to Race 1 (including Gros Michel) and also plantains (Musa $\mathrm{ABB}$ ) remain important sources of incomes and represent around $30 \%$ of the global banana production (Aurore et al. 2009; Soto 2011). At the end of the 20th century TR4 appeared and started to spread affecting most banana cultivars including the important Cavendish cultivar.

Efficient practices to eradicate or control Foc in infested soils are lacking. Foc is a highly competitive fungus and it can survive in the soil for decades (Buddenhagen 2009). Soil flooding was widely implemented to eradicate the soil-borne fungus during the outbreak of Race 1. Rather than eradicating Foc, this practice contributed to the further dissemination of Race 1 (Stover et al. 1953, Stover 1961, 1962). Other control practices, such as the application of fungicides, replanting, and the eradication of infested plants, were tested but with mostly negative results. In most cases the aggressive character of the disease did not allow for further commercial banana production (Rishbeth 1955; Stover 1962).

Despite a general awareness of the potential of soil management in the control of this disease (Rishbeth 1955; Stover 1962; Borges et al. 1983; Domínguez et al. 2008; Segura et al. 2018, 2019; Orr and Nelson 2018; Segura-Mena et al. 2021), it is still not considered as a viable 
strategy to control FW in banana. The experimental results in the literature are inconsistent making it difficult to identify recommendations for soil management to control or alleviate the effect of the disease. In general, soil properties are known to influence the predisposition of crops to diseases (Doran et al. 1996; Ghorbani et al. 2008; Huber et al. 2012). Therefore, it is likely that crop predisposition to diseases can be influenced by soil management (Dordas 2008; Amtmann et al. 2008). However, given the large number of soil properties, it is important to identify which soil properties influence the predisposition of a crop to diseases. Soil properties that can be changed easily through management (e.g., fertilization, liming, tillage, and drainage) can be considered as first candidates for crop disease management.

Although many soil properties and their interactions are involved in crop development and production, some soil properties are commonly referred to in the scientific literature as important drivers for disease development in crops. Nonetheless, the scientific community still lacks a proper understanding of the role of soil properties on crop disease development. In this study, we focus on abiotic soil properties that can be influenced by soil management. Soil pH and nitrogen $(\mathrm{N})$, for instance, are two important soil factors in crop production. Besides, they are frequently mentioned to influence the crop response to diseases (Oritsejafor 1986; Höper and Alabouvette 1996; Harrison and Shew 2001; Janvier et al. 2007). Other nutrients as calcium (Ca) (Sugimoto et al. 2007; Huber et al. 2012; Serrano et al. 2012), magnesium (Mg) (Huber and Jones 2012), and manganese (Mn) (Brennan 1992) are reported to influence crop diseases (Stoorvogel and Segura 2018).

The relation between soil properties and FW is mostly studied in greenhouse experiments. The advantage of the greenhouse experimentation is the possibility to vary one or a limited number of properties under controlled conditions to derive a specific relationship. The disadvantages of the greenhouse experiments with large perennial crops like banana is that it is very difficult to carry out the experiment for an entire crop cycle, let alone over multiple crop cycles. Many greenhouse experiments with banana are carried for a relatively short period of 815 weeks on small plants. Therefore, it is very important to confirm the results from greenhouse experiments under field conditions (Gibson et al. 1999). Alternatively, farm surveys are carried out where FW is observed on farms and correlated to soil analyses from those locations (Orr and Nelson 2018; Segura et al. 2019). Agro-ecological conditions can be extremely variable and require many observations to carry out multivariate analysis to unravel the complex relationships 
(Tripp and Woolley 1989). Performing field experiments in representative banana producing areas, over multiple crop cycles can provide useful information about the Foc-soil-banana interactions. Field experiments looking at the banana response to the Foc infestation over various crop cycles under natural ecological conditions can show the true potential of soil management on the disease expression and how it affects crop production.

Given the impact of FW on banana production and the ineffectiveness of current management strategies to control or eradicate the fungus from infested soils, there is an urgent need for new approaches. Genetic resistance is considered an effective solution against FW and has proven itself in the past (Hwang and Ko 2004; Dale et al. 2017). However, it requires time to develop resistant varieties that are accepted by the producer and consumer. Integral solutions to face current problems caused by FW in the diverse banana scenarios are required. This paper hypothesizes on the basis of experimental proof from greenhouse experiments that soil properties influence the predisposition of banana to Foc Race 1. This study aims to evaluate whether the crop behaves similarly under field conditions and over multiple crop cycles. Experiments with Gros Michel banana and Foc Race 1 may also help in preparing for the arrival of Foc TR4 and the Cavendish production. The role of soil properties on Foc Race 1 was found to be similar to the role of soil properties on Foc TR4 (Segura et al. 2021). The latter is especially relevant with the recent arrival of Foc TR4 in LAC (Lambert et al. 2005; García-Bastidas et al. 2020).

\subsection{Materials and Methods}

\subsubsection{Study area}

The main banana region of Costa Rica is located in the Caribbean lowlands in the North East of the country (Segura et al. 2015). The region exhibits diverse soil conditions and is typically divided into two sub-regions defined by the location with respect to the Reventazón river. Soils east of the Reventazón river are predominantly sedimentary, fertility, (loamy) clay soils. Soils at the western side originate from sedimentary materials and volcanic ashes with (sandy) loam textures and an intermediate soil fertility (Lopez and Solís 1991; Arias et al. 2010a, b). More than $95 \%$ of the Costa Rican banana production takes place on those soil types (Segura et al. 2015). 
Experimental sites were established on two locations within the representative soils used for banana production. Both experiments are located on research stations of the Costa Rican Corporation of Banana Producers (CORBANA). The experiment in the western region (Expwest) was located at the La Rita experimental station (132 m.a.s.l.; 10¹5'54” N, 8346’26” W). The experiment in the eastern region (Exp-east) was located in 28 Millas (4 m.a.s.l.; $10^{\circ} 06^{\prime} 40^{\prime \prime}$ $\mathrm{N}, 8^{\circ} 22^{\prime} 53^{\prime}$ W). Both locations have a perhumid tropical climate with an average annual rainfall of 3000-3500 mm well distributed throughout the year and with minimum temperatures around $17^{\circ} \mathrm{C}$ and maximum temperatures around $35^{\circ} \mathrm{C}$.

\subsubsection{Experiments setup}

Exp-west covered 0.5 ha in an area that was used for banana production but fallow two years prior to the experiment. Exp-east covered 0.8 ha in an area that was used for plantain production, but that also had been fallow two years prior to the experiment. The experiments took place between November 2014 and July 2018. The fallow vegetation was cleared manually. The experiments were designed as a factorial trial studying the effect of four different soil properties: $\mathrm{pH}$, Nitrogen $(\mathrm{N})$, Calcium + Magnesium $(\mathrm{CaMg})$, and Manganese $(\mathrm{Mn}) . \mathrm{Ca}$ and $\mathrm{Mg}$ are found to be highly correlated in Costa Rican banana soils (Klinkert 2014) and are therefore included in a combined treatment in the experimental setup. Each of the soil properties were studied at two levels and the overall experiment had four replications. The area was sub-divided into 64 plots (16 treatments with 4 replications) as displayed in Figure 5-1. Planting was done with tissue culture plants, following standard commercial practices. In both experiments planting was done in a triangular planting pattern at a density of approx. 1600 plants per ha corresponding to an average commercial plant density. Each plot in Exp-west included 7-8 plants with a total of 486 plants in total for the entire experiment. Plots in the larger Exp-east included 15-18 plants with a total of 1160 plants for the entire experiment. At planting $1.0 \mathrm{~kg}$ of compost was added in the base of each planting hole. A basic nutritional package was applied to all plants during the first 7 weeks after planting. The nutritional package was differentiated for the different treatments eight weeks after planting as explained in detail in Section 2.4. The experiment was maintained for 4 crop cycles. 


\begin{tabular}{|l|l|l|l|}
\hline $1: 0: 0: 0$ & $1: 0: 1: 1$ & $0: 0: 0: 0$ & $0: 0: 1: 1$ \\
\hline $1: 1: 0: 1$ & $1: 1: 1: 0$ & $0: 1: 0: 1$ & $0: 1: 1: 0$ \\
\hline $0: 0: 1: 0$ & $0: 1: 1: 1$ & $1: 1: 0: 0$ & $1: 0: 0: 1$ \\
\hline $0: 1: 0: 0$ & $0: 0: 0: 1$ & $1: 0: 1: 0$ & $1: 1: 1: 1$ \\
\hline
\end{tabular}

\begin{tabular}{|l|l|l|l|}
\hline $1: 1: 0: 1$ & $1: 0: 1: 1$ & $0: 1: 0: 1$ & $0: 1: 1: 0$ \\
\hline $1: 1: 1: 0$ & $1: 0: 0: 0$ & $0: 0: 0: 0$ & $0: 0: 1: 1$ \\
\hline $0: 0: 0: 1$ & $0: 1: 0: 0$ & $1: 0: 0: 1$ & $1: 1: 0: 0$ \\
\hline $0: 1: 1: 1$ & $0: 0: 1: 0$ & $1: 0: 1: 0$ & $1: 1: 1: 1$ \\
\hline
\end{tabular}

\begin{tabular}{|l|l|l|l|}
\hline 1:1:0:0 & $1: 0: 1: 0$ & $0: 1: 0: 0$ & $0: 0: 1: 0$ \\
\hline $1: 0: 0: 1$ & $1: 1: 1: 1$ & $0: 0: 0: 1$ & $0: 1: 1: 1$ \\
\hline $0: 1: 0: 1$ & $0: 0: 1: 1$ & $1: 0: 0: 0$ & $1: 0: 1: 1$ \\
\hline $0: 0: 0: 0$ & $0: 1: 1: 0$ & $1: 1: 1: 0$ & $1: 1: 0: 1$ \\
\hline
\end{tabular}

\begin{tabular}{|l|l|l|l|}
\hline $1: 1: 0: 0$ & $1: 1: 1: 1$ & $0: 0: 0: 1$ & $0: 1: 0: 0$ \\
\hline $1: 0: 0: 1$ & $1: 0: 1: 0$ & $0: 0: 1: 0$ & $0: 1: 1: 1$ \\
\hline $0: 1: 0: 1$ & $0: 1: 1: 0$ & $1: 0: 0: 0$ & $1: 1: 0: 1$ \\
\hline $0: 0: 0: 0$ & $0: 0: 1: 1$ & $1: 1: 1: 0$ & $1: 0: 1: 1$ \\
\hline
\end{tabular}

Figure 5-1 Experimental design of the factorial trial with 2 levels of $\mathrm{pH}, \mathrm{N}, \mathrm{CaMg}$, and $\mathrm{Mn}$ (represented as $\mathrm{pH}: \mathrm{N}: \mathrm{CaMg}: \mathrm{Mn}$ with a 0 for the low level and a 1 for the higher level) with 4 repetitions of each treatment.

\subsubsection{Plant inoculation}

Although Foc Race 1 is regarded as endemic in Costa Rican banana soils, to ensure the plant infestation with Foc, each plant within the experiments was inoculated twice with $5 \mathrm{~g}$ of rice colonized with Foc Race 1 collected from Costa Rican soils and cultivated by CORBANA's Laboratory of Biological Control. The procedure of rice inoculation is novel and in process of publication, but the density of rice colonization was at least $1 \times 10^{-5}$ Foc conidia per $g$ rice. The initial inoculation took place seven weeks after planting and a second inoculation took place at the end of the first cycle, around 50 weeks after planting. The rice (with Foc Race 1) was buried 15 $\mathrm{cm}$ deep at the base of the plant for the first inoculation, and in front of the following sucker for the second inoculation. 


\subsubsection{Soil management}

Both experiments were established in a complete factorial design considering four main soil properties for banana production ( $\mathrm{pH}, \mathrm{N}, \mathrm{CaMg}$ and $\mathrm{Mn}$ ) with two contrasting levels (low and high) each. Soil management corresponding to each treatment is described in Table 5-1.

Table 5-1 Soil management of the factorial trial to study the effect of soil management on FW in Gros Michel banana in two banana regions form Costa Rica.

\begin{tabular}{|c|c|c|}
\hline Treatment & Management & Intervals \\
\hline pH-low & $300 \mathrm{ml}$ of $5 \% \mathrm{HCl}$ solution per plant & $\begin{array}{l}\text { In replanting: (one week before } \\
\text { planting in each plant area). Post }\end{array}$ \\
\hline pH-high & Approx. $400 \mathrm{~g}$ of calcium hydroxide per plant & $\begin{array}{l}\text { planting: } 8 \text { weeks after planting and } \\
\text { between cycle } 2 \text { and } 3\end{array}$ \\
\hline N-low & $\begin{array}{l}232 \mathrm{~kg} \text { ha year }{ }^{-1} \text { with ammonium nitrate and } \\
\text { calcium nitrate }\end{array}$ & \multirow{2}{*}{$\begin{array}{l}\text { Divided in } 17 \text { times year }^{-1} \text { in } 3- \\
\text { weekly applications }\end{array}$} \\
\hline N-high & $\begin{array}{l}605 \mathrm{~kg} \text { ha year }{ }^{-1} \text { with ammonium nitrate and } \\
\text { calcium nitrate }\end{array}$ & \\
\hline CaMg-low* & 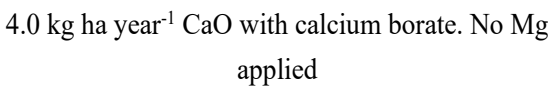 & \multirow{3}{*}{$\begin{array}{l}\text { Divided in } 17 \text { times year }^{-1} \text { in } 3- \\
\text { weekly applications }\end{array}$} \\
\hline \multirow[t]{2}{*}{ CaMg-high } & $\begin{array}{l}315 \mathrm{~kg} \text { ha year }{ }^{-1} \mathrm{CaO} \text { with calcium borate and } \\
\text { calcium nitrate }\end{array}$ & \\
\hline & $150 \mathrm{~kg} \mathrm{MgO} \mathrm{ha} \mathrm{year}^{-1}$ with magnesium sulphate & \\
\hline Mn-low & No Mn applied & \multirow{2}{*}{$\begin{array}{l}\text { Divided in } 17 \text { times year }^{-1} \text { in } 3- \\
\text { weekly applications }\end{array}$} \\
\hline Mn-high & $32 \mathrm{~kg} \mathrm{ha}^{-1}$ year $^{-1} \mathrm{Mn}$ with manganese sulphate & \\
\hline \multicolumn{2}{|c|}{$\begin{array}{l}\text { Basic nutritional package[36]: } 105 \mathrm{P}_{2} \mathrm{O}_{5}, 610 \mathrm{~K}_{2} \mathrm{O}, 60 \mathrm{~S}, 9.2 \mathrm{Zn} \text { and } \\
3.2 \mathrm{~B} \text { (in kg ha year-1) }\end{array}$} & $\begin{array}{l}\text { Divided in } 17 \text { times year }^{-1} \text { in } 3- \\
\text { weekly applications }\end{array}$ \\
\hline \multicolumn{3}{|c|}{$\begin{array}{l}\text { * The expected } \mathrm{CaO} \text { is zero, but the basic input of } \mathrm{B} \text { in the whole experiments, implies the application of } \\
\text { calcium borate. }\end{array}$} \\
\hline
\end{tabular}

\subsubsection{Evaluated variables}

Plant mortality was recorded as a percentage during the four crop cycles as the main indicator of the Fusarium wilt incidence. Plant mortality by FW was obtained by registering the harvested plants at the end of each cycle against the total plants at the beginning of the experimental period. An infested plant (showing symptoms) died in most of the cases. Plants that 
were not harvested almost exclusively died as a result of FW as indicated by the typical symptoms of wilting and pseudostem splitting. Those plants were not replaced during the experiment. Mortality was therefore a cumulative number over the entire experiment.

Soil chemical properties were analyzed at the beginning of the experiments (Mehlich 1984), a second analysis took place between the first and second cycle and a third analysis took place between the third and the fourth cycle. Soils were sampled at $0-30 \mathrm{~cm}$ depth in front of the following sucker at flowering with a gouge auger.

Leaf samples from the medium section of the third leave of plants were taken for a complete foliar analysis at flowering in cycles 1 and 2. Agronomic performance was measured in terms of plant height, steam circumference, and clusters or hands per bunch at flowering (Segura et al. 2015). The bunch weight was measured at harvest (the end of each cycle) 80 days after flowering (the standard harvesting age in Costa Rican plantations). With the bunch weight, the density per ha and the plant mortality, a projection of the total harvested fruit ha ${ }^{-1}$ cycle $^{-1}$ was calculated in each cycle in each experiment. Sampling and data collection were carried out during the first and the second crop cycles. Due the detrimental effect of the disease on the plants after the second cycle, the evaluation of agronomic performance and leaf nutrient analysis were not performed for the third and the fourth cycles.

\subsubsection{Statistical analysis}

Data analysis was done separately for each region but following the same protocol. The mean was modeled by a full factorial design of five fixed factors, namely $\mathrm{pH}, \mathrm{N}, \mathrm{CaMg}, \mathrm{Mn}$, and crop cycle. The whole data analysis was performed using R statistics (R Development Core Team 2010).

Plant mortality was analyzed using the logit of dead plants $(\operatorname{logit}(\mathrm{p})=\log (\mathrm{p} /(1-\mathrm{p})$, where $\mathrm{p}=$ proportion of dead plants) as response variable. The generalized estimation equation (GEE) technique was used, taking as repeated measures the counts of dead plants by FW across the second, third and fourth production cycles. The first cycle was omitted in the analysis because its plant mortality ranged within the normal limits of healthy plantations (around 2\%). The binomial variance function was applied to model residues distribution since mortality outcomes are of the binomial type. Also, the first order autoregressive (ar1) correlation structure was chosen to model 
the repeated measures after being compared to the "independence" and "exchangeable" structures. The geeglm function of the geepack package (Yan 2002; Yan and Fine 2004; Højsgaard and Yan 2006). Apart from the above-described analysis, an ordinary regression analysis of percent of plant mortality on soil $\mathrm{pH}$ values of the whole plots in each experiment was performed.

All the agronomic variables (height, diameter, bunch weight, number of clusters per bunch) and the leaf nutrient concentrations were analyzed using a linear mixed model in which replicates were the only random factor and cycle was a repeated measures factor. Heteteroscedasticity across cycles and correlated measurements were accounted for through the varFixed correlation structure. The lme function of the nlme package were used for computations. The soil and leaf nutrient analyses were similar to those of the agronomic variables, except that it was not necessary to include heteroscedasticity in the model.

In all the analysis the means of main factors levels and of combinations of them were obtained and tested using the emmeans package (Russell et al. 2021).

\subsection{Results}

\subsubsection{Plant mortality}

Plant mortality was relatively low in the first and the second cycle. However, after the second cycle plant mortality increased rapidly (Figure 2). In the first cycle, the average mortality was minimal (around 1\%) in both experiments. The second cycle showed an increase in mortality in the experiments up to $11 \%$ in Exp-west and 20\% in Exp-east. A rapid and significant increase $(\mathrm{P} \leq 0.001)$ of plant mortality occurred after the second cycle in both experiments (Figure 5-2). 


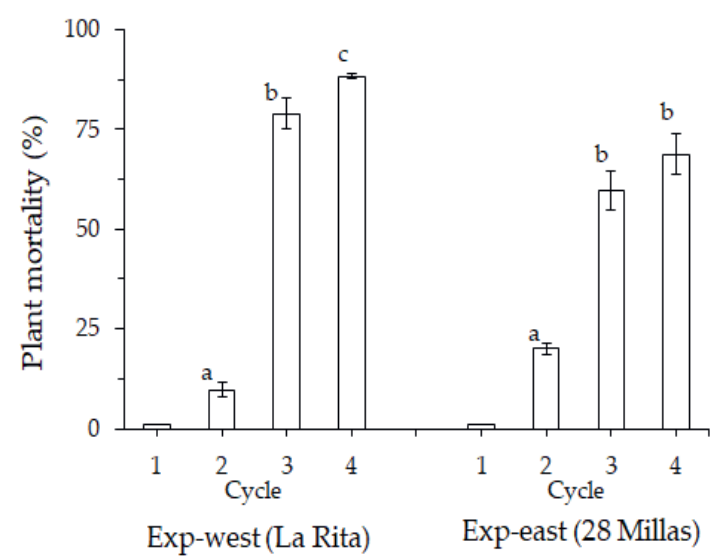

Figure 5-2 Plant mortality by Fusarium wilt (Foc race 1) of Gros Michel banana plants during four crop cycles in two experiments (Exp-west and Exp-east) in different locations (La Rita and 28 Millas respectively) in the Costa Rican banana region. Bars with different letter in cycles are significantly different. $\mathrm{N}=486$ in Exp-west and 1646 in Exp-east. (I= standard error).

Plant mortality also differed as a result of the different treatments in the $2^{\text {nd }}, 3^{\text {rd }}$, and $4^{\text {th }}$ cycle (Figure 5-3). pH-low was linked with a higher plant mortality by FW for both experiments in the third $(\mathrm{P} \leq 0.000)$ and the fourth $(\mathrm{P} \leq 0.001)$ cycles. Differences in mortality between $\mathrm{pH}-\mathrm{low}$ and $\mathrm{pH}$-high varied from 14 to $17 \%$ in the Exp-west and from 16 to 22\% in Exp-east. The $\mathrm{N}$ level did not influence the plant mortality in the third $(\mathrm{P}=0.873)$ and the fourth $(\mathrm{P}=0.162)$ cycles in Exp-west. In Exp-east a higher plant mortality was linked with N-high only in the third $(\mathrm{P} \leq 0.030)$ cycle. The effect was less significant $(\mathrm{P} \leq 0.070)$ in the fourth cycle, but the same trend was observed. The effect of $\mathrm{CaMg}(\mathrm{P} \leq 0.025)$ and $\mathrm{Mn}(\mathrm{P} \leq 0.005)$ in the plant mortality were significant only in the second cycle of Exp-west.

The relation between plant mortality and soil $\mathrm{pH}$ for each individual plot in the third cycle for both experiments is presented in Figure 5-4. The inconsistent results in the literature are not surprising, if we see the scatter in the relation between $\mathrm{pH}$ and mortality in the Figure. However, the figure clearly shows that a low soil $\mathrm{pH}$ always corresponds to a high plant mortality irrespective of the other conditions. The clear role of soil $\mathrm{pH}$ is visually confirmed on an aerial photo of the plantation between the second and the third cycle in Exp-east (Figure 5-5). The aerial perspective shows a clear reduction in soil cover in the $\mathrm{pH}-\mathrm{low}$ plots as it was observed in both experiments. 
In Exp-west, plant mortality was also influenced by the interaction of $\mathrm{pH}$-low and N-high $(\mathrm{P} \leq 0.010)$, pH-high and Mn-high $(\mathrm{P} \leq 0.016)$, and CaMg-low and Mn-high $(\mathrm{P} \leq 0.007)$ (Figure 56). There were no differences in plant mortality in relation of the interaction of the tested soil properties in Exp-east (Figure 5-7).

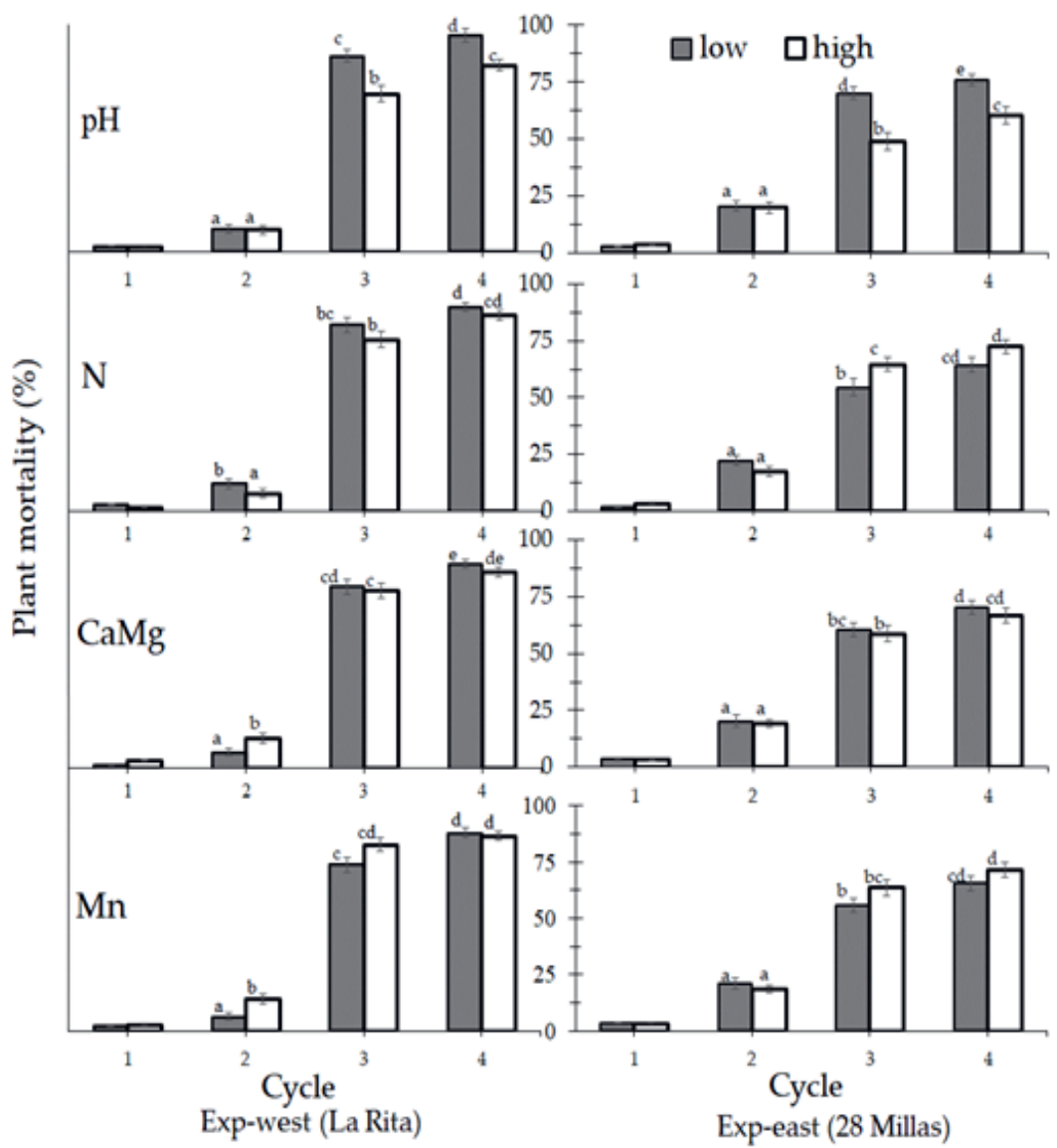

Figure 5-3 Plant mortality by Fusarium wilt (Foc race 1) of Gros Michel banana plants according to the management of four soil properties $(\mathrm{pH}, \mathrm{N}, \mathrm{CaMg}$ and $\mathrm{Mn}$ ) during four crop cycles in two experiments (Exp-west and Exp-east) in two different locations (La Rita and 28 Millas respectively) within the Costa Rican banana region. Bars with different letter in cycle are significantly different according to the soil property. Total plants per treatment is 243 in Exp-west and 823 in Exp-east. (I= standard error). 


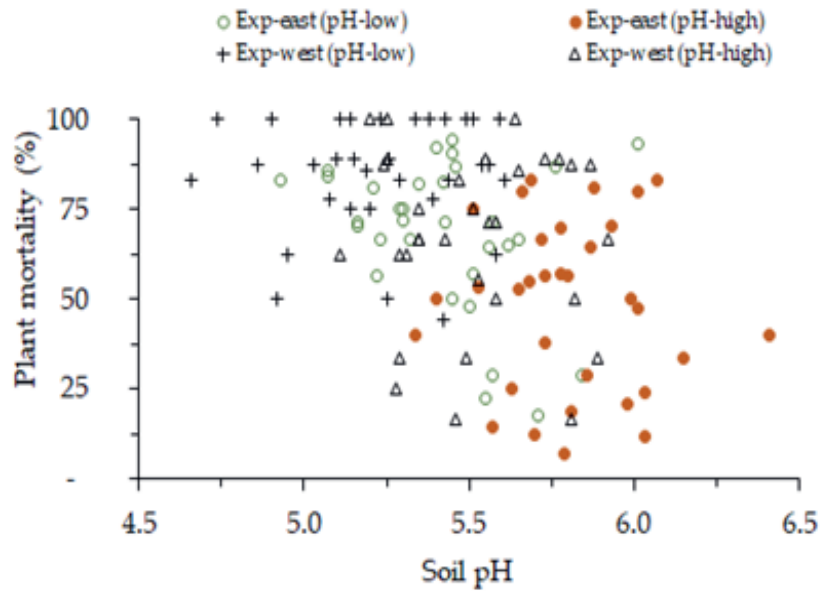

Figure 5-4 Dispersion of plant mortality by Fusarium wilt (Foc Race 1) of banana Gros Michel in relation with soil $\mathrm{pH}$ during the third cycle of two experiments (Exp-west and Exp-east) in two different locations (La Rita and 28 Millas respectively) within the Costa Rican banana region.

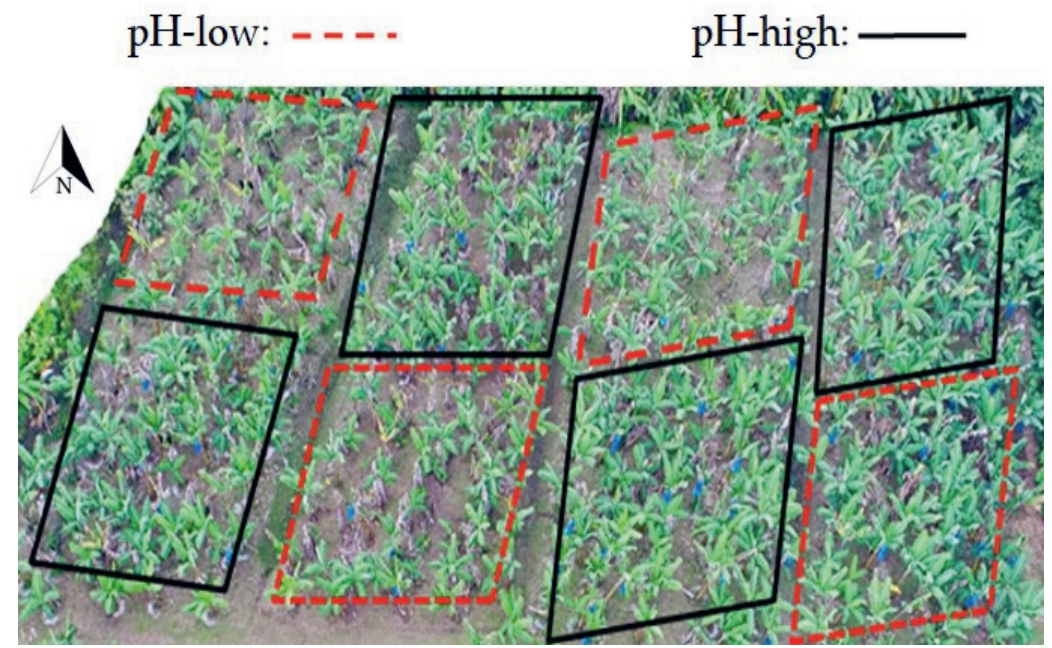

Figure 5-5 Aerial perspective from $30 \mathrm{~m}$ above the ground level of the impact of soil $\mathrm{pH}$ on plant mortality caused by Fusarium wilt (Foc race 1) in the Exp-east,28 Millas, Costa Rica between the second and third crop cycles (aerial photo: Jean-François Michaud, CBC, Radio-Canada). 

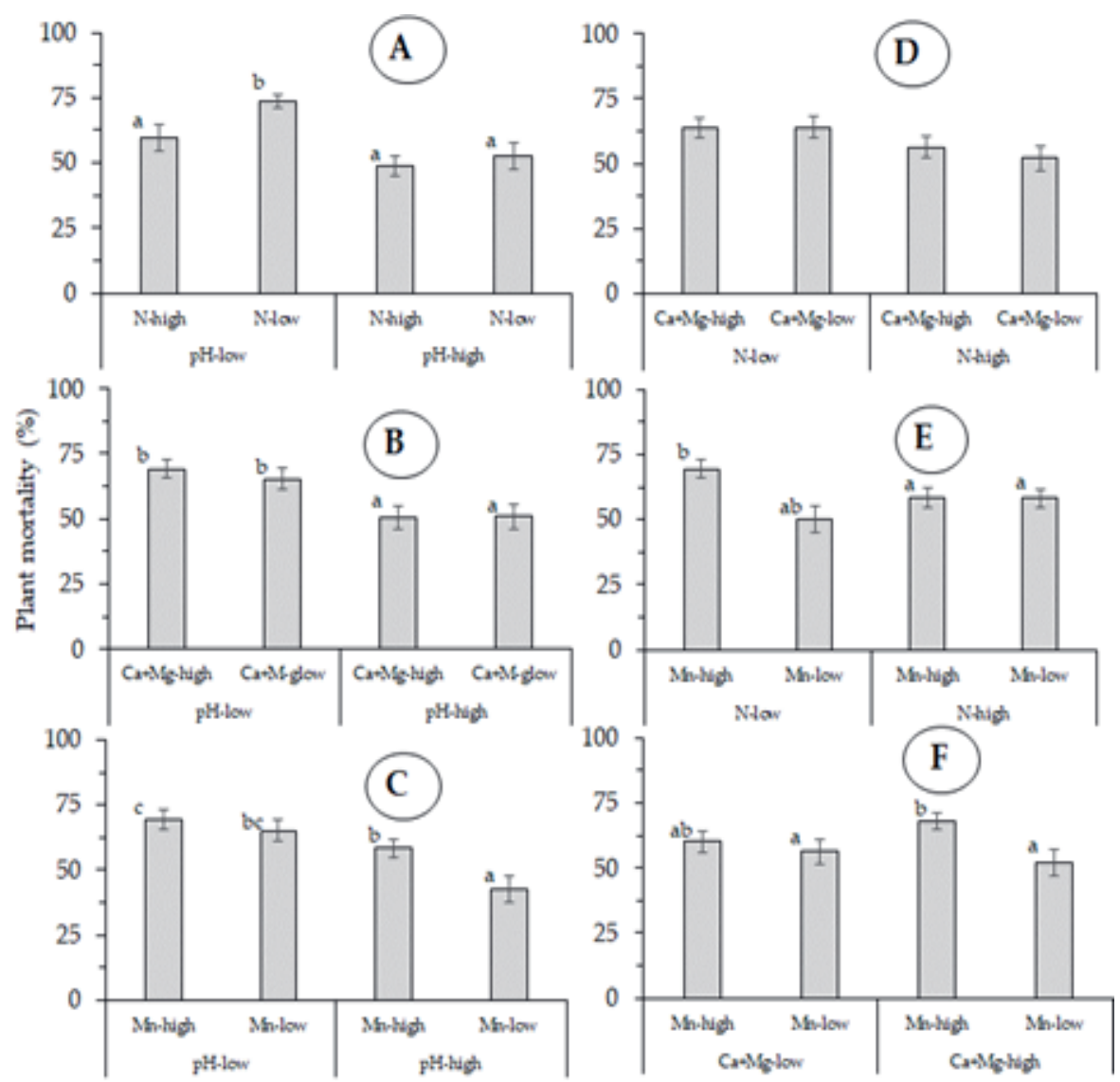

Figure 5-6 Average effect during three crop cycles (second, third and fourth) of the interaction of five soil properties: A: pH- N, B: pH-CaMg, C: pH-Mn, D: N-CaMg, E: N-Mn and F: CaMg-Mn, on plant mortality of Gros Michel banana plants infested with Fusarium wilt (Foc Race 1) in the Exp-west, La Rita, Costa Rica. ( $\mathrm{I}=$ standard error). 


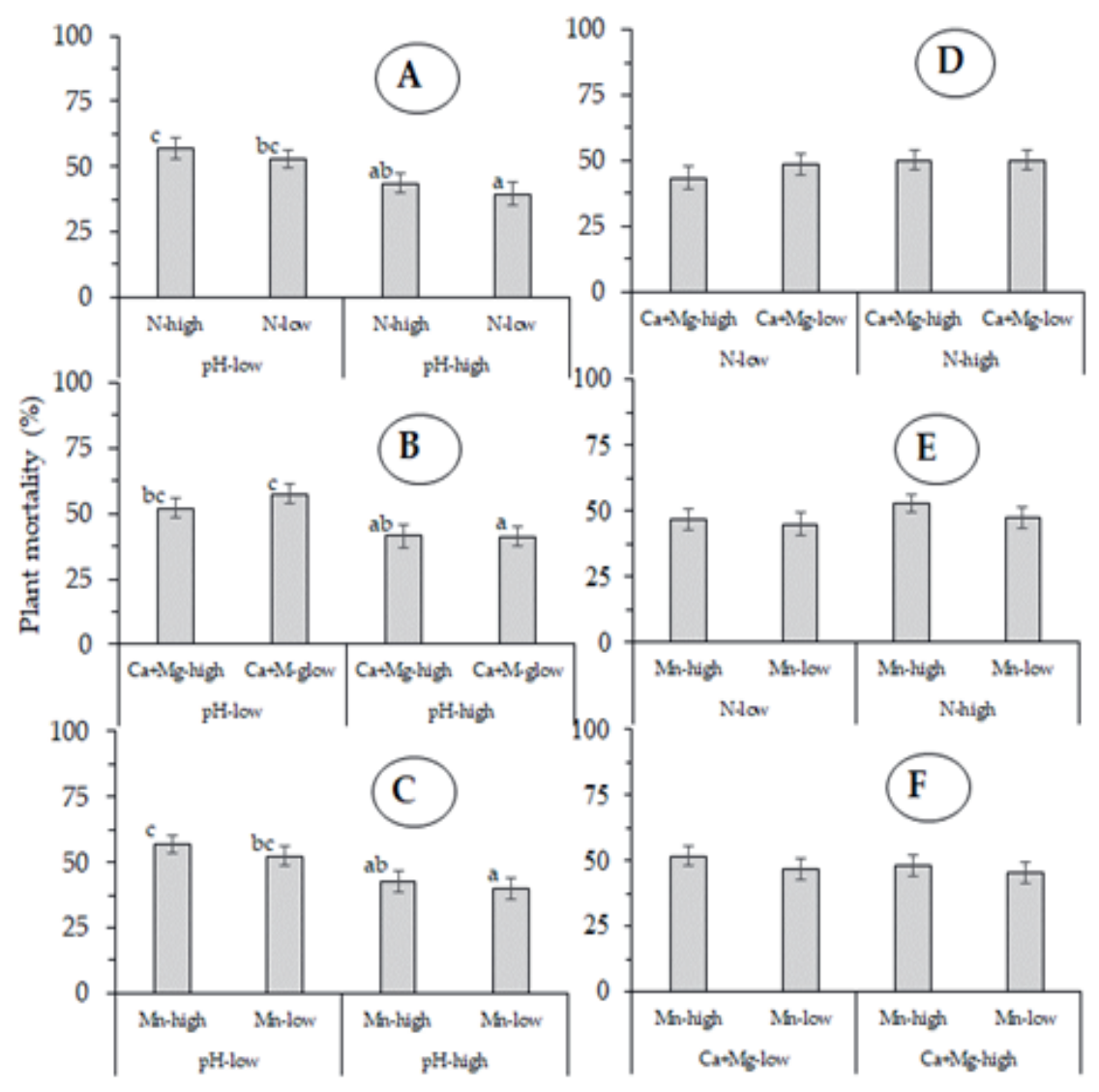

Figure 5-7 Average effect during three crop cycles (second, third and fourth) of the interaction of five soil properties : A: pH- N, B: pH-CaMg, C: pH-Mn, D: N-CaMg, E: N-Mn and F: CaMg-Mn, on plant mortality of Gros Michel banana plants infested with Fusarium wilt (Foc Race 1) in Exp-east,28 Millas, Costa Rica. ( $\mathrm{I}=$ standard error).

\subsubsection{Analysis for managed soil properties}

Soil management resulted in significant differences in soil conditions in the second and the third analysis, during the four evaluated crop cycles in Exp-west. The trend in values for evaluated soil properties followed a significant trend respect to the level for $\mathrm{pH}, \mathrm{Mg}$, and $\mathrm{Mn}$. In Exp-east only $\mathrm{pH}$ and $\mathrm{Mn}$ maintained significant differences in the second analysis. In the third analysis, only soil $\mathrm{pH}$ had significant difference according to the soil treatment. The rest of the soil properties did not present significant differences under the various treatments (Table 5-2). 
Table 5-2 Soil properties in two experiments (Exp-west and Exp-east) from two locations (La Rita and 28 Millas respectively) of the Costa Rican banana region during the experimental period of four crop cycles. ( $\mathrm{n}=$ 32 per soil property in each region and cycle).

\begin{tabular}{|c|c|c|c|c|}
\hline \multirow[t]{2}{*}{ Treatment } & \multirow[t]{2}{*}{ Units } & \multicolumn{3}{|c|}{ Soil analysis } \\
\hline & & Start & cycle $1-2$ & cycle 3-4 \\
\hline \multicolumn{5}{|c|}{ Exp-west (La Rita) } \\
\hline N-low & $\%$ & n.d & 0.30 & 0.30 \\
\hline N-high & $\%$ & n.d & 0.31 & 0.30 \\
\hline pH-low & - & 5.5 & $5.4 * * *$ & $5.1 * * *$ \\
\hline pH-high & - & 5.5 & 5.7 & 5.6 \\
\hline Ca-low & $\operatorname{cmol}(+) \mathrm{kg}^{-1}$ & 4.60 & 4.18 & 4.06 \\
\hline Ca-high & $\operatorname{cmol}(+) \mathrm{kg}^{-1}$ & 4.60 & 4.26 & 4.26 \\
\hline Mg-low & $\operatorname{cmol}(+) \mathrm{kg}^{-1}$ & 2.90 & $1.41 * *$ & $1.84 * * *$ \\
\hline Mg-high & $\operatorname{cmol}(+) \mathrm{kg}^{-1}$ & 2.90 & 1.67 & 2.35 \\
\hline Mn-low & $\mathrm{mg} \mathrm{kg}^{-1}$ & 11 & $15^{* * *}$ & $16^{* * *}$ \\
\hline Mn-high & $\mathrm{mg} \mathrm{kg}^{-1}$ & 11 & 18 & 23 \\
\hline \multicolumn{5}{|c|}{ Exp-east (28 Millas) } \\
\hline N-low & $\%$ & n.d & 0.16 & 0.15 \\
\hline N-high & $\%$ & n.d & 0.17 & 0.14 \\
\hline pH-low & - & 6.3 & $5.4^{* *}$ & $5.4 * * *$ \\
\hline pH-high & - & 6.3 & 5.8 & 5.9 \\
\hline Ca-low & $\operatorname{cmol}(+) \mathrm{kg}^{-1}$ & 22.2 & 21.9 & 22.6 \\
\hline Ca-high & $\operatorname{cmol}(+) \mathrm{kg}^{-1}$ & 22.2 & 21.8 & 22.8 \\
\hline Mg-low & $\operatorname{cmol}(+) \mathrm{kg}^{-1}$ & 10.9 & 9.65 & 9.83 \\
\hline Mg-high & $\operatorname{cmol}(+) \mathrm{kg}^{-1}$ & 10.9 & 9.54 & 10.2 \\
\hline Mn-low & $\mathrm{mg} \mathrm{kg}^{-1}$ & 88 & $90 * * *$ & 88 \\
\hline Mn-high & $\mathrm{mg} \mathrm{kg}^{-1}$ & 88 & 133 & 87 \\
\hline
\end{tabular}

${ }^{*} \mathrm{P}<0.050,{ }^{* * \mathrm{P}}<0.010,{ }^{*} * * \mathrm{P}<0.001 ;$ comparison between the low and the high level of each soil property

\subsubsection{Leaf nutrient concentration}

Soil $\mathrm{pH}$ and $\mathrm{N}$ levels were the treatments that influenced nutrient leaf concentrations in the first two cycles (Table 5-3). 
Table 5-3 Nutrient concentration in the leaf tissue of of Gros Michel banana plants infected with Fusarium wilt (Foc Race 1) in relation with two levels of soil abiotic properties in two experiments (Exp west and Exp east) at two different Costa Rican regions (La Rita and 28 Millas). ( $\mathrm{n}=32$ per soil property per season and level of soil property).

\begin{tabular}{|c|c|c|c|c|c|c|c|c|c|c|c|}
\hline $\begin{array}{l}\text { Soil } \\
\text { property }\end{array}$ & $\mathrm{N}$ & $\mathrm{P}$ & $\mathrm{K}$ & $\mathrm{Ca}$ & $\mathrm{Mg}$ & $\mathrm{S}$ & $\mathrm{Fe}$ & $\mathrm{Cu}$ & $\mathrm{Zn}$ & $\mathrm{Mn}$ & B \\
\hline level & \multicolumn{6}{|c|}{$\%$ dry matter ${ }^{-1}$} & \multicolumn{5}{|c|}{$\mathrm{mg} \mathrm{Kg}{ }^{-1}$} \\
\hline \multicolumn{12}{|c|}{ Exp-west (La Rita), first cycle } \\
\hline pH-low & 2.93 & 0.21 & 4.32 & 0.60 & 0.28 & 0.19 & 67 & 9 & 17 & $172 *$ & $8^{*}$ \\
\hline pH-high & 2.90 & 0.21 & 4.39 & 0.57 & 0.27 & 0.19 & 64 & 9 & 17 & 147 & 9 \\
\hline N-low & 2.86 & 0.21 & 4.43 & $0.56^{*}$ & 0.27 & $0.19^{*}$ & 67 & 9 & 17 & $149 *$ & 9 \\
\hline N-high & 2.96 & 0.21 & 4.28 & 0.61 & 0.29 & 0.20 & 64 & 9 & 16 & 169 & 8 \\
\hline CaMg-low & 2.92 & 0.21 & 4.34 & 0.58 & $0.27 *$ & 0.19 & 67 & 9 & 17 & 165 & 8 \\
\hline CaMg-high & 2.91 & 0.21 & 4.36 & 0.59 & 0.29 & 0.19 & 64 & 9 & 17 & 154 & 9 \\
\hline Mn-low & 2.89 & 0.21 & 4.40 & 0.57 & 0.28 & 0.19 & 65 & 9 & 17 & $149 *$ & 9 \\
\hline Mn-high & 2.94 & 0.21 & 4.30 & 0.60 & 0.28 & 0.20 & 66 & 9 & 17 & 170 & 8 \\
\hline \multicolumn{12}{|c|}{ Exp-west (La Rita), second cycle } \\
\hline pH-low & 2.55 & 0.19 & 3.77 & 0.67 & 0.28 & 0.18 & 58 & 7 & 17 & $183^{*}$ & $9 *$ \\
\hline pH-high & 2.54 & 0.19 & 3.82 & 0.75 & 0.26 & 0.18 & 57 & 7 & 17 & 163 & 11 \\
\hline N-low & $2.50 *$ & $0.20 *$ & $3.86^{*}$ & $0.66^{*}$ & 0.27 & $0.19^{*}$ & $59 *$ & 7 & $18^{*}$ & $155^{*}$ & $10^{*}$ \\
\hline N-high & 2.59 & 0.18 & 3.73 & 0.76 & 0.27 & 0.18 & 56 & 7 & 17 & 190 & 9 \\
\hline CaMg-low & 2.53 & 0.19 & 3.80 & 0.71 & $0.26^{*}$ & 0.18 & 58 & 7 & 17 & 176 & 10 \\
\hline CaMg-high & 2.56 & 0.19 & 3.79 & 0.71 & 0.28 & 0.18 & 57 & 7 & 17 & 170 & 10 \\
\hline Mn-low & 2.53 & 0.19 & 3.83 & 0.71 & 0.27 & 0.18 & 58 & 7 & 17 & $157^{*}$ & 10 \\
\hline Mn-high & 2.56 & 0.19 & 3.76 & 0.72 & 0.27 & 0.18 & 58 & 7 & 17 & 189 & 10 \\
\hline \multicolumn{12}{|c|}{ Exp-east (28 Millas), first cycle } \\
\hline pH-low & 2.42 & 0.19 & $3.70^{*}$ & 0.66 & 0.28 & 0.17 & 58 & 7 & $17 *$ & 408 & 12 \\
\hline pH-high & 2.44 & 0.19 & 3.58 & 0.63 & 0.27 & 0.17 & 56 & 7 & 16 & 351 & 12 \\
\hline N-low & $2.34 *$ & $0.20^{*}$ & $3.73 *$ & $0.60^{*}$ & $0.26^{*}$ & 0.17 & 57 & 7 & 17 & 355 & 12 \\
\hline N-high & 2.52 & 0.19 & 3.55 & 0.69 & 0.28 & 0.17 & 58 & 7 & 17 & 403 & 11 \\
\hline
\end{tabular}




\begin{tabular}{lccccccccccc}
\hline CaMg-low & 2.44 & 0.19 & $3.74^{*}$ & 0.65 & 0.27 & 0.17 & 58 & 7 & 17 & 378 & 12 \\
CaMg-high & 2.43 & 0.19 & 3.54 & 0.64 & 0.28 & 0.17 & 57 & 7 & 17 & 382 & 12 \\
Mn-low & 2.42 & 0.19 & $3.71^{*}$ & 0.64 & 0.27 & 0.17 & 57 & 7 & 17 & $366^{*}$ & 11 \\
Mn-high & 2.45 & 0.19 & 3.57 & 0.65 & 0.28 & 0.17 & 58 & 7 & 17 & 394 & 12 \\
& & & Exp-east $(28$ Millas), second cycle & & & & \\
pH-low & 2.50 & 0.19 & 3.27 & $0.81^{*}$ & 0.36 & 0.18 & 66 & 8 & 17 & 298 & 10 \\
pH-high & 2.49 & 0.19 & 3.27 & 0.89 & 0.36 & 0.18 & 67 & 7 & 17 & 272 & 11 \\
N-low & $2.43 *$ & $0.20^{*}$ & $3.39^{*}$ & $0.78^{*}$ & $0.34^{*}$ & 0.18 & 67 & 7 & 17 & 289 & 11 \\
N-high & 2.55 & 0.18 & 3.16 & 0.91 & 0.38 & 0.18 & 67 & 8 & 17 & 282 & 10 \\
CaMg-low & 2.50 & 0.19 & 3.34 & 0.85 & 0.36 & 0.18 & 67 & 8 & 17 & 294 & 11 \\
CaMg-high & 2.49 & 0.19 & 3.21 & 0.85 & 0.37 & 0.18 & 67 & 8 & 17 & 276 & 10 \\
Mn-low & 2.51 & $0.20^{*}$ & 3.29 & $0.83 *$ & 0.36 & 0.18 & 67 & 8 & 17 & 287 & 11 \\
Mn-high & 2.48 & 0.18 & 3.26 & 0.87 & 0.36 & 0.18 & 66 & 7 & 17 & 283 & 10 \\
\hline
\end{tabular}

$* \mathrm{P}<0.050, * * \mathrm{P}<0.010,{ }^{* * *} \mathrm{P}<0.001$; comparison between the low and the high level of each soil property

\subsubsection{Agronomic plant response}

Managing soil properties had a minimal influence on the agronomic performance of the crop in the first and the second cycles. Only $\mathrm{N}$ with a direct effect on the bunch weight $(18.8 \mathrm{Kg}$ in N-low vs $19.9 \mathrm{~kg}$ in N-high) and clusters per bunch (8.9 in in N-low vs 9.0 in N-high) in the cycle 1 of the Expeast and CaMg in the bunch weight (26.2 kg in CaMg-low vs $24.8 \mathrm{~kg}$ in N-high in the first cycle of Exp-west). No differences in the rest of the agronomic variables were found in the two evaluated cycles. There were significant $(\mathrm{P} \leq 0.050)$ differences in the average of the agronomic variables between the cycles (first and second) in both experiments. The second cycle show higher values respect to the cycle 1 , as is usual in new banana plantations (Table 5-4). 
Table 5-4 Average of agronomic variables of Gros Michel banana plants infected with Foc Race 1 in two experiments (Exp-west and Exp-east) from two locations (La Rita and 28 Millas respectively) of the Costa Rican banana region. ( $\mathrm{n}=64$ in both experiments).

\begin{tabular}{ccccccc}
\hline Variable & \multicolumn{2}{c}{ Exp-west La Rita } & & \multicolumn{2}{c}{ Exp-east 28 Millas } \\
\cline { 2 - 3 } \cline { 6 - 7 } & $1^{\text {st }}$ Cycle & $2^{\text {nd }}$ Cycle & & $1^{\text {st }}$ Cycle & $2^{\text {nd }}$ Cycle \\
\hline Plant height $(\mathrm{cm})$ & 337 & 369 & & 300 & 355 \\
Pseudostem circumference $(\mathrm{cm})$ & 75 & 83 & & 64 & 79 \\
Bunch weight $(\mathrm{kg})$ & 25.2 & 29 & & 19.3 & 24.8 \\
Clusters bunch & -1 & 9.2 & 10.3 & & 8.5 & 8.9 \\
Harvested fruit $\left(\right.$ ton $\left.^{-1}\right)$ & 39.9 & 41.3 & & 30.6 & 31.8 \\
\hline
\end{tabular}

\subsection{Discussion}

\subsubsection{Plant mortality}

Plant mortality in relation to soil management was analyzed according to its behavior during four crop cycles. Despite the significative results with soil $\mathrm{pH}$ and its interactions with the other tested soil properties, the very high plant mortality after the second cycle (around $80 \%$ ) limits the effect of those properties on FW expression. The final mortality in both experiments exceeded that observed in the literature, but it took longer to reach that high level. A study focusing on the effect of flooding on FW reported a mortality from 14 to $56 \%$ under field conditions in the first two years after planting (Rishbeth 1955). Both experimental fields were fallow for two years. Despite the artificial plant inoculation, the time from the first inoculation to the end of the second cycle was probably not enough to present a higher level of infection. One could argue that the development of the disease in this type of experiments is strongly dependent on the type of inoculation in the experiment.

Soil $\mathrm{pH}$ is described in the literature as an important indicator for soil health and banana production (Pattison et al. 2008; Segura et al. 2015). The results clearly confirm that it also plays an important role in the expression of FW in banana. In the third and the fourth cycles, where the soil treatments showed significant effects in plant mortality, $\mathrm{pH}$ maintained a consistent behavior in its influence on the disease. Relatively low mortality rates were always linked to a higher soil $\mathrm{pH}$. It appears that increasing soil $\mathrm{pH}$ and avoiding soil acidification can reduce the impact of the disease in the medium-term. 
A higher soil $\mathrm{pH}$ (near and up to 6.0) can be linked with improved plant development but also to the lower plant mortality caused by FW. Both direct and indirect effects of soil pH can be playing a role in the findings. As a main soil property, $\mathrm{pH}$ affects other biotic and abiotic soil properties (Janvier et al. 2007; Chaperon and Sauvé 2007; Pattison et al. 2008; Almeida et al. 2018). The exact causal-effect of the suppressive effect of a higher soil $\mathrm{pH}$ values cannot be determined based on the current experiment. The variation in the effect can be caused by interactions with the other soil properties that were evaluated ( $\mathrm{N}, \mathrm{CaMg}$ and $\mathrm{Mn}$ ).

Although, it was demonstrated that soil management can modulate FW in banana, the high plant mortality rates also indicate how serious the disease is. The rapid development of the disease clearly hampers the cultivation of banana as a perennial crop. An alternative scenario would be annual cropping or for a maximum of two crop cycles. Otherwise, replanting every 4 - 5 year can be considered for having an acceptable production under a high soil infestation with Foc. Implementing these alternatives requires a thorough cost/benefit analysis. Besides, in a natural processes of plant inoculation (without the artificial forced inoculation in this experiment), a longer period to achieve the high disease mortality could be expected.

Nitrogen fertilization is an important cause for a lower soil $\mathrm{pH}$ in banana plantations. Particularly, the applied $\mathrm{N}$ ammonia sources in the experiments could decrease soil $\mathrm{pH}$. This $\mathrm{N}$ source is linked with a higher incidence of fungal diseases in crops (Huber and Watson 1974). Soil management has been identified as an option to suppress FW in banana (Geense et al. 2015). The results show that it can slow down the impact of $\mathrm{FW}$, but that soil management is still unable to control the disease.

The significant effect of $\mathrm{pH}-\mathrm{low}$ can be associated to a higher Mn availability in these treatments. Soils in both experiments have high natural Mn concentrations. Natural Mn can be solubilized in $\mathrm{pH}-\mathrm{low}$, even in Mn-low treatments. Then the $\mathrm{pH}-\mathrm{Mn}$ interaction can be partially causing plant mortality in the $\mathrm{pH}$-low treatments. This interaction was more evident in the Expwest with the lower soil fertility. The higher soil fertility in Exp-east could hide the effect of the soil properties (except to $\mathrm{pH}$ and $\mathrm{N}$ ) and their interactions on the plant mortality. Besides, the existence of the interactions of the soil properties in the expression of FW can imply a more complex scenario to use soil management to control or alleviate $\mathrm{FW}$ in banana.

The field experimentation brought along a high complexity to control the conditions in each experiment. The evaluated effect of soil management on FW expression was an indirect effect 
of the treatment. The disease expression in the plants was measured, but no data on the fungus population in the soil were collected. Besides, FW expression was certainly ruled by the artificial inoculation with Foc Race 1. Although the potential direct effect of soil properties on the Foc population in the soil was not measured, it would be hidden to a certain extent by the Foc inoculation. Future studies should include the measurement of the Foc population before the plant inoculation and monitor the concentrations during the experiment to disentangle the direct and indirect effects of the treatments.

Although inoculation took place twice before the rapid increase in plant mortality in the third cycle, it appears that the level of infestation was not critical to induce the disease in the $1^{\text {st }}$ and $2^{\text {nd }}$ cycle. Time appears to play an important role in the accumulative effect of the fungus in the soil and in the plant. This artificial inoculation obviously differs from natural plant infestation of the production system. However, the consistency of the difference in the plant mortality according to soil $\mathrm{pH}$, even in the $3^{\text {rd }}$ and $4^{\text {th }}$ cycle, shows the importance of this soil property in disease development. Besides, the disease aggressiveness and dissemination could be influenced by the interaction of Foc with other biotic factors such as nematodes (Rocha et al. 2020) and the banana weevil (Guillén et al. 2021) that may be influenced by soil management.

Experiments with diseases in perennial crops over a short period in e.g. greenhouses may hide certain effects. Nevertheless, testing diseases in greenhouse experiments can give useful information about the relation of the soil and the crop disease, but it is typically concluded that it requires further evaluation at the field level (Segura et al. 2018; Segura-Mena et al. 2021). In the current study, every crop cycle provided a different pattern of disease expression in relation to soil properties. The varying duration of experiments in the literature could be another reason for the inconsistent results in experiments with soil management and FW (Stover 1962).

The selection of representative locations is also important as illustrated by the differences between the two experiments were evident. This implies that only taking one subregion only tells part of the story, but also that the differences in ecological conditions can explain the inconsistent results in experiments with soil management and Fusarium wilt 


\subsubsection{Analysis for tested soil properties}

Some soil properties did not show significant differences in crop performance and FW. For example, the $\mathrm{Ca}$ concentration did not differ significantly between $\mathrm{Ca}$-low and $\mathrm{Ca}$-high. In addition, $\mathrm{Ca}$ and $\mathrm{Mg}$ concentrations dropped during the experiments. Similarly, despite the differences in $\mathrm{N}$ applications, the soil concentration did not differ significantly between N-high and N-low. This can be explained by the perhumid conditions in the region and the exceptionally high rainfall of $6900 \mathrm{~mm}$ during the $1^{\text {st }}$ and $2^{\text {nd }}$ cycle that may have led to considerable nutrient leaching (Sandoval et al. 2015). This could have caused the general drop in soil pH and the lack of differences in soil conditions in both experiments in the $1^{\text {st }}$ and $2^{\text {nd }}$ cycle as shown in the second soil analysis. Nevertheless, it is evident that soils from Exp-east maintained a higher soil fertility than soils in Exp-west during the whole experimental period, except for the $\mathrm{N}$ concentration. The binding of soil organic matter to the allophanes in the volcanic ash soils in Exp-west may explain this specific difference for N (Arias et al. 2010a, b). The influence of soil management was less apparent in the fertility soils in Exp-east as shown by the similarity in nutrients concentration in these soils despite the differences in treatments. The lower inherent soil fertility in Exp-west makes it more likely to exhibit differences as a result of soil management.

\subsubsection{Leaf nutrient concentration according to soil properties management}

The higher mortality in the $3^{\text {rd }}$ and $4^{\text {th }}$ cycle could be linked to the nutritional status of the plants due as indicated by the differences in nutrient concentrations in leaf samples. This effect was cumulative, and it began in the $1^{\text {st }}$ and $2^{\text {nd }}$ cycle. Nutrient concentrations can be linked to the plant predisposition to Foc (Rishbeth 1955; Stover 1961; Batista et al. 2008; Domínguez et al. 2008; Deltour et al. 2017). However, it is difficult to draw hard conclusions as the fungus will damage the vessels in the plant resulting in problems with nutrient transport. Although soil $\mathrm{pH}$ and $\mathrm{N}$ can influence plant mortality by FW, integrated nutrient management based on foliar analysis can be part of the strategy to reduce the predisposition of the crop to the disease.

\subsubsection{Agronomic plant response according to soil management}

Soil management influenced agronomic performance as expected (Segura et al. 2015, 2018; Stoorvogel and Segura 2018) in the $1^{\text {st }}$ and $2^{\text {nd }}$ cycle. It appears that it is possible to maintain 
an acceptable crop production with a low impact of the disease at least during those cycles. Potentially, more intensive changes to soil management can delay the rapid increase in mortality. However, agronomic performance of the "surviving plants" shows that production can be maintained in the first cycles after the infection. Although the infection appears to be devasting, gaining time to find alternative strategies or implementing a crop rotation may help the production system considerably.

\subsection{Conclusions}

This study confirmed the potential role of soil management on FW wilt expression in banana. The results of the field experiment were comparable to earlier results in greenhouse experiments with a very clear effect of $\mathrm{pH}$. Effects were most significant until the $3^{\text {rd }}$ cycle after which the accumulative effect became very serious with very high mortality rates. Soil $\mathrm{pH}$ appeared to be a key factor explaining differences in mortality rates. A higher soil $\mathrm{pH}$ can alleviate FW expression in the first two crop cycles after planting. However, the interactions between the various soil properties limit the development of specific soil management strategies for FW control. Besides, differences in plant mortality appear to be relatively small and not warrant the investment of a large soil management program to control Foc in bananas at the farm level. However, maintaining a higher soil $\mathrm{pH}$ and applying adequate $\mathrm{N}$ doses and $\mathrm{Ca}$ and $\mathrm{Mg}$ fertilizers can be included as part of the strategy focusing in reducing plant mortality and maintaining the production in the short and probably the medium-term. Otherwise, these practices can be integrated with other crop management such as replanting and annual cropping to alleviate the effect of the disease on the production. This kind of medium-term field experimentation is essential for banana and other perennial crops as the effects clearly may differ over the crop cycles. This allows to evaluate the accumulated effect of the disease over time and to minimize the risk of wrong conclusion induced by partial results obtained in the short term. 


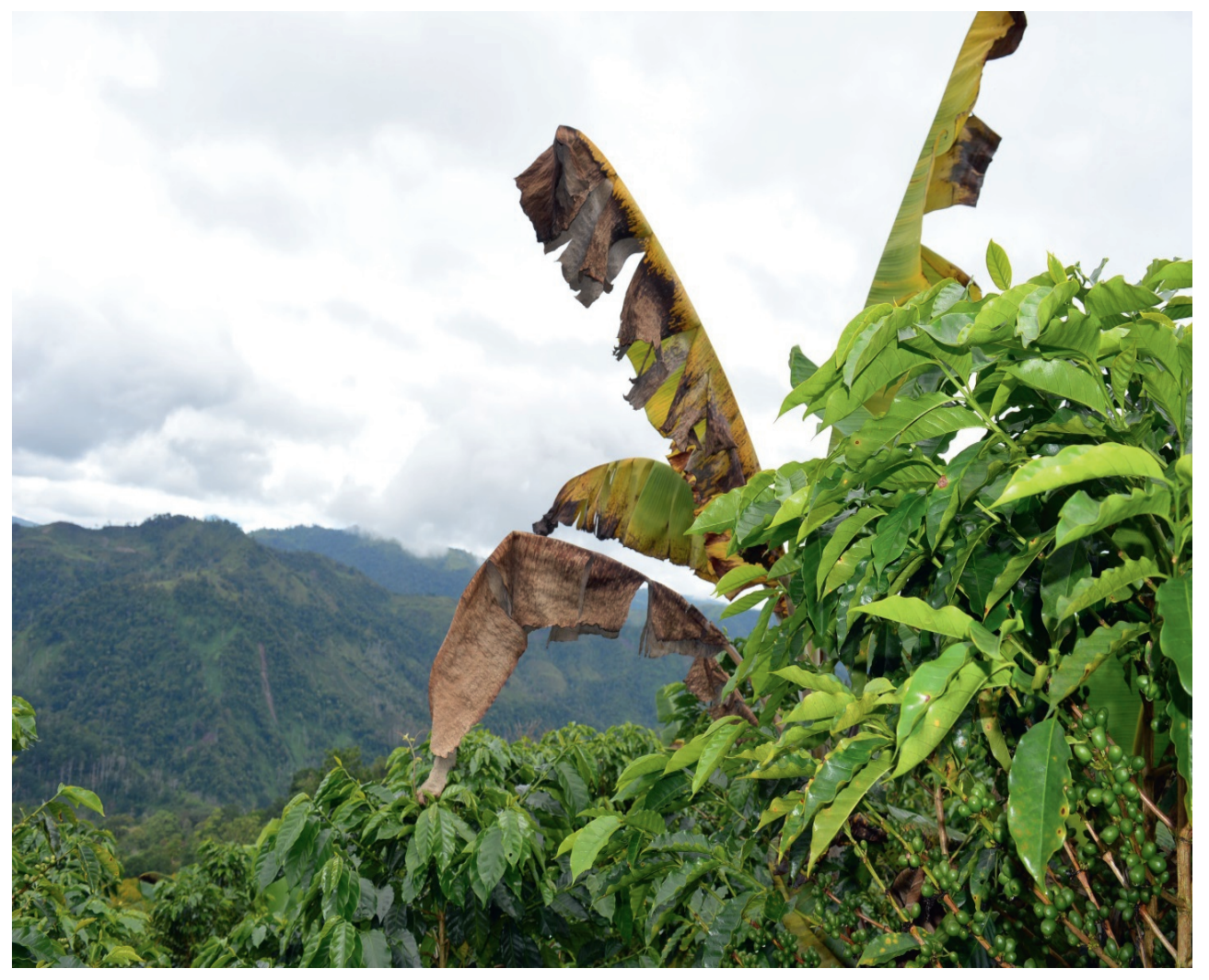




\section{Chapter 6}

\section{Fusarium wilt (Foc Race 1) in relation with soil properties in smallholder's farms of 'Gros Michel' banana (Musa AAA) in Costa Rica}

The aim of the study was to understand the relationship between soil properties and Fusarium wilt (FW) by Foc Race 1 in banana cv. 'Gros Michel'. The experimentation was based on soils from the Turrialba region in Costa Rica. A first analysis took place under greenhouse conditions with Foc Race 1 inoculated plants and grown in two representative soil types from the region. The disease expression in relation with two soil $\mathrm{pH}$ levels (lower than 5.0 and higher than 6.0) and three weekly $\mathrm{N}$ doses (low: $0.00 \mathrm{~g}$ plant $^{-1}$, medium: $0.08 \mathrm{~g} \mathrm{plant}^{-1}$ and high: $0.25 \mathrm{~g} \mathrm{plant}^{-1}$ ) applied with an ammonium nitrate solution in water. Soil type, $p H$ and their interactions significantly affected the disease, where plants grown in the lower $\mathrm{pH}$ showed a higher FW expressed as a lower biomass. A second analysis used information at 20 farms in the region, where 49 fields were studied. FW expressed as a Severity Index (SI) was measured. Besides, agroecological variables such as altitude, slope, annual rainfall, average temperature, and soil fertility were determined. In addition, management variables as plant density and soil cover were gathered. A higher SI of FW was linked with a lower organic matter (SOM), and a higher acidity, calcium, and magnesium concentration in the soil. Other agroecological and management evaluated variables were not linked with the SI of FW. Given the fact that soil properties were highly correlated, it is difficult to attribute differences in SI of FW to individual soil properties. Each case should be considered as independent; however, results provide new insights into the relationship Soil-FW in banana. Practices of soil management such as liming, SOM founds application, and an adequate nutrient package are important options to alleviate the impact of the disease in the midterm in banana regions with Foc infested soils.

This chapter is based on:

Segura RA, Stoorvogel JJ, Bosman M, Sandoval JA (2019) Fusarium wilt (Foc race 1) in relation to soil properties in smallholder's farms with 'Gros Michel' banana (Musa AAA) in Costa Rica. CORBANA 45:67-82. (Available at: https://edepot.wur.nl/541314) 


\subsection{Introduction}

Fusarium wilt (also known as Panama disease) is recognized impacting disease in bananas production. It is caused by a soilborne fungus, Fusarium oxysporum f. sp. cubense or Foc (Stover 1962; Stover and Simmonds 1987). Race 1 of Foc (one of the strains of the fungus) devastated large-scale commercial production of Gros Michel bananas in Latin America and the Caribbean (LAC) in the last century (Ploetz and Churchill 2011). In the large-scale production systems, the problem was resolved through the switch to the resistant Cavendish cultivar. However, Foc Race 1 is still a serious problem in smallholder production systems in several countries of LAC (Dita et al. 2013). Although these systems in Costa Rica continue to suffer from Fusarium wilt (Foc Race 1), after shifting this cultivar by the Cavendish as the main for exportation cultivar, research in Fusarium wilt decreased. The awareness of the new threat of Foc TR4 (Pocasangre et al. 2011), re-initiated research into this disease in LAC, using the model Gros Michel- Foc Race 1.

Production of banana cv. 'Gros Michel' (Musa AAA) in Costa Rica takes place due its specific and appreciated traits resulting in higher prices in local and regional markets. The production of this cultivar covers around 4,400 ha. Most production occurs in Talamanca followed by the Turrialba region. In general, the production occurs on small farms with areas between 1 and 2 ha in association with sugar cane and coffee (Tapia et al. 2009; Escobedo 2010; Chaves 2019). However, control of Foc Race 1 is still timely, as i) eradication from the soil is almost impossible due to the competitiveness of the fungus (Stover 1962), ii) almost all banana soils in Latin America are infected with the fungus, and iii) local markets still demand the 'Gros Michel' cultivar for its attractive traits. As a result, even though a resistant cultivar (Cavendish) is available in the country

for the exportation, alternative options to deal with the disease in the cv. 'Gros Michel' are necessary.

Agroecological conditions have been shown to influence soilborne pests and diseases (Mazzola 2002; Ghorbani et al. 2008). For example, climatic conditions influence the occurrence of bacterial wilt in the East African highlands (Bouwmeester et al. 2016) and soil properties have been linked to nematode infestation in banana production (Pattison et al. 2008; Geense et al. 2015). It is also known that, for instance, soil $\mathrm{pH}$ and nitrogen concentrations influence Fusarium incidence in banana production (Rishbeth 1955; Segura et al. 2021). Soil conduciveness or suppressiveness for soilborne diseases is linked to specific biotic and abiotic soil conditions (Weller 
et al. 2002; Janvier et al. 2007; Orr and Nelson 2018). It has been shown that some soils suppress Fusarium wilt (Shen et al. 2015; Orr and Nelson 2018). Soil properties affect both the plant and the pathogen. For example, soil chemical, physical, and biological conditions directly influence the fungus population in the soil. At the same time, soil properties influence the plant nutritional status (Stoorvogel and Segura 2018) and, indirectly, this can modify the predisposition to Fusarium wilt. A better nurtured plant will be healthier and less predisposed to be affected by the fungus. Soil $\mathrm{pH}$, moisture, and temperature were reported as factors associated with Fusarium wilt expression (Peng et al. 1999).

Disentangling the complex relationship between agroecology and crop disease incidence is a major challenge for scientists, the main being that there is a plethora of soil properties together with environmental conditions and crop management that determine the disease incidence. Different approaches can be followed, including greenhouse experiments (Gibson et al. 1999) and studies on farmer fields (Tripp and Woolley 1989). The advantage of greenhouse experiments is that we can keep many factors constant and only vary one or a limited number of factors to derive a specific relationship but results from greenhouse experiments need in most of the cases subsequent validation under field conditions. On-farm trials or farm surveys are typically challenged by the variation that occurs under natural conditions. The advantage is that the experiment takes place under the actual farm conditions, but the disadvantage is the difficulty to attribute specific conditions to disease incidence. Field conditions can be extremely variable, requiring a larger number of observations so that one may carry out multivariate analyses to understand the complex relationships.

There is a lack in the known about the relationship between agroecological, soil conditions and Fusarium wilt in banana. However, insight into this relationship could provide opportunities to reduce Fusarium wilt through agricultural management. It is the generally accepted that soil properties influence the incidence of Fusarium wilt in bananas (Orr and Nelson 2018). Nonetheless, this relation and the subsequent impact of soil management on Fusarium wilt has not been quantified. Despite the advantages that management could offer to control Fusarium wilt, the disease control package rarely includes soil management. Therefore, this study aimed to obtain insight to what extent soil properties play a role in the incidence of Fusarium wilt by Foc Race 1 in banana cv. 'Gros Michel'. 


\subsection{Materials and Methods}

\subsubsection{The study area}

The study focused the region of Turrialba in Costa Rica (09 $\left.47^{\prime} 14^{\prime \prime} \mathrm{N}, 83^{\circ} 34^{\prime} 03^{\prime \prime} \mathrm{W}\right)$, located within the central cordillera with considerable volcanic activity. The life zone of the region includes tropical premontane and montane belt (Holdridge 1987). Environmental conditions in the mountainous region varied considerably with high volcanos and steep river valleys. Altitude ranges from 157 to 2,900 meters above sea level (m.a.s.l.), average annual temperatures varied between 10.8 and $25.5^{\circ} \mathrm{C}$ with minimal variability within the year, and average annual rainfall varied between 2,122 and 4,586 mm/year with a rainy season from May to November. Soil conditions vary in the area with Inceptisols, Ultisols, Andisols and Nitisols being present (Dijkshoorn et al. 2005). Most soils are suitable for the cultivation of bananas, although soil depth and acidity locally limit banana production (Kass et al. 1995). In a greenhouse experiment, the role of two soil properties as $\mathrm{pH}$ and nitrogen $(\mathrm{N})$, commonly related to Foc incidence were tested. Besides, a gather of information at farm level looked the Foc-banana relationship at the farm level in different agroecological conditions including soil properties in the region.

\subsubsection{Greenhouse experiment}

A factorial greenhouse experiment was established to evaluate the effect of soil properties on the incidence of Fusarium wilt by Foc Race 1 in plants of the cv. 'Gros Michel'. During a previous survey of banana soils in the Turrialba region, two representative soil types were selected (Klinkert 2014). These soils were described in detail and large topsoil $(0-30 \mathrm{~cm})$ samples were taken. The soils were analyzed for $\mathrm{pH}$, acidity, soil organic matter ( $\mathrm{SOM}$ ), $\mathrm{Ca}, \mathrm{Mg}, \mathrm{K}, \mathrm{P}, \mathrm{Zn}, \mathrm{Cu}$, $\mathrm{Fe}, \mathrm{Cu}$, and $\mathrm{Mn}$ following the methodologies described by Díaz-Romeu and Hunter (1978) and Mehlich (1984). The location of the samples and results of the analysis are presented in Table 61. Soil samples were used in a greenhouse experiment at the experimental station of CORBANA in La Rita (132 m.a.s.1., $10^{\circ} 15^{\prime} 54^{\prime}{ }^{\prime} \mathrm{N}, 8^{\circ} 46^{\prime} 26^{\prime}$ ' W, minimum temperature $17^{\circ} \mathrm{C}$ and maximum temperature $35^{\circ} \mathrm{C}$, average temperature of $28^{\circ} \mathrm{C}$ with an $85 \%$ relative humidity and $12 \mathrm{~h}$ daylight). The factorial design included 2 soil types $\mathrm{x} 2$ levels of Foc Race 1 inoculation x 2 levels of soil pH $\mathrm{x} 3$ levels of $\mathrm{N}$ fertilization $\mathrm{x} 3$ replications resulting in 72 pots. Two contrasting soil $\mathrm{pH}$ levels 
were tested: 1) $\mathrm{pH}$ low with a $\mathrm{pH}$ lower than 5.0, and 2) $\mathrm{pH}$ high with a $\mathrm{pH}$ higher of 6.0. Soil $\mathrm{pH}$ was adjusted to these target levels by either applying a hydrochloride acid solution $(10 \% \mathrm{HCl})$ to decrease $\mathrm{pH}$ or lime $\left(\mathrm{CaCO}_{3}\right)$ to increase soil $\mathrm{pH}$. Soil $\mathrm{pH}$ was adapted before plant inoculation and planting. In each case, the acid or alkaline required units to achieve the lower and the higher $\mathrm{pH}$ were calculated before liming and/or acidifying. Soil $\mathrm{pH}$ was analyzed before each treatment and eight days after liming or acidification. The acidified soil samples reached $\mathrm{pH}$ values between 4.7 and 4.8, and limed soil samples reached $\mathrm{pH}$ values between 6.4 and 6.5. Typically, banana plants grow better in soils with $\mathrm{pH}$ above 5.5. Lower $\mathrm{pH}$ levels may result in poor banana development and production (Segura et al. 2015).

A total of 72 hardened 2-month-old tissue culture banana plants (Musa AAA, cultivar "Gros Michel") were used in the experiment. These plants were grown in potting mix before the experiment. Two levels of Foc Race 1 inoculation by root dipping (Dita et al. 2010; GarcíaBastidas et al. 2014; Ordoñez et al. 2016) were tested: 1) Ino: a control group, 30 minutes in clean water, and 2) $\mathrm{In}_{1}$ : an inoculated group, 30 minutes in a solution of water with $10^{5}$ conidia $\mathrm{mL}^{-1}$ of Foc Race 1. The fungus strain was collected from Costa Rican soils and cultivated by CORBANA`s Center of Biological Control. Soil samples for the greenhouse experiment were collected from a banana region. As the soil samples were not sterilized to the experiment in order to not disturb the plant response to the natural soil conditions, the plants in the control are exposed to a relatively low concentration of Foc Race 1 (but uniform for each of the soil types). Plants in Ino can therefore still be infected but at a much lower level compared to $\mathrm{In}_{1}$. Immediately after inoculation, plants were planted in $2 \mathrm{~L}$ pots (one plant per pot) filled with the treated soil samples. Three levels of $\mathrm{N}$ fertilization were established by varying the $\mathrm{N}$ dose: 1) $\mathrm{N}_{\text {low }}$ with no $\mathrm{N}$ addition, 2) $\mathrm{N}_{\text {med }}$ with $0.08 \mathrm{Ng}$ plant week ${ }^{-1}$, and 3) $\mathrm{N}_{\text {high with } 0.25 \mathrm{~N} \text { g plant week }}{ }^{-1}$. $\mathrm{N}$ doses were respectively achieved through applications of $300 \mathrm{~mL}$ of differentiated solutions of water with ammonia nitrate (35-0-0) in concentrations of $0.00 \mathrm{~g} \mathrm{~L}^{-1} \mathrm{~N}, 0.14 \mathrm{~g} \mathrm{~L}^{-1} \mathrm{~N}$ and $0.43 \mathrm{~g} \mathrm{~L}^{-1} \mathrm{~N}$, every 34 days. $\mathrm{N}_{\text {med }}$ emulated the average $\mathrm{N}$ requirement of plants during the first 10 weeks after planting in real field conditions. No other nutrients and agro-chemicals (e.g., fungicides and insecticides) were applied to the plants. Plants were followed for 8 weeks and were evaluated weekly on external symptoms. At the end, of the 8 weeks, total (above ground plus roots) fresh biomass ( $\mathrm{g} \mathrm{plant}^{-1}$ ) of each plant was measured as the key indicator for disease incidence. 
Table 6-1 Soil analysis for two representative soils types grown with 'Gros Michel' banana form the Turrialba region, Costa Rica.

\begin{tabular}{|c|c|c|c|c|c|c|c|c|c|c|c|}
\hline \multirow[t]{2}{*}{ Soil type } & SOM & \multirow[t]{2}{*}{$\mathrm{pH}$} & Acidity & $\mathrm{Ca}$ & $\mathrm{Mg}$ & K & $\mathrm{P}$ & $\mathrm{Fe}$ & $\mathrm{Cu}$ & $\mathrm{Zn}$ & $\mathrm{Mn}$ \\
\hline & $\%$ & & \multicolumn{4}{|c|}{$\operatorname{cmol}(+) \mathrm{kg}-1$} & \multicolumn{5}{|c|}{$\mathrm{mg} \mathrm{kg-1}$} \\
\hline Dystrudept & 6.3 & 5.6 & 0.24 & 14 & 3.9 & 0.6 & 14 & 226 & 7 & 3 & 44 \\
\hline Haplohumult & 12.3 & 6.1 & 0.05 & 5 & 0.9 & 0.6 & 3 & 78 & 4 & 1 & 13 \\
\hline
\end{tabular}

\subsubsection{Farm experiment}

Previous studies in the region looked at the status of 'Gros Michel' banana production and Fusarium wilt by Foc Race 1 (Ramirez et al. 2010; Chaves et al. 2015). Those studies worked on 73 smallholders' banana farms (1-2 ha) in the Turrialba region. The region was divided in subregions to cover the most representative predominant agroecological conditions such as altitude, slope, temperature, and annual precipitation. A total of 20 farms were selected based on the level of cooperation of the farmer and the adoption of disease management practices in the earlier studies (to minimize the variation within the survey). Besides, by covering the various sub-regions and ensuring the accessibility due the irregular landscape of the region. A gather of information was performed in each farm concerning current condition of the banana plants, the disease, age, and production. With this information a total of 49 field areas (1, 2 or 3 per farm) were surveyed. Then, a strict protocol was followed for field area observations and soil sampling. Field area characteristics were registered including location and altitude with a GPS device, plant density and percentage cover crops. Banana production in the studied farms takes place in a narrow band between 617 and 1,065 m.a.s.l. The field observations aimed to get detailed insight into the agroecology, management (cover crop and plan density) and the disease incidence. In general, in the region mean annual temperature comes from 20 to $23^{\circ} \mathrm{C}$, mean annual precipitation is ranging from 2,666 to $3,155 \mathrm{~mm} / \mathrm{yr}$, and slopes varying between 3 and $33^{\circ}$. Plant density varied from a single plant to 2,000 plants $\mathrm{ha}^{-1}$. Cover crops varied from 0 to $100 \%$. The observations were complemented with secondary data on total annual precipitation and average annual temperature (Fick and Hijmans 2017) and topography (NASA/METI/AIST/Japan Spacesystems And U.S./Japan ASTER Science Team 2009). Fusarium wilt incidence was determined using a standard grading system (Poveda 2013). This system exists of five progressive classes of severity ( $\mathrm{i}=1$ to 5) with 
- Class 1: absence of symptoms,

- Class 2: minor symptoms in the leaves and pseudostem (small cracks),

- Class 3: moderate cracks in the pseudostem, shortening in petioles distance and new leave chlorosis, small size, and deformation,

- Class 4: severe cracks in the pseudostem, chlorosis and wilting in new and old leaves and leave deformation, and

- Class 5: all previous symptoms with plant wilting leading to plant death.

The percentage of plants with symptoms according to each class $\left(\mathrm{CS}_{\mathrm{i}}\right.$ in \%) in each field area was measured. Finally, a severity index (SI) for the field was calculated as:

$$
S I=\sum_{i=1}^{5} i \cdot C S_{i}
$$

This resulted in a continuous value describing disease severity index (SI) on a scale from 100-500. As such, disease severity is composed by the proportion of plants affected and the expression of the disease in the plants (Peng et al. 1999). Composite topsoil $(0-30 \mathrm{~cm})$ samples were randomized taken from the fertilization band of 3-4 banana plants (in any status) throughout each field area. Those samples were analyzed for $\mathrm{pH}, \mathrm{SOM}$, acidity, $\mathrm{N}, \mathrm{Ca}, \mathrm{Mg}, \mathrm{K}, \mathrm{P}, \mathrm{Zn}, \mathrm{Cu}, \mathrm{Fe}$, $\mathrm{Cu}$ and Mn (following the methodologies by Díaz-Romeu and Hunter (1978), Mehlich (1984) and (Elementar Analysensysteme GmbH 2011).

\subsubsection{Statistical analysis}

The greenhouse experiment aimed to reveal the effect of soil properties on the expression of Fusarium wilt. Data were analyzed using a factorial analysis of variance to evaluate the effect of four factors (soil type, inoculation, soil $\mathrm{pH}$ and $\mathrm{N}$ ) and their interactions on the biomass. The differences in biomass according to the soil properties were evaluated through a Tukey's range test.

The focus of the statistical analysis of the farm gather of information was to find variables that influence the severity of Fusarium wilt in banana plantations. In the gather, many different agroecological conditions differ between the field areas (in contrast to the controlled conditions in the greenhouse experiment). The relation of individual agroecological properties with disease severity was studied in three ways. First, the field areas were split in two equal groups with low and high disease severity (using an admittedly arbitrary threshold of 350). Independent T-tests 
were performed to identify agroecological conditions that differed significantly between the two groups. Second, to analyze the system in a more integrated manner, the variation in soil properties was summarized in a K-means cluster analysis resulting in two cluster which can be interpreted as major soil types. In an independent T-test, the difference in disease severity was tested. Thirdly, a principal component analysis was carried out to summarize the variation in soil conditions. The independent principal components were correlated with disease severity after which the soil properties underlying the correlated principal components were identified.

\subsection{Results}

\subsubsection{Greenhouse experiment}

Results of the experiment in terms of biomass per plant are summarized in Figure 6-1 and Figure 6-2. Without inoculation no external and internal symptoms of Foc were detected. The Dystrudept soil showed very limited effects of $\mathrm{pH}$ and $\mathrm{N}$ on biomass. However, the Haplohumult soil showed a significantly lower biomass under low $\mathrm{pH}(\mathrm{P} \leq 0.0001)$, but no effect of $\mathrm{N}$. Inoculation resulted in a considerable $(63 \%)$ and significant $(\mathrm{P} \leq 0.0001)$ lower biomass. In the Dystrudept, inoculation resulted in an on-average lower biomass of $74 \%$ under $\mathrm{pH}_{\text {low }}$ versus $55 \%$ under $\mathrm{pH}_{\text {high. }}$ The strongest effect of inoculation in this soil was found under $\mathrm{pH}_{\text {low }}$ and $\mathrm{N}_{\text {high }}$ resulting in a $93 \%$ lower biomass. In the Haplohumult, plant inoculation also resulted in a considerable and significant $(\mathrm{P} \leq 0.0001)$ lower biomass. Although the remaining biomass in the inoculated plants did not differ with $\mathrm{pH}$ and $\mathrm{N}$ treatments, the reduction was higher under high $\mathrm{pH}$ (75\%) compared to the low $\mathrm{pH}(64 \%)$. Overall, inoculation resulted in a significant lower biomass $(\mathrm{P} \leq 0.0001)$. In addition, the interaction between inoculation, soil type, and $\mathrm{pH}$ was found to be significant $(\mathrm{P}=0.0440)$. 

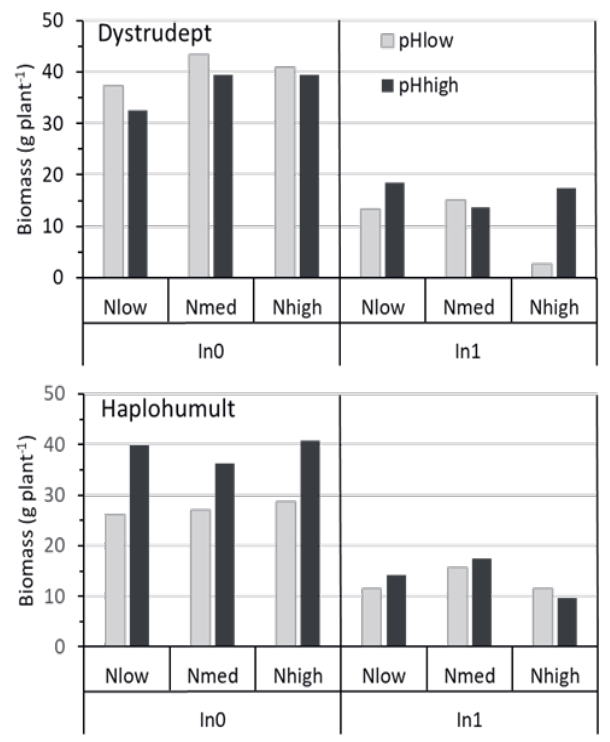

Figure 6-1 Plant biomass as an indicator for the effect of Fusarium wilt (Foc race 1) on 'Gros Michel' banana plants in a factorial greenhouse experiment testing two soil pH (lower than 5.0 and higher than 6.0) and three weekly $\mathrm{N}$ doses (low: $0.00 \mathrm{~N}$ g plant ${ }^{-1}$, med: $0.08 \mathrm{~N} \mathrm{~g}$ plant $^{-1}$ and high: $0.25 \mathrm{~N} \mathrm{~g} \mathrm{plant}^{-1}$ ) in two representative soils types from Turrialba, Costa Rica. In $0=$ not inoculated (control), In $1=$ Inoculated.

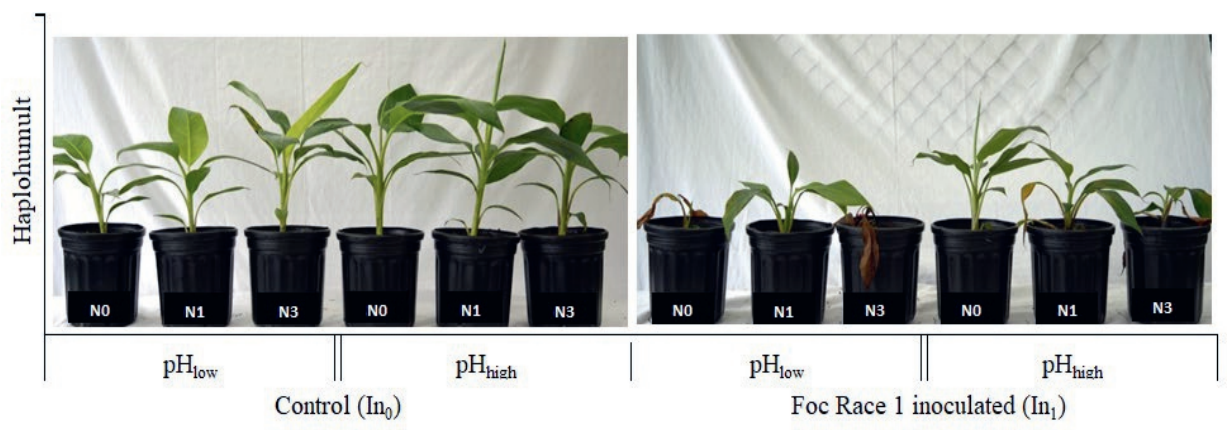

Treatment (Inoculation, Soil $\mathrm{pH}$ and $\mathrm{N}$ )

Figure 6-2 Example of inoculated $\left(\mathrm{In}_{1}\right)$ and not inoculated $\left(\mathrm{In}_{0}\right)$ 'Gros Michel' (Musa AAA) banana plants (Greenhouse experiment) under two soil $\mathrm{pH}$ (lower than 5.0 and higher than 6.0) and three weekly $\mathrm{N}$ doses (low: $0.00 \mathrm{~N} \mathrm{~g}$ plant $^{-1}$, med: $0.08 \mathrm{~N} \mathrm{~g} \mathrm{plant}^{-1}$ and high: $0.25 \mathrm{~N} \mathrm{~g} \mathrm{plant}^{-1}$ ) in one representative soil type from Turrialba, Costa Rica. 


\subsubsection{Farm experiment}

Fusarium wilt severity differed considerably between some field areas highly infested (SI= $500)$ whereas other field areas did not present any symptoms of the disease ( $\mathrm{SI}=100)$. The average of SI was 340 with a standard deviation of 112. To better understand the differences in disease incidence, agroecological conditions in the $50 \%$ fields with the highest SI were compared to conditions in 50\% field areas with the lowest SI. Results are presented in Table 6-2. No significant differences were found for the ecological and management variables. However, soil properties ( $\mathrm{SOM}$, acidity, $\mathrm{Ca}$, and $\mathrm{Mg}$ ) were significantly different between the two groups. A higher concentration of SOM and a lower soil acidity were linked with the lower range of the severity index of Fusarium wilt. However, disease severity cannot be linked to individual properties is not possible as soil properties are highly correlated to each other as shown in Table 6-3. This is partly illustrated by looking at the relation between acidity and disease severity (Figure 6-3).

An alternative way to look at the variation in disease severity, while considering the interactions between soil properties, is through a cluster analysis. In a cluster analysis the entire set of soil properties is considered, and the information is summarized by identifying clusters that can be considered to represent specific soil types. Subsequently, the differences in disease severity for the clusters was tested. The results are presented in Table 6-4. The clusters were significant differences in disease severity. SOM, acidity $\mathrm{Ca}$ and $\mathrm{Mg}$ were again linked with the SI of FW. The rest of soil properties were not linked with the disease. The variation in soil conditions can also be summarized through a principal component analysis as presented in Table 6-5. Five principal components were identified of which the second one, explaining $23 \%$ of the total soil variation, was significantly (at the 0.010 level) correlated to disease severity. The second principal component described particularly the variation in SOM and $\mathrm{N}$. 
Table 6-2 Agroecological conditions in 'Gros Michel' banana fields according to the severity index of Fusarium wilt (Foc race 1) in Turrialba Costa Rica. Differences are tested for significance by an independent ttest (standard deviation between parentheses)

\begin{tabular}{|c|c|c|c|}
\hline \multirow[b]{2}{*}{ Agroecological variables } & \multicolumn{3}{|c|}{ Severity index Fusarium wilt } \\
\hline & $<350$ & $\geq 350$ & Overall \\
\hline \multicolumn{4}{|l|}{ Ecological conditions } \\
\hline Altitude (m.a.s.l.) & $880(135)$ & $857(152)$ & $870(142)$ \\
\hline Slope $\left({ }^{\circ}\right)$ & $14.5(8.8)$ & $14(8.1)$ & $14.3(8.4)$ \\
\hline Temperature $\left({ }^{\circ} \mathrm{C}\right)$ & $21.6(0.6)$ & $21.7(0.91)$ & $21.6(0.8)$ \\
\hline Precipitation (mm/yr) & $2841(154)$ & $2826(120)$ & $2834(138)$ \\
\hline \multicolumn{4}{|l|}{ Soil conditions } \\
\hline $\mathrm{pH}(-)$ & $5.4(0.4)$ & $5.3(0.4)$ & $5.3(0.4)$ \\
\hline SOM $(\%)$ & $7.2(3.1)^{*}$ & $5.7(1.5)$ & $6.5(2.6)$ \\
\hline $\mathrm{N}(\%)$ & $0.35(0.11)$ & $0.33(0.07)$ & $0.34(0.1)$ \\
\hline Acidity $\left(\mathrm{cmol}(+) \mathrm{kg}^{-1}\right)$ & $1.41(1.63)^{*}$ & $2.65(2.28)$ & $2(2.05)$ \\
\hline $\mathrm{Ca}\left(\mathrm{cmol}(+) \mathrm{kg}^{-1}\right)$ & $7.3(5.8)^{*}$ & $11.0(6.1)$ & $9.1(6.2)$ \\
\hline $\operatorname{Mg}\left(\mathrm{cmol}(+) \mathrm{kg}^{-1}\right)$ & $1.87(1.38)^{* *}$ & $2.9(1.08)$ & $2.34(1.34)$ \\
\hline $\mathrm{K}\left(\mathrm{cmol}(+) \mathrm{kg}^{-1}\right)$ & $0.38(0.26)$ & $0.40(0.32)$ & $0.39(0.28)$ \\
\hline $\mathrm{P}\left(\mathrm{mg} \mathrm{kg}^{-1}\right)$ & $11(17)$ & $10(13)$ & $11(15)$ \\
\hline $\mathrm{Fe}\left(\mathrm{mg} \mathrm{kg}^{-1}\right)$ & $151(48)$ & $173(45)$ & $161(47)$ \\
\hline $\mathrm{Cu}\left(\mathrm{mg} \mathrm{kg}^{-1}\right)$ & $4.5(2.1)$ & $4.9(2.1)$ & $4.7(2.1)$ \\
\hline $\mathrm{Zn}\left(\mathrm{mg} \mathrm{kg}^{-1}\right)$ & $3.1(6.2)$ & $2.4(2.5)$ & $2.8(4.7)$ \\
\hline $\operatorname{Mn}\left(\mathrm{mg} \mathrm{kg}^{-1}\right)$ & $58(56)$ & $70(52)$ & $64(53)$ \\
\hline \multicolumn{4}{|l|}{ Crop management } \\
\hline Plant density (plants/ha) & $570(290)$ & $390(410)$ & $480(360)$ \\
\hline Cover crop (\%) & $31.5(33.5)$ & $46.7(40.4)$ & $38.7(37.3)$ \\
\hline
\end{tabular}

$* \mathrm{P}<0.050,{ }^{* *} \mathrm{P}<0.010,{ }^{* * *} \mathrm{P}<0.001$ 
Table 6-3 Correlations between soil properties in 'Gros Michel' banana fields in Turrialba, Costa Rica.

\begin{tabular}{cccccccccccccc}
\hline & $\mathrm{pH}$ & Acidity & $\mathrm{Ca}$ & $\mathrm{Mg}$ & $\mathrm{K}$ & $\mathrm{P}$ & $\mathrm{Fe}$ & $\mathrm{Cu}$ & $\mathrm{Zn}$ & $\mathrm{Mn}$ & $\mathrm{SOM}$ & $\mathrm{Ca}$ & $\mathrm{N}$ \\
\hline $\mathrm{pH}$ & - & & & & & & & & & & & & \\
Acidity & $\mathbf{- 0 . 6 7}$ & - & & & & & & & & & & & \\
$\mathrm{Ca}$ & $\mathbf{0 . 6 3}$ & -0.13 & - & & & & & & & & & & \\
$\mathrm{Mg}$ & $\mathbf{0 . 5 3}$ & -0.06 & $\mathbf{0 . 8 0}$ & - & & & & & & & & \\
$\mathrm{K}$ & 0.43 & -0.13 & 0.42 & 0.33 & - & & & & & & & \\
$\mathrm{P}$ & $\mathbf{0 . 5 0}$ & -0.23 & $\mathbf{0 . 5 6}$ & 0.37 & $\mathbf{0 . 6 1}$ & - & & & & & & \\
$\mathrm{Fe}$ & 0.29 & -0.18 & $\mathbf{0 . 6 4}$ & $\mathbf{0 . 5 3}$ & $\mathbf{0 . 5 2}$ & $\mathbf{0 . 5 1}$ & - & & & & & \\
$\mathrm{Cu}$ & 0.11 & -0.28 & 0.11 & -0.03 & 0.12 & 0.00 & 0.43 & - & & & & & \\
$\mathrm{Zn}$ & 0.35 & -0.17 & 0.12 & 0.06 & 0.35 & 0.18 & 0.02 & 0.29 & - & & & & \\
$\mathrm{Mn}$ & 0.13 & -0.12 & 0.03 & 0.31 & -0.04 & -0.19 & 0.03 & -0.33 & -0.12 & - & & & \\
$\mathrm{SOM}$ & -0.05 & -0.25 & -0.40 & $\mathbf{- 0 . 5 1}$ & -0.11 & -0.09 & -0.32 & 0.39 & 0.02 & -0.41 & - & & \\
$\mathrm{Ca}$ & 0.17 & -0.27 & -0.26 & -0.36 & 0.62 & 0.25 & -0.06 & 0.15 & 0.37 & -0.21 & 0.46 & - & \\
$\mathrm{N}$ & -0.01 & -0.16 & -0.29 & -0.39 & -0.04 & 0.04 & -0.29 & 0.31 & 0.02 & -0.38 & $\mathbf{0 . 9 2}$ & 0.06 & - \\
\hline
\end{tabular}

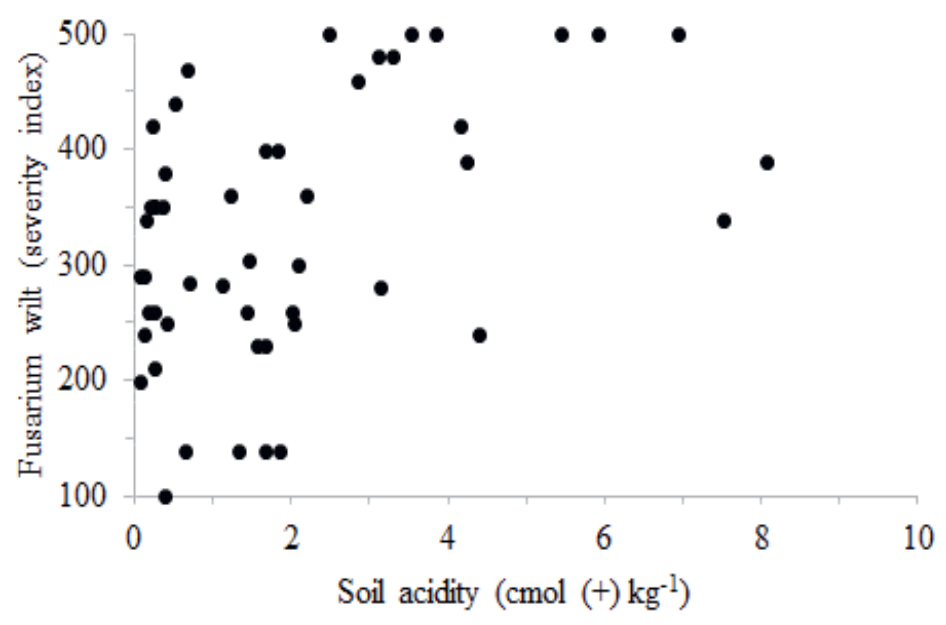

Figure 6-3 Scatter plot of soil acidity versus Fusarium wilt index of severity by Foc Race 1 in 'Gros Michel' banana fields in Turrialba, Costa Rica. 
Table 6-4 K-means cluster analysis on soil properties in 'Gros Michel' plantations from Turrialba, Costa Rica including a test for differences between the clusters for soil properties and Fusarium wilt (Foc Race 1) SI in 'Gros Michel' bananas fields (standard deviation between parentheses).

\begin{tabular}{|c|c|c|c|c|}
\hline Variable & Cluster 1 & Cluster 2 & Overall & T-Test $(\mathrm{P} \leq \mathrm{f})$ \\
\hline pH (-) & $5.4(0.4)$ & $5.3(0.4)$ & $5.3(0.4)$ & n.s \\
\hline SOM (\%) & $7.4(3.3)$ & $5.7(1.4)$ & $6.5(2.6)$ & 0.001 \\
\hline $\mathrm{N}(\%)$ & $0.36(0.12)$ & $0.33(0.06)$ & $0.34(0.10)$ & n.s \\
\hline Acidity $\left(\mathrm{cmol}(+) \mathrm{kg}^{-1}\right)$ & $1.19(1.1)$ & $2.69(2.4)$ & $2.0(2.1)$ & 0.010 \\
\hline $\mathrm{Ca}\left(\mathrm{cmol}(+) \mathrm{kg}^{-1}\right)$ & $7.10(6.0)$ & $10.7(5.9)$ & $9.1(6.2)$ & 0.050 \\
\hline $\operatorname{Mg}\left(\operatorname{cmol}(+) \mathrm{kg}^{-1}\right)$ & $1.78(1.4)$ & $2.86(1.1)$ & $2.4(1.3)$ & 0.001 \\
\hline $\mathrm{K}\left(\mathrm{cmol}(+) \mathrm{kg}^{-1}\right)$ & $0.37(0.25)$ & $0.41(0.32)$ & $0.39(0.28)$ & n.s \\
\hline $\mathrm{P}\left(\mathrm{mg} \mathrm{kg}^{-1}\right)$ & $10(15)$ & $11(14)$ & $11(15)$ & n.s \\
\hline $\mathrm{Fe}\left(\mathrm{mg} \mathrm{kg}^{-1}\right)$ & $150(49)$ & $171(44)$ & $161(47)$ & n.s \\
\hline $\mathrm{Cu}\left(\mathrm{mg} \mathrm{kg}^{-1}\right)$ & $3(2.2)$ & $5(2.0)$ & $4.7(2.1)$ & n.s \\
\hline $\mathrm{Zn}\left(\mathrm{mg} \mathrm{kg}^{-1}\right)$ & $3(6.6)$ & $3(2.4)$ & $3(4.7)$ & n.s \\
\hline $\operatorname{Mn}\left(\mathrm{mg} \mathrm{kg}^{-1}\right)$ & $58(57)$ & $68(50)$ & $64(53)$ & n.s \\
\hline Fusarium wilt (SI) & $229(59)$ & $416(64)$ & $330(112)$ & 0.001 \\
\hline
\end{tabular}


Table 6-5 Principal component analysis on soil properties in 'Gros Michel' banana plantations from Turrialba, Costa Rica including the correlation of the principal components with the Fusarium wilt (Foc Race 1) severity index.

\begin{tabular}{cccccc}
\hline & \multicolumn{5}{c}{ Principal Component } \\
\cline { 2 - 6 } & 1 & 2 & 3 & 4 & 5 \\
\hline Variance explained (\%) & 31.2 & 22.8 & 12.3 & 8.0 & 7.5 \\
Correlation with FW SI & 0.019 & $0.496^{* *}$ & 0.274 & 0.063 & -0.149 \\
\hline SOM & -0.197 & 0.922 & 0.103 & 0.119 & 0.100 \\
$\mathrm{~N}$ & -0.134 & 0.852 & 0.184 & 0.158 & 0.231 \\
$\mathrm{pH}$ & 0.823 & 0.116 & -0.302 & -0.170 & 0.207 \\
$\mathrm{Al}$ & -0.591 & -0.498 & 0.569 & 0.023 & 0.093 \\
$\mathrm{Acid}$ & -0.560 & -0.503 & 0.603 & 0.027 & 0.073 \\
$\mathrm{Ca}$ & 0.788 & -0.350 & 0.199 & 0.087 & -0.009 \\
$\mathrm{Mg}$ & 0.667 & -0.520 & 0.000 & 0.096 & -0.033 \\
$\mathrm{~K}$ & 0.651 & -0.028 & 0.352 & -0.194 & 0.244 \\
$\mathrm{P}$ & 0.719 & 0.030 & 0.344 & 0.096 & 0.430 \\
$\mathrm{Fe}$ & 0.729 & -0.191 & 0.300 & 0.255 & -0.415 \\
$\mathrm{Cu}$ & 0.291 & 0.522 & 0.281 & -0.079 & -0.710 \\
$\mathrm{Zn}$ & 0.324 & 0.185 & 0.106 & -0.820 & 0.001 \\
$\mathrm{Mn}$ & 0.104 & -0.417 & -0.646 & 0.208 & 0.012 \\
\hline
\end{tabular}

$* \mathrm{P}<0.050, * * \mathrm{P}<0.010, * * * \mathrm{P}<0.001$

\subsection{Discussion}

Banana plants in young stages from tissue culture, as used in this experiment are more sensitive to Foc infestation (Brake et al. 1995; Smith et al. 2008). This ensured plant response to the disease according to the soil tested treatments. Found results indicate that soil $\mathrm{pH}$ indeed influenced the effect of inoculation expressed in the plant biomass but that the effect differs per soil type. Overall, soil type, $\mathrm{pH}, \mathrm{N}$, and inoculation explained $68 \%$ of the variation in the biomass. The lower biomass in the inoculated plants was caused by growth reduction as well as wilting of the leaves and the end of the greenhouse experiment.

Literature identifies soil $\mathrm{pH}$ as an important indicator for soil health for banana systems (Segura et al. 2015; Orr and Nelson 2018) and its influence on soil suppressiveness for Foc (Pattison et al. 2008; Geense et al. 2015). The role of $\mathrm{pH}$ is confirmed by the greenhouse 
experiment, although its effect differs between the two soil types. As a result, general validity referring management recommendations (in terms of e.g., liming and the avoidance of acidification) should be warranted. This is also confirmed by previous reports indicating that a multitude of chemical and physical soil properties would be linked to soil conduciveness of Fusarium wilt (Scher 1980; Domínguez et al. 2001; Orr and Nelson 2018). Confirming the role of the soil type and $\mathrm{pH}$ in $\mathrm{FW}$ expression, as in current results, is essential to find adequate strategies to at least alleviate the effect of Fusarium wilt in banana.

The farm experiment showed the importance of $\mathrm{SOM}, \mathrm{Ca}, \mathrm{Mg}$ and acidity in the expression of the disease. SOM plays an important role in banana soil quality (Rivero et al. 2004; Riveros et al. 2006). Although $\mathrm{Ca}$ and $\mathrm{Mg}$ are two main nutrients in banana (Stoorvogel and Segura 2018), both were significantly higher in the range of high disease severity. A higher $\mathrm{Ca}$ concentration for instance is linked with a lower severity of fungal diseases in crops (Sugimoto et al. 2007; Heyman et al. 2007). Found results in this experiment with this soil property disagree with those previous results. At the same time, the graph of the soil acidity and the disease allows to illustrate that the correlation between soil properties ( 2 or more) can play a role in the expression of the disease. It is expected after the significance of the acidity according the disease level a higher SI of Fusarium wilt in the field areas with the higher acidity. However, a low acidity appears not to tell much about disease severity. In that case, likely other properties and their correlation also influence the disease. Besides, the possible implementation of managing soil properties implies considering the effect of changing one single soil property in other properties and their interaction in the disease incidence.

The cluster analysis confirmed the role of $\mathrm{SOM}, \mathrm{Ca}, \mathrm{Mg}$ and acidity in the disease. Probably those soil properties that were not correlated to disease severity played an important role in the definition of the clusters. SOM (and N) are considered to be important soil properties for the soil quality (Pattison et al. 2008). An optimal condition of SOM and N in the soil are crucial in the banana plant status. Besides, SOM is reported in the suppression of soil borne fungal diseases (Bananomi et al. 2007; Janvier 2007), as is the case of Fusarium wilt. Soil N concentration can be related with the plant response to the disease. Soil $\mathrm{N}$ was correlated with SOM and it also can be playing a role in the disease expression. Probably their role in the disease severity is also linked with other soil properties, but this was not evidenced in this research. Soil texture and particle size, for instance are linked with the incidence of Fusarium wilt in banana (Domínguez et al. 2001). 
Soil properties were found to have significant relationship with Fusarium wilt expression in both performed experiments. The interaction between inoculation and soil $\mathrm{pH}$ was significant in one of the evaluated soils with biomass as the key element of the disease expression at the greenhouse experiment. In the farm experiment, it also became apparent that many different soil properties are interacting, which hampers the quantification of the effect of individual soil properties. In general, the field survey confirmed the effect of soil properties such as SOM, Ca, $\mathrm{Mg}$ and acidity on the disease. Furthermore, correlations between soil properties were found. This shows the complexity of the systems and how more soil properties, even the soil type, can be playing a role in the disease.

The call for alternative control packages for diseases like Fusarium wilt is highly relevant as currently the very aggressive strain, the Foc Tropical Race 4 (Foc TR4) is ravaging through many banana productions systems (Ploetz and Churchill 2011; García-Bastidas et al. 2014; Ploetz 2015b). In a worst scenario where Foc TR4 in already reported in LAC (Garcia-Bastidas et al. 2019) and the fact that resistant varieties will become available after year, there is an urgent need to develop control packages that allow farmers to manage the disease and slow down its dissemination.

\subsection{Conclusions}

The long-term goal of the research is to identify management strategies that may result in a reduction in the risk of Foc infestation. Results suggest that an integral soil management, including for example, SOM founds as organic amendments, liming to rise $\mathrm{pH}$, and a balanced $\mathrm{N}$ fertilization, may be considered as part of the strategy for alleviating the disease in smallholder farms of the cv. "Gros Michel" and with other susceptible cultivars. These practices are being tested in current field experiments. Results also show that soil properties and their interactions play a role in the disease severity, contrary to the more general statements found in handbooks (e.g., (Marschner 2012) and studies from other regions (Alvares et al. 1981; Zhang et al. 2013; Sun et al. 2018). A soil integral management as a key factor of the integral management of banana crop is a current and urgent necessity. 


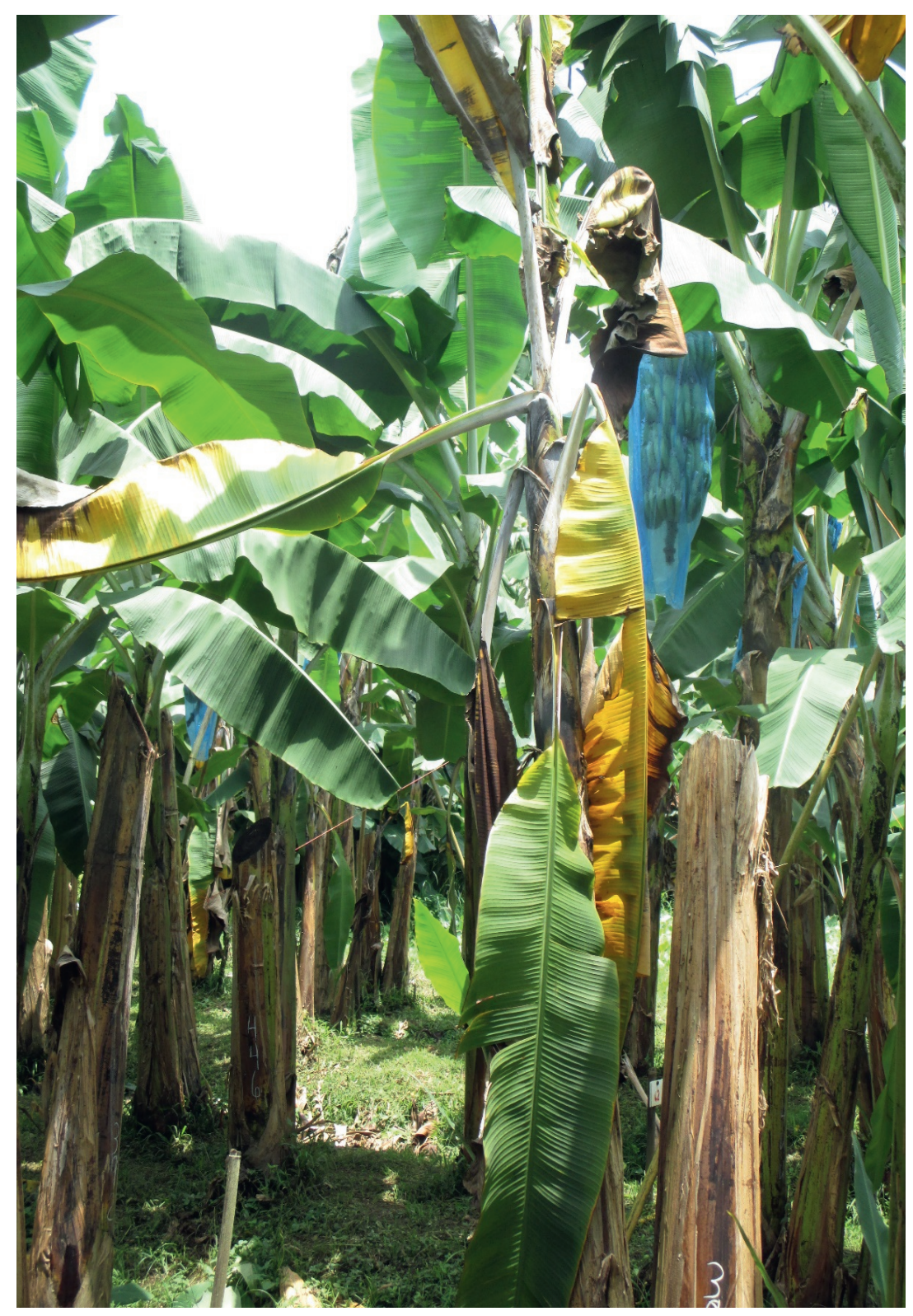


7. Synthesis 


\subsection{Crop disease management}

Crop disease management is an important aspect of crop production. Almost every crop has at least one critical disease serious impacting its production (Oerke 2005). In addition, new crop diseases or strains of pathogens appear continuously. Although conventional chemical options to control crop diseases are effective in some cases, their implementation is not always possible either through the costs, the potential environmental impacts, or simply the lack of an effective chemical control. In addition, consumers and markets are increasingly calling for ecofriendly alternatives for chemical control, whereas at the same time the loss in efficacy of many chemical agents make it necessary to increase their use. As a result, there is an urgent call for alternative approaches to crop disease management including e.g. crop rotation and breeding for genetical resistance.

There is no "silver bullet" to solve crop diseases. Crop production will therefore continue to face losses in production due to crop diseases. Integrated crop management is therefore an important pathway, where different practices are combined. Soil conditions are known to influence crop diseases either by suppressing the diseases or conducing the diseases (Amir and Alabouvette 1993; Höper and Alabouvette 1996; Janvier et al. 2007). Soil management is therefore a real option to be considered in crop management to control (or alleviate) the effects of crop diseases, especially in the case of soil borne pathogens. This study focused specifically on the chemical soil properties that can be easily managed through e.g., fertilization and liming.

Fusarium wilt in bananas is a good example of this struggle for efficient and environmental disease control. When the disease became a problem in the beginning of the $19^{\text {th }}$ century research started to evaluate alternative strategies for crop disease control (Rishbeth 1955; Stover 1962). When the resistant Cavendish cultivar was found that also had the proper traits for commercialization most of the research was stopped although Fusarium wilt remained a serious problem for the small production of the Gros Michel cultivar. When several decades ago a new strain of Foc (TR4) started to become a serious problem, efforts to find effective control measures were reinitiated. A possible devastation of the banana production system because of an uncontrolled Fusarium wilt breakout would imply a huge and multilevel tragedy as history has shown. The high aggressiveness and pathogenicity of Foc TR4 and the wide range of susceptible cultivars make Fusarium wilt by this Foc strain a lot more critical. An Foc TR4 infestation can 
devastate small and large farms, Cavendish and Gros Michel plantations, as well as export and local markets. From this perspective, there are risks for all the actors in banana production. Not only would there be an economic and social negative impact, but also, negative effects in food security and possible multilevel depression of an extremely important commercial activity as is the case of banana trade.

The Foc-banana is an ideal model to illustrate the complexity of dealing with a very competitive pathogen in a crop. Besides, conventional control practices in this case are not very effective. The fungus eradication from infested soils is practically impossible. Other approaches to disease management (like crop rotation) are difficult due to implement in the perennial production system. It is therefore extremely important to look for alternative approaches like soil management to tackle the disease.

\subsection{Studying the potential of soil management for Foc control}

Limitations in the current control package against Foc in bananas make it necessary to search for non-conventional alternatives like soil management. However, there are different ways to study the potential of soil management for Foc control. In this thesis, I followed two parallel research lines to study the potential impact of soil management on disease expression. The two research lines are presented in Figure 7-1. In a first methodological research line, different research tools, each with their own specific advantages and disadvantages were combined including a literature survey, an analysis of spatial variability, greenhouse experiments, field experiments, and a farm survey. By combining, the various approaches, I was able to get better insight in the relation between soil properties and Foc expression. An alternative research line, aimed to unravel the complexity of the system by looking at specific elements of the system and answering specific questions like i) Which soil properties are known to have an important role in disease expression,

ii) Does the relation between Foc and soil differ for TR4 and R1?, iii) How does the infection build up over time?, and iv) Does the relationship differ under different soil types or agro-ecological conditions? The two research lines will be discussed in Section 7.3 and 7.4. 


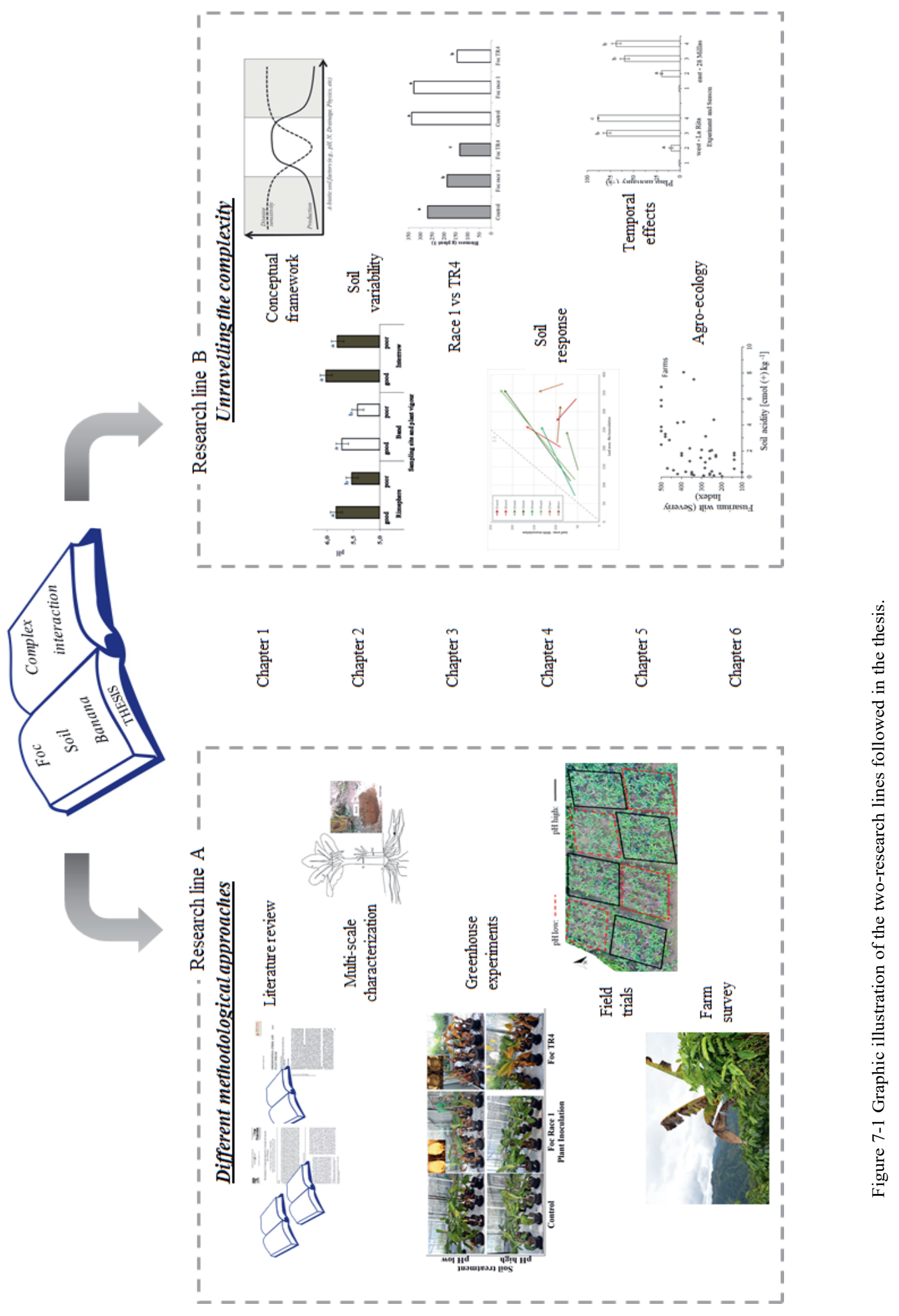




\subsection{Different methodological approaches (Research line A)}

Researchers have a considerable toolbox available that allows them to study the complexity of agronomic systems. Literature reviews can combine the results of a large number of case studies or specific experiments. In the case of crop diseases in relation to soil management, a literature study was used to identify which soil properties are known for their influence on soil-borne diseases. (Chapter 1). In a more detailed scope, also the relation of soil properties and Fusarium wilt in banana was studied in the literature. Both literature studies identified soil $\mathrm{pH}$ and $\mathrm{N}$ as the two main soil properties in crop (including banana) production with potential to regulate crop disease susceptibility (including Fusarium wilt in banana). Before, looking into the relation between soil properties and Fusarium wilt, first a multi-scale characterization of the different banana systems in Costa Rica to study the influence of soil properties (chemical and biological) in production was done (Chapter 2). Greenhouse experiments are extremely useful to study specific relations under very controlled conditions keeping all but a few factors constant. The greenhouse experiments were carries out in a number of cases to show that e.g., soil $\mathrm{pH}$ and $\mathrm{N}$ indeed affect Fusarium wilt (Chapter 2), and that different soil types respond differently in the impact of soil properties on Foc R1 (Chapter 2). An additional advantage of the greenhouse experiments was that it allowed for an experiment with Foc TR4 that would never be allowed under field conditions. An experiment with TR 4 in a country without banana production (the Netherlands) with strict biocontrol measures was only possible as a greenhouse experiment. The experiment showed that both Foc R1 and TR4 are affected by soil properties. A major limitation of the greenhouse experiments is that the conditions never fully replicate the field conditions. In the case of banana almost all reported greenhouse experiments deal with very young plants and almost no experiment continuous to monitor the banana plant until fruit production.

The results from the greenhouse experiments require in almost all cases, subsequent verification in the field. This was the aim of two field trials in this thesis (Chapter 5). The field trials were maintained during four crop cycles, during which the effect of five main soil properties ( $\mathrm{pH}, \mathrm{N}, \mathrm{Ca}, \mathrm{Mg}$ and $\mathrm{Mn}$ ) were studied in relation to Fusarium wilt (Race 1) incidence and the production of the banana (cv. 'Gros Michel') system under a Foc infestation. The differences between the two experiments and the effect of time (over the 4 crop cycles) were evaluated. 
Although the field experiments confirmed the role of soil properties like $\mathrm{pH}$ and $\mathrm{N}$, the experiment also showed that after a few crop cycles the entire experiment was heavily infected and no commercial production was possible irrespective of the soil conditions. The soil conditions were able to slow down the infestation. Although field trials represent a more real scenario, probing results at the farm level can be a more realistic. In a farm survey (Chapter 6) the effect of agroecological variation Fusarium wilt in small-scale production of 'Gros Michel' was studied. Soil properties also appeared to play a role under those conditions.

In the experiments different soil properties were linked to the predisposition of banana to Fusarium wilt. Despite this response, soils were managed to evaluate the plant in extreme levels of each tested soil property. Finally, a greenhouse experiment and a farm survey were linked (Chapter 6) to evaluate that banana response to Fusarium wilt in a true production environment while dealing with a true variation in agro-ecological conditions and farm management. The greenhouse experiment showed the response to the disease according to soil $\mathrm{pH}$. The farm survey evaluated the disease status according to the soil properties found at the fields. Although the survey was defined by the disease's pressure and aggressiveness, there were several other environmental factors, even crop management in each farm, that could be involved in the banana's response to the disease. The farm survey is the inverse of the experiments. Where the experiments control everything and you have only a limited number of factors that vary, in the farm survey all factors are changing simultaneously, and it can be extremely difficult to extract the driving factors behind a single factor like disease incidence. Nevertheless, differences in soil condition and the disease expression were found significant, confirming the importance of the soil in disease incidence. The results from the farm survey complemented the results of the experiments, showing that the expression of the disease is naturally influenced by soil properties.

\subsection{Unraveling the complexity (Research line B)}

The complexity of the relations between the soil and Fusarium wilt in banana was unravelled step by step. First an analysis focused on the determination of the key soil properties that play an important role (and that can be managed through soil management). Literature unequivocally showed that $\mathrm{pH}$ and $\mathrm{N}$ are important and relevant soil properties (Chapter 1). The 
role of $\mathrm{pH}$ and $\mathrm{N}$ has been confirmed in a range of experiments and surveys (Chapter 3, 4, 5, 6). The role of $\mathrm{pH}$ and $\mathrm{N}$ is found for both $\mathrm{R} 1$ and TR4 (Chapter 3), making the research relevant for both the smallholder farmers of Gros Michel as well as the larger export-oriented production of Cavendish. However, literature indicated that the result of studies did not produce uniform results. An evaluation showed that soil variation in the banana region in Costa Rica is considerable between and within plantations (Chapter 2). The response of differences in soil $\mathrm{pH}$ and $\mathrm{N}$ differ considerably per soil type (Chapter 3 and 4). In addition, agro-ecological conditions appear to play an important role (Chapter 6). In Chapter 1, a conceptual framework was proposed on the basis of available literature. The traditional curve of plant response in function of soil properties was complemented with a theoretical curve of response to diseases with respect to soil properties. The model hypothesizes that an optimal plant nutrition reduces the susceptibility to diseases. Despite this effect in an indirect effect of soil properties on diseases expression in crops, probing the existence of this relationship in the model Foc-banana is crucial for defining the way to follow in this research line. Although inconsistences in the effects of soil properties on crops diseases. finding main soil properties in crop production as soil $\mathrm{pH}$ and $\mathrm{N}$ with an important number of reports relating them with crop diseases also improve the knowledge to focus the research.

Chapter 2 shows how the influence of soil properties in status and production in a complex and variable production system. Soil $\mathrm{pH}$, acidity and microbiologic (biotic) soil properties were linked with the biometric and productive responses in commercial banana (Cavendish) plantations. Although the importance of soil properties to banana production, the multi-scale characterization allowed to probe the importance of soil $\mathrm{pH}$ and other soil properties such as $\mathrm{Ca}, \mathrm{Mg}$ and $\mathrm{Al}$ (negative effect). This relation in production can be related with the plant response to diseases. However, the systems variability should be considered in an eventual implementation of the practices to manage soil properties for both production and dealing with diseases. In Chapter $\mathbf{3}$, research in soil management and Foc in banana from the 1950's was re-taken. Results verified the influence of soil $\mathrm{pH}$ and the interaction of $\mathrm{pH}$ and $\mathrm{N}$ in the incidence of the disease with the model between Foc Race 1and the cultivar 'Gros Michel', but also the same relationships were found in the model between Foc TR4 and the cultivar Cavendish. This knowledge opens opportunities for soil management when dealing with Fusarium wilt with TR4 as a current threat to banana production. Besides, more soil properties can be playing a role in the incidence of the disease as well, just as it was demonstrated in the rest of the research. 
On top of corroborating the importance of single soil properties and their interactions, the Chapter 4 showed the impact of soil types on banana predisposition to Fusarium wilt. Soil $\mathrm{pH}$ and its interaction with $\mathrm{N}$, were found to significantly influence Fusarium wilt. It was also possible to show the role of soil type in disease expression. Although plant predisposition according to the tested soil properties followed consisted trends, the weight and the trend of the response depending on the soil type also was significant. This result implies that implementing soil management to control Foc in banana is more complex than just defining standard recommendations. Although the disease incidence and aggressiveness can be modulated through managing soil properties, each soil showed a differential behaviour. Before implementing soil management for disease control, in-depth knowledge of the properties of each soil should be determined. Soil properties as an integral system are more significant than individually tested soil properties. Aspects such as soil quality and health should also take part in this scenario. Additionally, it is important to include natural soil properties in the scheme of alternative options to control diseases based on soil management. This result is critical for applying soil management in disease control not only in bananas, but also in any other crops. Besides, result at the greenhouse is not enough to demonstrate the potential of managing soil properties in disease modulation. It is known that greenhouse experiments in general have more possibilities of being successful because of the ability to fully control the conditions. In addition, those soil properties, $\mathrm{pH}$ and $\mathrm{N}$, affect per se banana development, is it was demonstrated in the previous phase. The real effect of those soil properties on the disease could be hidden due to their primary effect on banana.

Measuring banana response to the disease at the field in the Chapter $\mathbf{5}$ allowed to study the soil and the disease interactions in a real scenario. Analysing various complete crop cycles made it possible to follow not only the influence of the soil properties on the disease, but also to measure the consequent results in the yield (a very important element). Through soil treatments, changing main soil properties as $\mathrm{pH}, \mathrm{N}, \mathrm{Ca}+\mathrm{Mg}$ and $\mathrm{Mn}$ with two contrasting soils and different ecology conditions, distinguishing banana behaviour against Fusarium wilt was feasible. But more than modulating the disease, the impact on the crop production was measured. There are two main critical conclusions that can be extracted from the fact that soil properties influenced the disease and banana production. First, these experiments demonstrated that implementing some soil management practices such as liming and nutrient application could modulate Fusarium wilt at the field. Second, the influence of the time (temporal effect) in the complex relationship of Foc and 
banana was evident. This was shown through the different disease expression between the evaluated cycles. Under the experimental conditions, not all present soil properties interactions could be observed, but their potential role in the results cannot be discarded. It is remarkable that the tested soil properties, especially soil $\mathrm{pH}$, maintained a consistent influence on plant mortality during the evaluated cycles. In the third and the fourth cycles, the infection level achieved a nonmanageable crop condition due to the disease. Plots with low $\mathrm{pH}$ almost completely succumbed to the disease at the end of the experiments. Despite this, the pressure level of the disease raised also in soils with a higher $\mathrm{pH}$ level. This implies that there is a limited effect of soil conditions in the incidence of the disease. The lack of an integrative management package, as was the reality of this experiment, makes the influence of one single alternative - such as soil management - futile due to the pathogen's competitiveness. More components should be involved in disease management, including the conventional and non-conventional options.

\subsection{From research to management recommendations.}

Despite soil $\mathrm{pH}$ and its interactions with $\mathrm{N}$ appear as a primary soil property, the collected information indicates that more soil properties are involved in the incidence of Fusarium wilt in banana. Other soil properties such as $\mathrm{Ca}, \mathrm{Mg}, \mathrm{Mn}$ and $\mathrm{SOM}$ were found significant in the relation with the disease expression. Besides, more than the single effect, through the whole research, the interactions were consistently found to influence banana response to Fusarium wilt. It is expected that more interactions of soil properties are present in disease expression and the experimental design was not able to show all of them.

The proposed conceptual framework (Chapter 1) was evaluated, but more soil properties and their interactions according to the soil type and the ecology should be considered to evaluate their incidence on Fusarium wilt expression in banana. Moreover, this indicates that an integrative management of the disease requires the coordinated effort of specialists from diverse but related disciplines. The agronomists, the plant physiologists, the plant pathologists, and the soil scientists should work together with the growers to achieve a sustainable way to control or alleviated the effects of the disease in the productive systems. 
In an overall perspective of the research, results between the experimental phases varied in significance or consistence and it makes more difficult to conclude about the studied topic. This can be the explanation of the inconsistence in previous studies about soil properties and crop diseases (included Foc and banana). Besides, concluding only taking in count results of one single experimental phase appear to be risky. Results between the greenhouse and the field and the farms varied. Although in the greenhouse similar results were found, the magnitude of results from these experiments with similar methodology (Chapters 3 and 4) differed. Chapters 5 and 6 confirmed that soil properties influence the disease but, there were inconsistences with previous phases. This points the strengthens the results from the systematic study approach (literature review, greenhouse experiments, field experiments) helped to clarify the effects. Besides, it makes evident the importance of implementing different experimental strategies including the time as an important component to study diseases in perennial crops as is in the case of Fusarium wilt in banana.

Given that there is a need to find alternatives to control the diseases or at least maintain the productive systems, the findings of this research can give opportunities to apply various practices in the crops. From the overall results, soil properties have been found to influence both plant production and the response to the disease. Although there are no standard recommendations, integrating this knowledge with conventional options could lead to a synergy between the strategies. Integrating conventional options, such as soil disinfestation with bio-fumigation, can be implemented to alleviate infested conditions. Managing soil abiotic properties to reduce banana crop predisposition to Fusarium wilt can also be applied after disinfestation. Furthermore, SOM concentration can be increased as a soil health quality indicator. Amendments can be applied through liming where required, as well as microorganisms to increase soil activity, because this is linked with a higher banana production. All those practices can increase soil health and quality. A healthier soil is expected to have more opportunities to exclude Foc or at least better resist the fungus infestation. Additionally, bananas grown in this soil will be less predisposed to the disease and can have a higher and more acceptable yield.

Although there is not possible yet to design general recommendations based in soil management to deal with Foc in bananas, a practical application of the knowledge acquired through this research can be carried out in the regions where it was found, the Costa Rican banana region. Although the evidence indicated a differential behavior of the disease depending on the soil type and the predominant ecologic conditions, specific strategies according to soil properties 
in each region can be implemented. First, stability should be achieved between the critical range of significant soil properties with influence on crop production and the disease. Second, the findings of this research can be integrated to implement soil management practices for both scenarios: non- Foc infestation and soil infestation. Integrative strategies should be structured to achieve and maintain both a high banana production and Foc prevention, with an acceptable production even under Foc infestation in the mid-term (2-3 crop cycles as an ideal scenario) before plant renovation (Table 7-1).

Table 7-1 Proposed targets of soil management focused in preventing or dealing with a Foc infestation in Costa Rican "banana" soils.

\begin{tabular}{lc}
\hline Target & Practices \\
\hline High $\mathrm{pH}$ & Liming to rise $\mathrm{pH} /$ less acidifying N fertilizers \\
High SOM \% & High and constant application \\
Balanced N rates & Adjusted inputs to balance the extractions \\
Higher $\mathrm{Ca}$ & Constant application with fertilizers and amendments \\
Higher $\mathrm{Mg}$ & Constant application with fertilizers and amendments \\
Lower $\mathrm{Mn}$ & Decrease solubility through an optimal drainage \\
\hline
\end{tabular}




\subsection{Key conclusions}

- The potential of soil management to be included as an option to control or alleviate Fusarium wilt in bananas has been demonstrated.

- Through the experimental phases, the influence of specific soil properties in the incidence and severity of Fusarium wilt in bananas was demonstrated.

- The interactions of two or more soil properties appear to be more significant than the effect of a single property in the expression of the disease.

- Soil type can naturally influence disease expression; each soil type should be considered as an individual package of properties with the influence of the ecology and the time (age of plantation).

- The approach of a systematic study including literature, greenhouse, field experiments and the farm survey was effective to analyze the soil in the incidence of the disease.

- This methodology can be implemented to study other soil banana diseases and other diseases in perennial crops. 


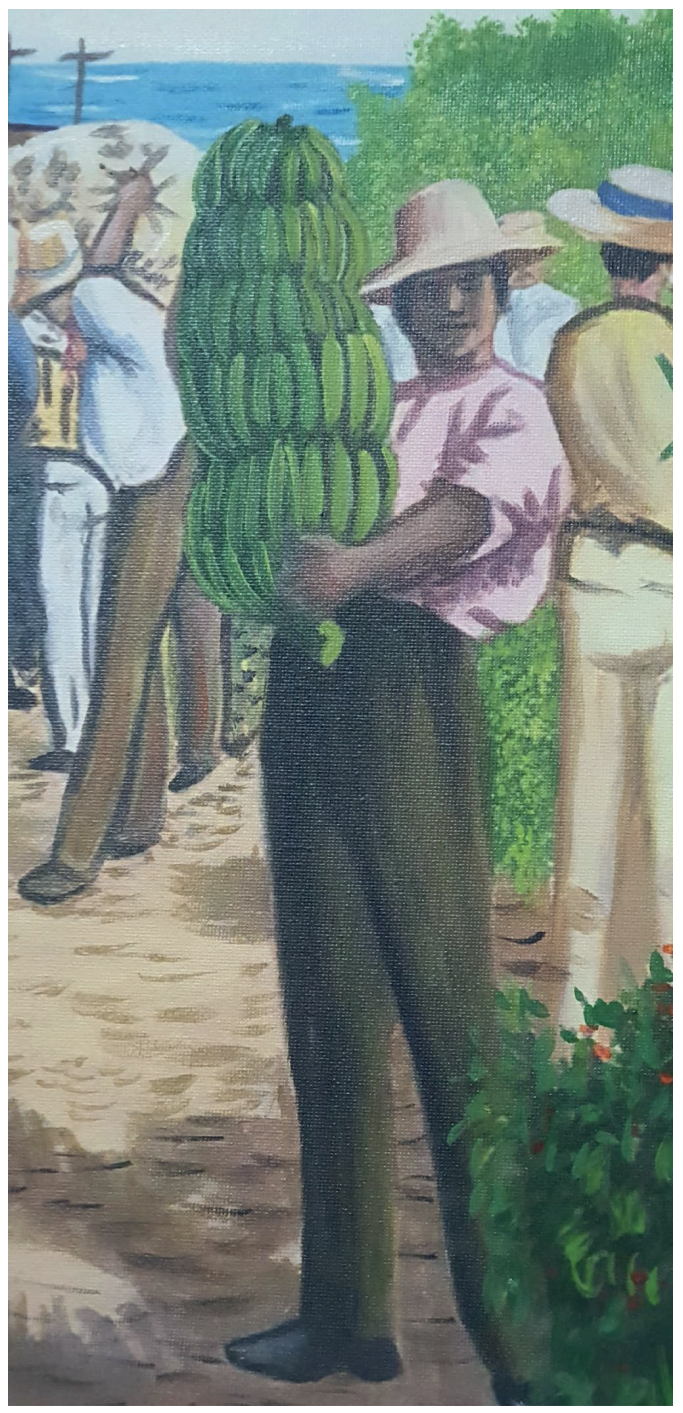




\section{General Abstract}

Crop diseases imply a high cost to control them and losses in the yield and its quality. At the same time of a rising in the crop diseases and their aggressively, effectiveness of conventional control methods such as pesticides can decrease in their effectiveness. The constant demographic growth means that an increase in production is necessary in order to satisfy the demand of this expanding population. Besides the modern society demands systems and products less environmental impacting and healthier. The search for alternatives to control crop diseases is a primary necessity in agricultural production. There is a greater awareness of the fact that the optimal crop disease management system requires a combination of different approaches. Integrated control strategies that allow for more sustainable production systems with a lower impact are desirable.

Soil management as part of the disease triangle may be a component that would allow us to modulate the expression of crop diseases, especially the ones caused by soilborne pathogens. Despite the wide range of reports on the influence of soil conditions in the incidence and control of diseases, the results are inconsistent. Only in a reduced number of cases is soil management considered as a real option to be included in the control package of crop diseases. Based on the literature, a conceptual framework is proposed, where three types of soil influence in disease incidence are identified: the first, a direct influence, where the pathogen is affected; the second, an indirect influence, where the plant's response to the disease is modulated, and the third, where both the first and the second cases occur simultaneously (Chapter 1). To test the model, the effect of soil properties on disease incidence was examined for the case of Fusarium wilt (Fusarium oxysporum f. sp. cubense or Foc) in banana (Musa sp.).

Foc is one of the main threats to banana systems around the world. Tropical Race 4 (Foc TR4), one strain of this soil borne fungus is being spread in banana locations and it could sweep away $80 \%$ of the whole banana worldwide. Other races of Foc, such as Race 1, Race 2, and Subtropical Race 4 are also a problem for banana production in different latitudes. This disease represents a high risk not only for the large-scale banana production for exportation, but also for small-system banana production, where it is important for subsistence and local consumption. This 
is found mainly in the rural areas of developing countries, where banana production is vital for millions of people. The magnitude of the effect of the disease can be illustrated with the devastation of banana plantations from the sub-group Gros Michel (Musa AAA) caused by Foc Race 1 in Latin America and the Caribbean (LAC) during the $20^{\text {th }}$ century. The social and economic impacts were truly significant. Foc in a very competitive fungus that resists the conventional method controls as fungicides or replanting. Besides reproductive structures of Foc can survive in the soil for decades. The solution that saved banana production was the shift of the Gros Michel to cultivars from de largely resistant to Foc Race 1 sub-group Cavendish (Musa AAA). This was a temporary solution, as Foc TR4 can infect Cavendish. After the shifting the research in about this disease declined. With the reports of the new strain Foc TR4 and its wide range of susceptible cultivars, the research in the disease was reactivated.

In general, it is challenging to identify and isolate the soil properties that are involved in crop diseases caused by soilborne pathogens (and other agronomic problems) when studying these directly in the field. Soil property interaction with the crop and the environment could hide the real influence of a specific property. To better understand this relationship, the thesis was divided in five phases following two parallel research lines: A: a methodological approach study and B: unraveling the complexity. In the line A, different research tool with advantages and disadvantages were combined: literature, greenhouse experiments, field experiments and farm survey. The B research lines aimed to unravel the complexity of the system by looking at specific elements of the system and answering specific questions like i) Which soil properties are known to have an important role in disease expression, ii) Does the relation between Foc and soil differ for TR4 and R1?, iii) How does the infection build up over time?, and iv) Does the relationship differ under different soil types or agro-ecological conditions?

Chapter 2 presents a retrospective analysis of commercial plantations of the Cavendish cultivar in the banana-producing region of Costa Rica. In this experimental phase, the chemical and biological soil properties that are linked to crop production and health were determined. Based on productive history, 3 farms with high productivity and 3 with low productivity were selected. Then, within each field, the areas with the highest and lowest relative productivity were identified and analyzed for their soil abiotic and biotic properties at each status and production level. It was found that soils with high $\mathrm{pH}$, low acidity, high $\mathrm{Ca}$ and $\mathrm{Mg}$, low $\mathrm{Fe}$ and $\mathrm{Cu}$, and large populations of microorganisms (fungi, bacteria and actinomycetes) in soil and roots were linked to healthier 
plants and a higher production. Specific soil properties were found to have a stronger link to production. This defines the primary crop variables that could also play a role in disease response and could be modified through soil management. From the point of view of management and complexity of interaction, a series of abiotic soil properties were chosen to be studied in relation to management and incidence of Fusarium wilt in banana.

In Chapter 3 Soil $\mathrm{pH}$ and nitrogen $(\mathrm{N})$, described in the literature as the two properties that have been mostly related to disease incidence, including the cases of Foc in banana. This phase re takes the research line from the last century where reports were obtained with the model Foc Race 1 and banana Gros Michel and and also explores the response of the disease in Cavendish according to soil management. In two complementary greenhouse experiments with a type of soil each, $\mathrm{pH}$ was managed to reach two levels (lower than 5.2 and equal to or higher than 6.0). The first experiment in Costa Rica (Gros Michel and Foc Race 1) and the second experiment in the Netherlands (Cavendish and Foc TR4 and Foc Race 1) showed that a pH lower than 5.2 accelerated disease symptoms, expressed as a lower plant biomass. In addition, low $\mathrm{pH}$ was found to produce disease symptoms caused by Foc Race 1 in Cavendish banana, even though Cavendish is resistant to this Foc strain (Experiment 2). Furthermore, this indicates that the tested soil properties have a considerable potential in modulating Fusarium wilt in banana not only in Gros Michel but also in Cavendish bananas.

These results were confirmed in another greenhouse experiment (Chapter 4), using 8 representative soil types where banana is usually cultivated in Costa Rica and applying the same treatments. The model used was Gros Michel and Foc Race 1. Besides, the soil type was relevant in this case, as it played a role in disease expression. Even though low pH was linked with higher wilting and lower biomass production, each soil had a different behavior. This highlights the fact that it is not appropriate to offer general recommendations based on soil management for crop disease control. Instead, each soil should be considered as a specific package of soil conditions that will naturally modulate crop behavior towards diseases based on the status of its properties.

The main results found in the greenhouse phase were translated into experimental plots in the field (Chapter 5). In two agroecological banana regions in Costa Rica, during four crop cycles, the studied soil properties, all significantly important in crop production ( $\mathrm{pH}, \mathrm{N}, \mathrm{Ca}+\mathrm{Mg}$ y $\mathrm{Mn}$ ), and their interactions were found to influence Gros Michel banana response to Foc Race 1. High $\mathrm{pH}$ decreased disease incidence and its interactions with the rest of the soil properties modulated 
disease expression and crop production. Additionally, time was found to play a crucial role in the disease triangle: the highest wilt incidence became present after the second evaluated cycle. This may open the possibility to establish harvest cycles, implementing soil management to control the disease, but for specific periods of time before renewing plantations as required depending on disease pressure.

To validate these preliminary results, a greenhouse experiment was carried out (Chapter 6), along with retrospective surveys at different plantations in a predominantly Gros Michel banana-producing region with presence of Foc Race 1 in the soil. The greenhouse experiment included two representative soils from the area and the same treatments that were applied in the previous phases. For the survey, 49 locations were visited. The plantations were classified according to the aggressiveness of the disease symptoms. The greenhouse experiment verified the effect of $\mathrm{pH}$ and its interaction with $\mathrm{N}$ in disease incidence, maintaining a difference in behavior according to the soil type. Soil sample analyses showed that the most infected areas had a higher soil acidity and $\mathrm{Ca}$ and $\mathrm{Mg}$. A higher content of soil organic matter (SOM) was linked to a lower disease incidence. Furthermore, environmental factors may also play a role in the expression of Fusarium wilt in banana. Crop predisposition to the disease based on soil conditions is complex, and the environmental conditions of each region may also interact with the soil and its properties to determine crop disease incidence.

The general results showed that specific soil properties can influence the expression of Fusarium wilt in banana. Even though crop disease management through soil management is possible, it is complex. Aspects such as soil type and environmental conditions play a role in disease expression, crop predisposition, or both. The systematic study approach (literature review, greenhouse experiments, field experiments) let us unravel the complexity of interaction between the soil, Foc and banana. Although there is no "silver bullet" to solve the problem of crop diseases, especially Foc in banana, soil management emerges as a complex, but real option to be included in the disease control package (Chapter 7). This is particularly relevant due to the growing need to implement alternative management methods that allow for more eco-friendly crops. This would be feasible as long as the particular soil conditions and the possible ecological implications are considered before implementing soil management practices, as has been demonstrated for the case of Fusarium wilt in banana. 


\section{Resumen General}

Las enfermedades de los cultivos implican altos costos en su control y perdidas tanto de producción como de su calidad. Al mismo tiempo de un incremento en el número de las enfermedades y su agresividad, los métodos convencionales de control como el uso de pesticidas pueden estar disminuyendo su efectividad. El constante crecimiento demográfico indica que un incremento en la producción de los cultivos es necesario para satisfacer la demanda de una población creciente. También, la sociedad moderna demanda sistemas y productos menos impactantes al ambiente y más saludables. La búsqueda de alternativas para controlar las enfermedades de los cultivos es una necesidad primaria en la producción agrícola. Existe una gran conciencia acerca de la realidad que sistemas de manejo óptimos para controlar las enfermedades de los cultivos requieren de una combinación de diferentes enfoques. Estrategias integradas de control de enfermedades de los cultivos que permitan sistemas de producción más sostenibles con un menor impacto, son deseables.

El manejo de los suelos como parte del triángulo de las enfermedades puede ser un componente que permita modular la expresión de las enfermedades de los cultivos, especialmente aquellas causadas por patógenos del suelo. A pesar de un extenso rango de publicaciones sobre la influencia de condiciones del suelo y el control de las enfermedades, los resultados son inconsistentes. Solo en un número reducido de casos se considera al manejo de los suelos como una opción real para incluir en el paquete de control de enfermedades de los cultivos. Con base en la literatura se propone un modelo conceptual, donde tres tipos de influencia de los suelos en la incidencia de las enfermedades de los cultivos son identificados: el primero, el efecto directo, sonde el patógeno es afectado; el segundo, un efecto indirecto, donde la respuesta de la planta hacia la enfermedad es modulada; y el tercero, donde los dos efectos previamente mencionados ocurren simultáneamente (Capítulo 1). Para evaluar el modelo, el efecto de propiedades del suelo sobre la incidencia de enfermedades fue estudiado para el caso de la marchitez por Fusarium o "Fusarium wilt" (Fusarium oxysporum f. sp. cubense o Foc) en banano (Musa sp.). 
Foc es una de las principales amenazas para los sistemas bananeros alrededor del mundo. La Raza 4 Tropical (Foc R4T), una cepa de este hongo del suelo está siendo diseminada en áreas bananeras y puede devastar a más del $80 \%$ de todos los tipos de banano. Otras razas de Foc como la Raza 1, la Raza 2, y la Raza 4 Subtropical son también un problema para la producción de banano en diferentes latitudes. Esta enfermedad representa un alto riesgo no solo para la producción de banano a gran escala para la exportación, sino también para la producción de banano en pequeños sistemas, donde es importante para la subsistencia y el consumo local. Esto se da principalmente en las áreas rurales de los países en desarrollo, donde la producción de banano es vital para millones de personas. La magnitud del efecto de la enfermedad se puede ilustrar con la devastación de las plantaciones de banano del subgrupo Gros Michel (Musa AAA) provocada por Foc Raza 1 en América Latina y el Caribe (ALC) durante el siglo XX. Los impactos sociales y económicos fueron verdaderamente significativos. Foc en un hongo competitivo que resiste los métodos convencionales de control como fungicidas o la renovación de la plantación. Además, las estructuras reproductivas de Foc pueden sobrevivir en el suelo durante décadas. La solución que salvó la producción de banano fue el cambio de Gros Michel a cultivares del subgrupo Cavendish (Musa AAA), con gran resistencia al Foc Raza 1. Esta fue una solución temporal, ya que Foc R4T puede infectar también al Cavendish. Después del cambio, la investigación sobre esta enfermedad declinó. Con los reportes de la nueva cepa Foc R4T y la amplia gama de cultivares que puede infestar, se reactivó la investigación en la enfermedad.

En general, es retador identificar y aislar las propiedades del suelo que están envueltas con enfermedades de los cultivos causados por patógenos del suelo (y en otros problemas agronómicos) cuando son estudiados directamente en el campo. La interacción de las propiedades del suelo con el cultivo y el ambiente pueden esconder la influencia real de una propiedad específica. Para entender mejor esta relación, la tesis fue dividida en cinco fases seguidas con dos líneas paralelas de investigación: A: un enfoque de estudio metodológico y B: revelando la complejidad. En la línea A, diferentes herramientas de investigación con ventajas y desventajas fueron combinadas: literatura, experimentos de invernadero, experimentos de campo y encuestas en fincas. La línea de investigación B tuvo como objetivo revelar la complejidad del sistema a través de la visualización de elementos específicos y contestar preguntas específicas como i) ¿Cuáles propiedades del suelo se conocen con un rol importante en la expresión de enfermedades?, ii) ¿Es diferente la relación entre Foc y el suelo en el caso de R4T y de Raza 1?, iii) ¿Como progresa 
la infestación en el tiempo? y iv) Difiere la relación bajo diferentes tipos de suelo y condiciones agroecológicas?

El Capítulo 2 presenta un análisis retrospectivo de plantaciones comerciales del cultivar Cavendish en la región productora de banano de Costa Rica. En esta fase experimental se determinaron las propiedades químicas y biológicas del suelo que están vinculadas con la producción y salud del cultivo. Con base en el histórico productivo, 3 fincas con alta productividad y 3 con baja productividad fueron seleccionadas. Entonces, en cada uno de esos campos, áreas con la mayor y la menor productividad relativa fueron identificados y analizados para sus propiedades bióticas y abióticas del suelo en cada condición y nivel de producción. Se encontró que suelos con $\mathrm{pH}$ alto, baja acidez, alto $\mathrm{Ca}$ y $\mathrm{Mg}$, bajo $\mathrm{Fe}$ y $\mathrm{Cu}$, y con mayores poblaciones de microorganismos (hongos, bacterias y actinomicetes) en el suelo y las raíces, fueron relacionados con plantas más sanas con mayor producción. Se encontró que propiedades específicas del suelo se vinculan fuertemente con la producción. Esto define propiedades primarias en el cultivo que pueden también jugar un papel en la respuesta a las enfermedades y que pueden ser modificadas a través del manejo de los suelos. Desde el punto de vista de manejo y la complejidad de las interacciones, una serie de propiedades abióticas del suelo fueron seleccionadas para ser estudiadas en relación con manejo del suelo y la incidencia de la marchitez por Fusarium en banano.

En el Capítulo $3 \mathrm{el} \mathrm{pH}$ y el nitrógeno del suelo, descritos en la literatura como las dos propiedades del suelo mayormente relacionadas con la incidencia de enfermedades en los cultivos, incluyendo Foc en banano. Esta fase retoma la línea de investigación del siglo pasado donde resultados fueron publicados con el modelo entre Foc Raza 1 y el banano Gros Michel y también explora la respuesta a la enfermedad en Cavendish de acuerdo con el manejo del suelo. En dos complementarios experimentos en invernadero con un tipo de suelo en cada uno, el pH fue manejado para alcanzar dos niveles (menor que 5.2 e igual o mayor que 6.0). El primer experimento en Costa Rica (Gros Michel y Foc Raza 1) y el segundo en los Países Bajos (Cavendish y Foc R4T y Foc Raza 1) mostraron que un pH menor de 5.2 aceleró los síntomas de la enfermedad, expresados como una menor biomasa de la planta. Adicionalmente, se encontró que el pH bajo causó síntomas de la enfermedad en el Cavendish, aun cuando Cavendish es resistente a esta cepa de Foc (Experimento 2). Esto además indica que las propiedades del suelo evaluadas tienen un potencial considerable para modular la marchitez por Fusarium no solo en el banano Gros Michel, sino que también en el banano Cavendish. 
Estos resultados fueron confirmados en otro experimento de invernadero (Capítulo 4), usando 8 tipos de suelo representativos de Costa Rica usualmente cultivados y aplicando los mismos tratamientos. El modelo utilizado fue el Gros Michel y el Foc Raza 1. También, el tipo de suelo fue relevante en este caso, dado que tuvo un papel en la expresión de la enfermedad. Aun cuando el pH bajo fue vinculado con una mayor marchitez y una menor producción de biomasa, cada suelo presentó un comportamiento diferencial. Esto resalta el hecho que no es apropiado brindar recomendaciones generales basadas en manejo del suelo para controlar enfermedades en los cultivos. En cambio, cada suelo debe considerarse como un paquete específico de condiciones que naturalmente modulará el comportamiento del cultivo contra las enfermedades basado en el estado de sus propiedades.

Los principales resultados encontrados en las fases de invernadero fueron trasladados en parcelas experimentales en el campo (Capitulo 5). En dos regiones agroecológicas en Costa Rica, durante cuatro ciclos de cultivo, las propiedades del suelo estudiadas, todas ellas importantes en la producción del cultivo $(\mathrm{pH}, \mathrm{N}, \mathrm{Ca}+\mathrm{Mg} \mathrm{y} \mathrm{Mn})$, y sus interacciones fueron encontradas influenciando la respuesta del banano Gros Michel al Foc Raza 1. Un pH alto redujo la incidencia de la enfermedad y sus interacciones con el resto de las propiedades del suelo modularon la expresión de la enfermedad y la producción del cultivo. Adicionalmente, se encontró que el tiempo juega un papel crucial en triangulo de la enfermedad: La mayor incidencia de la marchitez apareció después del segundo ciclo evaluado. Esto puede abrir la posibilidad de establecer ciclos de cultivo, implementando manejo del suelo para controlar la enfermedad, pero por periodos específicos de tiempo antes que sea requerido renovar las plantaciones dependiendo en la presión de la enfermedad.

Para validar estos resultados preliminares, un experimento de invernadero fue realizado junto con una encuesta en diferentes plantaciones de una región con predominancia en la producción del banano Gros Michel con presencia de Foc Raza 1 en el suelo (Capítulo 6). El experimento de invernadero incluyó dos suelos representativos y se aplicaron los mismos tratamientos usado en las fases previas. Para la encuesta, 49 sitios fueron visitados. Las plantaciones fueron clasificadas de acuerdo con la agresividad de los síntomas de la enfermedad. El experimento de invernadero verificó el efecto del $\mathrm{pH}$ y de sus interacciones con el $\mathrm{N}$ en la incidencia de la enfermedad, manteniendo un comportamiento diferente de acuerdo con el tipo de suelo. Los análisis de las muestras de suelo mostraron que áreas con una mayor infestación 
tuvieron una mayor acidez del suelo, $\mathrm{Ca}$ y $\mathrm{Mg}$. Un alto contenido de materia orgánica del suelo (MOS) fue relacionada con una menor incidencia de la enfermedad. Además, factores ambientales también pueden influir en la expresión de la marchitez por Fusarium en banano. La predisposición del cultivo a las enfermedades basada en las condiciones del suelo es compleja, y las condiciones ambientales en cada región pueden también interactuar con el suelo y sus propiedades para determinar la incidencia de enfermedades en los cultivos.

En general los resultados mostraron que propiedades específicas del suelo pueden influenciar la expresión de la marchitez por Fusarium en banano. Aunque el manejo de las enfermedades de los cultivos a través del manejo del suelo es posible, esto es complejo. Aspectos como el tipo del suelo y las condiciones ambientales influyen en la expresión de la enfermedad, la predisposición del cultivo o ambas. El enfoque de estudio sistemático (revisión de la literatura, experimentos de invernadero, experimentos de campo) nos permitió desentrañar la complejidad de la interacción entre el suelo, Foc y el banano. Aunque no existe una "bala de plata" o solución milagrosa para resolver el problema de las enfermedades de los cultivos, especialmente el Foc en el banano, el manejo del suelo surge como una opción compleja pero real para ser incluida en el paquete de control de enfermedades (Capítulo 7). Esto es particularmente relevante debido a la creciente necesidad de implementar métodos de manejo alternativos que permitan cultivos más eco- amigables. Esto sería factible siempre que se consideren las condiciones particulares del suelo y las posibles implicaciones ecológicas antes de implementar prácticas de manejo del suelo, como se ha demostrado en el caso de la Marchitez por Fusarium en banano. 


\section{References}

Acuña O, Peña W, Serrano E, et al (2006) La importancia de los microorganismos en la calidad y salud de los suelos. In: Soprano E, Adami F, Lichtemberg L, Silva M (eds). Joinville, Brasil, pp 222-233

Allmaras R (2003) Impaired internal drainage and Aphanomyces euteiches root rot of pea caused by soil compaction in a fine-textured soil. Soil Tillage Res 70:41-52. https://doi.org/10.1016/S0167-1987(02)00117-4

Almeida NO, Teixeira RA, Carneiro FA, et al (2018) Occurrence and correlations of nematodes, Fusarium oxysporum and edaphic factors on banana plantations. J Phytopathol 166:265272. https://doi.org/10.1111/jph.12683

Alvares CE, García V, Robles J, Díaz A (1981) Influence des caractéristiques du sol sur l'incidence de la Maladie de Panama. Fruits 36:71-81

Amir H, Alabouvette C (1993) Involvement of soil abiotic factors in the mechanisms of soil suppressiveness to Fusarium wilts. Soil Biol Biochem 25:157-164

Amtmann A, Troufflard S, Armengaud P (2008) The effect of potassium nutrition on pest and disease resistance in plants. Physiol Plant 133:682-691. https://doi.org/10.1111/j.13993054.2008.01075.x

Araya M, Blanco F (2001) Changes in the Stratification and Spatial Distribution of the Banana ( $<\mathrm{i}>$ musa $<$ II $>$ AAA cv. Grand Naine) Root System of Poor, Regular, and Good Developed Plants. J Plant Nutr 24:1679-1693. https://doi.org/10.1081/PLN-100107306

Arias F, Alvarado A, Mata R, et al (2010a) Clay mineralogy and soil fertility of banana plantation alluvial soils at Costa Rica's Caribbean lowlands. Agron Costarric $32: 223-236$

Arias F, Mata R, Alvarado A, et al (2010b) Chemical properties and classifica-tion of soils cultivated with banana in the Caribbean lowlands of Costa Rica. Agron Costarric 32:177-195

Atim M, Beed F, Tusiime G, et al (2013) High Potassium, Calcium, and Nitrogen Application Reduce Susceptibility to Banana Xanthomonas Wilt Caused by Xanthomonas campestris pv. musacearum. Plant Dis 97:123-130. https://doi.org/10.1094/PDIS-07-12-0646-RE

Aurore G, Parfait B, Fahrasmane L (2009) Bananas, raw materials for making processed food products. Trends Food Sci Technol 20:78-91. https://doi.org/10.1016/j.tifs.2008.10.003

Batista E, de Brito E, Henrique C, et al (2008) Influência de fatores químicos do solo sobre a incidência do mal-do-Panamá na bananeira cv. pacovan na Paraíba. Rev Biol E Ciênc Terra 8:100-109 
Bélanger RR, Benhamou N, Menzies JG (2003) Cytological evidence of an active role of silicon in wheat resistance to powdery mildew (Blumeria graminis f. sp. tritici). Phytopathology 93:402-412

Bertsch F (1998) La Fertilidad de los Suelos y su Manejo. Asociación Costarricense de la Ciencia del Suelo, San Jose, Costa Rica

Bhatti MA (1992) Influence of soil bulk density on root tot and wilt of chickpea. Plant Dis 76:960 963

Borges A, Trujillo JDC I, Gutierrez F, Angulo D (1983) Estudio sonre el Mal de Panamá en las Islas Canarias. II.- Influencia de los mecanismos de resistencia de la plantera (Cavendish enana) al Mal de Panamá. Fruits 38:755-758

Bottomley PS, Angle JS, Weaver RW (1994) Methods of Soil Analysis. Part 2. Chemical and Microbiological Properties

Bouwmeester H, Heuvelink GBM, Stoorvogel JJ (2016) Mapping crop diseases using survey data: The case of bacterial wilt in bananas in the East African highlands. Eur J Agron 74:173184. https://doi.org/10.1016/j.eja.2015.12.013

Bowen A, Orr R, McBeath AV, et al (2019) Suppressiveness or conduciveness to Fusarium wilt of bananas differs between key Australian soils. Soil Res 57:158. https://doi.org/10.1071/SR18159

Brake VM, Pegg KG, Irwin JAG, Chaseling J (1995) The influence of temperature, inoculum level and race of Fusarium oxysporum $\mathrm{f}$. sp. cubense on the disease reaction of banana $\mathrm{cv}$. Cavendish. Crop Pasture Sci 46:673-685

Brennan RF (1992) The role of manganese and nitrogen nutrition in the susceptibility of wheat plants to take-all in Western Australia. Fertil Res 31:35-41

Brock TD, Madigan MT (1991) Biology of microorganisms. Prentice Hall Internat, London

Buddenhagen I (2009) Understanding strain diversity in Fusarium oxysporum f. Sp. Cubense and history of introduction of "Tropical race 4" to better manage banana production. Acta Hortic 193-204. https://doi.org/10.17660/ActaHortic.2009.828.19

Butler D (2013) Fungus threatens top banana. Nature 504:195-196. https://doi.org/10.1038/504195a

Cabrera J, Galán V (2005) Evaluation of the banana cultivars Zelig, Grande Naine and Gruesa under different environmental conditions in the Canary Islands. Fruits 60:357-369. https://doi.org/10.1051/fruits:2005041

Campanella V, Ippolito A, Nigro F (2002) Activity of calcium salts in controlling Phytophthora root rot of citrus. Crop Prot 21:751-756 
Chaperon S, Sauvé S (2007) Toxicity interaction of metals $(\mathrm{Ag}, \mathrm{Cu}, \mathrm{Hg}, \mathrm{Zn})$ to urease and dehydrogenase activities in soils. Soil Biol Biochem 39:2329-2338. https://doi.org/10.1016/j.soilbio.2007.04.004

Chaves N (2019) Epidemiología y manejo del mal de Panamá (Fusarium oxysporum F.SP. Cubense) y Radopholus similis en banano "Gros Michel" (AAA) en cafetales bajo sombra en Turrialba, Costa Rica. UNiversidad de Costa Rica, San Jose, Costa Rica

Chaves N, Schilly A, Salcedo AI, Staver C (2015) Marchitez por Fusarium en Costa Rica, resultados de investigación. Santa Catarina, Brasil

Chérif M, Benhamou N, Menzies JG, Bélanger RR (1992) Silicon induced resistance in cucumber plants against $<\mathrm{i}>$ Pythium ultimum $</ \mathrm{i}>$. Physiol Mol Plant Pathol 41:411-425

Ciamporova M (2002) Morphological and Structural Responses of Plant Roots to Aluminium at Organ, Tissue, and Cellular Levels. Biol Plant 45:161-171. https://doi.org/10.1023/A:1015159601881

Conway KE (1996) An overview of the influence of sustainable agricultural systems on plant diseases. Crop Prot 15:223-228

Dale J, Paul J-Y, Dugdale B, Harding R (2017) Modifying Bananas: From Transgenics to Organics? Sustainability 9:333-346. https://doi.org/10.3390/su9030333

Datnoff LE, Elmer WH, Huber DM (2007) Mineral nutrition and plant disease. American Phytopathological Society, St. Paul, Minn

Delhaize E, Ryan PR (1995) Aluminum Toxicity and Tolerance in Plants. Plant Physiol 107:315321. https://doi.org/10.1104/pp.107.2.315

Deltour P, C. França S, Liparini Pereira O, et al (2017) Disease suppressiveness to Fusarium wilt of banana in an agroforestry system: Influence of soil characteristics and plant community. Agric Ecosyst Environ 239:173-181. https://doi.org/10.1016/j.agee.2017.01.018

Delvaux B, Rufyikiri G, Dufy J (2005) Ion absorption and proton extrusion by banana roots. In: Turner D, Rosales F (eds). San Jose, Costa Rica, pp 114-121

Díaz-Romeu R, Hunter A (1978) Metodología de Muestreo de Suelos, Análisis Químico de Suelos y Tejido Vegetal y de Investigación en Invernadero. CATIE. Turrialbal, Costa Rica

Dijkshoorn JA, Hunting JRM, Tempel P (2005) Update of the 1:5 million Soil and Terrain Database for Latin America and the Caribbean (SOTERLAC; version 2.0). ISRIC - World Soil Information, Wageningen, The Netherlands

Dita M, Barquero M, Heck D, et al (2018) Fusarium Wilt of Banana: Current Knowledge on Epidemiology and Research Needs Toward Sustainable Disease Management. Front Plant Sci 9:1468. https://doi.org/10.3389/fpls.2018.01468 
Dita MA, Garming H, Van den Bergh I, et al (2013) Banana in Latin America And The Caribbean: Current State, Challenges and Perspectives. Acta Hortic 365-380. https://doi.org/10.17660/ActaHortic.2013.986.39

Dita MA, Waalwijk C, Buddenhagen IW, et al (2010) A molecular diagnostic for tropical race 4 of the banana fusarium wilt pathogen. Plant Pathol 59:348-357. https://doi.org/10.1111/j.1365-3059.2009.02221.x

Domínguez J, Negrín MA, Rodríguez CM (2008) Soil Potassium Indices and Clay-Sized Particles affecting Banana-Wilt Expression Caused by Soil Fungus in Banana Plantation Development on Transported Volcanic Soils. Commun Soil Sci Plant Anal 39:397-412. https://doi.org/10.1080/00103620701826522

Domínguez J, Negrín MA, Rodríguez CM (2001) Aggregate water-stability, particle-size and soil solution properties in conducive and suppressive soils to Fusarium wilt of banana from Canary Islands (Spain). Soil Biol Biochem 33:449-455. https://doi.org/10.1016/S00380717(00)00184-X

Doran JW, Sarrantonio M, Liebig MA (1996) Soil Health and Sustainability. In: Advances in Agronomy. Elsevier, pp 1-54

Doran JW, Zeiss MR (2000) Soil health and sustainability: managing the biotic component of soil quality. Appl Soil Ecol 15:3-11. https://doi.org/10.1016/S0929-1393(00)00067-6

Dordas C (2008) Role of nutrients in controlling plant diseases in sustainable agriculture. A review. Agron Sustain Dev 28:33-46. https://doi.org/10.1051/agro:2007051

Duffy BK, Ownley BH, Weller DM (1997) Soil chemical and physical properties associated with suppression of take-all of wheat by Trichoderma koningii. Phytopathology 87:1118-1124

Durieux RP, Bartlett RJ, Magdoff FR (1995) Separate mechanisms of aluminium toxicity for nitrate uptake and root elongation. Plant Soil 172:229-234. https://doi.org/10.1007/BF00011325

Eckstein K, Fraser C, Husselmann J, Hobson EM (2000) The evaluation of promising new banana cultivars and selections in Southern Africa. Acta Hortic 191-198. https://doi.org/10.17660/ActaHortic.2000.531.29

Ecobichon DJ (2001) Pesticide use in developing countries. Toxicology 160:27-33. https://doi.org/10.1016/S0300-483X(00)00452-2

Elementar Analysensysteme GmbH (2011) Vario macro cube elemental analyzer condensed manual

Escobedo A (2010) Cadena productiva de banano criollo ('Gros Michel') de Costa Rica 
Fassbender HW, Bornemisza E (1987) Química de suelos con énfasis en suelos de América Latina, 2nd. rev. and enl. Instituto Interamericano de Cooperación para la Agricultura, San José, Costa Rica

Fernandez-Falcon M, Fox RL, Trujillo EE (1984) Interactions of soil pH, nutrients and moisture on phytophthora root rot of avocado. Plant Soil 81:165-176. https://doi.org/10.1007/BF02197148

Fick SE, Hijmans RJ (2017) WorldClim 2: new 1-km spatial resolution climate surfaces for global land areas. Int J Climatol 37:4302-4315. https://doi.org/10.1002/joc.5086

Flores H (1999) "Radicle" biochemistry: the biology of root-specific metabolism. Trends Plant Sci 4:220-226. https://doi.org/10.1016/S1360-1385(99)01411-9

Fortunato AA, Rodrigues FÁ, Baroni JCP, et al (2012) Silicon Suppresses Fusarium Wilt Development in Banana Plants. J Phytopathol 160:674-679. https://doi.org/10.1111/jph.12005

Francl LJ (2001) The..Disease Triangle: A Plant Pathological Paradigm Revisited. Plant Health Instr. https://doi.org/10.1094/PHI-T-2001-0517-01

García-Bastidas F, Laghari HB, Akkary MY, et al (2016) First Report of Fusarium oxysporum f. sp. cubense Tropical Race 4 Causing Panama Disease in Cavendish Bananas in Pakistan and Lebanon. Plant Dis 100:209. https://doi.org/10.1094/PDIS-12-14-1356-PDN

García-Bastidas FA, Ordóñez N, Konkol J, et al (2014) First Report of Fusarium oxysporum f. sp. cubense Tropical Race 4 Associated with Panama Disease of Banana outside Southeast Asia. Plant Dis 98:694-694. https://doi.org/10.1094/PDIS-09-13-0954-PDN

García-Bastidas FA, Quintero-Vargas JC, Ayala-Vasquez M, et al (2020) First Report of Fusarium Wilt Tropical Race 4 in Cavendish Bananas Caused by Fusarium odoratissimum in Colombia. Plant Dis 104:994-994. https://doi.org/10.1094/PDIS-09-19-1922-PDN

Geense P, Pattison AB, Kukulies TL, et al (2015) Can Changes in Soil Properties in Organic Banana Production Suppress Fusarium Wilt? Nat Resour 06:181-195. https://doi.org/10.4236/nr.2015.63017

Ghorbani R, Wilcockson S, Koocheki A, Leifert C (2008) Soil management for sustainable crop disease control: a review. Environ Chem Lett 6:149-162. https://doi.org/10.1007/s10311008-0147-0

Gibson DavidJ, Connolly J, Hartnett DavidC, Weidenhamer JeffreyD (1999) Designs for greenhouse studies of interactions between plants. $J$ Ecol 87:1-16. https://doi.org/10.1046/j.1365-2745.1999.00321.x

Gilroy S, Jones DL (2000) Through form to function: root hair development and nutrient uptake. Trends Plant Sci 5:56-60. https://doi.org/10.1016/S1360-1385(99)01551-4 
Goto K (1985) Relationships Between Soil pH, Available Calcium and Prevalence of Potato Scab. Soil Sci Plant Nutr 31:411-418. https://doi.org/10.1080/00380768.1985.10557448

Guillén C, Tixier P, Tapia Fernández A, et al (2021) Can the banana weevil Cosmopolites sordidus be a vector of Fusarium oxysporum f.sp. cubense race 1? Unravelling the internal and external acquisition of effective inoculum. Pest Manag Sci ps.6339. https://doi.org/10.1002/ps.6339

Haddad F, Rocha LS, Soares ACF, et al (2018) Management of Fusarium wilt of bananas in Minas Gerais, Brazil. Acta Hortic 137-146. https://doi.org/10.17660/ActaHortic.2018.1196.16

Harper JL (1950) Studies in the resistance of certain varieties of banana to panama disease. Plant Soil 2:383-394. https://doi.org/10.1007/BF01343358

Harrison UJ, Shew HD (2001) Effects of soil $\mathrm{pH}$ and nitrogen fertility on the population dynamics of Thielaviopsis basicola. Plant Soil 228:147-155

Hawes MC, Gunawardena U, Miyasaka S, Zhao X (2000) The role of root border cells in plant defense. Trends Plant Sci 5:128-133. https://doi.org/10.1016/S1360-1385(00)01556-9

Heyman F, Lindahl B, Persson L, et al (2007) Calcium concentrations of soil affect suppressiveness against Aphanomyces root rot of pea. Soil Biol Biochem 39:2222-2229. https://doi.org/10.1016/j.soilbio.2007.03.022

Hinsinger P, Plassard C, Jaillard B (2006) Rhizosphere: A new frontier for soil biogeochemistry. J Geochem Explor 88:210-213. https://doi.org/10.1016/j.gexplo.2005.08.041

Hoffland E, Jeger MJ, van Beusichem ML (2000) Effect of nitrogen supply rate on disease resistance in tomato depends on the pathogen. Plant Soil 218:239-247

Hoffland E, van Beusichem ML, Jeger MJ (1999) Nitrogen availability and susceptibility of tomato leaves to Botrytis cinerea. Plant Soil 210:263-272. https://doi.org/doi:10.1023/A:1004661913224

Højsgaard S, Yan J (2006) The $R$ Package geepack for Generalized Estimating Equations. J Stat Softw 15:. https://doi.org/10.18637/jss.v015.102

Holdridge RL (1987) Ecología basada en zonas de vida. Instituto Interamericano de Cooperación para la Agricultura

Höper H, Alabouvette C (1996) Importance of Physical and chemical properties in the suppressiveness of soils to plant diseases. Eur J Soil Biol 32:41-58

Höper H, Steinberg C, Alabouvette C (1995) Involvement of clay type and pH in the mechanisms of soil suppressiveness to fusarium wilt of flax. Soil Biol Biochem 27:955-967. https://doi.org/10.1016/0038-0717(94)00238-V 
Huang C-H, Roberts PD, Datnoff LE (2011) Silicon Suppresses Fusarium Crown and Root Rot of Tomato: Silicon Suppresses Fusarium Crown and Root Rot of Tomato. J Phytopathol 159:546-554. https://doi.org/10.1111/j.1439-0434.2011.01803.x

Huber D, Römheld V, Weinmann M (2012) Relationship between Nutrition, Plant Diseases and Pests. In: Marschner's Mineral Nutrition of Higher Plants. Elsevier, pp 283-298

Huber DM, Graham DR (1999) The role of nutrition in crop resistance and tolerance to disease. In: Mineral nutrition of crops fundamental mechanisms and implications. Food Product Press, pp 205-226

Huber DM, Haneklaus S (2007) Managing nutrition to control plant disease. Landbauforsch Volkenrode 57:313-322

Huber DM, Jones JB (2012) The role of magnesium in plant disease. Plant Soil 368:73-85. https://doi.org/10.1007/s11104-012-1476-0

Huber DM, Watson R (1974) Nitrogen form and plant disease. Annu Rev Phytopathol 12:139165

Hung TN, Hung NQ, Mostert D, et al (2018) First Report of Fusarium Wilt on Cavendish Bananas, Caused by Fusarium oxysporum f. sp. cubense Tropical Race 4 (VCG 01213/16), in Vietnam. Plant Dis 102:448-448. https://doi.org/10.1094/PDIS-08-17-1140-PDN

Hwang S-C, Ko W-H (2004) Cavendish Banana Cultivars Resistant to Fusarium Wilt Acquired through Somaclonal Variation in Taiwan. Plant Dis 88:580-588. https://doi.org/10.1094/PDIS.2004.88.6.580

Illes P, Schlicht M, Pavlovkin J, et al (2006) Aluminium toxicity in plants: internalization of aluminium into cells of the transition zone in Arabidopsis root apices related to changes in plasma membrane potential, endosomal behaviour, and nitric oxide production. J Exp Bot 57:4201-4213. https://doi.org/10.1093/jxb/erl197

Janvier C, Villeneuve F, Alabouvette C, et al (2007) Soil health through soil disease suppression: Which strategy from descriptors to indicators? Soil Biol Biochem 39:1-23. https://doi.org/10.1016/j.soilbio.2006.07.001

Jaramillo R, Vásquez A (1990) Manual de procedimiento para la presentación de estudios detallados de suelos y clasificación de tierras para el cultivo de banano

Joner EJ, Eldhuset TD, Lange H, Frostegård A (2005) Changes in the microbial community in a forest soil amended with aluminium in situ. Plant Soil 275:295-304. https://doi.org/10.1007/s11104-005-2287-3

Jones CF, Morrison PC (1952) Evolution of the Banana Industry of Costa Rica. Econ Geogr 28:119

Jones JB (2012) Plant nutrition and soil fertility manual, 2nd ed. CRC Press, Boca Raton 
Juroszek P, von Tiedemann A (2015) Linking Plant Disease Models to Climate Change Scenarios to Project Future Risks of Crop Diseases: A Review. J Plant Dis Prot 122:3-15. https://doi.org/10.1007/BF03356525

Kandeler F, Kampichler C, Horak O (1996) Influence of heavy metals on the functional diversity of soil microbial communities. Biol Fertil Soils 23:299-306

Karlen DL, Ditzler CA, Andrews SS (2003) Soil quality: why and how? Geoderma 114:145-156. https://doi.org/10.1016/S0016-7061(03)00039-9

Kass DHL, Jimenez M, Kauffman JH, Herrera-Reyes C (1995) Costa Rica: Reference soils of the Turrialba valley and slopes of the Irazú volcano. Soil Brief Costa Rica 2. CATIE-ISRIC, Wageningen, The Netherlands

Kim SG, Kim KW, Park EW, Choi D (2002) Silicon-Induced Cell Wall Fortification of Rice Leaves: A Possible Cellular Mechanism of Enhanced Host Resistance to Blast. Phytopathology 92:1095-1103. https://doi.org/10.1094/PHYTO.2002.92.10.1095

Klikocka H, Haneklaus S, Bloem E, Schnug E (2005) Influence of Sulfur Fertilization on Infection of Potato Tubers with Rhizoctonia solani and Streptomyces scabies. J Plant Nutr 28:819833. https://doi.org/10.1081/PLN-200055547

Klinkert S (2014) A Mechanistic approach to soil variability at different scale levels: A case study for the Atlantic Zone of Costa Rica. Wageningen UR, The Netherlands

Kochian LV, Piñeros MA, Hoekenga OA (2005) The Physiology, Genetics and Molecular Biology of Plant Aluminum Resistance and Toxicity. Plant Soil 274:175-195. https://doi.org/10.1007/s11104-004-1158-7

Lacey MJ, Wilson CR (2001) Relationship of common scab incidence of potatoes grown in Tasmanian ferrosol soils with $\mathrm{pH}$, exchangeable cations and other chemical properties of those soils. Jorunal Phytopatology 149:679-683

Lambert DH, Powelson ML, Stevenson WR (2005) Nutritional interactions influencing diseases of potato. Am J Potato Res 82:309-319. https://doi.org/10.1007/BF02871961

Lambert J (2019) Alarm as devastating banana fungus reaches the Americas. Nature d41586-01902489-5. https://doi.org/10.1038/d41586-019-02489-5

Leitch MH, Jenkins PD (1995) Influence of nitrogen on the development of Septoria epidemics in winter wheat. J Agric Sci 124:361. https://doi.org/10.1017/S0021859600073329

Lemes EM, Mackowiak CL, Blount A, et al (2011) Effects of Silicon Applications on Soybean Rust Development Under Greenhouse and Field Conditions. Plant Dis 95:317-324. https://doi.org/10.1094/PDIS-07-10-0500

Lopez A, Espinosa J (eds) (2000) Manual on Nutrition and Fertilization of Banana, National Banana Corporation and Potash and Phosphate Institure. INPOFOS, Quito, Ecuador 
Lopez A, Solís P (1991) Contenidos e interacciones de los nutrimentos en tres zonas bananeras de Costa Rica. CORBANA 15:15-25

Ma JF, Ryan PR, Delhaize E (2001) Aluminium tolerance in plants and the complexing role of organic acids. Trends Plant Sci 6:273-278. https://doi.org/10.1016/S1360-1385(01)019616

Manlay RJ, Feller C, Swift MJ (2007) Historical evolution of soil organic matter concepts and their relationships with the fertility and sustainability of cropping systems. Agric Ecosyst Environ 119:217-233. https://doi.org/10.1016/j.agee.2006.07.011

Marschner H (2012) Mineral nutrition of higher plants. Elsevier

Marschner H (2008) Mineral nutrition of higher plants, 2. ed., [9. Repr.]. Acad. Press, Amsterdam

Matsumoto H, Yamamoto Y (2002) Plant Roots under Aluminum Stress: Toxicity and Tolerance. In: Weisler Y, Eshel A, Kafkafi U (eds) Plant Roots: the hidden half, 3rd edn. Marcel Dekker, New York, pp 821-838

Mazzola M (2002) Mechanisms of natural soil suppressiveness to soilborne diseases. Antonie Van Leeuwenhoek 81:557-564

McCully M (1995) How Do Real Roots Work? (Some New Views of Root Structure). Plant Physiol 109:1-6. https://doi.org/10.1104/pp.109.1.1

McKinney RH (1923) Influence of soil temperature and moisture on infection of wheat seedlings by Helminthosporium sativum. J Ag Res 6:195-218

Mehlich A (1984) Mehlich 3 soil test extractant: A modification of Mehlich 2 extractant. Commun Soil Sci Plant Anal 15:1409-1416. https://doi.org/10.1080/00103628409367568

Miller JS, Rosen CJ (2005) Interactive effects of fungicide programs and nitrogen management on potato yield and quality. Am J Potato Res 82:399-409. https://doi.org/10.1007/BF02871970

Molina AB, Fabregar EG, Sinohin V, et al (2008) Tropical Race 4 of Fusarium oxysporum f.sp. cubense causing new Panama wilt epidemics in Cavendish varieties in the Philippines. Phytopathology 98:S 108

Nam MH, Jeong SK, Lee YS, et al (2006) Effects of nitrogen, phosphorus, potassium and calcium nutrition on strawberry anthracnose. Plant Pathol 55:246-249. https://doi.org/10.1111/j.1365-3059.2006.01322.x

Nardi S, Concheri G, Pizzeghello D, et al (2000) Soil organic matter mobilization by root exudates. Chemosphere 41:653-658. https://doi.org/10.1016/S0045-6535(99)00488-9

NASA/METI/AIST/Japan Spacesystems And U.S./Japan ASTER Science Team (2009) ASTER Global Digital Elevation Model 
Neumann G, Römheld V (2012) Rhizosphere Chemistry in Relation to Plant Nutrition. In: Marschner's Mineral Nutrition of Higher Plants. Elsevier, pp 347-368

Oerke E-C (2005) Crop losses to pests. J Agric Sci 144:31. https://doi.org/10.1017/S0021859605005708

Oerke E-C, Dehne H-W (2004) Safeguarding production-losses in major crops and the role of crop protection. Crop Prot 23:275-285. https://doi.org/10.1016/j.cropro.2003.10.001

Olesen JE, JøRgensen LN, Petersen J, Mortensen JV (2003) Effects of rate and timing of nitrogen fertilizer on disease control by fungicides in winter wheat. 1. Grain yield and foliar disease control. J Agric Sci 140:1-13. https://doi.org/10.1017/S0021859602002885

Ollagnier M (1976) Effect of potassium on the resistance of oil palm to Fusarium disease. Oleagineux 31:203-208

Orcutt DM, Nilsen ET (2000) The physiology of plants under stress. Wiley, New York

Ordoñez N, García-Bastidas F, Laghari HB, et al (2016) First Report of Fusarium oxysporum f. sp. cubense Tropical Race 4 Causing Panama Disease in Cavendish Bananas in Pakistan and Lebanon. Plant Dis 100:209. https://doi.org/10.1094/PDIS-12-14-1356-PDN

Ordoñez N, Seidl MF, Waalwijk C, et al (2015) Worse Comes to Worst: Bananas and Panama Disease-When Plant and Pathogen Clones Meet. PLOS Pathog 11:e1005197. https://doi.org/10.1371/journal.ppat.1005197

Oritsejafor JJ (1986) Influence of moisture and $\mathrm{pH}$ on growth and survival of Fusarium oxysporum f.sp. elaeidis in soil. Trans Br Mycol Soc 87:511-517. https://doi.org/10.1016/S00071536(86)80091-2

Orr R, Nelson PN (2018) Impacts of soil abiotic attributes on Fusarium wilt, focusing on bananas. Appl Soil Ecol 132:20-33. https://doi.org/10.1016/j.apsoil.2018.06.019

Oyarzun PJ, Gerlagh M, Zadoks JC (1998) Factors associated with soil receptivity to some fungal root rot pathogens of peas. Appl Soil Ecol 10:151-169. https://doi.org/10.1016/S09291393(98)00042-0

Pattison AB, Moody PW, Badcock KA, et al (2008) Development of key soil health indicators for the Australian banana industry. Appl Soil Ecol 40:155-164. https://doi.org/10.1016/j.apsoil.2008.04.002

Pattison T, Lindsay SJ (2006) Banana Root and Soil Health User's Manual. Department of Primary Industries and Fisheries, Brisbane, Australia

Peng HX, Sivasithamparam K, Turner DW (1999) Chlamydospore germination and Fusarium wilt of banana plantlets in suppressive and conducive soils are affected by physical and chemical factors. Soil Biol Biochem 31:1363-1374 
Perez-Vicente L (2004) Fusarium wilt (Panama disease) of bananas: an updating review of the current knowledge on the disease and its causal agent. Fitosanidad 8:27-38

Persson L, Olsson S (2000) Abiotic characteristics of soils suppressive to Aphanomyces root rot. Soil Biol Biochem 32:1141-1150

Pinstrup-Andersen P (2000) The future world food situation and the role of plant diseases. Can J Plant Pathol 22:321-331. https://doi.org/10.1080/07060660009500451

Ploetz RC (1990) Vegetative compatibility in Fusarium Oxysporum f.sp.cubense: Classifying previosly noncharacterized strains. Acta Hortic 699-706

Ploetz RC (2015a) Fusarium Wilt of Banana. Phytopathology 105:1512-1521. https://doi.org/10.1094/PHYTO-04-15-0101-RVW

Ploetz RC (2006) Fusarium Wilt of Banana Is Caused by Several Pathogens Referred to as Fusarium oxysporum f. sp. cubense. Phytopathology 96:653-656. https://doi.org/10.1094/PHYTO-96-0653

Ploetz RC (2015b) Management of Fusarium wilt of banana: A review with special reference to tropical race 4. Crop Prot 73:7-15. https://doi.org/10.1016/j.cropro.2015.01.007

Ploetz RC, Churchill CL (2011) Fusarium Wilt: the Banana Disease that Refuses to Go Away. Acta Hortic 897:519-526

Pocasangre LE, Perez-Vicente L, Ferris H (2017) Organic Banana Disease Management. In: Plant Diseases and Their Management in Organic Agriculture. The American Phytopathological Society, pp 354-365

Pocasangre LE, Ploetz RC, Molina AB, et al (2011) Raising Awareness of the Threat of Fusarium Wilt Tropical Race 4 in Latin America and the Caribbean. Acta Hortic 897:331-337. https://doi.org/10.17660/ActaHortic.2011.897.45

Popp J, Pető K, Nagy J (2013) Pesticide productivity and food security. A review. Agron Sustain Dev 33:243-255. https://doi.org/10.1007/s13593-012-0105-x

Portugal V, Aguilera L (1998) Microorganismo y biodiversidad. Terra 16:289-292

Poveda L (2013) Evaluación de tratamientos biológicos y químicos para el combate del mal de Panamá en banano Gros Michel (Musa AAA, cv. Cocos). Turrialba, Costa Rica

R Development Core Team (2010) a language and environment for statistical computing: reference index. R Foundation for Statistical Computing, Vienna

Ramirez C, Tapia A, Calvo P (2010) Quality evaluation of the banana of height produced in the 421 area of Turrialba, Costa Rica. Intersedes XI:

Rengel Z (2000) Mineral nutrition of crops: fundamental mechanisms and implications 
Rengel Z (1996) Uptake of aluminium by plant cells. New Phytol 134:389-406. https://doi.org/10.1111/j.1469-8137.1996.tb04356.x

Reuveni M, Agapov V, Reuveni R (1995) Suppression of cucumber powdery mildew (Sphaerotheca fuliginea) by foliar sprays of pbospbate and potassium salts. Plant Pathol 44:31-39. https://doi.org/10.1111/j.1365-3059.1995.tb02713.x

Rishbeth J (1955) Fusarium Wilt of Bananas in Jamaica. II. Some Aspects of Host-parasite Relationships. Ann Bot NS XXI:215-245

Rivero C, Chirenje T, Ma LQ, Martinez G (2004) Influence of compost on soil organic matter quality under tropical conditions. Geoderma 123:355-361. https://doi.org/10.1016/j.geoderma.2004.03.002

Riveros A, Rosales F, Romero J, et al (2006) Estandarización de enmiendas orgánicas para banano en América Latina y el Caribe. In: Soprano E, Adami F, Lichtemberg L, Silva M (eds). Joinville, Brasil, pp 234-240

Robinson JC, Galán V (2010) Bananas and plantains, 2nd ed. Du Roi Laboratory: Gobierno de Canarias, Instituto Canario de Investigaciones Agrarias : CABI, Wallingford, Oxfordshire, UK ; Cambridge, MA

Rocha A de J, Ferreira M dos S, Rocha L de S, et al (2020) Interaction between Fusarium oxysporum $\mathrm{f}$. sp. cubense and Radopholus similis can lead to changes in the resistance of banana cultivars to Fusarium wilt. Eur J Plant Pathol. https://doi.org/10.1007/s10658-02002081-y

Rodgers-Gray BS, Shaw MW (2000) Substantial reductions in winter wheat diseases caused by addition of straw but not manure to soil. Plant Pathol 49:590-599. https://doi.org/10.1046/j.1365-3059.2000.00497.x

Romero A, Munévar F, Cayón G (2011) Silicon and plant diseases. A review. Agron Colomb 29:473-480

Ronald P (2011) Plant Genetics, Sustainable Agriculture and Global Food Security. Genetics 188:11-20. https://doi.org/10.1534/genetics.111.128553

Rufyikiri G, Genon JG, Dufey JE, Delvaux B (2003) Competitive Adsorption of Hydrogen, Calcium, Potassium, Magnesium, and Aluminum on Banana Roots: Experimental Data and Modeling. J Plant Nutr 26:351-368. https://doi.org/10.1081/PLN-120017141

Russell V, Buerkner P, Herve M, et al (2021) emmeans: Estimated Marginal Means, aka LeastSquares Means

Salacinas M, Kema GHJ, Meijer HJG (2019) Managing Panama disease of banana in the Philippines. Wageningen, The Netherlands 
Sandoval JA, Guzmán JA, Gonzálex M, Segura RA (2015) Impacto de Eventos Climáticos Extremos Sobre la Producción de Banano en Costa Rica. Santa Catarina, Brasil

SASInstitute SAS (1999) SAS/STAT User's Guide, Version 8. SAS Institute

Savary S, Ficke A, Aubertot J-N, Hollier C (2012) Crop losses due to diseases and their implications for global food production losses and food security. Food Secur 4:519-537. https://doi.org/10.1007/s12571-012-0200-5

Scher FM (1980) Mechanism of Biological Control in a Fusarium-Suppressive Soil. Phytopathology 70:412. https://doi.org/10.1094/Phyto-70-412

Schoeneweiss DF (1975) Predisposition, stress, and plant disease. Annu Rev Phytopathol 13:193211

Seeley HW, VanDemark PJ, Lee JJ (1991) Microbes in action: A laboratory manual of microbiology, 5th Ed. Freeman, New York

Segura RA, Serrano E, Pocasangre L, et al (2015) Chemical and microbiological interactions between soils and roots in commercial banana plantations (Musa AAA, cv. Cavendish). Sci Hortic 197:66-71. https://doi.org/10.1016/j.scienta.2015.10.028

Segura RA, Stoorvogel JJ, Bosman M, Sandoval JA (2019) Fusarium wilt (Foc race 1) in relation to soil properties in smallholder's farms with 'Gros Michel' banana (Musa AAA) in Costa Rica. CORBANA 45:67-82

Segura-Mena RA, Stoorvogel JJ, García-Bastidas F, et al (2021) Evaluating the potential of soil management to reduce the effect of Fusarium oxysporum $\mathrm{f}$. sp. cubense in banana (Musa AAA). Eur J Plant Pathol 160:441-455. https://doi.org/10.1007/s10658-021-02255-2

Segura RA, Stoorvogel JJ, Samuels JZ, Sandoval JA (2018) Managing the interactions between soil abiotic factors to alleviate the effect of Fusarium wilt in bananas. Acta Hortic 163168. https://doi.org/10.17660/ActaHortic.2018.1196.19

Segura-Mena RA, Stoorvogel JJ, García-Bastidas F, et al (2021) Evaluating the potential of soil management to reduce the effect of Fusarium oxysporum $\mathrm{f}$. sp. cubense in banana (Musa AAA). Eur J Plant Pathol. https://doi.org/10.1007/s10658-021-02255-2

Serrano E (2005) Acidificación inducida por fertilizantes nitrogenados de reacción ácida sobre los suelos bananeros en la Zona Caribe de Costa Rica y su relación con el aumento en los contenidos de aluminio intercambiable. In: Sandoval JA (ed). Guápiles, Costa Rica, p 31

Serrano E, Ortega R, Zúñiga J, et al (2008) Factores físicos, químicos y microbiológicos del suelo que afectan la nutrición del cultivo de banano (Musa AAA): un sistema en proceso de cambio. In: Borja J, Nogales C, Orrantia C, et al. (eds). Guayaquil, Ecuador, p 56 
Serrano E, Sandoval JA, Pocasangre L, et al (2006) Importancia de los indicadores físico químicos en la calidad del suelo para la producción sostenible del banano en Costa Rica. In: Soprano E, Adami F, Lichtemberg L, Silva M (eds). Joinville, Brasil, pp 207-221

Serrano MS, Fernández-Rebollo P, Vita P, Sánchez ME (2012) Calcium mineral nutrition increases the tolerance of Quercus ilex to Phytophthora root disease affecting oak rangeland ecosystems in Spain. Agrofor Syst 87:173-179. https://doi.org/10.1007/s10457012-9533-5

Sharma SR, Kolte SJ (1994) Effect of soil-applied NPK fertilizers on severity of black spot disease (Alternaria brassicae) and yield of oilseed rape. Plant Soil 167:313-320. https://doi.org/10.1007/BF00007958

Shen Z, Ruan Y, Wang B, et al (2015) Effect of biofertilizer for suppressing Fusarium wilt disease of banana as well as enhancing microbial and chemical properties of soil under greenhouse trial. Appl Soil Ecol 93:111-119. https://doi.org/10.1016/j.apsoil.2015.04.013

Singh D, McLaren RG, Cameron KC (2008) Effect of pH on Zinc Sorption-Desorption by Soils. Commun Soil Sci Plant Anal 39:2971-2984. https://doi.org/10.1080/00103620802432873

Singh S, Tripathi DK, Singh S, et al (2017) Toxicity of aluminium on various levels of plant cells and organism: A review. Environ Exp Bot 137:177-193. https://doi.org/10.1016/j.envexpbot.2017.01.005

Smith LJ, Smith MK, Tree D, et al (2008) Development of a small-plant bioassay to assess banana grown from tissue culture for consistent infection by Fusarium oxysporum f. sp. cubense. Australas Plant Pathol 37:171. https://doi.org/10.1071/AP08006

Soil Survey Staff (2014) Keys to Soil Taxonomy, 12th edn. USDA-Natural Resources Conservation Service, Washington, DC

Soto M (2011) Situación y avances tecnologicos en la producción bananera mundial. Rev Bras Frutic 33:13-28. https://doi.org/10.1590/S0100-29452011000500004

Steingrobe B, Claassen N (2000) Potassium dynamics in the rhizosphere and K efficiency of crops. J Plant Nutr Soil Sci 163:101-106. https://doi.org/10.1002/(SICI)15222624(200002)163:1<101::AID-JPLN101>3.0.CO;2-J

Stoorvogel JJ, Segura RA (2018) Nutrition and soil management in banana cultivation. In: Kema GHJ, Drenth A (eds) Burleigh Dodds Series in Agricultural Science. Burleigh Dodds Science Publishing, pp 223-234

Stotzky G, Dawson JE, Martin RT, Ter Kuile CHH (1961) Soil Mineralogy as Factor in Spread of Fusarium Wilt of Banana. Science 133:1483-1485. https://doi.org/10.1126/science.133.3463.1483

Stover RH (1962) Fusarial wilt (panama disease) of bananas and other Musa species. The Common wealth Mycological Institute, Kew Surrey 
Stover RH (1961) Studies on Fusarium Wilt of Bananas. I. Field Control. Can J Bot 39:197-206

Stover RH (1986) Disease management strategies and the survival of the banana industry. Annu Rev Phytopathol 24:83-91

Stover RH (1953) The effect of soil moisture on Fusarium species. Botany 31:693-697. https://doi.org/10.1139/b53-050

Stover RH, Simmonds NW (1987) Bananas. Longman Scientific \& Technical, Harlow

Su H, Hwang S-C, Ko W-H (1986) Fusarial Wilt of Cavendish Bananas in Taiwan. Plant Dis $70: 814-818$

Sugimoto T, Watanabe K, Yoshida S, et al (2007) The Effects of Inorganic Elements on the Reduction of Phytophthora Stem Rot Disease of Soybean, the Growth Rate and Zoospore Release of Phytophthora sojae. J Phytopathol 155:97-107. https://doi.org/10.1111/j.14390434.2007.01196.x

Sun J, Zou L, Li W, et al (2018) Rhizosphere soil properties and banana Fusarium wilt suppression influenced by combined chemical and organic fertilizations. Agric Ecosyst Environ 254:60-68. https://doi.org/10.1016/j.agee.2017.10.010

Tapia A, Vargas M, Brenes S (2009) Evaluación de sistemas orgánicos y tradicionales de banano de altura en Turrialba, Costa Rica. Rev Bras Agroecol 4:464-468

Tate RL (2000) Soil microbiology, 2nd ed. John Wiley, New York

Tiedemann AV (1995) Single and combined effects of nitrogen fertilizations and ozone on fungal leaf diseases on wheat. J Plant Dis Protection 103:409-419

Tripp R, Woolley J (1989) The planning stage of on-farm research: identifying factors for experimentation. CIMMYT ; CIAT, Mexico, D.F. : Cali, Colombia

Uribe L (1999) Uso de indicadores microbiológicos de suelos: ventajas y limitantes. San Jose, Costa Rica, pp 39-46

Walker T S, Bais H P, Grotewold E, Vivanco JM (2003) Root Exudation and Rhizosphere Biology: Fig. 1. Plant Physiol 132:44-51. https://doi.org/10.1104/pp.102.019661

Walters DR, Paul ND, Ayres PG (1984) Effects of Mildew and Nitrogen on Grain Yield of Barley Artifically Infected in the Field. Ann Bot 54:145-148. https://doi.org/10.1093/oxfordjournals.aob.a086768

Weller DM, Raaijmakers JM, Gardener BBM, Thomashow LS (2002) Microbial populations responsible for specific soil suppressiveness to plant pathogens. Annu Rev Phytopathol 40:309-348. https://doi.org/10.1146/annurev.phyto.40.030402.110010 
White PJ (2012) Ion Uptake Mechanisms of Individual Cells and Roots. In: Marschner's Mineral Nutrition of Higher Plants. Elsevier, pp 7-47

Wiese J, Bagy MM, Schubert S (2003) Soil properties, but not plant nutrients (N, P, K) interact with chemically induced resistance against powdery mildew in barley. J Plant Nutr Soil Sci 166:379-384

Wiese J, Kranz T, Schubert S (2004) Induction of Pathogen Resistance in Barley by Abiotic Stress. Plant Biol 6:529-536. https://doi.org/10.1055/s-2004-821176

Yan J (2002) Geepack: Yet another package for generalized estimating equations. R-News 2/3:1214

Yan J, Fine J (2004) Estimating equations for association structures. Stat Med 23:859-874. https://doi.org/10.1002/sim.1650

Zhang M-X, Zhang M-C, Chen P, et al (2013) Influence of nitrate/ammonium ratio on the plant growth of banana and related wilt disease development. J Plant Nutr Fert 19:1241-1247 


\section{PE\&RC Training and Education Statement}

With the training and education activities listed below the PhD candidate has complied with the requirements set by the C.T. de Wit Graduate School for Production Ecology and Resource Conservation (PE\&RC) which comprises of a minimum total of 32 ECTS ( $=22$ weeks of activities)

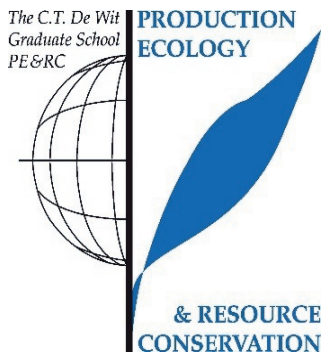

\section{Review of literature (4.5 ECTS)}

Soil management as a strategy for crop disease alleviation: the case of Panama disease in banana (2013)

\section{Writing of project proposal (4.5 ECTS)}

- Islands of susceptible banana germplasm in Panama disease (race 1) infected areas: interactions between abiotic stress and crop vulnerability (2013)

\section{Post-graduate courses (3.8 ECTS)}

Introduction to R; PE\&RC (2013)

- Adoption of agricultural and conservation practices: insight from behavioral theory and the decision making process; WASS (2017)

World soils and their assessment; ISRIC (2017)

- $\quad$ Linear models; PE\&RC / SENSE (2017)

\section{Laboratory training and working visits (0.9 ECTS)}

- United Fruit Co. archives: soils and Fusarium wilt; Library of Honduran Research Foundation (FHIA) (2016)

\section{Invited review of (unpublished) journal manuscript (1 ECTS)}

- Chemical Science International Journal: quality characters and shelf life of banana (Musa spp.) cv. Barjahaji as influenced by bunch feeding (2017)

\section{Deficiency, refresh, brush-up courses (6 ECTS)}

- Inventory techniques for geosciences; SGL group (2013)

\section{Competence strengthening / skills courses (5 ECTS)}

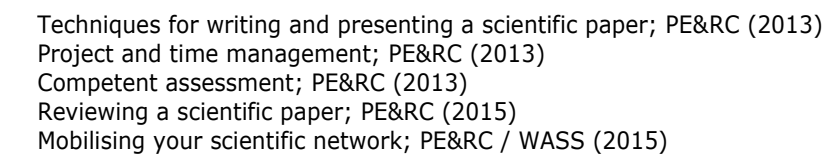

PE\&RC Annual meetings, seminars and the PE\&RC weekend (2.5 ECTS)

PE\&RC Introduction weekend (2013)

PE\&RC Day $(2013,2015)$

Wageningen PhD symposium; oral presentation (2017)

\section{Discussion groups / local seminars / other scientific meetings (5.7 ECTS)}

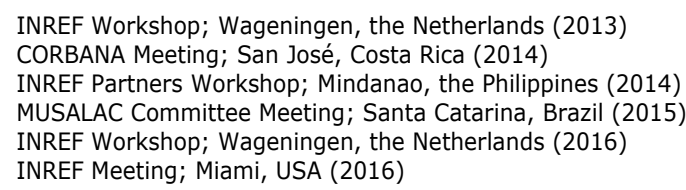


ACCS: Costa Rican Soil Science Meeting; San José, Costa Rica (2017)

\section{International symposia, workshops and conferences (10.4 ECTS)}

- Latin America and the Caribbean Congress about bananas; poster presentation; Santa Catarina, Brazil (2015)

Soil Conference; oral presentation; Wageningen, the Netherlands (2015)

- International Congress about bananas, ACORBAT-CORBANA; oral and poster presentation; Miami, USA (2016)

- $\quad$ PROMUSA- ISHS, International Symposium; oral presentation; Montpelier, France (2016)

- International Congress about bananas CORBANA; oral presentation; Miami, USA (2017)

\section{Supervision of MSc students (9 ECTS)}

\section{Organic matter dynamic in banana soils}

Regional soil conditions according origin

Nutrients dynamics in soils, world banana map 


\section{Acknowledgements}

The author (and his family) wants to express the mayor gratitude to his employer CORBANA in the figures of Mr. Eduardo Gómez B. (Board President), Mr. Romano Orlich C. ( $†$, former Board President), Mr. Jorge A. Sauma A. (General Manager), Mrs. Marjorie Ureña C. (Vice-General Manager) and Mr. Jorge A. Sandoval F. (Research Director, and my Co-promotor) by all the received support.

Since the beginning of my $\mathrm{PhD}$ many persons have been part of this long trip in CORBANA and Wageningen. In CORBANA, my special gratitude goes to Sonia Loria M. for her wise advises and life knowledge, to my workmates and friends Jose Miguel Gonzales Z. and Sonia Jara C., for always being there, and a very special thanks to my work team Roddy, Veda, Juan and Pedro. Fabio Blanco is acknowledged for supporting experimental designs and statistical analysis and Claudiana Carr from the Biological Control Lab for supporting plants inoculation (greenhouse and field at Costa Rica). In Wageningen, my gratitude goes to my colleagues and friends of the Soil Geography and Landscape Group (SGL). Special thanks to Jakob Wallinga (Chair of SGL), to my contemporary PhD colleagues Marcos ("el Che", and his family), Maricke, Chantal, Luc, Femke, Kasia, Cindy, Marijn, Afsaneh, Simona and Jasper, and to Lennart and Claudius from PE\&RC graduate school. I want to thank the good moments to my Latin American community (almost a family) in Wageningen, specially to Sandra (and Ger), Minor (and family), Lillian (and Sjerp), Ricardo (and family), Priscila (and Hans), Lisbeth (and Richard), Shirley (and Sytze), and Clara (my appreciated landlady).

I would like to thank my partners of the banana team (Banana Friends Forever) Fernando, Nadia, Caucasella, Pablo, Nani, Lamia, Amir, Maricar, Fajar, Iman, Rocky (also partner at SGL), Jaye and Malou. Very special thanks to Dr. Gert (Gerardo) Kema for all his support and for inviting me to join the Panama Disease Project. I have special memories from all our meetings, workshops, conferences, and social activities. 
Finally, I would like to thank my Supervisor and Promotor Dr. Jetse Stoorvogel. Afterwards, I am aware that a $\mathrm{PhD}$ program is a journey with a known beginning but with an uncertain way and end. The advices and feedbacks, always in a professional manner and with the sincere intention to improve my scientific performance, really made the difference to achieve the objectives and to complete my $\mathrm{PhD}$ program. Besides for the hospitality with his family when they received me and the $\mathrm{PhD}$ colleagues at their home, great memories!

To all of you iiheel erg bedankt, many thanks, muchas gracias!!

A special acknowledgement goes to Maria Fernanda Sandoval S. for her arts designing the cover of this thesis. 


\section{About the Author}

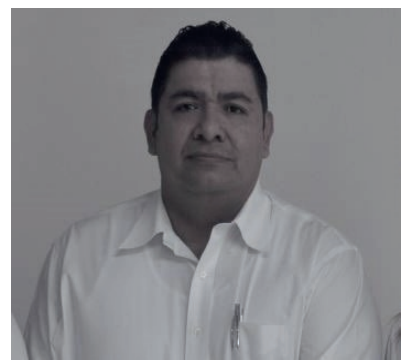

Rafael A. Segura Mena is a soil scientist specialized in the banana crop. He was borne in El Carmen Central, San Jose, Costa Rica on the $14^{\text {th }}$ of July 1974 . He obtained the degree of Agronomist Engineer in EARTH University in Guácimo, Costa Rica, in 1999. Since February 2000 he works as researcher in the CORBANA's Research Center in La Rita, Limón, Costa Rica. His experience includes plant nutrition, soil management, soil health and quality, soil microbiology and fertility. In 2010, he graduated as MSc with emphasis in Soil Science at the University of Costa Rica. Since April 2013, Rafael is enrolled as $\mathrm{PhD}$ Candidate in the Soil Geography and Landscape Group of the Wageningen University. During the time of his program, he combined the academic program with his work as the current Head of the Soil and Plant relationship Group in the CORBANA's Research Center. 


\section{Funding}

The PhD Program and the Research were financially supported by the Interdisciplinary Research and Education Fund (INREF) of Wageningen University and Corporación Bananera Nacional S.A. (CORBANA) from Costa Rica. 



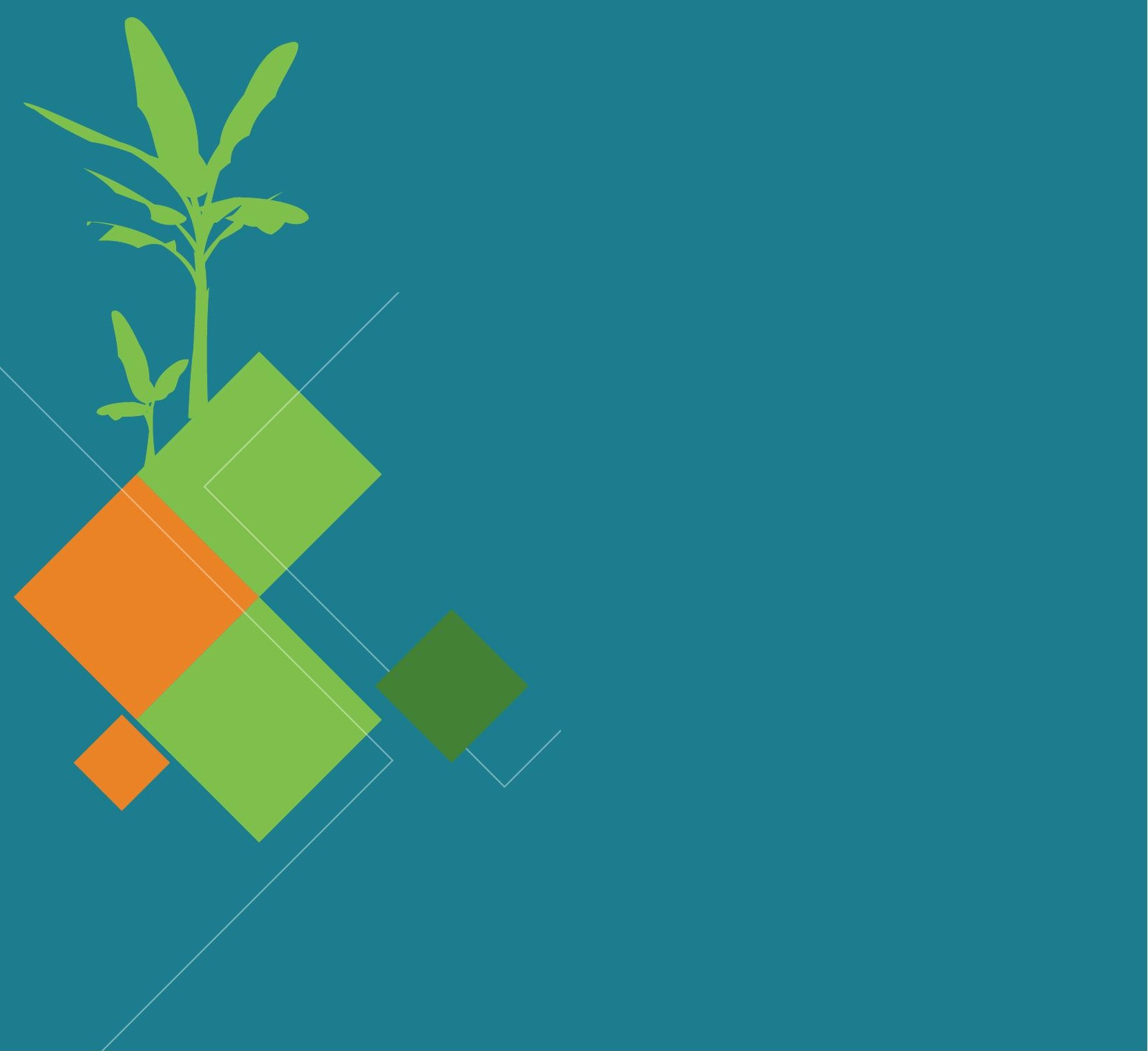

